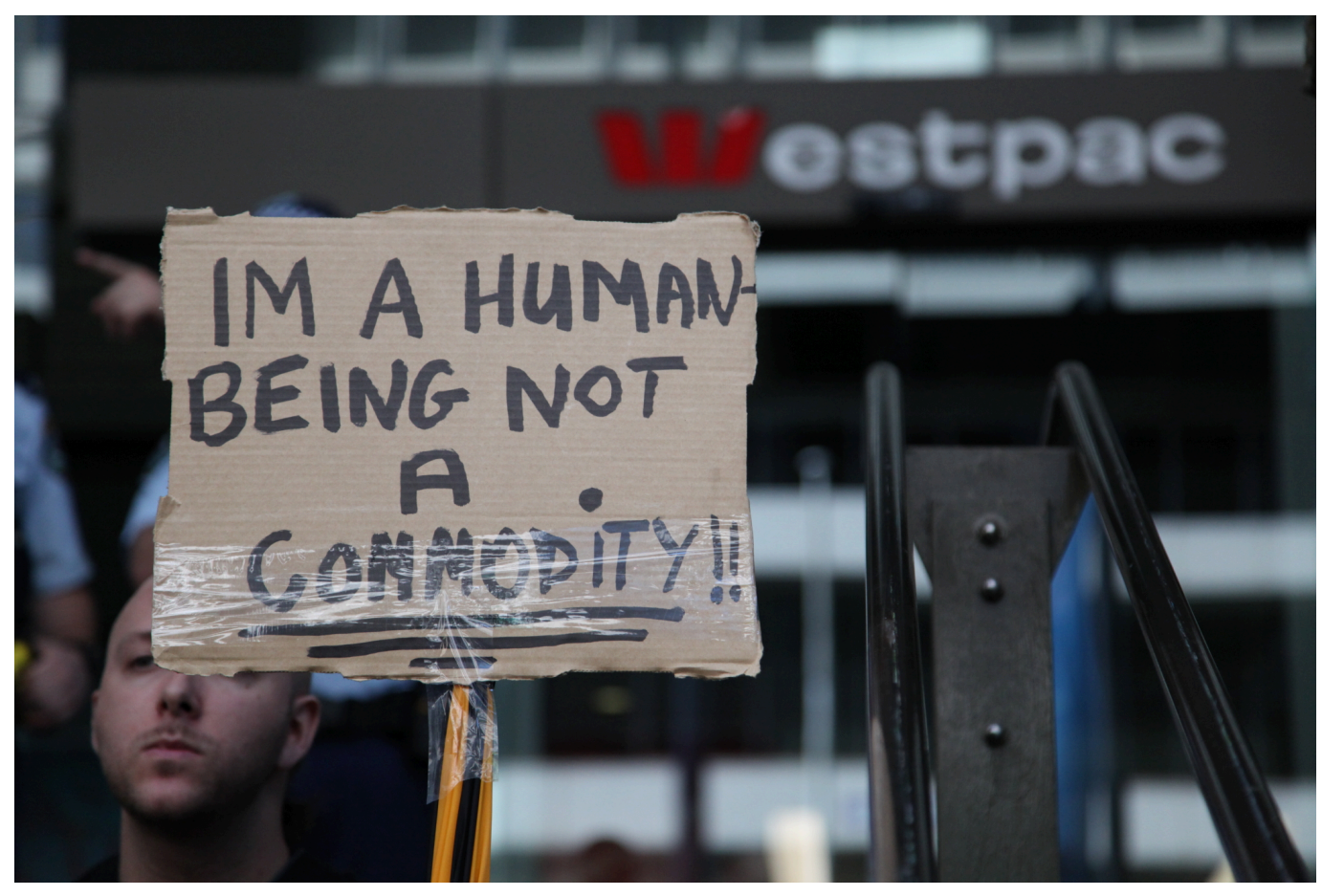

From Global Justice to Occupy and Podemos: Mapping Three Stages of Contemporary Activism

Special Issue of tripleC: Communication, Capitalism \& Critique (http://www.triple-c.at)

Edited by Todd Wolfson, Emiliano Treré, Paolo Gerbaudo, Peter Funke ${ }^{1}$ tripleC 15 (2), 2017, pp. 390-542

\footnotetext{
${ }^{1}$ Please note that the editors appear in reversed alphabetical order, not in order of importance. This special issue represents a collective effort, and all the four editors contributed equally to it.
} 


\title{
Multiple Temporalities of the Movements
}

\author{
Michael Hardt
}

Duke University, Durham, USA, hardt@duke.edu

The clocks seem to be running faster these days. A new cycle of struggle explodes on the scene and then in a few short years it seems to have burnt out and passed on to another. Even the recent past quickly fades from view as we speed past. Cycles of struggle used to continue to develop over decades. Think of the waves of slave rebellions that emanated from the Caribbean through much of the $19^{\text {th }}$ century, or the communist agitation in the decades leading up to and following the Soviet 1917 , or the anti-colonial revolts throughout the $20^{\text {th }}$ century. Even the explosion of movements across the world in 1968 extended at least throughout the 1970s. Rather than lamenting that contemporary movements are too brief and stunted, however, we should recognize the ways they are embedded in multiple temporalities that link them to the past and embed them in long-term political projects.

A standard narrative of recent cycles of struggle, limiting its vision to Europe and North America, goes something like this. The alterglobalization movements gained global visibility in Seattle in 1999 and reached their demise not long after the Genoa protests two years later; the encampments and occupations of the 2011 movement of squares seemed to be exhausted after Gezi Park was cleared in 2013; and the new electoral projects that mix with social movements - the success of national parties, such as Syriza and Podemos are most visible, but the municipal victories, such as that in Barcelona, are at least as important have been the focus of much political energy since 2015. Moreover, this narrative of brief cycles and rapid extinction is often told in terms of failures and lessons learned, and thus passages to different - even opposite - organizational strategies. According to this view, for example, the errors of the alterglobalization movement, specifically its nomadic character, moving from one summit meeting to the next, from the WTO protests to those of the G8, was answered and redressed by the local, sedentary nature of the encampments and occupations. Similarly, the failure of both the alterglobalization movements and the movement of squares to achieve electoral, institutional change and their refusal to pose limited policy demands led to the formation of new parties and electoral coalitions. The narrative appears to trace the trajectory of a ping-pong ball, passing over to the opposite side each time a lesson is learned.

The impression of rapid change in social movement organization is often reinforced by the focus on media and communication: the swift rate of technological change gives the impression of accelerated rhythms of political shifts. The independent media centers of the alterglobalization movements, for example, contrast with the use of social media in the movement of squares and 
the electronic structures of "liquid democracy" experimented with by some new electoral formations. Technological innovations that replace old communications systems seem to render obsolete also the old political and organizational strategies.

The essays in this special issue, from different perspectives and in different national contexts, all resist treating technology as determining political horizons. They perform the important function of bringing communications technologies back to the political terrain and posing organizational strategies in centre stage. Highlighting political dynamics in this way provides a foundation for situating contemporary movements in a longer temporal frame and developing richer relationships to the past.

There is some truth, of course, in the narrative of rapid shifts, and even oppositions, in movement strategies. It helpfully brings into relief some of the primary organizational challenges and the alternatives that the movements face, such as how to link local revolt to national and global forces, how or if to engage the traditional structures of political representation, and how to confront the established institutions of power. We lose a lot, however, when we fail to recognize the ways in which the organization strategies, critical standpoints, and political aspirations of today's movements are linked to and continue to develop those of the recent and more distant past.

One counternarrative disrupts the standard periodization of rapid discontinuities simply by expanding the geographical frame beyond the North Atlantic, recognizing especially the profound connections and affiliations with movements to the South. Many in the alterglobalization movement, for example, were inspired by the Zapatista experience, which began several years earlier and continues today; the 2011 encampments in Spain, Greece, the US, and elsewhere drew, obviously, from the struggles in Tunisia and Egypt that began that earlier year; and the prominent electoral projects since 2015, especially those in Spain, are motivated and informed by Latin American governing experiences, especially in those Venezuela, Bolivia, and Ecuador over the previous decade. Once the geographical frame is expanded, the dates and duration of each struggle shift.

Profound temporal shifts also result from considering how some recent movements extend long national trajectories. In some respects, for example, the $15 \mathrm{M}$ in Spain in 2011 reopened unresolved issues of the "transition to democracy" that emerged in the immediate post-dictatorship period. An even broader temporal arc is suggested by the way that the political project of Black Lives Matter, which shares many elements of the protest repertoire and media practices of Occupy, stretches back across a long history, ultimately highlighting the continuing need to wrestle with the legacies of slavery and Jim Crow, reaffirming the goal of an abolition democracy.

A fuller view of contemporary movements emerges when we keep in mind their many, diverse temporalities. In addition to recognizing the shifts in emphasis among the three waves of the standard narrative I sketched earlier, then, we should see the profound continuity that runs throughout the last decades of struggle. One common element that emerges, for instance, is the aspiration to 
new forms of democracy. The successive phases - protesting at summit meetings, occupying squares, and even constructing new electoral coalitions are really different faces of this larger project: to reveal the hollowness of the claims to democracy of the ruling system and to experiment with fuller forms of democratic participation. Contemporary social movements and radical electoral projects are not necessarily opposed from this perspective but, at least potentially, complementary.

This approach also helps us recognize that in most cases the movements of the recent decades did not fail but were defeated, by ideological and media forces, by the police, and by the ruling institutions. Whereas failure is closed in a dead end, political projects that suffer defeat live on beyond their death and are often reanimated in new form.

Recognizing diverse temporalities, then, has benefits not only for scholarship. The movements themselves are enriched by maintaining multiple attachments to the past. Just as important as learning lessons from mistakes, then, is recognizing the need and possibility to continue the projects of past movements and develop them in new ways.

\section{About the Author}

Michael Hardt

Michael Hardt is author with Antonio Negri of Assembly (2017). They are also coauthors of the Empire trilogy - Empire (2000), Multitude (2004), and Commonwealth(2009) - as well as Declaration (2012). At Duke University he teaches in the Literature Program and is co-director of the Social Movements Lab. He serves as editor of The South Atlantic Quarterly. 


\title{
From Global Justice to Occupy and Podemos: Mapping Three Stages of Contemporary Activism
}

\author{
Peter N. Funke* and Todd Wolfson** \\ *Associate Professor of Politics, School of Interdisciplinary Global Studies, \\ University of South Florida, Tampa, USA, pnfunke@usf.edu, \\ www.peterfunke.net
}

${ }^{* *}$ Associate Professor, Department of Journalism and Media Studies, Rutgers University, New Brunswick, USA, twolfson@rutgers.edu, www.toddwolfson.org

\begin{abstract}
Surveying the varied contributions to this special issue, this article examines the relationships, points of inspirations and contradictory dynamics that characterize the current epoch of social movement politics and global protest. The authors argue that with the progression of neoliberal capitalism and the explosion of new technologies, a shared logic of social movement politics has emerged. This logic spans from the Zapatistas and the Global Justice Movement to the uprisings in North Africa and the Middle East, the Occupy struggles and the most recent wave characterized by Podemos. While each of these waves of contention has a particular character, together they make up a broader epoch of struggle that thrives on multiplicity, emphasized radical participatory democracy, the innovative use of media and the heterogeneity of political struggle.
\end{abstract}

Keywords: social movements, protest, digital activism, neoliberal capitalism, inequality, class theory, Black Lives Matter, Podemos, Occupy, economic crisis

\section{Introduction}

On Friday, February 17 (\#F17), 2017, over 200,000 people joined together across the United States to hold work-actions, boycotts, teach-ins, walkouts and protests to challenge the new U.S. regime and the accelerated slide into authoritarianism. Francine Prose, an author and visiting professor of Literature at Bard University, made the original call for F17 in the Guardian. She argued, "I believe that what we need is a nonviolent national general strike of the kind that has been more common in Europe than here... a day when no one shops or spends money, a day on which we truly make our economic and political power felt..."

While the idea of a national strike on February 17 emanated from the urgent voice of an author cum activist, the web played a vital role in circulating the struggle. Within days of the original article, a digital activist posted an event page for a General Strike on F17. The site quickly drew in 50,000 attendees, and over 
the course of two weeks, over 100 events were planned across the country and posted on Facebook garnering well over 200,000 attendees.

While there was a small central coordinating committee for $F 17$, the social media presence for the day facilitated the massive explosion of events, and despite the mainstream media's relative silence, F17 made a mark on the American political terrain through the use of Facebook and Twitter to coordinate on-the-ground actions. The event was structured around the slogan "Find your people, make your plan," which offers a window onto the decentralized, selforganizing strategy behind F17 and converges with the spontaneous uprisings that have overwhelmed the United States since the inauguration of Donald Trump.

If we isolate some of the core attributes of $\mathrm{F} 17$, there is a similar modus operandi between F17 and many protests movements and uprisings that have erupted over the last decade. The event was largely mediated through social media and particularly Facebook. There was no central organization that ran or dictated F17 and the planning was largely left to local coordinating teams that did not have to adhere to a set of shared principles or a collective vision. This openness allowed for a great deal of diversity in F17 actions, from local job actions and protests focused on police brutality by local Black Lives Matter chapters, to prayer circles for the Muslim community, and corporate boycotts. In this sense, protests on F17 were at least in part, made possible by a particular organizing logic that stresses local autonomy, diversity, horizontality, and the use of social media. While autonomy, diversity, horizontality, as well as the reliance on Internet powered social media lends itself well for short-term campaigns such as protest mobilizations as evidenced by the fact that while F17 was a productive day of resistance, there was little lasting effect. In this sense, the attributes of diversity and horizontality have, at times, been coupled with a suspicion around institution building or the creation of mechanisms that can lead to building longterm collective power. In this sense, there is a contradiction embedded in the strategy of F17, as it was an impressive and useful day of resistance while the day itself illustrated the flaws in the underlying logic of movement organizing. This paradox within the multivalent logic of contemporary movements, and specifically how that logic has transformed in the last 25 years, are precisely the set of dynamics we wish to explore in this special issue.

\section{Three Waves of Protest}

We open with the events of $\mathrm{F} 17$, as it is a moment in the current wave of resistance that exemplifies some of the characteristics of a broader epoch of contention that has emerged since the 1990s (Funke 2014, Wolfson 2014). We argue that while this logic of resistance has mutated over the last 25 years, there are some core attributes that have been sustained, and together these defining attributes constitute the dominant logic of the larger epoch of contention.

As a prelude to the special issue, we argue that the world has witnessed three distinct waves of protests from the early 1990s to the present: "The Global Justice Wave" (e.g. Global Justice Movement [Wolfson 2014, Funke 2012]), "The Crisis Wave" (e.g. Arab Spring, anti-austerity protests, Occupy Wall Street [Fuchs 
2014, Funke and Wolfson 2015; Funke, Vanden and Prevost 2017]) and the "Post-Crisis Wave" (e.g. Umbrella Movement, BlackLivesMatter, Syriza/Podemos [Gerbaudo 2017]). Each of these waves is connected both by the transformations in global capitalism and the rise of the digital age, while still displaying differences or rather developments in movement-based organizing. Together however, we can conceive of these three waves as part of one broader epoch of contention. In this special issue, we examine the logic of these waves of protest (or generations of digital activism) in order to explore their similarities and differences. The goal of the special issue is to mine history from a diachronic perspective, but more concretely to understand the strengths and weaknesses of this epoch of contention as we watch the current wave of struggle unfold.

The remainder of this introductory article outlines the shared meta-logic informing movement politics of the current epoch of contention. We argue that the shared logic, which we have elsewhere described as "Cyber Left" (Wolfson 2014), "Rhizomatic Left" (Funke 2012, 2014), or "Nomadic Logic" (Funke and Wolfson 2015) is linked to shifting dynamics of capitalism, histories of movement politics and transforming information and communication technologies. Albeit contextually colored by their respective socio-political spaces and times, the shared movement logic finds expression in the diversity of mobilizations, protests, and demonstrations from the 1990s to today. As such, we also argue that it is different from the previous epoch of resistance during the periods of the so-called Old and New Left.

In what follows, we first offer a set of theoretical arguments on the shifting dynamics of capitalism and movement politics as they intersect with the information revolution. We then outline our understanding of the currently dominant movement logic. We argue that this logic is distinguishable from earlier movement axioms and practices. In particular, five dimensions (diversity, use of social media, pre-figurative politics, grassroots democracy, distrust of established institutions) of this new logic we highlight as they bring out its distinctiveness and illustrate the particular desire of contemporary activists for horizontality.

After outlining the currently dominant movement logic we introduce the articles of this special issue. We conclude this introductory essay by highlighting some of the challenges and shortcoming of the dominant movement logic of our times.

\section{From the Old Left to New Social Movements}

As we argue elsewhere, the shifts in capitalism and the correspondent transformations in technology have altered the contours, logics, and trajectories of resistance in general and social movement politics in particular (Funke and Wolfson 2015). When looking at social movement politics across the twentieth century, distinctions have generally been made between the Old Left and the New Left (e.g., Diggins 1992). The Old Left was dominant in the first half of the twentieth century and arguably privileged a class-based analysis, pitching the working class against the bourgeoisie. Following from this, the New Left emerged in the 1960s and 1970s, partially in reaction to the Old Left, thus shifting the struggle for power away from the realm of work to what Alain Touraine called "the 
setting of a way of life, forms of behavior and needs" $(1988,25) .{ }^{1}$ These changes in strategy, structure, and governance of social movements must be linked to shifts in the nature of the political economy in order to more fully understand the development, progression, and implications of social movements.

Succinctly put, the Old Left emerged and developed in the era of industrial capitalism, under the imperative of mass production and the goal of building economies of scale. This led to the development of massive factories and dockyards, inflexible production processes, stable work patterns, standardized mass consumption (structured along class lines), and seemingly fixed gender roles. This particular type of capital accumulation, and its intrinsically linked sociopolitical arrangements and regulations, dialectically generated a particular type of Left resistance. Along these lines, this "Fordist" system was, at times unconsciously, mirrored by the Old Left, which forged mass parties and unions, hierarchical organizational structures, and comparatively rigid understandings of race, gender, and sexual orientation. Movement and party organizing was mostly done on the shop floor or in working-class neighborhoods, where the Old Left constituency tended to work and live together in similar conditions, leading to a physical and cognitive/cultural proximity that allowed workers to share experiences and build solidarity. Labor unions and political parties tended to use hierarchically organized governing structures to engage and negotiate with similarly organized owners and government officials or to mobilize their constituencies for protests and strikes.

The New Left emerged in the 1960s on the heels of the Civil Rights Movements (Kelley 1990), during the growing crises within the Fordist system, brought about through changes to production, distribution, and consumption patterns as well as to its sociopolitical regulations. Patterns shifted from more standardized mass production and consumption to more individualized and flexible production and consumption. This in turn started to shift the nature of the workforce as Fordist "conveyor belt"-style work was replaced with more flexible arrangements typified by part-time, outsourced, and subcontracted forms of labor. This new flexible work experience has been characterized as informal and often precarious.

In this period-which is marked by the 1973 oil shock that spurred low growth rates, rising inflation, and increasing unemployment-employers faced rising national and international competition as liberalization and deregulation policies were implemented, and they advanced antiunion campaigns to increase productivity by driving down labor costs. While labor, and in particular rank-andfile workers, fought back (Brenner, Brenner, and Winslow 2010), Reagan's 1981 destruction of the Professional Air Traffic Controllers Organization (PATCO) and Thatcher's defeat of the long miner strike in 1983/84 are symbolic of the end of the "Fordist compromise." This meant an intensifying war on labor and the beginnings of large-scale neoliberal restructuring policies.

\footnotetext{
${ }^{1}$ We recognize that there are problems in thinking of periods, because they both elide continuity and paper over dissonance within a specific moment in time, but as Jameson (1990) argues, if we do not see patterns in history, then we are forced to argue that the contemporary moment is an anarchic jumble of phenomena with no sociohistorical link.
} 
Along with the changing nature of production, distribution, and consumption came the emergence of what European scholars called new social movements. In the postwar "golden age of capital," in which material needs were met for many in the West, nonmaterial issues emerged, and with them struggles related to questions around race, gender, and sexual equality, abortion rights, the antiwar movement, or environmentalism. Often in tension with Old Left concerns, these new social movements stressed the monotony and rigidness of social life. This vision of a stultifying, hierarchical society led movement activists to fight for what Anthony Giddens called "life politics . . . issues which flow from processes of selfactualization in post-traditional contexts" $(1991,214)$ as opposed to "emancipatory politics," which address the politics of inequality.

Through this transition to life politics, the New Left allegedly shifted the struggle for power away from the realm of work and toward questions of identity such as gender and race. In fact, many of the so-called New Left's concerns were aimed at the Old Left and the "Fordist compromise," making alliances between the Old and New Left challenging. While the Old Left was associated with, for example, somewhat outdated understandings of the family and gender roles, a disregard for the environment, organizational structures that emphasized more hierarchical party- and union-like structures, as well as a still predominately nation-state focus, the New Left sought novel organizational models beyond the labor movement and notions of class struggle. ${ }^{2}$ Despite a "strategic strain" within the New Left (Breines 1989), the dominant tendency stressed more pre-figurative politics and unconventional forms of political organizing. As such, the New Left was critical of representative structures and central authority and distrusted institutional politics writ large, embracing instead communitarianism and autonomism, spontaneity, and participatory and process-oriented movement politics.

\section{New Movement Logic}

With this historical view on the intersection between the Old and New Left in mind, we argue that novel resistance formations have been emerging since the end of the Cold War-fueled by the advancement of neoliberal capitalism, the "financialization of daily life," the emergence of the information revolution, and the perceived shortcomings of the Old and New Left. These formations function on the basis of a distinct logic of movement politics, seeking to bridge Old and New Left concerns of anti-capitalism and identity politics. Alongside capitalist dynamics and the influence of previous periods of movement politics, contemporary movement organizing has also been shaped by the technological transformations of the information age. The use of these technologies by activists and organizers, in particular social media and other emerging digital

\footnotetext{
${ }^{2}$ We do not suggest that questions of identity were irrelevant for the Old Left or that class issues were absent during the time of the New Left. We maintain, however, that changes in the capitalist system shifted the principle concerns and central foci of the respective movements and with them the commanding fronts and preeminent strategies of struggles in the transition from the Old to the New Left and onward to the current time.
} 
technologies, has facilitated a sea change in how activists organize, mobilize and publicize (Wolfson 2014; Gerbaudo 2012). We argue that these three factors, the transformation in the economy, the emergence and impact of the internet and other digital tools as well as the history of emancipatory movements, laid the groundwork for the contemporary logic of resistance.

We have identified five core characteristics of this contemporary logic of resistance that set it apart from prior movement politics and allow us to identify what we call the Global Justice Wave of the 1990s/2000s, the Post-Crisis Wave of the early 2010s and the Post-Crisis Wave since 2014 as part of the same broader epoch of contention. These characteristics are as follows:

1. An acceptance and embrace of the diversity and equality of actors and their different struggles.

2. The use of social media by participants and organizers, elevating it to play an infrastructural role for movement politics.

3. A commitment to leaderless and pre-figurative forms of organizing.

4. A decision-making process based in grassroots democracy and consensusbased decision-making.

5. A distrust of institutional actors such as traditional parties and unions as well as the existing political institutions writ large.

Taking each of these characteristics in turn, one of the core attributes of contemporary organizing is a belief that all forms of struggle are equally important. In this sense, no particular front of resistance, whether it is the struggle over class-based exploitation or racism and patriarchy, has priority over other points of struggle. The vision, then, is to build a network of interconnected struggles, where all of these forms of resistance are equally important, and while acting in solidarity, are able to maintain their autonomy and right to dissent.

A second characteristic of the contemporary epoch of contention and its three constitutive waves of resistance is a deep engagement with and use of technology in general and social media in particular. Arguably traceable to the EZLN's use of the internet in their struggle with the Mexican state, and the subsequent formation of the Indymedia network (Wolfson 2014), the Internet and its technologies have taken center stage in social movement politics with the emergence of an information- and technology-driven form of neoliberal capitalism. While movements have used technology differently, some of the core attributes are the use of social media to popularize struggles while employing its networking power to knit different actors and issues into a collective tapestry, though one where all actors maintain their autonomy.

A third characteristic, pre-figurative politics, emerged out of the anarchist movement and movement praxis of the New Left in the 1960s more generally. The concept of pre-figurative politics is to create the practices, structures and vision within the movement, that can actualize now, the society activists wish to build in the future. Pre-figurative politics also reverses the means-ends logic, as the means now trump the ends and are no longer only in the service of the goals the movement aspires to achieve. In the case of contemporary movements, 
prefiguration tends to mean refraining from creating long-term strategic plans, while building non-hierarchical organizations through direct democratic processes.

In line with the pre-figurative and horizontal or leaderless forms of organizing that characterize this new epoch, the dominant decision making mechanism in contemporary movement-based groups is direct democracy and consensusbased decision-making. This can be contrasted to decision-making processes adopted in representative forms of democracy, where leaders are voted in, occupy specific positions in a hierarchy, and exercise varying degrees of power by making decisions for the larger movement on the basis of their place in the hierarchy.

Finally, within contemporary movements activists and organizers tend to distrust hierarchically organized institutions such as parties and unions as well as the state and its established mechanisms. This distrust is grounded in a belief that these bureaucratic entities and institutions tend to mirror, perpetuate and recreate the injustices activists and organizers struggle against. From this perspective, engagement with any part of the establishment, including state institutions, can at best lead to minor achievements and at worst to the cooptation of movements and groups. However, at least within the Post-Crisis Wave, we can see a shift towards re-engaging the broader state-apparatus. Podemos, Syriza, and to a lesser degree the Sander's presidential campaign in the U.S. are indicative of these developments.

Looking at the broad contours of this logic of social movement practices, we also suggest that it develops in conversation with the history of left-based organizing as well as in relation to the material world or political economy that activists inhabit. In this sense, while it is clear that contemporary activists are responding to their perception of the successes and challenges of previous movement logics, the new logic is informed by the nature of neoliberal capitalism, including shifting technological dynamics. To be clear, however, we are not arguing that the particularities of protest forms from the EZLN to the Arab uprisings or anti-austerity protests in Greece are identical. The shared metalogic, defined by the five broad core characteristics outlined above, is of course colored by space and time, and thus finds different and diverse manifestations in the jungle of Chiapas, the streets of Seattle or Porto Alegre, in Tahrir Square, Zuccotti Park or the Puerta del Sol Square in Madrid. Nevertheless, the shared context of neoliberal capitalism and new information and communication technology, as well as the movements' willingness to embrace the core characteristics discussed above, allow us to identify these apparently different events as constituting a distinct epoch of contention. An epoch that ranges from the Zapatistas to the Arab uprisings and the BlackLivesMatter mobilizations, to the most recent wave of movement-powered party-building attempts of Podemos and Syriza, and anti-Trump and anti-nationalist mobilizations in Europe.

\section{The Special Issue}

The editors of this special issue all agree with the contention that we have witnessed three generations, or waves of protest, across the last $20-25$ years. In 
the chapters to come, we see scholars from across the globe wrestling with the logic(s) of contemporary activism, while attempting to place it in a broader frame. This leads to a rich dialogue across the articles in the issue, that brings to the fore a dynamic vision of the way protest and struggle have developed and the structures and tensions that activists and organizers face in their day-to-day praxis. It is vital to note, that the articles in this issue have different modes of analysis. Some scholars offer a deep analysis of one particular movement, other scholars focus on comparing two movements within the same wave of resistance and others still, focus on comparing movement logics across the different waves that make up this broader epoch of contention. While each of these articles articulates a different scale, taken together they offer a rich picture of the tapestry of resistance that has been woven across the last two decades.

In the remainder we briefly introduce each article before we conclude this introductory article with some cautionary remarks on the challenges the currently dominant movement logic faces.

In "Comparing Digital Protest Media Imaginaries: Anti-austerity Movements in Spain , Italy and Greece," Emiliano Treré, Sandra Jeppesen, and Alice Mattoni juxtapose social movement and communications frameworks by comparing digital protest media imaginaries across recent anti-austerity protests in southern Europe. They show the emergence of "three different imaginaries: technopolitical in Spain; techno-fragmented (Italy), and techno-pragmatic (Greece). Their research reveals how pivotal the temporal and geographical dimensions are when analyzed using theoretical perspectives from both communications and social movement research. Furthermore, it emphasizes the importance of studying translocal digital protest media imaginaries as they shape movement repertoires of contention and communication.

Elise Thorburn's article "Social Reproduction in the Live Stream" explores how feminist social reproduction occurs through digital networks in contemporary social movements. Looking at the Concordia University Television's live streaming of Quebec's 2012 student strike, she shows how technology is not only used as an alternative but is re-appropriated as "a new way of collaboratively accounting for collective interests and constituting sites of resistance within and beyond social and political contestations."

In "Technopopulism: The Emergence of a Discursive Formation," Marcos Deseriis argues for the convergence of two discursive formations (populism and technolibertarianism) in the wake of the 2008 financial crisis and the 2011 wave of struggles. Deseriis argues that this new discursive formation produces both tensions and possibilities as it gives rise to radical participatory democratic models while at the same time empowering technopopulist parties led by charismatic leaders.

Emile Husted and Allan Dreyer Hansen compare two distinct radical political projects, Occupy Wall Street and the Danish political party The Alternative in their article, "The Alternative to Occupy? Radical politics between protest and parliament." This theoretically focused article proposes a conceptual distinction between radical movements and radical parties. The authors argue for a radical politics that neither sidesteps nor gets absorbed by the state. 
In From cyber-autonomism to cyber-populism: an ideological history of digital activism, Paolo Gerbaudo identifies two main waves of digital activism. These waves correspond not only to two phases of technological development of the Internet (the so-called web 1.0 and web 2.0), but also to two different protest waves, the anti-globalisation movement, and the movement of the squares that began in 2011, each with its own dominant ideology. Reflecting the seismic shift in perceptions and attitudes produced by the 2008 financial crash, and the connected shifts in social movement ideology, Gerbaudo argues that digital activism has moved from the margins to the centre of the political arena, from a countercultural posture to a counterhegemonic ambition.

Kamilla Petrick examines the temporal dimension of the Occupy Movement in "Occupy and the Temporal Politics of Prefigurative Democracy." Looking at the Anti-Globalization Movement Petrick argues that we need to pay attention to different dimensions of temporality within movements. This temporal analysis she argues-which includes digital media, prefiguration and durability-enables us to better understand the practices and affects of popular resistance in movements like Occupy.

Eugenia Siapera and Michael Theodosiadis focus on the history and evolution of Greek anarchist/self organizing movements with attention to communication practices in (Digital) activism at the interstices: anarchist and self-organizing movements in Greece. Offering an analysis of the history of the left in 20th century Greece, the authors examine the critiques, discourses and communicative practices of the antagonistic movement as a whole. Siapera and Theodosiadis argue that antagonistic movements can offer an alternative path to populist hegemony, cultivating fundamental shifts in political subjectivity.

Finally, in "Student Protests. Three Periods of University Governance" Joan Ramon Rodriguez-Amat and Bob Jeffrey look specifically at the periodization of university governance and how it impacts student protest. The authors identify three periods of university governance: Enduring Democracy from 1964-1985, Global University from 1985-2005 and the Millennial Turn from 2006 to the present. They argue that with each period there is a different governing apparatus, which structures the nature of student protest.

\section{Conclusion}

The articles in this special issue highlight, from various vantage points, the diverse expressions of the dominant movement logic of resistance in the $21^{\text {st }}$ century. This logic emerged during a time of great economic and technological upheaval. We first saw glimpse of this new logic when the EZLN declared war on the Mexican state and across the next 20 years since that declaration, we have watched this logic mutate as it traveled from Seattle to the upsurge of struggle from the Middle East and North Africa to Wall Street and Athens, and most recently to the movement-powered party building attempts in Europe and beyond.

While we have seen important successes in the current epoch of contention, we want to caution against the overly laudatory perspective that many observers of contemporary social movements have taken. Instead we suggest scholars take 
a more analytical perspective, examining the strengths and weaknesses of the prevailing logic of resistance. While a thoroughgoing critique of the currently dominant movement logic is beyond the bounds of this article, we want to conclude by pointing to some important blind spots or concerns we have with the logic of social movements and its implications for sustained movement building.

The supposition that all actors and concerns are similarly important, that no struggle or actor can be prioritized within the more general fight for emancipation and against exploitation, is highly problematic. For one, the capitalist structures forge the meta-matrix within which all other forms of exploitation are linked and find themselves interconnected. Struggles over gender inequality, environmental degradation, or racism are critically part of capitalist dynamics and as such, we argue that all of these struggles need to be centrally concerned with the forms of power and exploitation that emerge through the capitalist political economy and the class positions it creates. Moreover, in that capitalism, as an exploitive system, generates multiple intersectional forms of oppression, the fight against capitalism and its multiple forms of exploitation offers a critical strategic unity for interlinking and generating a more resilient and shared doctrine across multiple fronts of struggle. The realization of the centrality of capitalism as interconnecting most forms of struggle, provides relief for the often ungrounded nature of much movement politics. In this sense, an analysis that foregrounds capitalism would lead to the inclusion of those poor and working poor communities that are most disaffected by neoliberal capitalism and would allow activists to move beyond the often middle-class nature of many movements and groups today.

While scholars have shown that social media is a tool of capitalist surveillance (Fuchs and Trotter 2015), the use of new technology and social media in particular, is a hallmark of the movement-logic defining the current epoch of contention (Fuchs 2014). Internet-based media has altered organizing, and as we have argued elsewhere, this demands a more nuanced understanding of the relationship between (old and new) media and contemporary social movements (Treré 2012; Wolfson, Funke 2014). The successful use of old and new media depends on important contextual issues, such as access to technology, and geographic as well as scalar aspects of a movement's constituency, calling for a more careful assessment of the use and impact of media in contemporary activism (Treré 2015).

Similarly, the belief in radically participatory democracy and the ideal of consensus decision making, leading at times to privileging procedural aspects of prefiguration over strategic leadership and decision-making processes also presents a potential challenge for successful movement building. The fetishization of form over function has often led to a privileging of certain members that have the time and social capital to engage in these activities and functions. This becomes a problem as the dominance of communities with more social capital (read: the middle class) makes it hard for many contemporary movements to merge with the mass of the working class, thus forging partial movements that cannot connect the social forces necessary for real change. Moreover, it allows for a politics of acceptance of diversity for diversity's sake instead of using democratic governance mechanisms to work through this 
diversity and to generate a new and shared synthesis-to "become other together," as Nunes (2006: 305) put it.

Finally, while we have identified a distrust of and dis-engagement with the broader state apparatus, including political parties and traditional unions during the Global Justice- and Crisis-Wave, we recognize a re-alignment during the current Post-Crisis Wave. Possibly inspired by the "Pink Tide" in Latin America, movement-formations no longer sidestep state institutions but seek to engage them. This includes the forming of new movement-powered parties or alliances that have won or done well in general elections such as Syriza in Greece or Podemos in Spain as well as the BlackLivesMatter campaign and electoral victories of leaders of the Umbrella Movement in Hong Kong.

Throughout this special issue, scholars from across the globe, highlight the successes, challenges, and potential shortcomings of the current epoch of struggle. These analyses span from in-depth investigation of particular struggles to broader examinations of the epoch that has emerged in conversation with neoliberal capitalism and the explosion of new communication technologies. Taken together, the articles in this volume bring to the fore the rich tapestry that constitutes the logic of struggle, which has unfolded over the last quarter century.

\section{References}

Breines, Wini. 1989. Community and Organization in the New Left, 1962-1968: The Great Refusal. New Brunswick, NJ: Rutgers University Press.

Brenner, Aaron, Robert Brenner, and Cal Winslow, eds. 2010. Rebel Rank and File: Labor Militancy and Revolution from Below During the Long 1970s. New York: Verso Press.

Diggins, John Patrick. 1992. The Rise and Fall of the American Left. New York: W. W. Norton.

Fuchs, Christian. 2014. OccupyMedia: The Occupy Movement and Social Media in Crisis Capitalism. Winchester, UK: Zero Books.

Fuchs, Christian, Daniel Trottier. 2015. "Towards a Theoretical Model of Social Media Surveillance in Contemporary Society" Communications 40(1): 113-135.

Funke, Peter. 2012. "The Rhizomatic Left and Neoliberal Capitalism: Theoretical Interventions on Contemporary Social Movements in the Global North," International Critical Thought, Vol. 2, No. 1, March 2012, pp. 30-41.

Funke, Peter. 2014. "Building Rhizomatic Social Movements? Movement-Building Relays during the Current Epoch of Contention." Studies in Social Justice 8: 27-44.

Funke, Peter, Todd Wolfson. 2015. "Contemporary Social Movements and the Emergent Nomadic Political Logic," in Culture, Catastrophe, and Rhetoric: The Texture of Political Action, edited by Ralph Cintron and Robert Hariman New York: Berghahn Books.

Funke, Peter, Gary Prevost, Harry Vanden. 2017. The New Politics: Global Social Movements in the $21^{\text {st }}$ Century. New York: Routledge.

Gerbaudo, Paolo. 2017. The Mask and the Flag: The Rise of Anarchopopulism in Global Protest. London: Hurst Publisher.

Gerbaudo, Paolo. 2012. Tweets and the Streets: Social Media and Contemporary Activism London: Pluto Press. 
Giddens, Anthony. 1991. Modernity and Self Identity: Self and Society in the Late Modern Age. Cambridge: Polity Press.

Kelley, Robin. 1990. Hammer and Hoe: Alabama Communists During the Great Depression. Chapel Hill, NC: University of North Carolina Press.

Lamas, Andrew, Todd Wolfson, Peter Funke. 2017. The Great Refusal: Herbert Marcuse and Contemporary Social Movements. Philadelphia: Temple University Press.

Nunes, Rodrigo. 2006. "Nothing Is What Democracy Looks Like: Openness, Horizontality and The Movements of Movements." In Shut Them Down! The G8, Gleneagles 2005 and the Movement of Movements, edited by David Harvie, Keir Milburn, Ben Trott, and David Watts, 299-319. New York: Autonomedia.

Prose, Francine. 2017. Forget Protest. Trump's actions warrant a general national strike. The Guardian. January 30, 2017. Accessed April 25, 2017. https://www.theguardian.com/commentisfree/2017/jan/30/travel-ban-airport-protestsdisruption

Touraine, Alain. 1988. Return to the Actor: Social Theory in Postindustrial Society. Minneapolis: University of Minnesota Press.

Treré, Emiliano. 2015. The Struggle Within: Discord, Conflict and Paranoia in Social Media Protest, Critical Perspectives on Social Media and Protest: Between Control and Emancipation, edited by Lina Dencik and Oliver Leistert. Lenham MD: Rowman \& Littlefield, 163-180.

Treré, Emiliano. 2012. Social Movements as Information Ecologies: Exploring the Coevolution of Multiple Internet Technologies for Activism. International Journal of Communication, 6, 2359-2377.

Wolfson, Todd. 2014. Digital Rebellion: The Birth of the Cyber Left. Urbana: University of Illinois Press.

Wolfson, Todd, Peter Funke. 2016. "The Contemporary Epoch of Struggle: AntiAusterity Protests, Egyptian Uprising and Occupy Wall Street," in Translating Dissent: Voices from and with the Egyptian Revolution, edited by Mona Baker. New York: Routledge, 60-74.

Wolfson, Todd, Funke, Peter. 2017. "Contemporary Social Movements and Media: The Emergent Nomadic Political Logic and its Nervous System," in Social Movements and World-System Transformation, edited by Jackie Smith, Michael Goodhart, Patrick Manning, John Markoff. New York: Routledge.

\section{About the Author}

\section{Peter Funke}

Peter Nikolaus Funke received his Ph.D. from the University of Pennsylvania and his "Vordiplom" from the Freie Universität Berlin. His research focuses on social movements \& contentions politics, capitalism \& class, media \& technology. Peter has published in various peer reviewed journals such as Globalizations, New Media \& Society, Rethinking Marxism, New Political Science, Social Movement Studies, or Transforming Anthropology. He is the co-editor of "The Great Refusal: Herbert Marcuse and Contemporary Social Movements" (2017) and "The New Global Politics: Global Social Movements in the $21^{\text {st }}$ Century" (2017).

Todd Wolfson

Todd Wolfson's research focuses on the intersection of new media and contemporary social movements and he is author of Digital Rebellion: The Birth of the Cyber Left 
(2014) and co-editor of, Great Refusal: Herbert Marcuse and Contemporary Social Movements (2017). Wolfson believes in the importance of engaged scholarship that leads to tangible action in the world, and to that end, he is a co-founder of the Media Mobilizing Project (MMP) based in Philadelphia, PA. MMP is an award-winning organization that aims is to use new media and communications to build the power of poor and working people. 


\title{
Comparing Digital Protest Media Imaginaries: Anti-austerity Movements in Spain, Italy \& Greece
}

\author{
Emiliano Treré* ${ }^{*}$ Sandra Jeppesen ${ }^{* *}$ and Alice Mattoni*** \\ *Scuola Normale Superiore, Florence, Italy \& Lakehead University, Orillia, Canada, \\ emiliano.trere@sns.it, https://scuola.academia.edu/EmilianoTreré
}

**Lakehead University, Orillia, Canada, SandraJeppesen@lakeheadu.ca, https://lakeheadu.academia.edu/SandraJeppesen

***Scuola Normale Superiore, Florence, Italy, alice.mattoni@sns.it, https://scuola.academia.edu/AliceMattoni

\begin{abstract}
This article presents findings from an empirical study of repertoires of contention and communication engaged during anti-austerity protests by the Indignados in Spain, the precarious generation in Italy, and the Aganaktismenoi in Greece. Drawing on 60 semi-structured interviews with activists and independent media producers involved in the 2011 wave of contention, we bring together social movement and communications theoretical frameworks to present a comparative critical analysis of digital protest media imaginaries. After examining the different socio-political and protest media contexts of the three countries translocally, our critical analysis emphasizes the emergence of three different imaginaries: in Spain the digital protest media imaginary was technopolitical, grounded in the politics and political economies of communication technologies emerging from the free culture movement; in Italy this imaginary was techno-fragmented, lacking cohesion, and failed to bring together old and new protest media logics; and finally in Greece it was techno-pragmatic, envisioned according to practical objectives that reflected the diverse politics and desires of media makers rather than the strictly technological or political affordances of the digital media forms and platforms. This research reveals how pivotal the temporal and geographical dimensions are when analyzed using theoretical perspectives from both communications and social movement research; moreover it emphasizes the importance of studying translocal digital protest media imaginaries as they shape movement repertoires of contention and communication; both elements are crucial to better understanding the challenges, limitations, successes and opportunities for digital protest media.
\end{abstract}

Keywords: anti-austerity; social movements; digital media; social media; protest media; media imaginaries; protest cultures; Indignados; Aganaktismenoi; Spain; Greece; Italy.

Acknowledgement: This research was supported by an Insight Development Grant from the Social Sciences and Humanities Research Council of Canada [file number 430-2014-00181] held by Sandra Jeppesen at Lakehead University Orillia, Canada.

\section{Introduction: Toward Complexity in the Analysis of Digital Protest Media}

If two decades ago, the study of social movement engagement with digital technologies and the role of alternative protest media could be considered nothing but an interesting micro-niche in the academy, the last ten years have witnessed an 
astonishing flourishing of the field, in part because of the hype over social media and big data, and in part because of the intensification of globalized protest. The influences are felt in two fields of research: communications technology and social movements. While the social movement literature has typically either neglected or downplayed the role of communication within social movements, the new wave of digital activism literature does exactly the opposite: it is often not only media centred (which is to a certain extent understandable) but also media-centric, attributing more power to media platforms than to the histories, socio-political contexts, and protest cultures of the social movements that use them. Both approaches have associated risks. The first risk is that "by concentrating our gaze solely on new forms of mediation of radical politics, we are seduced by the thrills and excitement of revolutionary possibilities on offer [by technologies] and forget the politics itself" (Fenton 2015, 347); the second is precisely the converse, namely we risk examining only the politics of social movements, neglecting the technological affordances and communicative actions of specific contexts. This paper therefore puts communication technologies literature into dialogue with the literature of social movements, both in conjunction with empirical research in which our participants spoke as much about anti-austerity protest movements as about their uses of digital protest media and technologies. Taking this approach, the first research bias we aim to correct for is the tendency toward a media-centric analysis in digital activism research.

Moreover, much of the research on the political potential of digital media has either praised the revolutionary possibilities offered for extending creativity and increasing participation (Jenkins 2006) and even altering the balance of power in the network society (Shirky 2011; Castells 2009), or quite the opposite, it has criticized the structural and political limitations of platforms deeply embedded in the exploitative mechanisms at the heart of communicative capitalism (Dean 2005; Fuchs 2013; Curran, Fenton and Freedman 2012). Our analysis therefore aims to correct for a second bias found in the oversimplification of this binary logic; we do so by considering the communicative complexity of contemporary social movements (Treré and Mattoni 2016) through a critical analysis of digital protest media imaginaries emergent in different socio-political contexts of mass movement mobilizations.

Furthermore, research on the 2011 wave of contention in Europe has demonstrated the need for comparative, translocal analytical frameworks in researching digital activism (Vatikiotis 2016; Couldry and Hepp 2015; Kyriakidou and Olivas 2014). We therefore compare digital protest media imaginaries in anti-austerity protests that occurred in three Southern European countries: Spain, Italy, and Greece. While differing in some aspects, the anti-austerity protests in these three countries belong to the same "protest cycle" (Tarrow 1998) or "protest wave" (Koopmans 2004), with collective action frames and repertoires of contention travelling from one country to another through mechanisms of thin diffusion (Gerbaudo 2013; della Porta and Mattoni 2014). Acknowledging the similarities, here we pay close attention to the differences characterizing these three 2011 anti-austerity mobilizations, in particular their divergent digital protest media imaginaries. Engaging a systematic comparative translocal approach, we attempt to correct for a third bias in digital activism research toward hyper-localized analysis, which has obvious shortcomings in a globalized network society (Castells 2000).

This article is structured as follows: first, we describe the methodology employed to gather and analyze interview data regarding Spain, Italy and Greece. Next, we introduce our analytical framework introducing the concept of digital protest media 
imaginaries. We then present our comparative analysis across the three countries. In conclusion, we consider the key political and communicative outcomes of this analysis.

\section{Methodology}

Our methodology was developed with the aim of comparing mobilizations against austerity in different European countries, paying particular attention to the social movement and communication assemblages that developed and sustained them. We conducted in-depth interviews with social movement and media activists in Spain, Italy and Greece, people who played key roles in organizing and producing media about the anti-austerity protests, including journalists, web managers and developers, social media curators, graphic designers, media activists, and precarious media researchers.

The interviews were structured to gather data both on the anti-austerity protests and on the mediation and communication flows that sustained and influenced them. Semi-structured interviews of an hour and a half allowed researchers to familiarize themselves with the social movement situation, to become acquainted with physical organizing spaces, and to discuss specific activist digital media technology uses and practices. A snowball sampling strategy was used to select approximately 20 participants per country (Italy $\mathrm{N}=19$; Spain $\mathrm{N}=20$; and Greece $\mathrm{N}=21$ ), covering a range of social movement organizations: from well-established radical activist groups to informal groups of newly politicized individuals; from traditional hierarchical social movement organizations to horizontal, grassroots social movement groups such as anarchist, free culture, or hacker collectives; from non-activist social media users to very experienced tech activists; and from inexperienced citizen journalists to unemployed professional journalists contributing to alternative media.

The resultant data set was coded and analyzed with ATLAS.ti software, considering the following crucial dimensions of digital protest media: the historical trajectories of each of the three anti-austerity protest mobilizations; the protest cultures that characterized each mobilization and their concomitant media practices; and the formative, emergent digital protest media imaginaries. In this paper, we present the results based on the last dimension, using the first two dimensions to inform our understanding of the context. In the next section we propose a theoretical framework to ground our analysis.

\section{Analytical Framework}

Our empirical analysis aims at understanding how different socio-political and cultural contexts intersected with digital protest media imaginaries that emerged during protests in Spain, Italy and Greece, in particular regarding social media but also examining other digital information and communication technologies (ICTs).

Once a neglected dimension of social movement research, culture is now recognized by many social movement scholars as a key lens through which the dynamics of collective action can be scrutinized (Polletta and Jasper 2001; Jasper 2014). In the social movement literature, definitions of culture vary greatly, ranging from Weberian conceptions that stress values, beliefs, and systems of meanings, to narrower understandings centred on schemata of cognition or action frames (Baumgarten et al. 2014). Recognizing the importance of the cultural dimension of protest, scholars working at the intersection of social movements and digital media have explored the linkages between protest cultures and media cultures from different 
perspectives. Some have focused on the cultural logic of networking in contemporary cyber-movements (Juris 2008; Wolfson 2014). Others have tackled the mutual influence between protest cultures and digital cultures within the Global Justice Movement (Kavada 2013) or the Occupy movement (Costanza-Chock 2012). Yet others have explored media ideologies (conceived as systemic beliefs about power, media and communications) held by activists regarding the use and effectiveness of specific social media platforms (Comunello et al. 2016).

Rather than communicative logics, cultural representations or media ideologies, in this paper we focus on ways in which activists perceive and imagine media technologies, drawing on the literature on media imaginaries. Scholars in this field investigate the "imaginary matrix" (Cabrera 2006) of communication technologies (Flichy 2007; Gitelman 2006; Marvin 1988; Mattelart 2003; Mosco 2005), highlighting ways in which the introduction of any new technology tends to lead to binary utopian vs. dystopian imaginaries that shape and are shaped by people's conceptions of the relationship between technology and society (Marvin 1988). This literature pays particular attention to the mythical dimension of digital media, scrutinizing the "digital sublime" (Mosco 2015) in relation to the material dimension of media, to reveal ways in which these two dimensions deeply influence one another.

Media imaginaries are largely disregarded in the research on media activism (for a notable exception, see Barassi 2015), but they are worth studying because they reveal how digital protest media platforms operate as sites for the realization of multiple political potentialities, values, desires and ideals. Digital and social media activist practices are embedded in wider media and protest ecologies, fuelling and being fuelled by digital protest media imaginaries. Treré and Barassi (2015) have shown that media imaginaries are not separate or evanescent realities, but have material consequences for political practice: the ways in which digital technologies are imagined, including how specific perceived meanings, values, capabilities, and ideologies are ascribed to them, shape the practices developed to engage with them and can thereby configure distinct types of digital activism, leaving others aside. It is also imperative to move beyond just social media imaginaries, as digital protest media practices and desires far exceed what is currently offered by corporate social media platforms, with the recent wave of movement participants actively engaged in creating blogs, websites, radio, podcasts, video activism, online comedy, digital documentaries, and more. Thus we define digital protest media imaginaries as the multilayered ways in which social movement actors enact particular values, ideologies, assumptions, desires, and attitudes in their media practices based on their conception or vision of the opportunities and limitations of particular communication technologies, beyond what the material affordances of the technologies themselves or their intended uses might indicate (Nagy and Neff 2015).

In the next section we will map out the socio-political and cultural contexts of the 2011 wave of anti-austerity movements in Spain, Italy and Greece to provide context for our analysis of the different digital protest media imaginaries that have both shaped and been shaped by media practices in a translocal dialectical tension.

\section{Socio-Political \& Cultural Contexts: 2011 in Spain, Italy \& Greece}

In Spain, the $15 \mathrm{M}$ or Indignados movement that emerged in 2011 represented the culmination of a social movement process, both a climax in its own right and a refinement of the repertoires of contention of previous mobilizations. As Barba and 
Sampedro (2011) have shown, the 15M Movement learned from its predecessors to combine online and offline activism strategies to strengthen and motivate movement actors. As such it represents one of the most powerful examples of a social movement originating from a digital media call to action on a non-corporate website, the ¡Democracia Real YA! platform designed and run by alternative media activists, with the slogan, "We are not commodities in the hands of the politicians and bankers." It can be characterized as a refinement and an improvement because previous movements were strong but nonetheless unable to build consistent momentum. The $13 \mathrm{M}$ demonstration in 2004 , in response to the electoral manipulation of the terrorist attacks of $11 \mathrm{M}$, where mobile phones played an important role, did not manage to coalesce into a social movement, disappearing the morning after. The subsequent Movement for the Right to Housing that emerged in 2006 broke through this intermittence, and demonstrated the ability of digital media, in particular the combination of websites and emails, to organize, mobilize and provide resources for activists. Despite the capacity of these movements to bring together significant multitudes in the streets, they were politically neutralized.

In 2009-2010, however, we can locate a historical shift in the wave of contention, signalled by the protest against the so-called Sinde Law, a repressive Internet copyright law heavily contested online by hacktivists, lawyers, bloggers and other activists whom Postill calls freedom technologists (2016), a loose grouping of activists who have played a prominent role in the Spanish context ${ }^{1}$. The Sinde Law protests, unlike those of 2004 and 2006, resulted in the formation of a broad-based social movement, albeit one that operated almost exclusively online. Moreover it served as a test-bed, a precursor to the digital media practices, experiences, and imaginaries of the $15 \mathrm{M}$ or Indignados Movement. The Indignados of 2011 thus represent the most recent heirs in this line of social movements, producing another climax in an intense decades-long history of mobilizations in Spain, the culminating actions in a flow of civil disobedience iteratively materializing almost every five years over the past twenty years (Sampedro, Duarte and Manuel 2011).

In Italy, conversely, the year 2011 marks an implosion, a collapse of anti-austerity mobilizations, rather than the culmination of years of activism seen in Spain. While the Italian struggle against austerity began before the Spanish movement, it followed a path of radicalization then fragmentation, which can be divided into three phases, as outlined by Zamponi (2012). The first phase began in 2008, with the Anomalous Wave student movement and its slogan "We won't pay for their crisis." This phase shares commonalities with the Indignados, particularly the use of non-violent civil disobedience and the critique of neoliberal austerity measures. In the second phase (2010-11) increasingly politicized students filled the squares protesting against the neoliberal restructuring of post-secondary education, denouncing the social conditions of the 'precarious generation' of Italian youth, and making demands for radical sociopolitical change. In this phase, we witness a radicalization of the movement: their

\footnotetext{
1 "I use the term freedom technologists to refer to those political actors - both individual and collective - who combine technological know-how with political acumen to pursue greater digital and democratic freedoms. Indeed, freedom technologists regard the fate of the internet and of human freedom as being inextricably entwined. Far from being the techno-utopian dreamers or ineffectual "slacktivists" of a certain strand of internet punditry, my anthropological research shows that most of them are, in fact, techno-pragmatists; that is, they take a highly practical view of the limits and possibilities of new technologies for political change". (Postill, 2016: 149).
} 
repertoire of contention evolves from university occupations to blockades of highways to clashes against police violence. This phase ends with the global day of action against austerity-October 15, 2011-which, in Italy, represented a failed attempt to apply an Occupy or Indignados framework, largely due to tensions between different groups and coalitions. Featuring violent clashes between protesters and police, which have become normalized during mass demonstrations, this mass protest also featured disruptive clashes between different social movement factions. For most of our interview participants, this day represented the death of every possibility for building a broad-based movement in Italy. Around the same time, the weak Berlusconi government was replaced with the technocratic administration of Mario Monti, which numbed the movement. 2011 in Italy thus marks the reaffirmation of parochialism, and the subsequent third phase (2012-13) is characterized by a fragmented social movement landscape comprised of different social movement factions with disjointed claims and disjunctive sites of struggle. There was ultimately no adoption of a clear self-defined movement identity that we saw with the Indignados or Occupy (We are the $99 \%$ ).

In Greece the 2011 wave of protesters, following the Spanish example, proclaimed their collective indignation. This followed on the heels of the month-long riots in 2008 in Athens, Thessaloniki and other cities, sparked by the December 6th police shooting of 15-year-old student Alexandros Grigoropoulos in Exarcheia, Athens (Vradis and Dalakoglou 2011; Dalakoglou 2012). High school students engaged in civil disobedience walkouts, university students occupied buildings, and workers' unions called for a general strike (Rocamadur 2011). This wave of protest escalated for months, and then partially subsided. However, soon neoliberal policies would deepen the economic crisis in Greece: in 2010, the government was forced to accept the first of several austerity bailout and structural adjustment programs imposed by the EU, the IMF and the European Central Bank (Sotirakopoulus and Sotiropoulus 2013), a capitulation met with protests and riots in many Greek cities. In early 2011, prompted by the provocative viral meme by the Spanish Indignados accusing the Greek people of sleeping (Ibid., 446), an anonymous Facebook call went out for a protest gathering in Syntagma Square on May 25th. This came not from seasoned activists, but from a small group of what one interview participant called "hipster activists," who did not belong to any traditional organization or political affiliation. To everyone's amazement, twenty-five thousand people converged. Following the model of Tahrir Square in Egypt (Ibid.; Aouragh and Alexander 2011), they did not just gather for one event, but created a local micro-community with the square becoming an occupied acampada for several months, thus initiating the Greek Indignados or Aganaktismenoi movement (Prentoulis and Thomassen 2013, 171). The occupation of the square in Athens, according to our interview participants, soon split into two segments, with the more liberal participants, and even some right-wing nationalists, camping and protesting closer to the parliament buildings, while the radical left, including anarchists and autonomists, camped at the far end of the park, organizing according to general assemblies and working groups, including a media working group. Greek mobilizations developed a protest culture of horizontalism and self-governance that saw the creation of specific types of activist interventions such as theatre occupations (e.g. EMPROS in Athens), factory occupations (e.g. VIO.ME. in Thessaloniki), social centers and squats organized into productive co-operatives, social services including medical care offered collectively by unemployed professionals, and alternative media projects such as the Press Project instigated by unemployed journalists. While media activism was highly 
mobilized, and the spirit of indignation against austerity was certainly shared with Spain, the 'freedom technologist' or free culture approach emergent in the Spanish context did not take hold in the translocal mobilizations of the self-proclaimed Aganaktisemenoi or Indignados of Greece.

Here we note similarities and differences among contexts in the three countries, paying particular attention to their specific political and economic contexts as well as to the unfolding of particular protest events in each country. In Spain, May 15, 2011 saw the culmination of a long process of learning by the Indignados (Romanos 2013), who sparked the Greeks to action on May 25th. Also in Spain, the consequences of the Great Recession were aggravated by neoliberal policies adopted by both centreleft and centre-right governments under pressure from electorally unaccountable institutions such as the European Central Bank, and by speculation in the financial sector. Similarly, in Greece the crisis was sparked by a bailout of the state, which was itself bankrupted by crony capitalism. In Greece and Spain, anti-austerity movements advocated for better democratic practices, with the Spanish Indignados in particular opposing capitalism (Sotirakopoulos and Ntalaka 2015, 78-79). The global day of action in October in Greece and Spain brought with it a measure of hope and success, whereas in Italy the same mobilization ground the movement to a halt.

These divergent outcomes can be understood through an analysis of the cultural context in which the specific forms of protest developed. In a comparative study of anti-austerity mobilizations, Andretta and della Porta (2015) have shown that while the precarious generation was almost equally present in Italy and Spain, in Spain it was able to build a more radical and cohesive collective identity-as self-proclaimed Indignados-based on a more informal, digitally-integrated movement network, while in Italy the social movement's embeddedness in more formal, traditional networks that relied on older protest logics prevented the formation of a broader collective identity. The same patterns emerge from the analysis of our interview data. In the Italian context, the organizational logics and identitarian traits of the older generation prevailed, remaining static, and never fully embracing the model of longer-term square occupations, or the collective subject-position of indignants or the $99 \%$. The newer generation of activists was not able to emancipate itself from the influence of entrenched social movement actors, including both informal and more formal institutionalized ones.

In Greece, despite a long tradition of general strikes, groups, networks and individuals from all walks of life mobilized around the collective identity of Aganaktismenoi, similar to the Indignados of Spain, quickly abandoning the limitations of traditional top-down institutional organizations, such as unions and NGOs, in favor of the occupied square model initiated in Tahrir Square, and copied by Occupy and the Spanish Indignados to generate participatory, directly democratic processes for social movement organization and action. Andretta and della Porta (2015) point out the importance of considering the specific tendencies of civil society in each context. In Spain in 2011, decentralized grassroots organizing prevailed, resonating with libertarian traditions and giving value to "discursive public opinion" and "deliberative democracies" (Sampedro and Lobera 2014). In Italy, clashes among the three main nodes of the earlier global justice movement (eco-pacifists, anti-neoliberals, and postautonomists) partially contributed to the failure of the October 15, 2011 global day of action against austerity, and produced a weak opposition to Mario Monti's government. While organized civil society in Italy may be stronger, it is extremely structured, even when it comes to less institutionalized grassroots activism, while in 
Spain and Greece it is perhaps weaker, but more autonomous and horizontal, in part influenced by the long history of anarchist movements in both countries. Thus, in the Spanish scenario there was more space for the construction of an inclusive horizontal collective identity when a new protest culture demanding a more participatory and transparent politics emerged fueled by the $15 \mathrm{M}$ protests. Whereas in Italy, the fragmentation of social movement actors together with the less permeable, static, topdown tendencies of movement organizations impeded the development of a cohesive collective identity or unified protest culture.

Greece is similar to Italy and Spain in terms of its relative propensity toward protest: all three have a higher incidence of protest than other European countries, but what is perhaps a key difference is that Greece has a long history of general strikes with one almost every year in the past decade (Rüdig and Karyotis 2013, 492). They also have an astonishing number of protests: in 2010, "7,123 demonstrations took place in Greece" (497), with 4,268 in Athens alone (498). The weak civil society of pre-crisis Greece, and in particular the perceived apathy of young people who receive no civic education in school, is thus overcome by the Aganaktismenoi movement, partly shaped by its crucial precursor, the December 2008 youth-led anti-police-brutality riots, organized by a highly mobilized youth-oriented civil society networked through social media, who took these networks offline into the streets and squares (Theocharis 2011; Milioni and Panos 2011).

In 2011 they did so not just through protests and square occupations but also through the construction of collectives, cooperatives, voluntary organizations and other non-institutionalized civic and communicative actions. Interestingly, the 2010-11 wave of contention in Greece was not dominated by youth, but rather by experienced middle-aged social movement actors in the 45-54 year-old range, which comprised the largest group of strikers and protesters (Rüdig and Karyotis 2013, 506). The younger activists of the precarious generation who became active in 2008 worked side by side in 2011 with the more experienced middle-aged activists from the global justice movement. Perhaps because in Greece anti-austerity mobilizations were not limited to the precarious generation, as in Italy, but were intergenerational like the Spanish Indignados, the Aganaktismenoi were able to carry forward the wave of anti-austerity protests in Syntagma Square and beyond, integrating emergent social media practices of the younger generation into a well-established horizontal and decentralized protest culture of the older generation, and this despite having one of the lowest internet penetration rates in Europe at 68\% in 2016, with only 30,000 Greeks having Twitter accounts still in 2011 (Theocharis 2016, 4).

Here we see a clear picture emerging of the socio-political context and protest cultures in Spain, Italy and Greece. We now move on to consider how these contexts shape the very different digital protest media imaginaries in the three countries.

\section{Comparing Digital Protest Media Imaginaries}

In Spain, the digital activism of the $15 \mathrm{M}$ represented the refinement, culmination and enhancement of previous movement tactics, giving birth to technopolitics, a sophisticated form of communicative action that is a complex blend of technological knowledge and digital expertise used for radical political purposes with the technology itself seen as a site of contestation (Toret et al. 2015; Sáez 2011). It is key to note that the term technopolitics is defined and used by tech media activists themselves. Technopolitics in the Spanish mobilizations included: massive mobilization of hackers before, during and after the protests; key contributions of bloggers, citizen journalists, 
academics, micromedia entrepreneurs, and tech-lawyers (the so-called freedom technologists) throughout the anti-austerity protests; and the strong connection to a free culture milieu through the lessons and repertoires of the Sinde Law protests rooted in a non-hierarchical, collaborative and open spirit (Fuster Morell 2012; Postill 2016). Drawing attention to the strong connection between free culture values and the 15M digital protest media imaginary, one of our interview participants remarked:

It is not just that the hackers tell the people what to do, it is much more than that: it is a hybridization so strong between the technopolitical practices and the dynamics of the movement that it reaches a point where it is part of the same DNA [SP05].

The Free Culture Movement in Spain can thus be understood to have contributed to the $15 \mathrm{M}$ movement in several key ways (Fuster Morell 2012), in particular: by influencing the agenda of the movement in relation to information and knowledge policies and practices; by situating the digital commons as a pivotal topic and a crucial site of contention (Fuster Morell and Subirats 2012); and by shaping the movement's organizational logic through horizontal, decentralized coordination that relied heavily on digital media while following a hacktivist logic or ethos (Milan 2015).

Technopolitics includes practices such as the tactical appropriation of corporate social media platforms such as Facebook and Twitter (Galis and Neumayer 2016), used in an effective combination with tools for internal communication like pads, WhatsApp and Telegram in order to coordinate actions, build trending topics that influence public opinion, direct the mainstream media agenda, and control the protest narrative in the public sphere. But, critically, it also means imagining specific kinds of anti-capitalist technological alternatives. In Spain, activists created their own radical media, the N-1 alternative social media platform, as well as the iDemocracia Real YA! website, they created, shared and utilized free and open-source software, and they advocated for technological infrastructure sovereignty and self-determination where feasible. Finally, in Spain the technopolitics of the Indignados had a notable prefigurative character, consisting of the experimental development of prototypes or micro-utopias (Gutiérrez 2013) that point toward alternative futures by creating them in the here and now. Communicative transparency, self-determination and knowledge sharing were pivotal, manifesting in a strong component of "radical media education" consisting of a never-ending flow of online tutorials, seminars and peer-to-peer skillshare workshops about digital media tactics ${ }^{2}$. According to our interview participants, almost every protest, squat or camp action was accompanied by a sophisticated decentralized but coordinated media strategy that included clear and simple explanations on how best to adopt and spread a series of Twitter hashtags, the most favourable hours to create a trending topic for a particular campaign, the lists of pads that were covering that specific topic, the Facebook groups created to mobilize around a particular set of grievances, and more.

It was not only that every single protest action had its digital counterpart; it was that every campaign would be simply unimaginable without its related online components - they were intrinsically connected as part of the same technopolitical process or 'part of the same DNA' as our interviewee suggested. The profound embrace of technopolitics can therefore be seen as the prime characteristic of the

${ }^{2}$ As an example, see this online guide on Twitter activism and social media campaigns: https://ciberactivismosol.wordpress.com/2014/03/18/twitter-para-activistas-como-conseguiruna-buena-campana-en-redes-sociales/. The guide was also translated into Italian: http://www.dinamopress.it/news/twitter-per-attivisti-istruzioni-per-una-campagna-vincente 
Spanish digital protest media imaginary, an imaginary where the technical insights of media activists, who argue that "corporate social media have to be used because now most of the people are there, but we have to use them wisely" [SP07], meets the hands-on, experimental attitude of the hacker and free culture milieu [SP06], coexisting with the prefigurative creation of alternative networks and infrastructures [SP04], all underpinned by discourses of technological autonomy from corporations and the state $^{3}$. In this digital protest media imaginary, the technological and the political are intrinsically integrated-technology is political and politics are technological-and the possibilities of this intermixture are fully realized.

In contrast, Italian digital protest media imaginaries reflected the fragmented and parochial landscape from which they originated. While interviewees acknowledged that in recent years various powerful mobilizations with a strong digital component had flourished in the Italian context (e.g. The Purple People, the People of the Wheelbarrows, Teatro Valle in Rome, and Macao in Milan), the use of digital media during the Italian anti-austerity mobilizations appears as a divided landscape of isolated platforms and voices, each one belonging to a particular coalition or local group (e.g. infoaut.org, milanoinmovimento.com, global project.info, dinamopress.it, etc.). These groups and their digital counterparts favoured more traditional, old logics of both media and protest movements, lacking the free and open-source digital networks of the free culture movement, and disconnected from the prefigurative futuristic digital political logics and radical technopolitics of hackers and techies. Italian digital activism was instead constituted by factionalization, ideologues, and territorialism, all with defined perimeters and gatekeepers. Part and parcel of the old communicative logic, the Italian digital protest media imaginary is marked by a deep scepticism regarding the effectiveness of social media platforms for political action, accurately rejecting them as capitalistic perhaps, but then not developing autonomous platforms in their stead. In the following illuminating excerpt, an Italian activist compares the Spanish and Italian attitudes toward digital technology in political activism:

We [Italians] have always had this idea that the media do not make the movements, but are just means of communication. They [Spanish activists] always thought that the Internet creates a movement, but I guess we'll never think that. It's a different approach: they are post-ideological and they started from the indignation, while for us the indignation was never enough: the web indignation made us laugh, we called them 'keyboard lions', those activists on Facebook all the time. [IT05]

This attitude toward digital technology seems to be one of arrogant perplexity and resignation, not experimentation and empowerment, where digital media are envisioned as something only used "because you have to," and then just as a "means of communication," while more important things are imagined to be organized elsewhere and otherwise-activists should not spend so much time on their keyboards. Underpinning this attitude is the argument that Facebook and Twitter are not properly political arenas because they do not leave enough space for the development of coherent thought, something that "real politics" demands [IT11]. This idea tends to be endorsed by more experienced, older activists in Italy, while younger ones are more keen to appropriate newer media, but in Italy this new generation of

${ }^{3}$ On the development of autonomous platforms, see in particular the reflections developed by $15 \mathrm{M}$ engaged academics on the issue of technological sovereignty (Candón Mena 2012; Hach and Franco 2010). 
activists found it difficult to overcome the general trend toward scepticism, and their relevance within the ranks of Italian activism was relatively weak, with the older generation maintaining a position of power.

An old activist logic regarding the use of digital media, therefore, can be seen to include both a general aversion to embracing technological innovation, and a (mis)understanding of digital platforms as functioning just like 'old media', with more emphasis on their broadcasting or 'point to many' (and thus centralized and hierarchical) capabilities, neglecting or perhaps actually rejecting their 'peer-to-peer' (and thus horizontal and decentralized) possibilities, or the potential inherent in what Shirky (2008) calls 'here comes everybody'. Finally, the fragmentation of the Italian digital media imaginary was in part due to the strong presence of the 5 Star Party/Movement that perhaps catalyzed the energies of social movements, with a discourse of participatory horizontalism, while simultaneously and contrarily engaging in systematically authoritarian and anti-democratic practices, thereby failing to integrate the previous generation of top-down activists with the precarious generation of horizontal social media users (Treré and Barassi 2015). This co-optation of the digital protest media imaginary by the 5 Star Party/Movement was able, as one activist put it, to "defuse the digital power of social movements precisely in a period where more spontaneous rebellions were flourishing around the world" [IT12]. Therefore the characteristics of fragmentation, digital scepticism and traditional, old communicative logics served to shape the digital protest media imaginary in Italy that can best be labelled techno-fragmented.

In Greece we see a third type of translocal mobilization that is not entirely consistent with the collective autonomy and technopolitics of the Spanish Indignados, nor as fragmented and incoherent as the communicative imaginary of the Italian movement. In Greece over two million people participated in the anti-austerity movement (Sotirakopolous and Sotiropolous 2013, 448), with activists developing a pragmatic approach to digital protest media. The 2008 protesters used Twitter extensively to provide live-tweet updates, using them to track the protests and riots, and working in conjunction with the established Indymedia Athens site, which provided a platform for longer articles, images and videos (Milioni and Panos 2011). By 201011, active Facebook usage within the general population had surged, and in 2011, the main protest media website was the Indignados of Syntagma Square Facebook page, with 80,000 followers. Key Twitter hashtags included: \#RBnews (radio bubble news), \#greekrevolution and \#antireport. The activists we interviewed imagined various digital media platforms to have specific interconnected potentialities, which they would harness with particular objectives, exploiting what they saw as different technological opportunities. As one activist states:

Of course there are differences. Twitter is the king of protest reporting, because it's faster, direct... But then when you want to comment on what has happened Twitter is problematic because it doesn't give you enough space to post and you need longer posts. You may need to write an article and publish it through a blog or a website, and maybe after that you link it through Twitter. Or even if you don't have time or don't have enough materials to write an article you write a post on Facebook that can be something in between. [GR21]

Here we see the digital protest imaginary shaping up in the form of a network of various platforms envisioned to serve different purposes, when in fact the technological affordances of the platforms are not so distinct. In reality, Facebook could be used for brief live updates, or Twitter, blogs and activist-run websites could 
be used for action calls, etc. In addition to using social media, "the blogger community was very organized 2008-2011" [GR10], providing a space where longer articles were written in a collaborative journalistic process. Some saw corporate platforms such as Facebook offering a more general audience or wider reach than activist sites like Indymedia or radical hashtags such as \#antireport, so they chose Facebook to organize mobilizations, and to engage in public debates. These decisions were based on what they imagined it offered, largely ignoring the political economy of Facebook, including its capitalist ownership model, facilitation of state surveillance, and the limitations and control imposed by its algorithms, on the one hand, and on the other hand, different technological affordances for adaptation or reconfiguration that went unexplored. While media activists produced and distributed digital texts, audio, images and videos in other spaces (e.g. according to our interview participants: the widely influential 2011 film Debtocracy the magazine Unfollow, the Omikron satirical video projects, and various digital community radio stations), Facebook was purposefully used as an aggregator for the alternative media self-produced and self-representative content of the movement (e.g. articles written by Indymedia Athens, then cross-posted or linked on Facebook), as well as for directly posting action calls and debating strategies and tactics. Twitter was used less in 2011 than 2008, as several interviewees found that Greek Twitter had been taken over by trolls.

Greek media activists seized the means of production of representation in several platforms, using them for what they imagined they could achieve in a practical goaloriented attitude. While more experienced activists such as those involved in Indymedia Athens did discuss the technopolitics of platforms (Milioni 2009), particularly when the site was shutdown by the administration of the university that housed it (Croeser and Highfield 2015), the free culture technopolitics of Spanish media activists was not fully actualized by the protest culture that evolved in Greece. Contributing to this utilitarian approach to media was the fact that several mainstream media outlets in Greece were shut down, and newly unemployed professional journalists migrated to contribute to activist media and movement mobilizations; these professionally trained journalists did not come from the anarchist or anti-capitalist media activist milieus of Indymedia's alternative journalists, but nonetheless they adopted some of their values and corresponding practices. The Press Project, for example, a collective of unemployed professional journalists, was quickly accepted as being autonomous movement media by the general assemblies, and was the only video group, according to our respondents, allowed to film those large meetings.

Interestingly, these divergent media practices never came into conflict, where there seemed to be a sense that people would use whatever worked for them, being active on digital media platforms they felt comfortable with; the intensive skillsharing and comprehensive communicative strategizing of the technopolitical media activists in Spain was largely absent. The pragmatic imaginary in Greece that envisioned media practices through the imagined communicative affordances and limitations of specific forms or platforms of digital protest media, reveals both an understanding of the political exigencies of digital technologies, while still consisting of some (mis)perceptions shaped as much by objectives, desires, attitudes, protest cultures, or past alternative media experiences, rather than the actual technological opportunities, barriers, or political economies of the forms or platforms engaged. For example, there was a marked absence of analysis of the potential of state surveillance of the movement through Facebook, or the fact, as noted in social media labour scholarship, that social movement actors posting on Facebook are engaged in free labour for the 
capitalist exploitation of Facebook, garnering massive profits for the corporation (Brophy and de Peuter 2007; Cohen 2013; Dean 2014). Therefore we can characterize the digital protest media imaginary in the Greek 2011 wave of contention as largely techno-pragmatic.

In summation, Greek social movement actors envisioned the diversity of digital media opportunities much more techno-pragmatically than the divisive technofragmentation in Italy, but they did not go to the depths of technopolitical engagement evident in Spain, where the technological elements of media production were seen as a site of political contention in and of themselves, and a key sociotechnical dimension of the movement itself.

\section{Conclusion}

In this article we have discussed how translocal digital protest media imaginaries can reflect specific socio-political contexts and translocal protest media cultures. We have considered three specific interrelated dimensions of analysis in order to bring together social movement and digital media theoretical frameworks, attempting to correct three biases in the scholarship: the media-centric bias in communications research that tends to neglect social movements; the ahistorical bias in media research that risks ignoring the socio-political and cultural conditions; and the hyper-local bias in social movement studies that ignores the global network society. We have done so by comparatively analyzing the translocal anti-austerity protests with specific emphasis on digital protest media imaginaries in the 2011 wave of contention in Spain, Italy and Greece.

Our analysis reveals that in Spain the 15th of May 2011 saw the culmination of a decades-long process of organizing and protesting by groups and networks that coalesced to become the Indignados, who sparked the Greeks to action ten days later on May 25th. While the global day of action against austerity in October in Greece and Spain brought with it a measure of achievement and hope, in Italy the mobilization that day ground the movement to a halt due to insurmountable tensions between different groups and coalitions. While in Spain there was more space for the construction of an inclusive and horizontal collective identity when the new political culture of the Indignados emerged, in Italy fragmentation in the sphere of civil society, combined with its impermeable and static nature, hindering the emergence of a collective protest culture that could bring together a range of political actors or issues. Meanwhile in Greece, activists embraced the cohesive collective identity of Aganaktismenoi, effectively integrating the youth movement arising in the 2008 anti-police brutality protests together with citizens who were middle-aged and older from the strong history of general strikes and the global justice movement, and taking up action frames translocally from the Indignados of Spain and other global movements such as Tahrir square in Egypt.

This analysis casts light on the three different digital protest media imaginaries that emerged in the countries examined, imaginaries clearly linked to the specificities of their social, political and cultural contexts: the powerful technopolitical imaginary of Spain, where the political and the technical are imagined by activists to be intrinsically and inseparably linked; the demobilizing techno-fragmented imaginary of Italy, dominated by digital scepticism and traditional old movement logics; and the ad hoc techno-pragmatic imaginary of Greek activists who used digital media more cohesively than in Italy, but without the technopolitical savvy and experimentation of Spain's free culture influence. We have thus shown that the "imaginary matrix" of communication 
technologies (Cabrera 2006), in other words, the assumptions, visions and attitudes toward digital media used for protest and mass mobilizations, are shaped by a complex array of socio-technical, political, historical and cultural factors that cannot be reduced to simple explanations only centred on the technological affordances and communicative characteristics of online platforms (Mosco 2005; Reestorff 2014).

Taking our reflections a step further, we argue that digital protest media imaginaries-and perhaps media imaginaries in general-can contribute to shape protest cultures, media practices, social movement organizational structures, and the potential for a movement to define its objectives and achieve its outcomes, particularly when they are able to align these imaginaries closely with their social movement objectives. We do not imply that media imaginaries developed during the anti-austerity phase directly impacted the political formations that followed, as this conception would be problematically techno-deterministic, but we do suggest, along with other scholars, that there is an "elective affinity" (Romanos and Sádaba 2015) between specific media imaginaries and forms of deliberation and organization. This is evident if we look at the Spanish context, where the Indignados wave of activism paved the way for the subsequent mareas (tides) or smaller campaigns on specific issues such as education, public health, and culture. It also played a role in shaping Party $X$, Podemos and Ganemos, the party-wave that challenged established political parties by relying on innovative communicative strategies that blend digital deliberation platforms with traditional media where "technological mediation has modulated the transition from movement to party by generating an environment of horizontal deliberation, distributed participation and decentralized structure that reduces the visible differences between the two" (Ibid., 1). Whether this intensity of horizontal participation in political parties will be maintained over the long term remains an outstanding question worthy of investigation.

In the Italian context, contrary to Spain, the fragmented media imaginaries neither inspired nor produced innovative forms of sociotechnical action and the social movement sector remains divided, with only timid attempts to innovate at the level of digital communicative practices. The 5 Star Movement still dominates the scene, and grassroots communicative power remains largely dormant. Whereas in Greece, we see Syriza, a coalition party of the radical left, taking power in 2015, along with civil society impacts in terms of collective self-organization, both engaged with communicative innovations. One might debate whether the emergence of political parties out of broad-based social movements provides a voice for the movement, or conversely demobilizes it, with only certain leaders gaining power, and perhaps risking further co-optation by the top-down political process, however that takes us beyond these findings so must be left as a question for future research.

We have demonstrated the importance of multidisciplinary research for studying social movements and their communicative practices: we need the toolbox of social movement theories and methods, and here even cultural studies has been useful, even if we sometimes overlook these fields in the haze of fascination with big data, tweets and posts. Social movements and media activists are now digitally integrated, where media activists and alternative journalists work in similar contexts with social movement organizers, which can shape the characteristics of their contention and communicative repertoires and outcomes in similar ways.

Further studies will need to look closely at the dynamic interrelations between digital protest media practices and imaginaries, and their consequences for the political and organizational dynamics and outcomes of social movements and 
grassroots political parties. As research on digital protest media practices expands beyond a superficial fascination with social media and big data, it will be crucial to finetune the reflections on the infrastructure, imaginaries, protest cultures and historical trajectories that sustain and shape media activism and social movements, preferably in a comparative perspective that can shed further light on their translocal similarities, differences, challenges, and achievements.

\section{References}

Andretta, Massimiliano and Donatella della Porta. 2015. Contentious Precarious Generations in Anti-Austerity Movements in Spain and Italy. Revista de Ciencias Sociales 10 (1): 37-66.

Ardagna, Silvia and Francesco Caselli. 2014. Political Economy of the Greek Debt Crisis: A Tail of Two Bailouts. American Economic Journal: Macroeconomics 6 (4): 291-323.

Aouragh, Miryam and Anne Alexander. 2011. The Egyptian Experience: Sense and Nonsense of the Internet Revolution. International Journal of Communication 5: 1344-1358.

Barassi, Veronica. 2015. Activism on the web: Everyday struggles against digital capitalism: New York: Routledge.

Barba, Carmen Haro, and Víctor Sampedro. 2011. Activismo político en Red: del Movimiento por la Vivienda Digna al 15M. Teknokultura: Revista de Cultura digital y Movimientos sociales 8 (2): 157-175.

Baumgarten, Britta, Priska Daphi and Peter Ullrich (Eds.). 2014. Conceptualizing culture in social movement research. New York: Springer.

Brophy, Enda and Greig de Peuter. 2008. Immaterial Labor, Precarity, and Recomposition. In Knowledge Workers in the Information Society, edited by Catherine McKercher and Vincent Mosco. Lanham MD: Lexington.

Cabrera, Daniel Hectór. 2006. Lo tecnológico y lo imaginario: las nuevas tecnologías como creencias y esperanzas colectivas. Buenos Aires: Biblos.

Castells, Manuel. 2000. The Rise of the Network Society. Hoboken NJ: Wiley-Blackwell.

Castells, Manuel. 2009. Communication power. Oxford UK: Oxford University Press.

Cohen, Nicole S. 2013. Commodifying free labour online: Social media, audiences, and advertising. In The Routledge Companion to Advertising and Promotional Culture, edited by Matthew P. McAllister and Emily West, 177-191. New York: Routledge.

Comunello, Francesca, Simone Mulargia and Lorenza Parisi. 2016. The 'proper' way to spread ideas through social media: exploring the affordances and constraints of different social media platforms as perceived by Italian activists. The Sociological Review 64: 515532.

Costanza-Chock, Sasha. 2012. Mic check! Media cultures and the Occupy movement. Social Movement Studies 11 (3-4): 375-385.

Couldry, Nick and Andreas Hepp. 2015. Media Cultures in a Global Age: A transcultural approach to an expanded spectrum. In The Handbook of Global Media Research, edited by Ingrid Volkmer. 92-109. Hoboken NJ: Wiley-Blackwell.

Cristancho, Camilo. 2015. Social Media in the Mobilisation of Anti-Austerity Protest. In Social Protests and Democratic Responsiveness: Assessing Realities in Latin America and the Caribbean and the European Union, edited by EU-LAC Foundation. 73-102. Hamburg: EULAC Foundation.

Croeser, Sky and Tim Highfield. 2015. Harbouring Dissent: Greek Independent and Social Media and the Antifascist Movement. The Fibreculture Journal 193: 136-158.

Curran, James, Natalie Fenton and Des Freedman. 2012. Misunderstanding the Internet. London: Routledge.

Dalakoglou, Dimitris. 2012. The Crisis before 'The Crisis': Violence and Urban Neoliberalization in Athens. Social Justice 39 (1): 24-42. 
Dean, Jodi. 2005. Communicative Capitalism: Circulation and the Foreclosure of Politics. Cultural Politics 1 (1): 51-74.

Dean, Jodi. 2014. Communicative Capitalism and Class Struggle. Spheres Journal for Digital Culture 1: 1-14.

della Porta, Donatella. 2012. Mobilizing against the crisis, mobilizing for "another democracy": comparing two global waves of protest. Interface: a journal for and about social movements 4 (1): $274-277$.

della Porta, Donatella. 2015. Democratic Practices in Anti-Austerity Movements: From Forum to Camps, from Latin America to Europe. In Social Protests and Democratic Responsiveness: Assessing Realities in Latin America and the Caribbean and the European Union, edited by EU-LAC Foundation, 13-34. Hamburg: EU-LAC Foundation.

della Porta, Donatella and Alice Mattoni. 2014. Social networking sites in pro-democracy and anti-austerity protests: Some thoughts from a social movement perspective. In Social Media, Politics and the State: Protests, Revolutions, Riots, Crime and Policing in the Age of Facebook, Twitter and YouTube, edited by Daniel Trottier and Christian Fuchs, 39-67. London: Routledge.

della Porta, Donatella and Massimiliano Andretta. 2013. Protesting for justice and democracy: Italian Indignados? Contemporary Italian Politics 5 (1): 23-37.

Fenton, Natalie. 2015. Left Out? Digital Media, Radical Politics and Social Change. Information, Communication \& Society 19 (3): 346-61.

Flichy, Patrice. 2007. The Internet Imaginaire. Translated by Liz Carey-Libbrecht. Cambridge MA: MIT Press.

Fuchs, Christian. 2013. Social media: A critical introduction. London: Sage.

Fuster Morell, Mayo and Joan Subirats. 2012. Towards a New Policy Making? Cases of the Free Culture Movement and the Digital Commons and 15M in Catalonia. Research Report. IGOP-UAB for EAPC.

Fuster Morell, Mayo. 2012. The free culture and 15M movements in Spain: Composition, social networks and synergies. Social Movement Studies: Journal of Social, Cultural and Political Protest 11 (3-4): 386-392.

Galis, Vasilis and Christina Neumayer. 2016. Laying Claim to Social Media by Activists: A Cyber-Material Détournement. Social Media + Society (July-Sept): 1-14.

Gerbaudo, Paolo. 2013. Protest Diffusion and Cultural Resonance in the 2011 Protest Wave. The International Spectator 48 (4): 86-101.

Gitelman, Lisa. 2006. Always already new: Media, history and the data of culture. Cambridge: MIT Press

Gutiérrez, Bernardo. 2013. Spain's Micro-Utopias: The 15M Movement and its Prototypes. Accessed May 10, 2016. http://www.occupy.com/article/spains-micro-utopias-15mmovement-and-its-prototypes-part-1.

Jasper, James. 2014. Protest: A cultural introduction to social movements. Toronto: Wiley \& Sons.

Jenkins, Henry. 2006. Convergence Culture: Where Old and New Media Collide. New York: New York University Press.

Juris, Jeff. 2008. Networking futures: The movements against corporate globalization. Durham NC: Duke University Press.

Kavada, Anastasia. 2013. Internet cultures and protest movements: cultural links between strategy, organizing and online communication. In Mediation and protest movements, edited by Bart Cammaerts, Alice Mattoni and Patrick McCurdy, 75-94. Bristol: Intellect.

Koopmans, Ruud. 2004. Protest in Time and Space: The Evolution of Waves of Contention. In The Blackwell Companion to Social Movements, edited by David A. Snow, Sarah A. Soule and Hanspeter Kriesi, 19-47. Malden: Blackwell.

Kyriakidou, Maria and Jose Javier Olivas. 2014. The Indignados in the Spanish and Greek Press: constructing narratives of civic resistance. Accessed May 10, 2016. 
http://blogs.Ise.ac.uk/eurocrisispress/2014/01/24/the-indignados-in-the-spanish-and-greekpress-constructing-narratives-of-civic-resistancel

Marvin, Carolyn. 1988. When old technologies were new: Thinking about electric communication in the late nineteenth century. Oxford: Oxford University Press.

Mattelart, Armand. 2003. The information society: An introduction. Translated by Susan G. Taponier and James A. Cohen. London: Sage.

Milan, Stefania. 2015. Hacktivism as a radical media practice. In The Routledge Companion to Alternative and Community Media, edited by Chris Atton, 550-560. London: Routledge.

Milioni, Dimitra. 2009. Probing the online counterpublic sphere: the case of Indymedia Athens. Media, Culture \& Society 31 (3): 409-431.

Milioni, Dimitra and Dionysis Panos. 2011. New media and radical protest: Reflections from the 'Greek 2008 riots'. International Journal of Media and Cultural Politics 7 (2): 223-240.

Mosco, Vincent. 2005. Here Today, Outsourced Tomorrow: Knowledge Workers in the Global Economy. The Public: Journal of the European Institute for Communication and Culture 12 (5): 39-55.

Nagy, Peter, and Gina Neff. 2015. Imagined affordance: Reconstructing a keyword for communication theory. Social Media + Society 1 (2): 1-9.

Polletta, Francesca and James M. Jasper. 2001. Collective identity and social movements. Annual Review of Sociology 27: 283-305.

Postill, John. 2016. Freedom technologists and the future of global justice. Accessed May 10, 2016. https://www.tni.org/en/publication/freedom-technologists-and-the-future-of-globaljustice

Prentoulis, Marina and Lasse Thomassen. 2013. Political theory in the square: Protest, representation and subjectification. Contemporary Political Theory 12 (3): 166-184.

Reestorff, Camilla. 2014. Mediatised affective activism: The activist imaginary and the topless body in the Femen movement. Convergence: The International Journal of Research into New Media Technologies 20 (4): 478-495.

Rocamadur. 2011. The 'Indignados' Movement in Greece. SIC: International Journal for Communisation 1: 75-93.

Romanos, Eduardo. 2013. Collective learning processes within social movements: some insights into the Spanish 15M/Indignados movement. In Understanding European Movements: New social movements, global justice struggles, anti-austerity protests, edited by Cristina Flesher Fominaya and Laurence Cox, 203-219. New York: Routledge.

Romanos, Eduardo, and Igor Sádaba. 2015. La evolución de los marcos (tecno) discursivos del movimiento $15 \mathrm{M}$ y sus consecuencias. Empiria: Revista de metodología de ciencias sociales 32: 15-36.

Rüdig, Wolfgang and Georgios Karyotis. 2013. Beyond the Usual Suspects? New Participants in Anti-Austerity Protests in Greece. Mobilization: An International Quarterly 18 (3): 313330.

Sáez, Víctor Manuel Marí. 2011. Comunicar para transformar, transformar para comunicar. Tecnologías de la información desde una perspectiva de cambio social. Madrid: Editorial Popular.

Sampedro, Víctor, Sánchez Duarte and José Manuel. 2011. La red era la plaza [The net was the square]. Accessed May 10, 2016. http://www.ciberdemocracia.es

Sampedro, Victor and Josep Lobera. 2014. The Spanish 15M Movement: a consensual dissent? Journal of Spanish Cultural Studies 15 (1-2): 61-80.

Shirky, Clay. 2008. Here Comes Everybody. New York: Penguin

Shirky, Clay. 2011. The Political Power of Social Media: Technology, the Public Sphere, and Political Change. Foreign Affairs 90 (1): 28-41.

Sotirakopoulos, Nikos and Olga Ntalaka. 2015. From the streets and the occupied squares to the central political field: The narratives of the anti-austerity camp in Greece. In Beyond the 
Internet: Unplugging the Protest Movement Wave, edited by Rita Figueiras and Paula do Espírito Santo, 76-98. London: Routledge

Sotirakopoulos, Nikos and George Sotiropoulos. 2013. 'Direct Democracy Now!': The Greek Indignados and the present cycle of struggles. Current Sociology 61 (4): 443-456.

Tarrow, Sidney. 1998. Fishnets, internets, and catnets: Globalization and transnational collective action. In Challenging Authority: The Historical Study of Contentious Politics, edited by Michael P. Hanagan, Leslie Page Moch and Wayne Te Brake, 228-245. Minneapolis: University of Minnesota Press.

Theocharis, Yannis. 2016. Every Crisis is a Digital Opportunity: The Aganaktismenoi Movement's Use of Social Media and the Emergence of Networked Solidarity in Greece. In The Routledge Companion to Social Media and Politics, edited by Axel Bruns, Gunn Enli, Eli Skogerbø, Anders Olof Larsson and Christian Christensen, 184-197. New York: Routledge.

Theocharis, Yannis. 2011. Young people, political participation and online post-materialism in Greece. New Media and Society 13 (2): 203-223.

Theocharis, Yannis, Will Lowe, Jan W. van Deth and Gema García-Albacete. 2015. Using Twitter to mobilize protest action: online mobilization patterns and action repertoires in the Occupy Wall Street, Indignados, and Aganaktismenoi movements. Information, Communication \& Society 18 (2): 202-220.

Toret, Javier, Antonio Calleja-López, Oscar Marín Miró, Pablo Aragón, Miguel Aguilera, and Alberto Lumbreras. 2015. Tecnopolítica: La potencia de las multitudes conectadas. Barcelona: Editorial UOC.

Treré, Emiliano and Alice Mattoni. 2016. Media ecologies and protest movements: main perspectives and key lessons. Information, Communication \& Society 19 (3): 290-306.

Treré, Emiliano and Veronica Barassi. 2015. Net-authoritarianism? How web ideologies reinforce political hierarchies in the Italian 5 Star Movement. Journal of Italian Cinema \& Media Studies 3 (3): 287-304.

Vatikiotis, Pantelis. 2016. Social Media Activism: A Contested Field. In (R)evolutionizing Political Communications through Social Media, edited by Tomaž Deželan and Igor Vobič, 40-54. Hershey PA: Information Science Reference.

Vradis, Antonis and Dimitris Dalakoglou. 2011. Introduction. In Revolt and Crisis in Greece: Between a present yet to pass and a future still to come, edited by Antonis Vradis and Dimitris Dalakoglou, 13-28. London: AK Press \& Occupied London.

Wolfson, Todd. 2014. Digital rebellion: The birth of the cyber left. Champaign IL: University of Illinois Press.

Zamponi, Lorenzo. 2012. 'Why don't Italians Occupy?' Hypotheses on a Failed Mobilisation. Social Movement Studies: Journal of Social, Cultural and Political Protest 11 (3-4): 416426.

\section{About the Authors}

Emiliano Treré is a Research Fellow at the Institute of Humanities and Social Sciences of the Scuola Normale Superiore (Italy) and within the COSMOS Center on Social Movements Studies based at the same institution. He has published extensively in international journals and books on the challenges, the opportunities, and the myths of media technologies for social movements and political parties in Europe and Latin America. He is coeditor of "Social Media and Protest Identities" (Information, Communication \& Society, 2015) and "Latin American Struggles \& Digital Media Resistance" (International Journal of Communication, 2015). His book, provisionally titled Complexities of Contemporary Digital Activism: Social Movements and Political Parties in Spain, Italy and Mexico, is forthcoming with Routledge. [email: emiliano.trere@sns.it] 
Sandra Jeppesen is an activist, researcher and educator. She researches autonomous media and anti-authoritarian social movements from a queer, trans, feminist, anti-racist, anti-capitalist and anti-colonial perspective. A member of the former Collectif de Recherche sur l'Autonomie Collective (CRAC) Montreal, she is cofounder of the Media Action Research Group (MARG, mediaactionresearch.org), Associate Professor in Interdisciplinary Studies and Media Studies at Lakehead University Orillia, Canada. She currently holds the Lakehead University Research Chair in Transformative Media and Social Movements.

Alice Mattoni is Assistant Professor at the Scuola Normale Superiore (Florence, Italy). She investigates media practices and grassroots politics at the national and transnational level. Her work has been published in top-ranked international journals and she is the author of Media Practices and Protest Politics. How Precarious Workers Mobilise (Ashgate 2012). 


\title{
Social Reproduction in the Live Stream
}

\author{
Elise D. Thorburn
}

\author{
Brock University, St. Catharine's Ontario, Canada, ethorburn@brocku.ca
}

\begin{abstract}
In this paper I seek to explicate how alternative, particularly feminist, modes of social reproduction emerge through digital networks in contemporary social movements, using Concordia University Television's live streaming of Quebec's 2012 student strike as a case study. By examining this struggle in the light of more contemporary movements and technological changes. In this I seek to aid an understanding of technology use in social movements that presents itself not simply as a new or alternative political project, but as a new way of collaboratively accounting for collective interests. Sketching the changes since 2012 by looking to the live streaming initiatives in the anti-police brutality protests in Ferguson and Baltimore 2015, this paper will suggest future horizons of digital and embodied activism around social reproduction focused on media forms within social movements. Based on ethnographic research, including participant observation and interviews, I argue that the practices and projects of live streaming can expand forms of social reproduction autonomous from both the state and capital. The digital practices of social reproduction emerging in contemporary struggles can contribute to circumventing power while at the same time constituting sites of resistance within and beyond social and political contestations.
\end{abstract}

Keywords: Digital Media, Social Reproduction, Live Streaming, Social Media, Social Movements

Acknowledgement: This article makes use of interviews with CUTV volunteers and workers, and develops out of my own engagement with the live streaming project of the station. I want to thank all those volunteers and workers who brought the project to fruition through the Spring and Summer of 2012. Especially thanks to Laith Marouf and Gretchen King for their longstanding media activism, and for their continued interrogation into what we can learn from the experience of CUTV and how we can deepen our radical practices as media activists. I also want to thank the reviewers who provided such engaged and thoughtful feedback for this piece. Such careful attention to ideas is an act of solidarity.

\section{Introduction}

In the most recent cycle of struggles - those beginning in 2010 with the wave of resistances across the North Africa and the Arab world, continuing in the plaza occupations in Europe and the Occupy movement in North America - a changed logic of activism is evident (DyerWitheford, 2015). Research on these struggles has often emphasised the interactions of the digital (through online forms of activism, communication, and coordination) with the embodied (in assemblies, spatial occupations, and face-to-face encounters [Gerbaudo 2012]). Although gender has been considered in regard to these struggles (Herrera 2014) feminist concerns have been either neglected or - in the squares themselves - met with hostility (Ezquerra 2012). Each of the sites and movements in the post-210 cycle of struggle, though, have placed the practices of what can be considered "social reproduction" at the centre of the movement, even if they are never theorised as such. While key to the emergence and maintenance of the spatial occupations of this most recent cycle of struggles (Brown et al. 2013), social reproduction has been under-theorised in much of the literature charting these 
resistance movements, and its relationship - as embodied practices - to the prevailing digital technologies used in struggle has been almost absent in recent scholarly work.

Social reproduction refers to the capacities of populations to reproduce themselves and through this to reproduce the material basis of the economy (Bezanson and Luxton 2006; Federici 2012). It is a site wherein human beings and capital compete for the reproduction of living bodies, and contemporary social movements have become ground zero for such socially reproductive contestations (Thorburn 2016). Within contemporary movements, struggles over social reproduction are increasingly channelled through digital networks as well as embodied practices. This digital-embodied convergence opens up strengths and weaknesses in the contemporary epoch of social/political contestation.

Over the unfolding of the long neoliberal period, working class power and its capacities for resistance have been significantly destabilised (Dyer-Witheford 2015). As such, human beings have been made globally even more vulnerable to the shifts and swings of an unforgiving market economy, and the capitalist relations of the global South trickle upwards to impact the capitalist relations in the previously stable global North. Today the working class is segmented and uneven across the globe, and the dynamics that their struggles take are equally segmented and uneven. Yet these varied dynamics of struggle carry common threads: they emerge as a response to a crisis of care (Brown et al. 2013) or of social reproduction, and mark attempts by movements to re-assert autonomy from the market in our reproductive capacities, to build our lives and relationships outside of the cash nexus, outside of the imperatives of commodification and securitisation. While communicative technologies, such as social media, have been a key part of channelling socially reproductive labours into accumulative circuits (see Wages for Facebook, for instance) ${ }^{1}$ these technologies have also played an important role in the recuperative attempts at making social reproduction autonomous from both the market and the state.

In this paper I seek to explicate how alternative, particularly feminist, modes of social reproduction emerge through digital networks in contemporary social movements, using Concordia University Television's live streaming of Quebec's 2012 student strike as a case study. By examining this struggle in the light of more contemporary movements and technological changes. In this I seek to aid an understanding of technology use in social movements that presents itself not simply as a new or alternative political project, but as a new way of collaboratively accounting for collective interests. Sketching the changes since 2012 by looking to the live streaming initiatives in the anti-police brutality protests in Ferguson and Baltimore 2015 , this paper will suggest future horizons of digital and embodied activism around social reproduction focused on media forms within social movements. Based on ethnographic research, including participant observation and interviews, I argue that the practices and projects of live streaming can expand forms of social reproduction autonomous from both the state and capital. The digital practices of social reproduction emerging in contemporary struggles can contribute to circumventing power while at the same time constituting sites of resistance within and beyond social and political contestations.

This is not to argue that what we are witnessing in current digital-embodied resistant convergences and the focus on social reproduction marks a qualitatively and quantitatively different moment in the history of struggle. Rather, struggles over all those things that permit the reproduction of human beings as subjects antagonistic to capital's domination has been the centrepiece of all resistant movements. In neoliberal capitalism there is something novel, though, in the extend to which our reproductive capacities - particularly those involving communication - have been thrown onto the market and thus forge within us an alienation not only from our labour but also from our most intimate relationships with others, with our lives, leisures, and loves (Thorburn 2016; Andrejevic 2011). This commodification has been facilitated by emergent digital technologies. At the same time, these technologies - often the very same technologies - and their convergences with embodied practices can make a site for the reclamation of our reproductive capacities, broadly defined, in the contemporary moment. When viewed through the framework of feminist social reproduction theory, the digital-

\footnotetext{
${ }^{1}$ Wages for Facebook (http://wagesforfacebook.com/) and also Jung (2014).
} 
embodied nexus of contemporary struggle opens up a variety of future horizons towards which social movements can turn.

Because of the centrality of social reproduction theory to this argument, this paper begins with an examination and definition of the concept. I then chart the main lines of the 2012 Quebec student strike and focus on Concordia University Television's use of live streaming technology to cover the strike from within the very moments of contestation themselves. I examine how recuperative or autonomous attempts at social reproduction flowed through CUTV's live streaming project in three ways: its material composition, its expansion of "participatory journalism," and its immediacy. Finally, I briefly turn to the emergent technologies of live streaming to highlight both some of the limits of social reproduction across new media technologies and to suggest where digital-embodied convergences for recuperated social reproduction may emerge next.

\section{Social Reproduction}

In the fallout of the 2007-8 economic crises, Marxist categories for understanding the globally ascendant system of capitalism moved closer to the mainstream of academic and popular discourse. Generally circumscribed as an on-going relational struggle between waged workers and capitalist owners, this description of capitalism is both materially and theoretically incomplete. At its foundation, capital is a system of social relations engaged in a perpetual process of expansion through formal and real subsumption. As such, how this system and its participants are reproduced on a daily and intergenerational basis becomes an important frame through which to consider processes of accumulation. For Marxist feminists such as Dalla Costa and James (1973) and Federici $(2004,2012)$ social reproduction also became a key framing through which to understand how resistances to capitalism are produced and reproduced.

In Volume II of Capital, Marx (1978) analysed the reproduction of the capitalist system, noting that capital endeavours simultaneously to reproduce human labour-power alongside the conditions of capitalist social relations. In essence, then, for Marx social reproduction is the reproduction of capitalist society. But theorisations of the reproductive component of the capitalist mode of production did not extend, for Marx and many Marxists afterwards, to any sort of detailed analysis, until taken up by Marxist feminist writers around the 1970s. In the Marxist feminist theoretical tradition, social reproduction refers to the labour process that creates value through the production and reproduction of labour power (Vogel 1983). It can include the material means of subsistence such as the provisions of food, water, housing, and health care, or, most frequently associated with Italian feminist theorists, the particular kinds of labour involved in the daily and intergenerational regeneration of others - i.e., domestic, care, affective, and sexual work; labours primarily associated with women (Dalla Costa and James 1973; Federici 2004, 2012; Fortunati 2007). In more recent work on theories of social reproduction, the concept has been taken up to consider the struggles over the provisions of the welfare state - those social institutions and infrastructures that reproduce social relations on a grand scale - the school, public education systems, health care, social security, and pension plans (Bezanson and Luxton 2006). Social reproduction is all of those things which enable labour power to go to work another day, and which enable the basic means of existence through which we can create and sustain relationships, whether these relationships are to each other or to capitalism. It is the processes of social reproduction that sustain capitalist drives for accumulation. This feminist focus not only corrects a gender blindness at the core of most theories of the economy and class struggle - including Marxist theories - but suggests an alternative mode of understanding capitalist and anti-capitalist relations that place care-giving at the centre (Bezanson and Luxton 2006; Federici 2012).

The range of writings on social reproduction is broad, and hence coherent and unified theory is difficult to ascertain. In general Marxist theories of social reproduction signify three levels -1 ) the reproduction of individual labour power; 2) the reproduction of the total workforce of a given capitalist social formation; and 3) the reproduction of the capitalist system itself. For the purposes of this argument, I will follow the through line of the Italian Marxist 
feminists, touching on all three levels but focusing these levels primarily for their potential as sites of resistance to the reproduction of capitalist social relations, rather than the reproduction of them.

In this framework, social reproduction can be understood as the quotidian and intergenerational maintenance and reproduction of life, designating the ways in which the physical, emotional, and mental labour necessary for the production of human populations (and hence labour power) is socially organised. More important to my argument are the affective elements of social reproduction: the support we give, the regenerative activities of love and care we participate in, and the work of "maintaining a sustainable environment, or satisfying emotional needs" (Brown et al. 2013, 78). This is to focus on the web of social relations that maintain and reproduction human labour power as life, and to conceive of this as a site of work that can be, Federici (2012) insists, the "point zero" of revolutionary struggle. As a site of work, social reproduction involves conflict, violence, and exploitation, and becomes a powerful site for contestations because it is the least abstracted form of labour. Because social reproduction simultaneously produces human labour power and human life, relationships to capital and relationships to each other, it is a site of potential antagonism and struggle. In creating labour power social reproduction creates life - we become the subjects we know ourselves to be - friends, lovers, parents, workers, comrades - through sets of socially reproductive acts. These processes involve distorted relationships that are central to the reproduction of capitalism as a system of exploitation and domination, but also hold the kernel of its annihilation. Social reproduction creates and recreates labour power, yes, but none of us is reducible simply to our capacity for labour, and herein lies the opening for socially reproductive resistances. Federici (2012) argues that social reproduction holds a "dual character;" it can become a site for revolutionary self-activity and collective co-constitution. Social reproduction reproduces human beings "for capital, for the labour market, as labour power, but it also reproduces our lives and potentially it reproduces our revolt against being reduced to labour power" (Vishmidt 2013). This reproductive labour is fundamental to the continuation of social movements and struggle, and is often forms the ground on which struggle is articulated. Recognising the dual character of social reproduction allows us to determine which labours we can refuse (those that reproduce us for capital) and which we must use to foment social movements and struggles for social change.

There is a long history to struggles that make use of socially reproductive tactics in movements - the creation of "communities of care" and collective forms of reproduction that sustain movements have been at least partially present in the contestations of the twentieth century. It was the feminist movements of the mid-twentieth century that asserted that any revolution must begin at home (Haiven 2011). Regardless, reproductive labours of resistance have a similarly long history of reproducing the gendered relations and inequalities of daily life into movement spaces. Such clearly gendered reproductive labour remains in the more contemporary techno-centred movements of today. The division of labour in the 2011 Occupy movement was, for example, present but often ignored. As Boler et al. (2014) note, it was the "connective labour" taking place online that provided some of the space for reproduction in the Occupy encampments, and this labour was largely the domain of women. Connective labour, they note, is networked and affective, taking place online and through social media. It involves the work of administrating, documenting, and connecting via digital portals, and in Boler et al.'s research it was primarily feminized and frequently invisible, or ignored as an aspect of movement building. Very often, labours taking place online are disregarded as aspects of social movement struggle, and socially reproductive labour is thought to only exist in the very embodied interactions we have with each other in physical space.

In the remainder of this article, then, I want to chart some of the ways socially reproductive resistances emerged through the digital technologies used in contemporary expressions of social struggle. In this, I will focus on the affective dimensions of recreating human subjects as sites and actors in moments of resistance. While digital technologies share a problematic role in the commodification and securitization of socially reproductive capacities (Thorburn 2016), they also create new openings and the possibility of newly centred subjects in struggle. 
Before moving on to my case study I want to stress my position against a fetishisation of the digital. Technology is a broad term, what Leo Marx called a "hazardous concept" (2010) it refers not only to specific devices or inventions, but also complex socio-technological systems, such as institutions and organisations, infrastructures and belief systems, the ambiguous, messy and incoherent new formations of the social. Class struggles and social reproduction, then, have always been a merger of the deeply embodied and the highly technical, or what I have elsewhere called a human-machinic assemblage (Thorburn 2013a). While I am going to focus on the digital components of the strike today, my reading of the contemporary moment relies upon detailed understandings of the embodied aspects of social movements and social reproductions, while remembering that the embodied is always and has always been entangled with the technological.

I also want to note that much of the research for this article grew out of my own participation in the Quebec student strike, and from interviews, participant observation, and document analysis I engaged in during and after the strike. I spoke to organisers in student associations and participants in the strike, community members and student activists from the past, volunteers with CUTV, people active on the streets, long-time activists and newly radicalized students. I read through blog posts, newspaper stories, journal articles, and even diary entries to ascertain the experiences people had of the strike and to draw connections between the theories I was operationalising and the actual on-the-ground moments of struggle. I feel confident that what I present here is a more-or-less accurate reflection of the experiences, lessons, and structures of the Quebec student strike and the livestreaming at CUTV.

\section{Quebec Student Strike and CUTV}

In 2012 students at universities and colleges across Quebec engaged in a months long general strike, resisting a proposed tuition fee hike $-\$ 325$ annually for five years, for a total increase of $\$ 1625$ - which marked state-based politics at the heights of globally ascendant austerity politics. Throughout the seven months of the strike, roving marches marked the nights, economic disruptions marked the days. At its peak, 150,000 were on strike from classes. Demonstrations featuring at least a quarter of a million people celebrated the strike's anniversary each month. Striking students attended daily general assemblies in their departments and faculties, and sent representatives to the monthly assemblies of the provincewide coalition spearheading the strike, CLASSE. ${ }^{2}$

The Quebec student strike differed in form from the other contemporary assembly movements - it was not a spatial occupation and so socially reproductive practices like community kitchens, tent cities, childcare spaces, and care for the homeless were absent. While university classrooms or entrances were briefly blockaded, the strike was more an occupation of social reproduction as lived experience - as education, as affect, and as communication. With its focus on educational institutions, the Quebec student strike highlighted how processes of social reproduction are increasingly channelled through a state infrastructure that is beholden to the demands of the market, and thus fails those it claims to serve. Austerity, then, must be read as the latest iteration of a crisis of social reproduction.

Through both blustery and contemplative moments of the strike, amidst the relative calm of general assemblies and chaos of the street demos, a group of students and media activists undertook a project to revolutionise journalism, the use of technology in social movements, and the technological components of social reproduction. Using the latest in live streaming technology, teams of media activists from Montreal's CUTV (Concordia University Television) took to the streets, marching alongside protestors, filming the demonstrations and instantly live streaming those images to the internet, beaming them to computers across the province, country, and in fact the world. Although the use of digital technology was discouraged as a form of participation in Quebec assemblies, such machinic components did form a

${ }^{2}$ Coalition large de l'Association por une Solidarité Syndicale Étudiante (CLASSE) was the large student union that represented departments, faculties, and universities across several campuses in Quebec. 
key part of the strike in its processes of social reproduction. The stream highlighted the ways affective capacities of social reproduction channels through pathways of communication and how care/solidarity can be transmitted via digital networks.

CUTV is a student- and community-run television station based out of Concordia University in Montreal, Quebec, broadcasting via a closed-circuit TV network, DVD releases, internet distribution networks, and public access TV channels. It is the oldest university television station in Canada, founded in 1969. Undergoing a series of changes from $2009-2010^{3}$, the station emerged into a wider public spotlight with the decision, in the winter of 2012, to obtain high definition live streaming equipment, and to begin streaming video footage of the demonstrations underway in Montreal and across the province as part of the Quebec student strike $^{4}$. As a journalistic and social media form, CUTV's live stream project was contributed to the development of autonomous processes of social reproduction. The composition of the live stream teams allowed affective relationships to be created, communicated, and transmitted in both human and machinic forms; the live stream created a digital location for autonomous social reproduction. In this sense, the CUTV's live stream project offers us a concrete example of the role of technology in contemporary movements of socially reproductive resistances.

In the spring of 2012, the station leased equipment from LiveU - the apparatus provider and purchased platform space from Livestream at livestream.com. LiveU provided CUTV with an LU60 backpack, which contains the technology necessary to stream live video to a web platform. This includes encoding hardware, a Firewall cable, and a built-in wireless connection with six load-balanced $3 G$ modems that deliver data over $3 G$ and $4 G$ cellular networks. The LU60 backpack contains a transmission system that is connected via a lengthy wire to any shoulder-mounted camera. The transmission system takes video images, disassembles them, bonds them, and sends them over cellular networks to the Livestream platform where they are reassembled and uploaded. The backpack also contains its own modem and router, making it a mobile Wi-Fi hotspot, allowing again for constant connectivity but also permitting other mobile devices to connect to the Internet. The transmission system also si-

${ }^{3}$ In 2009 a referendum at the University saw an increase in the student levy directed towards CUTV (up to 34 cents per student), which effectively doubled the station's budget. This permitted the station to hire staff. Laura Kneale was hired as Station Manager in 2010 and Laith Marouf as Programme Director.

${ }^{4}$ The demonstrations that crossed Quebec, and reverberated in the rest of Canada in the winter, spring, and summer of 2012 were centred around student opposition to increased tuition fees at Quebec's publicly funded universities. The movement involved almost all university and CEGEP (college) campuses across the province, and was largely lead by a coalition of student associations and individual student unions under the umbrella of CLASSE (Coalition Large de I'ASSE) which operated on the basis of directly democratic decisionmaking through regular general assemblies. Soon garnering vast public support, monthly demonstrations sometimes involved 250,000-400,000 people including labour activists and community groups, and nightly demonstrations began lasting for several months consecutively. "Casserole" protests also began, inspired by the cacerolazos of Chile in the 1970s, and neighbourhood assemblies also began across the city of Montreal, incorporating community members into the organising and structure of the student strike. The strike had always been, but became clearly then, about much more than simply tuition fees, and instead was a sustained attack on the austerity policies of the Liberal government. With approximately 150,000 students on strike by May of 2012 the Liberal government soon folded, and declared an election which they lost. The fee increases have recently been re-negotiated by the victorious Parti Quebecois government, and will, in the long run, amount to greater increases than what the Liberal party was originally proposing. Therefore, although quiet now, student strikes could easily erupt again in Quebec in the coming months and years. For further writing on the student strike of 2012 see parts 1 and 2 of Wl: Journal of Mobile Media, Vol 6, No. 2, Spring 2012. 
multaneously analyses conditions in the field, and recommends the most suitable video settings for the prevailing conditions ${ }^{5}$.

In the winter and spring of 2012 CUTV broadcast live each night from the midst of the demonstrations. The camera and crew were on the ground and in the crowd whether the demonstration was a peaceable (though speedy) walk through Montreal's city streets or in the near war-zone of Victoriaville where teargas canisters and rubber bullets assailed protestors, injuring some and hospitalising others. CUTV's reporters and the live stream team did not remain at a distance from struggle, but were actively a part of it, following and aiding injured demonstrators, and often attacked themselves. In this way, CUTV's live streaming projects established itself not simply as passive, objective, side-lined media, but as collaborator, co-constructing new resistant subjectivities and with them new socially reproductive capacities. CUTV played an important role in the subjective transformations underway in the Quebec student strike.

The remainder of this article will explore these the ways in which socially reproductive capacities were expanded through the live streaming projects of CUTV. I will examine this first through the concept of participatory journalism that was deepened through the live stream project, and second, through the ways in which live-streaming's immediacy becomes a source of resistant socially reproductive capacities. This article will conclude with some thoughts on the ways newer, more mobile live streaming technologies potentially expand or contract such socially reproductive capacities within contemporary social movements.

\section{Participatory Journalism: The Assembly of CUTV and the Recuperation of Social Reproduction}

CUTV's live stream broadcasts greatly differed from most mainstream media footage (and from the live streaming footage of earlier demonstrations and riots) ${ }^{6}$ in that the station broadcast live from the centre of demonstrations, marching alongside the demonstrators, many of whom were their peers. These broadcasts provided activists, strike participants, and the broader community with opportunities for bold, unedited reflections on the struggle by strike participants themselves; self-representation and direct communication with audiences, mediated only through the participatory technologies at hand. Images and stories of strike participants were not channelled through the political yet purportedly "objective" lens of the mainstream media. ${ }^{7}$ For those unable to attend the actions, for those at far remove from Montreal, or for those impeded by mobility issues or familial responsibilities, the live stream gave insight into the motivations, ideas, analysis, and politics of the strikers and demonstrators from their own perspectives. These went far beyond the mainstream media's reliance on government platitudes and shocking images of rioters smashing windows or running from tear-gas happy police. ${ }^{8}$ This was a particular kind of journalism, a movement journalism for the prevailing technological conditions.

\footnotetext{
${ }^{5}$ All information about the LiveU LU60 backpack can be found through the LiveU website at www.liveu.tv

${ }^{6}$ For example, the live streaming of the Tahrir Square occupation was shot from a high angle, from a camera several hundred feet away and in the air. The same is true of the Greek riots, and the anniversary of the occupation in Egypt in 2012. CUTV, by contrast, placed itself in the very centre of the demonstrations.

${ }^{7}$ For critical analysis of mainstream media's objectivity refer to Herman and Chomsky, 1988. and Herman, 1996.

${ }^{8}$ This image of demonstrators as spoiled children engaged in wanton property destruction was especially prevalent in mainstream English-language media in the rest of Canada. But, while the coverage and analysis was better in French, students were rarely able to see complex, well-rounded descriptions and debates about their struggle.
} 
The notion of "participatory journalism" is similar to embedded journalism used by more mainstream news organisations in wartime scenarios, ${ }^{9}$ but unlike embedded reporters participatory journalists themselves have a stake in the struggles. These are invested media makers, creating new journalistic practices and alternative channels of communication using the power of emergent technologies and social media (Lievrouw 2011). The human component of the CUTV live stream team was largely made up of activists and students on strike or those sympathetic to the strike. Many volunteers were grounded within the student movement or in the broader Montreal anti-authoritarian social justice community (Jeppesen 2012). As CUTV volunteer Jadis Dumas argues, "part of why CUTV was so successful and why it had such a strong presence and longevity was because of the confidence it had already built within the radical community." ${ }^{10}$ The demographic makeup of the station and the affective networks of CUTV members allowed for the creation of bonds of trust and solidarity between strike participants and the media form. But the demographics also meant that CUTV journalists shared many of the class positions and concerns of striking students, and had inside knowledge of their aims and goals, and the actions of the movement. This departs from the usual separation that occurs between the mediated and the media makers, and as such confirms CUTV as a mode of participatory journalism.

But it is the affective dimensions of the relationship between journalism and participation that ties CUTV to processes of recuperating social reproduction from securitising or commodifying impulses. Dumas elaborated upon this relationship of movements to media:

"We worked within a radical framework, and the consistency of our coverage meant that even those who weren't yet radicalised still trusted CUTV because of the support we showed as individuals and as a group, and to other individuals and groups. I can think of countless examples of CUTV folks going in to support others as activists and not simply observing as reporters. It is important for me that that line becomes blurred. It is not possible - not even desirable - to separate oneself from activism as a journalist if that is your politics. I cannot imagine surviving the strike if we at CUTV hadn't been sharing and supporting each other and other strikers as human beings first and foremost."

Certainly, the support CUTV enjoyed from the student strikers developed out of the station's participatory role in the struggle and the consistency of their reporting, which created a sphere of autonomous communication. But such an infrastructure of social reproduction was impossible without the specific technology that created the possibility of the live stream as "participatory journalism." The necessity of both the human and technological components of this project were apparent, Laith Marouf notes, because:

We are not just trying to document things with high quality imaging, like some film collectives do, nor just be there when action happens, like some media activists do. We are trying to create television quality production with an open bias towards people's movements, so that we offer a real, high quality, produced alternative to both the public and the private sectors. It is very clear that the private

${ }^{9}$ Embedded journalism refers to news reporters being "embedded within" or attached to and given the protection of military units during armed conflicts. While it has some historical precedents with regards to interactions between journalists and military personnel, it became prevalent with the 2003 invasion of Iraq. Embedded journalism has been critiqued by media professionals themselves for the inherent bias that comes with covering an institution charged with protecting one's life. Critical articles include Cockburn, 2010 and Myers 2010. As well documentaries such as The War You Don't See and War Made Easy: How Presidents and Pundits Keep Spinning us to Death also take a critical approach to embedded reporting and journalistic bias in mainstream media organisations.

${ }^{10}$ Interview with Jadis Dumas, 7 Aug 2012. Skype. 
and the public arms of the fourth estate are not going to give any sort of support or even equitable voice to the students and their objectives. But our mandate is different from the public or the private. We are not beholden to shareholders, profits, or the state. We are there to represent communities that otherwise lack representation or are misrepresented in the mainstream media ... We exist to give a platform to those voices - a high quality, well produced platform that can offer a challenge to the 24 hour production cycle of huge TV stations and the quality of footage they produce. Carrying a laptop or filming with a cellphone isn't going to cut it for the quality of production we want. Citizen produced media is very important and worthwhile, but we want to produce something different - a sustainable, high quality alternative - and for that we needed to invest in the technology. (Thorburn 2013b)

Together, the technology and volunteers of CUTV gave legitimacy to the project of the live stream broadcasts: the mobility afforded by the LiveU backpack and camera meant that the station could broadcast live from the midst of demos each night; the activist credentials and clear bias towards students opened the demonstrators up to the station. Thus the convergence of technology with human bodies created a moment wherein socially reproductive resistances - in this case modes of communicative social reproduction in line with the goals and aims of participatory journalism - could emerge. Participatory journalism aims to provide insider perspectives on the struggle, thus helping marginalised communities "resist cultural domination and homogenisation;" creating and supporting "local, 'homegrown' media and content that better represents their interests" (Lievrouw 2011, 146). Such was the aim of CUTV, according to Marouf, who stated that the station existed to represent communities left out of mainstream or corporate media discourses, or not permitted to represent themselves (Thorburn 2013). CUTV's journalistic model developed the affective dimension of journalism, critiquing and opposing "the market-driven cynicism and detachment of the mainstream press" (Lievrouw 2011, 148).

Because CUTV developed bonds of trust with strikers and because journalists were movement participants themselves, they often possessed insider knowledge and were able to access spaces, places, and voices that mainstream and corporate media could not. This element of participatory journalism contributes to freer flows of information - as Lievrouw (2011) notes, breaking through the informational blockade often constructed by private media firms. Such far-reaching breakage of information blockades is only made possible through the advances in social media technologies in recent decades ${ }^{11}$ - social media emerged as an important source for the latest news and aided in keeping movement participants abreast of the latest developments throughout the 2011 cycle of struggles. As with other social media platforms CUTV's live stream used the same tools and sent information along the same globalised cybernetic flows that "transnational network capitalism" (Fuchs 2009) travels, while attempting to communicate in an oppositional and antagonistic mode. CUTV re-appropriated the digital tools of social reproduction (social media) to create sites for autonomous selfrepresentation and subject formation.

Against the standard definition of "participatory journalism," though, CUTV did not adhere to the "practices and values of professional journalism" (Lievrouw 2011, 148), such as objectivity, balanced reporting, and professionalism (Jeppesen 2012). Taking on the perspective of the students meant that CUTV was often unabashedly biased in their coverage. Laith Marouf, former Station Director and frequent camera operated stated explicitly that the "station favours the striking students and their supporters" and that if people want "the voice of the premier and the police and the university president amplified a thousand times"12 they can tune into mainstream media. In a workshop on "Autonomous Media" at the Montreal Anar-

${ }^{11}$ As noted in Chapter Two, Radio Alice was able to break through informational blockades by opening up phone lines to callers from the sites of struggle, but the reach of such free flowing information was limited by the broadcast range of the station.

${ }^{12}$ Interview with Laith Marouf, 22 Jun 2012. Montreal, QC. 
chist Bookfair, Station Manager Laura Kneale discussed the importance of bias in CUTV's reporting, suggesting that CUTV's bias removes the veil of objectivity from mainstream media, and reveals the biases inherent in media forms owned by corporate or state entities (Jeppesen 2012). When CUTV presents the viewpoints and voices of students in their entirety the absence of these same voices from mainstream media becomes glaringly apparent. ${ }^{13}$ Kneale notes:

The live streaming is important for me because I see people having access to information about what is going on in the demonstration and why, I see people being represented as they are, not as caricatures. And when people see this, they begin to feel empowered by the media; it isn't focussed on criticisms, doesn't emphasize only the vandalism of les casseurs. Instead, I feel that CUTV's live streaming coverage really popularised the movement and it also forced the mainstream media to reciprocate, to improve their coverage. The mainstream media had to begin covering the strike, or else our bias would be the only one people had access to. (Thorburn 2013b)

This purposeful bias is an important, socially reproductive element of CUTV's live stream, and it is at least partially possible because of the immediacy of the technology. In the forthcoming section I will discuss what role the immediate - and thus marginally mediated - plays in the construction of autonomous social reproduction. The immediate is the intimate; minimally mediated at least insofar as that is possible when visual information flows through the networks and nodes of the Internet.

\section{Immediacy and the Live Stream's Socially Reproductive Moments}

In a capitalist framework, immediacy contributes to the affective modes of panic or anxiety, that which Berardi (2009) and the Institute for Precarious Consciousness (2014) refer to as the dominant affective mode of our time. Immediacy is now "laced with anxiety" (Institute for Precarious Consciousness 2014), a perpetual present in which all are commanded to communicate and be communicable. But from the perspective of the human-technological media merger - in the context of a massive strike of millennial postsecondary students - immediacy proffered through CUTV's live stream builds the affective bonds that respond to anxiety or panic, deepening capacities for an autonomous social reproduction. The exhortation to communicate and be communicable becomes, through the lens of CUTV, instead an invitation to self-representation and participation similar to the participatory democracy embodied in the physical assemblies.

Invoking an autonomous social reproduction through the immediacy of CUTV's live stream will be demonstrated in three main ways. First, that the immediacy allowed for the direct and minimally-mediated transmission of the feeling of protest. Second, the expressions of these feelings on the part of strikers, through the live stream and to viewers, allowed for self-representation from striking students. And finally, both the transmission of feeling and the self-representation of strikers both contribute to an urgency that encourages participation from viewers at home.

As Jeppesen (2012) pointed out, what was unusual about CUTV's broadcasts, in comparison to mainstream video reporting, was the powerful conveyance of the emotions of protest that the live stream was capable of. Because they were live, and because they were close to the movement themselves - and also because they were frequently the targets of police violence - CUTV volunteers often responded emotionally to the situations they found themselves in. The intentional bias of the station and the movement-basis of the volunteer demographic also contributed to the high levels of affect that flowed through CUTV's live

\footnotetext{
${ }^{13}$ In fact, any coverage of the strike - especially in English media - was for a long time absent in its entirety. It was with the live streaming of the movement and with the heating up of tensions between strikers, the state, and police that mainstream coverage began to appear.
} 
stream. Because the volunteers placed themselves at the centre of protest, in the midst of striking students and in the face of police in riot gear, the video images transmitted were uniquely capable of creating and demonstrating the affective conditions of a demonstration often the confusion, the fear, the anger. As CUTV volunteer Mikelai Cervera notes "it is hard not to be emotional in the spur of the moment, if you are being charged by the police, if you are being kettled, if you witness something upsetting, or if you are a victim yourself."

The rawness of CUTV's footage - because perpetually live and unedited - transmitted the urgency of the demonstration as reporters cried for help and stumbled around confused after being pepper-sprayed by police, ran in fear from fired sound cannons and stun grenades, or gasped audibly and yelled in rage at police violence inflicted upon their friends and comrades. While controversial for some ${ }^{15}$ the expression of open and honest emotions - the impacts of being in the midst of, and part of, demonstrations created a level of honesty and transparency in the live stream. This honesty was communicated to viewers and contributed to the creation of bonds of trust. As well, the live stream transmitted the urgency of the demonstrations, giving voice to the affective dimensions of protest in ways that other social media forms cannot quite articulate. Live video conveys so much more, and much more viscerally, than other mainstream news coverage or even a Facebook post, Tweet, or YouTube uploads possibly can because it is ongoing, live, and raw. CUTV's live video stream incorporated viewers into the demonstrations, making them feel what participants felt, and in that making them participants themselves - slowly interpolating viewers into sympathisers and then actors.

But anger, fright, and rage were not the only emotions displayed through CUTV's live stream. As with the roving casseroles, live streaming the nightly marches also opened a window onto both the mundane moments of protest as well as the joyful ones. Marching for long evenings throughout Montreal could be devoid of the riotous cat-and-mouse game with the police, but the live video feed could then convey the conversations and friendships built through long collective night walks through the city's streets. The live stream could capture conversations amongst friends and was a space for demonstrators to come and share their own feelings and opinions. As well, the excitement of being engaged in acts of defiance and protest could be communicated through the live stream - both in the quiet moments and in the moments of action. The immediacy of the live stream conveyed to wide audiences the joy that Sterne (2012) and Barney (2012) found in voicing dissent collectively and building movements together, the emergence of a sociality without commodification. Moments captured by CUTV's live stream conveyed the temporary bubbles of joyous - as well as enraged - affect emerging throughout moments of protest. The stream captured the "outpouring of emotion and relief," and the "weighty sentimentality" (Sterne 2012, n.p.) that was enacted publicly each night in the roving demonstrations, and asserted both of the commonality of feeling and the commonality of the space the strike participants claimed. Through the live streaming video, strikers insisted on the space of the city as common, and made embodied "care" central to maintaining a collective ownership over this urban environment. In a letter to the editor of Quebec newspaper Le Devoir one writer noted that the being-together of protest was central to a sociality to come, and live video feeds of this emergent sociality was a central element of CUTV's socially reproductive capacity:

\footnotetext{
${ }^{14}$ Interview with Mikelai Cervera, 18 Jun 2012. Skype.

${ }^{15}$ Certainly there was dissent within the live stream teams about expressing certain levels of emotion, particularly anger. On one occasion, after being attacked by police from behind and pepper sprayed, several CUTV volunteers reacted angrily, screaming at a passing collection of riot police with epithets of "pigs!" and raising their middle fingers in the police's direction. Other members of the CUTV team were quick to admonish these actions saying that it made the station too overtly political and put the live stream team in danger of further police retaliation and attack. While emotions were demonstrated on camera regularly - and sometimes unintentionally, as is the nature of live video - it was not clear that all volunteers were entirely in favour of this.
} 
Now people greet and talk. Now neighbourhood meetings, discussions, vigils start up casually among neighbours on the steps and balconies of Montreal. The neighbourhood will be less and less alien. This is a true political victory!

We should repeat this friendly beating [the evocation of tapage doesn't quite work as well in English] possibly in other forms, until the land is occupied by neighbours who recognize one another, encounter one another each day by chance, and have known one another over the years. That is how we live in a place that is how we become citizens.

My heart swells with joy. ${ }^{16}$

In these moments of social movement resistance, social reproduction is reclaimed from the commodifying and securitising forces that capital seeks to impose upon it, and CUTV contributes to this reclamation through the diversity of affect the live stream was capable of displaying. Alongside rage, CUTV could clearly demonstrate "the camaraderie of intergenerational communities banging on pots and pans" and give voice to "the emotional impetus behind why people feel it is important to be in the streets, how people feel about austerity, and why they believe tuition should be free" (Jeppesen 2012, n.p.). Beyond simple binaries of joy and rage, CUTV's live stream could demonstrate the complexity of people's emotional engagement with protest, with movements, and with media. Action-driven emotions such as the tension and panic people feel when unintentionally trapped in a police kettle, or how temporarily disorienting tear gas or pepper spray attacks can be demonstrate "how traumatising certain interactions can be, particularly when police violence is experienced or witnessed" (Jeppesen 2012, n.p.). These affects are not as consistently and powerfully reproducible in mainstream media footage, nor in print or other social media venues. Live stream footage can, though, most accurately portray them.

The immediacy of the live stream also extended the ability of movement participants to engage in self-representation in the same honest, transparent, and affectively complex way to viewers. Both CUTV viewers and strike participants "felt really close to their media," as CUTV volunteer Jadis Dumas states, because of its unedited content. Viewers at home could "follow exactly what was going on in the streets" and people in the streets "knew that if they spoke to CUTV their words would be reproduced exactly." Much like the desire for selfrepresentation and the refusal to accept distant leadership at play in the politics of the assembly movements, the desire for a media form that permitted self-representation and hence some autonomous subject formation was met with the CUTV live stream. Because of the commitment of the CUTV volunteers to deliver transparent demonstrations of anger, frustration, and confusion in protests, as well as joy, excitement and love, movement participants developed an overall sense of kinship and solidarity with the station, and viewers could find common ground with the demonstrators. At demonstrations people who "felt the urgency to speak their mind would come right up to us and say what they had to say" says Dumas, and people watching at home would receive this information without editing or mediation.

The immediacy of the CUTV video form also developed intimate relations through digital technologies between movement participants and viewers at home. This allowed overlapping between viewers and participants to develop. Viewers could began to feel connected to both the individuals they were seeing on their screens and the struggle they were a part of, because they were privy to the unedited reflections from participants and their often harrowing experiences of the street. This connection between the assembly, assemblages, and immediacy contributes to the minor current of assemblage politics; increasing participation and interpolating new subjects into strugglers in class-based movements. CUTV volunteer Jesse Freeston argued that the live stream actually encouraged active participation amongst those viewing the feed. ${ }^{17}$ Instead of defeat or paralysis - feelings he claims are common when

16 The full text of the letter can be read on Le Devoir's website, available online here: http://www.ledevoir.com/politique/quebec/350721/victoire-collaterale Last accessed 5 Mar 2015.

${ }^{17}$ Interview with Jesse Freeston, 17 Jun 2012. Montreal, QC. 
watching distanced, biased corporate reporting, or in other forms of media produced at a remove from the action - the live stream encourages engagement and connection. Live streaming video shows "that not only does this movement exist, but it exists right now, it is happening right now" - its action is immediate, and therefore so too can be one's participation. This allows viewers to see that "not only are people not alone in thinking [that things aren't right and that education should be cheaper or free] but that there is a whole movement of people stepping up to the plate," and thus viewers can feel that their participation in the struggle is possible. The particular digital tools used in the Quebec Student Strike were a part of growing the minor current of the assembly, turning the immediacy of digital and social media from a force to rend apart social relations to a force for the bonding of and intimacy between people. The live stream itself became a site of recuperated social reproduction.

In its role as participatory journalism and through its immediacy, CUTV's live streaming formed a complex human-digital merging that proved integral to contemporary assembly movements. Through the modems, wireless signals, information packets, and the live stream, CUTV's digital body created an electronic fabric onto which viewers could stitch themselves. In this, they became implicated in the demonstrations - the live stream provided a framework for viewers' own autonomous formation of ideas, identities, and subjectivities. This itself served as social reproduction mediated through a very technologically sophisticated medium. Viewers and participants alike - sometimes found in the same body - could develop more radical subjectivities, more radical politics, through seeing oneself and one's comrades honestly, transparently, and complexly displayed. This contrasts with the anxiety and panic that Berardi (2009) and the Institute for Precarious Consciousness (2014) claim is the primary, or even exclusive, outgrowth of pervasive digital media's immediacy. With CUTV's live stream, comes the solidarity, kinship, desire to communicate, and bonds of trust necessary for constituting a recuperated social reproduction in the realm of communication but also, importantly, in the realm of the concrete, the political, the lived.

Since 2012, newer, more portable, and more accessible live streaming technologies have become popularly available. Although research on new live streaming apps such as Meerkat and Periscope is scant, their use is important to consider both for what they offer to social reproduction in resistance movements, but also for how they may contribute to the reinsertion of socially reproductive processes in circuits of commodification and securitisation. In this brief final section I will discuss some of these new apps and how they are being used in different sites and by different actors.

\section{Technological Change and the Future of Live Streaming}

Since 2012, live streaming has remained an important element of "citizen journalism" and the recent introduction of live streaming mobile apps like Periscope, Meerkat, and Facebook Live have proliferated the quantity - if not the quality - of "citizen" and "independent" journalists, especially those covering moments of social and political unrest across North America. The emerging mobile technologies for live streamlining are powerful tools for creating immediate, intimate portraits of social movements as they unfold in real time across the globe. But without careful consideration and careful use, they threaten to become just another weapon adopted and utilised against movements by corporate journalists and even by police forces. It is precisely in the ways that make live streaming politically powerful for social movements that they serve to threaten the interests and aims of corporate media.

In the 2014 uprisings across the United States against police violence, for example, mainstream journalists for corporate news outlets made use of emerging platforms such as Periscope and Meerkat to expand the coverage brought to their audiences, providing a more "authentic" view of the protests. Antagonistic to the socially reproductive elements of immediacy made evident through the live stream, such corporate engagements with live streaming sought to control the messaging as best they could. In a blog post for the BBC's "College of Journalism" site, the two journalists note: "Of course streaming live meant any profane language being shouted could not be censored (you can only 'mute' the phone by holding your fingers against the microphone). This is perhaps where the second journalist, the producer 
so to speak, was helpful, because we could pre-interview people, making sure they were aware of the nature of the live broadcast." (Botti and Strasser 2015, n.p.).

At the same time, the expansion of live streaming capabilities through new technologies and platforms, Facebook Live in particular, has had radically accessible disparate, often distant and isolated movements and actors. A proliferation of live streamers, even when not affiliated with larger bodies or organisations like CUTV, can deepen socially reproductive solidarities across and between movements. Recent live video from individual citizen journalists uploaded to Facebook Live have mobilised support for the land defenders of the \#NoDAPL protests in Standing Rock, ND and water protectors occupying Muskrat Falls in Labrador, Canada. Bearing witness to both the violence of the state - in the case of \#NoDAPL and the careful conversations of the water protectors - in the case of Muskrat Falls - was made possible through the live streaming video that have been present at both scenes.

It is the capacity of the live stream to expand the bonds of social reproduction that is so unsettling to the state, precisely because of the ways it inscribes viewers subjectively into the affective dimension of struggle. Because the mediation is so minimal, live stream footage uploaded and then archived via, for example, Facebook Live communicates the fear, the contemplation, the love, and the rage that are integral, embodied elements of social struggle. In a highly technical, cybernetic environment the socially reproductive aspects of live streaming form part of the unfolding historical lineage of more analogue, embodied media activities, and older practices of film and video. These include such disparate activities as letter writing, pamphleteering, consciousness raising groups operating alongside the older media forms of guerrilla television, pirate radio, and radical film and documentary-making (Boyle 1992; Askanius 2014; Gregory 2010, for example). In fact many of the questions of surveillance, security, safety, and activism have already been considered by earlier generations of activists and scholars considering the role of technology in social movements (Gregory 2010; Gregory et al. 2005). But what live streaming in general - but CUTV's collective project in particular - offers us that is unique is strengthened insight into how we develop and recover alternative modes of subject constitution. And these alternative modes are made clear precisely through an understanding of social reproduction focussed directly on these technologies of mediation. Through live streaming we can understand how social movement actors navigate the conditions before them and put their politics into practice, while also bearing witness to the might an power of the state to oppose their collective actions.

To continue and even deepen the capacity for social reproduction within the practices of the live stream requires more than just access to technology but rather careful engagement with it. It requires imagining the technology as an element in the toolkit of social movements, but one which is ambivalent regarding outcomes. It must be used to advance the struggles around which social movements situate themselves and when it not longer serves those purposes live streaming can be - must be - put away to avoid its use as a weapon against those same movements and struggles.

\section{References}

Andrejevic, Mark. 2011. "Surveillance and Alienation in the Online Economy." Surveillance and Society 8(3).

Askanius, Tina. 2014. "Video for Change." In Tufte, Thomas, Karin Gwinn Wilkins, and Rafael Obregon (eds). Handbook on Development Communication and Social Change. Wiley Blackwell. 453-470.

Barney, Darin. 2012. "Reflections on the 2012 Quebec Student Movement." Lecture given at Communication Studies Speakers Series, School of Journalism \& Communication. Carleton University, Ottawa, Ontario. 16 November. Available online at http://darinbarneyresearch.mcgill.ca/Work/Reflections on the 2012 Quebec Student St rike.pdf. Accessed 24 February 2015.

Berardi, Franco "Bifo." 2009. The Soul At Work: From Alienation to Autonomy. Los Angeles: Semiotext(e). 
Bezanson, Kate and Meg Luxton. 2006. Social Reproduction: Feminist Political Economy Challenges Neoliberalism. Montreal: McGill Queen's University Press.

Boler, Megan, Averie Macdonald, Christina Nitsou, and Anne Harris. 2014. "Connective Labour and Social Media: Women's Roles in the Leaderless Occupy Movement." Convergence 20(4): 438-460.

Botti, David and Franz Strasser. 2015. "Live-streaming the Ferguson Protests: We had to give Meerkat a try." BBC Academy. 17 March. Available online at: http://www.bbc.co.uk/blogs/collegeofjournalism/entries/40d417e6-1c21-449f-a2f3e299aa221b6d. Accessed 27 June 2016.

Boyle, Deirdre. 1992. "From Portapak to Camcorder: A Brief History of Guerrilla Television." Journal of Film and Video 44: 67-79.

Brown, Gareth, Emma Dowling, David Harvie, and Kier Milburn. 2013. "Careless Talk: Social Reproduction and the Fault Lines of the Crisis in the United Kingdom." Social Justice 39(1).

Chen, Adrian. 2014. "Is Livestreaming the Future of Media, or the Future of Activism?" New York Magazine. 7 December. Available online at: http://nymag.com/daily/intelligencer/2014/12/livestreaming-the-future-of-media-oractivism.html. Accessed 27 June 2016.

Cockburn, Patrick. 2010. "Embedded Journalism: A Distorted View of War." The Independent. November 27. Accessed 29 October 2016.

http://www.independent.co.uk/news/media/opinion/embedded-journalism-a-distorted-viewof-war-2141072.html

Dalla Costa, Mariarosa and Selma James. 1973. The Power of Women and the Subversion of the Community. Bristol: Falling Wall Press.

Dyer-Witheford, Nick. 2015. Cyber-Proletariat: Global Labour in the Digital Vortex. London: Pluto Press.

Ezquerra, Sandra. 2012. "Feminist Practice in the 15M Movement: Progress and Outstanding Issues." Open Democracy. 12 July. Available online at: https://www.opendemocracy.net/sandra-ezquerra/feminist-practice-in-15-m\#footnote2. Accessed 17 February 2015.

Federici, Silvia. 2012. Revolution at Point Zero: Housework, Reproduction, and Feminist Struggle. Oakland: PM Press.

Federici, Silvia. 2004. The Caliban and the Witch: Women, the Body, and Primitive Accumulation. Brooklyn: Autonomedia.

Fortunati, Leopoldina. 1996. The Arcane of Reproduction: Housework, Prostitution, Labour, and Capital. Brooklyn: Autonomedia.

Fuchs, Christian. 2009. "A Contribution to the Critique of Political Economy of Transnational Network Capitalism." Rethinking Marxism 21(3).

Gerbaudo, Paolo. 2012. Tweets and the Streets: Social Media and Contemporary Activism. London. Pluto Press.

Gregory, Sam. 2010. "Cameras Everywhere: Ubiquitous Video Documentation of Human Rights, New Forms of Video Activism, and Consideration of Safety, Security, Dignity, and Consent." Journal of Human Rights Practice 2(2): 191-207.

Gregory, Sam, Gillian Caldwell, Ronit Avni, and Thomas Harding (eds). 2005. Video for Change: A Guide for Advocacy and Activism. London: Pluto Press.

Haiven, Max. 2011. "Feminism, Finance, and the Future of Occupy: An Interview with Silvia Federici." Libcom.org. https://libcom.org/library/feminism-finance-future-occupy-interviewsilvia-federici. Accessed 29 October 2016.

Herman, Edward S. and Noam Chomsky. 1988. Manufacturing Consent: The Political Economy of Mass Media. New York: Pantheon Books.

Herman, Edward S. 1996. "The Propaganda Model Revisited." Monthly Review. July. Available online at: http://www.chomsky.info/onchomsky/199607--.htm. Accessed 9 March 2015. 
Herrera, Linda. 2014. Revolution in the Age of Social Media: The Egyptian Popular Insurrection and the Internet. New York: Verso Books.

Institute for Precarious Consciousness. 2014. "Anxiety, Affective Struggle, and Precarity Consciousness Raising." Interface: A Journal for and about Social Movements. 6(2): 271300.

Jeppesen, Sandra. 2012. "Livestreaming on CUTV: 'Emboldened riot culture' of Student Strike." Wi: Journal of Mobile Media 6(2).

Jung, Alex E. 2014. "Wages for Facebook." Dissent Magazine. https://www.dissentmagazine.org/article/wages-for-facebook. Accessed 29 October 2016.

Lievrouw, Leah A. 2011. Alternative and Activist New Media. Malden, MA: Polity Press.

Marx, Karl. 1978. Capital: A Critique of Political Economy Volume 2. New York: Penguin Books.

Marx, Leo. 2010. "Technology: The Emergence of a Hazardous Concept." Technology and Culture. 51(3): 561-577.

Myers, Steven Lee. 2010. "Embedistan: Embedding in Iraq During Invasion and Draw Down." New York Times. August 20. Accessed 29 October 2016. http://atwar.blogs.nytimes.com/2010/08/20/embedistan-embedding-in-iraq-during-theinvasion-and-the-drawdown/

Sterne, Jonathan. 2012. "Printemps érable: Quebec's Maple Spring." Theory and Event 15:3.

Thorburn, Elise. 2013a. "Social Media, Subjectivity, and Surveillance: Moving on From Occupy, the Rise of Live Streaming Video." Communication and Critical/Cultural Studies 11(1): 52-63.

Thorburn, Elise. 2013b. "Squarely in the Red: Dispatches from the Quebec Student Strike" in Upping the Anti: A Journal of Theory and Action No. 14.

Thorburn, Elise. 2016. "Networked Social Reproduction: Crises in the Integrated Circuit." tripleC: Communication, Capitalism \& Critique. Open Access Journal for a Global Sustainable Information Society 14(2): 380-396.

Vischmidt, Marina. 2013. "Permanent Reproductive Crisis: An Interview with Silvia Federici." Mute Magazine. http://www.metamute.org/editorial/articles/permanent-reproductive-crisisinterview-silvia-federici. Accessed 29 October 2016.

Vogel, Lise. 2014 (1984). Marxism and the Oppression of Women. Chicago: Haymarket Books.

\section{About the Author}

\section{Elise Thorburn}

Elise Thorburn is an Adjunct Professor of Sociology at Brock University and a Postdoctoral Fellow with the On the Move Partnership at Memorial University of Newfoundland. With On the Move she investigates the use of algorithmic shift scheduling software in low-wage work environments, particularly those with extended commutes. She is also the Principle Investigator on a SSHRC Insight Development Grant-funded project entitled "Between the Office and the Prison Yard: Mobile Monitoring of Social Life" which examines the genealogy and circulation of emerging mobile surveillance devices across a variety of institutional settings. Specifically she is looking at the increasing movement of monitoring technology from prisons into immigration detention, elder-care facilities, and corporate and extractive industries, creating what she calls an expanded "carceral infrastructure" of capital and the state. 


\title{
Technopopulism: The Emergence of a Discursive Formation
}

\author{
Marco Deseriis \\ Northeastern University, Boston, USA, m.deseriis@neu.edu, \\ http://neu.academia.edu/MarcoDeseriis
}

\begin{abstract}
This article contends that technopopulism is a discursive formation that emerges from the convergence of two preexisting discourses: populism and technolibertarianism. Whereas these discourses are historically distinct the 2008 financial crisis and the 2011 wave of struggles precipitated the political conditions for their intersection. Such convergence produces both tensions and possibilities. On the one hand, technopopulism engenders a radically participatory model of democracy, which is ultimately anti-institutional as citizens cooperate and engage in sophisticated decision-making without the mediation of professional politicians. On the other hand, the more electorally successful technopopulist parties are led by charismatic leaders who synthesize the positions that emerge from the netroots to mobilize them against the establishment. These two seemingly contradictory aspects precipitate in two variants of technopopulism: a leaderless-technocratic variant, which is derived from the open source mode of governance and from early experiments of the Global Justice Movement in networked self-government; and a leaderist-populist variant, which is more strictly focused on the electoral competition as an intrinsically hegemonic practice. The article concludes with a reflection on the discursive complementarity of these two variants.
\end{abstract}

Keywords: technopopulism, technolibertarianism, populism, electronic democracy, social media activism, Global Justice Movement, Free and Open Source Software, Podemos, Five Star Movement, Occupy

Technopopulism is the belief that the "government of the people, by the people, for the people" (Lincoln 1953 [1863]) is achievable by means of information communications technology. The term belief denotes here an ideology, not in the Marxian sense of false consciousness, but in the Althusserian sense of a set of ideas that have a material existence (Althusser 1971). Technopopulism can also be understood in Foucauldian terms as an emerging discourse (Foucault 1972), that is, as a body of knowledge, norms, attitudes, and practices that arise from the hybridization of two preexisting discourses: populism and technolibertarianism. Even though these discursive practices are historically separate, I contend that they have begun to converge after the global financial crisis of 2008 as widespread frustration at the ruling elites' mishandling of the crisis sparked international protest movements, and propelled a new generation of "technoparties" such as the Five Star Movement in Italy, Podemos in Spain, and the Pirate Party in Iceland.

The article distinguishes between two variants of technopopulism: a technocractic and leaderless variant, which pursues and enacts meritocratic forms of democratic participation; and a leaderist, more strictly populist, variant wherein charismatic leaders play a critical role in conferring unity and identity to their parties. The first tendency is materialized in the modes of governance of small technoparties such as the Pirate Parties, free and open source software development projects, open content communities, and the emerging discourse of Liquid Democracy. The nationalistpopulist tendency is most evident in Southern Europe, where mass parties such as 
Podemos and Five Star Movement have successfully combined charismatic leadership with participatory uses of networked media.

Each variant has a distinctive politics of its own. The leaderless-technocratic variant pursues an agonistic politics of forking, which is derived from the development process of Free and Open Source Software (FOSS). In the world of open source programming "forking" denotes the practice of duplicating the source code of a program to develop an alternate version of it. Because FOSS is by and large based on voluntary contributions, forks compete for the limited time and resources of software developers, who cannot contribute to all projects. In the context of online political deliberation and decision-making, however, duplicating a political initiative is not a zerosum game. On the contrary, as we will see, forking constitute the basis for organizing a common discursive space wherein different proposals compete before they get voted on.

The leaderist-nationalist variant of techno-populism also believes that networked participation is essential to the achievement of a fully realized democracy. But whereas the technocratic-leaderless variant attributes to the network itself the task of producing a shared political line, the leaderist-populist variant endows political leaders with the task of synthesizing different and conflicting positions that may emerge from the network. Drawing from Ronfeldt's definition of cyberocracy (1992) as rule by way of information I refer to this network-based centralized strategy as a cybercratic politics of unity that pits the people against the establishment.

Before turning to the two strands of technopopulism, the article reflects upon technolibertarianism as a stratified discursive formation that embeds contradictory elements. Because digital information is not only widely accessible but also easily exchangeable, editable, and actionable, the general cyberlibertarian dictum "information wants to be free" covers over different understandings of the value and function of information. Through the example of the SOPA-PIPA strike, the largest Internet protest ever organized, we will see how Internet activists are increasingly capable of cooperating remotely outside the boundaries of formal institutions. This self-organizing capacity of Internet users is a necessary condition of technopopulism, which begins when the networked coordination of thousands of Internet users threatens to displace a professional class of coordinators: the career politicians.

\section{Three Strands of Technolibertarianism: Capitalist, Communalist, and Activist}

Technolibertarianism (or cyber-libertarianism) is often referred to as an ideology that combines a blind faith in technological progress and free-market economics with a deep distrust in statist, bureaucratic, and hierarchical forms of authority. In "The Californian Ideology"-one of the first texts to identify this ideological formationCameron and Barbrook argue that cyber-libertarianism combines two seemingly contradictory attitudes: the freewheeling spirit of the hippies and anti-militarist ethos of the New Left with "the entrepreneurial zeal and can-do attitude championed by the Californian New Right" $(2014,26)$. Subsequent historical studies have outlined the critical influence of counterculture on software engineers of the 1960s and 1970s (Markoff 2005) and on inspirational figures of the New Economy such as Stewart Brand, Kevin Kelly, and Louis Rossetto (Turner 2006). ${ }^{1}$

${ }^{1}$ Fred Turner has added an important corrective to Cameron and Barbrook's analysis by noting that the Californian ideology was predicated on the disavowal of the social antagonism of the New Left and the subsumption of the "communalist" strand of the counterculture under "the computational metaphors and universal rhetoric of cybernetics" $(2006,209)$. Skeptical 
Technolibertarianism has undoubtedly an ideological dimension, which is epitomized by maxims such as "information wants to be free" (Brand 1985, 49) and "We reject: kings, presidents, and voting. We believe in: rough consensus and running code" (Clark 1992). This techno-utopian faith in the liberating, anti-authoritarian power of networked information technologies runs through prescient literary works on cyberspace (Gibson 1984) cyber-libertarian declarations, charters and manifestoes (Barlow 1996; Dyson et al. 1994; Levine et al. 2001), "musings" on software engineering methods (Raymond 1999), visionary magazines such as Wired and Mondo 2000 , and studies on the emergent and self-organizing properties of distributed networks (Kelly 1994; Johnson 2001; Barabási 2002).

Whereas this purely ideological dimension should not be overlooked, cyberlibertarianism is also embedded and embodied in the daily practices and institutions of software engineers, FOSS programmers, amateur cryptographers, digital rights advocates, civic hackers, 3D makers, and open data, open content, and open hardware enthusiasts. In order to account for this material and institutional dimension, I propose to frame technolibertarianism as an hegemonic formation. I borrow this heuristic device from Laclau and Mouffe $(1985,136)$, who have combined the Gramscian notion of hegemony with Michel Foucault's discourse analysis to develop an analytic for contemporary social struggles. As is known, Foucault describes a discursive formation as a principle of "regularity in dispersion," that is, as an ensemble of differential positions whose cohesion is given by certain "rules of formation" (1972, 31-39). Combining Gramsci and Foucault, Laclau and Mouffe argue that an hegemonic (discursive) formation presupposes a unifying principle that establishes an equivalence among the differential positions of the ensemble in opposition to a common enemy $(1985,127-45)$.

In the case of cyberlibertarianism, such unifying principle rests with the practical belief that the unfettered circulation of information is conducive to freer societies and thus that actors who build their power on information scarcity will logically tend to limit access to information. Whereas this belief resonates with longstanding tenets of modern liberalism such as freedom of the press and freedom of speech (Coleman 2013), it is important to note that computer networks do not only democratize access to information but also make the latter more easily reproducible, exchangeable, editable, and actionable. In this sense, the cyberlibertarian dictum "information wants to be free" conflates different conceptions of the value, function, and purpose of information and thus different notions of freedom. From this angle, cyberlibertarianism is a stratified discursive formation, whose unifying principle is a generic notion of information freedom, but within which we can isolate at least three distinct strands:

1. A techno-capitalist strand, which sees information primarily as a commodity and asset. For this strand the most significant properties of digital information are its accessibility, reproducibility, and exchangeability. Indeed, the capacity of digital

that the antagonistic approach of the New Left and the anti-war movement could bring about any social change, some hippies had been attracted to the cybernetic vision of the world as a self-regulating pattern of information (Ibid, 4). Whereas such holistic view resonated with a longstanding "artistic critique" of capitalism as productive of alienation and dull existential conditions it was much less compatible with a "social critique" of capitalism as productive of exploitation and social inequality (Boltanski and Chiapello 2006). By coopting the former and discarding the latter, cyberlibertarianism was thus able to turn the freewheeling spirit of the counterculture into ideological fodder for the New Economy's promise of a society of free, autonomous, and cooperating individuals. 
technologies to encode a wide range of inputs into a highly reproducible format based on binary digits makes information a commodity that is universally exchangeable and saleable.

2. A communalist strand, which sees information primarily as a common good. For this strand not only is information valuable for its accessibility and reproducibility but also and foremost for its modifiability. A community that is able to fully share and modify information can develop common repositories of knowledge (e.g. Wikipedia, Github) and non-proprietary technologies (e.g. Linux) that fulfil a wide range of needs.

3. An activist strand, which sees information primarily as a public good. For this strand the most valuable properties of information are its accessibility and actionability. Accessibility allows a society to establish shared truths and validity claims without which ethical action would be impossible (Habermas 1984). Actionability allows a community to deliberate on issues of common concern and organize decision-making processes that make such deliberation possible.

Even though these three strands are clearly distinct, they share an opposition to two common enemies: the modern nation-state, with its arbitrary checks and stoppages on the otherwise free flow of goods, people, and information; and the industrial corporation, whose heavily centralized structure and market dominance hampers the emergence of a spontaneous system of market transactions (Levine et al. 2001). It follows that cyberlibertarians see the alliance between industrial corporationsespecially those that own large stocks of information-and the state as a major threat to information freedom. Such threat, however, has different implications for each strand. For the techno-capitalists such an alliance can limit their ability to extract value from the circulation of informational commodities. For the communalists, a restrictive intellectual property regime limits Internet users' capacity to edit and share information with one another. And for the activists, limiting access to information hampers the public's capacity to make informed decisions without which the free exercise of democracy is impossible. In the next section we will see how the threat posed by this alliance to the two most fundamental properties of digital informationits accessibility and reproducibility - sparked the unified response of the three strands in what came down in history as the largest Internet protest of all times.

\section{The Internet Blackout and the Problem of Networked Activism's Autonomy}

On January 18, 2012, thousands of Internet websites blackened their home pages and posted messages of protest against the approval of the Stop Online Piracy Act (SOPA) and Protect IP Act (PIPA). A coalition of major copyright owners in the music, film, and TV industries as well as the pharmaceutical industry had promoted the two bills at the U.S. Congress with the goal of allowing government to shut down the domain names of copyright infringing websites. In the matter of weeks, a coalition of cyber-rights activist groups banded together with tech companies and online communities to denounce the chilling effect of the bills on freedom of speech and block their approval. Whereas the idea of an Internet strike was not new, its scale was unprecedented. It is estimated that over 115,000 websites joined the protest. On January 18 alone 3 million emails were sent and over 100,000 phone calls were made to Congress to express opposition to the bills; 10 million people signed petitions; 2.4 million Tweets contained keywords related to the strike, and 8 million Internet users looked up their representative on Wikipedia (Wortham 2012a; Netburn 2012). Additionally, thousands of demonstrators protested in front of their representatives' offices 
across the United States. These combined actions induced lawmakers in both branches of Congress to shelve the bills on January 20, 2012.

The reasons of the overwhelming success of the Internet Blackout are easy to identify. If the strike was coordinated by a handful of digital rights advocacy groups, it was made immensely visible by the participation of major Internet players such as Google, Wikipedia, Reddit, Tumblr, Flickr, Wordpress, Mozilla, and Craigslist. In this respect, we could say that SOPA and PIPA prompted a unified response from the three strands of technolibertarianism outlined above because they posed a threat to the most fundamental property of information-its accessibility. Yet the motivations of the actors who participated in the protests differed from one another. For tech companies such as Google and Facebook the two bills not only threatened to increase the costs of policing their own websites for copyright-infringing material but, more importantly, of cutting the advertising revenues associated with such material (Wortham 2012b). In the case of user-generated websites such as Wikipedia, Reddit, and Tumblr, SOPA and PIPA threatened their contributors' ability to post links to potentially infringing websites and to discuss related content. Finally, advocacy groups such as the Electronic Frontier Foundation emphasized that the anti-piracy bills could be used to cut funding to pro-human rights projects and NGOs such as the Tor Project, EngageMedia, and Wikileaks, which facilitate access to information whose value lies primarily in its actionability (Timm 2011).

Further, it should be noted that the success of the protests was made possible precisely by the shareable and actionable nature of the information that publicized them. As Shirky points out, native features of the social web such as hashtags, embeds, and comments allow users to share information with one another, collaborate and undertake collective action with no need of centralized supervision $(2008,47-$ 53). Shirky's key insight is that by building cooperation into the infrastructure the social web has caused a vertical fall of the economic costs of coordinating group activity (Ibid., 18). Thus loosely organized networked collectives can easily outsmart institutional opponents that rely on a slow and costly managerial structure to direct employee activity. The SOPA-PIPA strike perfectly illustrates this point on both an economic and political level. On an economic level, the strike was nothing but a confrontation between corporations that tried to protect assets produced under an industrial organization of the value chain and corporations whose profitability depends instead on a networked organization of the value chain. On a political level, it is significant that, notwithstanding the massive resources invested in lobbying Congress, the copyright holders were completely unable to organize an effective response to the strike. In contrast, the tech companies had merely to endorse and amplify the visibility of the calls to action to bring large networks of loosely coordinated activists on their side.

To be sure, such observation risks of overshadowing the initiative of the activists, who first organized against the bills, prompting the tech companies to follow suit. At the same time, it is undeniable that large capital investments in the Internet infrastructure-especially in the interoperability of social media platforms and accessibility of rich content via mobile technologies-have enabled the real-time cooperation of large numbers of Internet users, which proved essential to the success of the SOPAPIPA strike. These investments, however, have a political cost. Whereas the distributed nature of the TCP/IP protocol allows users to establish relations of reciprocity and mutually define the norms that undergird their interactions, social network sites (SNSs) are centralized systems whose administrators can silence users with no need of explanation (Hands 2011, 83-91). In this sense, the activists' reliance on SNSs 
such as Facebook, Twitter, and Tumblr poses the problem of their autonomy from these platforms or, conversely, of the democratic control of SNSs.

Further, there are at least three additional critiques that are moved to social media activism. First, if it is true that SNSs have proved quite effective for coordinating protest movements such as the Arab Spring, 15-M, and Occupy (Gerbaudo 2012), authoritarian governments can easily use the very same platforms to track down activists and crush dissent (Morozov 2011). Second, SNSs are often accused of fostering "slacktivism," a form of participation that requires a low level of engagement and is virtually risk-free. Because SNSs are largely built around weak ties, that is, connections among strangers and acquaintances, they would not lend themselves to the kind of "high-risk activism" that is predicated on strong ties and a shared sense of responsibility among activists (Gladwell 2010). Third, the lack of a recognizable structure, membership, and leadership would make SNSs incapable of thinking and acting strategically (lbid).

In sum, the criticism of SNS-based activism can be condensed as a three-part argument: 1) SNSs are not sufficiently autonomous from governments and corporations to function as vectors of social change; 2) Activists have no control over the norms of conversation, the modes of interaction, nor the data and metadata generated by their activities in SNSs; 3) Political participation via SNSs typically lacks the kind of organization and leadership that drives successful political movements. In a way, the third part of this argument is only the most recent iteration of a long-running (Leninist) critique of social movements as insufficiently structured and organized. Or, from a perspective that is more sympathetic to social movements, this critique is nothing but a revamp of historic cautionary tales on the risk for activists to fetishize "structurelessness" (Freeman 1970). Yet addressing the problem of organization exclusively through these lenses risks to overlook the specificity of networked activism.

To begin with, as noted, the social web has collapsed the transaction costs of coordinating group effort, allowing for the quick propagation of calls to action on an unprecedented scale. Further, the social web has facilitated the cooperation between activist networks and emerging modes of "weak-tie" participation. Indeed, the calls to action that circulated via Facebook prior to the Egyptian Revolution of January 2011 were created and shared by both "average" Egyptians and organized political actors such as the April 6 Movement (Ghonim 2012). This has led some social movement theorists to argue for a more hybrid framework, which can grasp the relationship between weak-tie activism and strong-tie activism, spontaneity and organization, in dialectical rather than oppositional terms (Nunes 2012; Kioupkiolis 2014).

If this approach is useful to bypass dichotomies that do little to advance our understanding of networked social movements, it still fails to address the question of their autonomy from capital and the state. One way to approach this question is to contrast Web 2.0 activism to the Global Justice Movement's attempt to create an autonomous communication infrastructure. As we will see in the next section, the GJM was committed to the network as an ideal organizational form that could facilitate the convergence of a variety of actors on shared objectives, without compromising their autonomy. This ideal was inspired to a set of discursive practices, such as those of the Free and Open Source Software movement, which embodied the notion that a network can govern itself. My wager is that contemporary technopopulism arises from the intersection of these two trajectories, that is, from the activist and communalist strands of technolibertarianism. 


\section{The Global Justice Movement's Experiments in Networked Self-Government}

The alter-globalization movement acquired its global dimension through the interconnection of local and regional networks of autonomous spaces, unions and workerowned coops, activist listservs and websites, community radios, hacklabs, and the newborn Independent Media Centers (Juris 2008; Wolfson 2014). Although chronically underfunded and maintained through voluntary efforts, this sociotechnical infrastructure supported the emergence of a set of practices that were clearly autonomous from and antagonistic to transnational capital and the supranational governance of institutions such as the IMF, World Bank, and the WTO. It is therefore striking to see how this infrastructure was abandoned or migrated to commercial platforms in the mid-to-late 2000s. Some scholars have identified the causes of the decline of these networks in their overreliance on technology and related inability to build structured organizations rooted in class analysis (Wolfson 2014). Others have argued that the growing centrality of social media to political mobilizations has contributed to shape a new "populist" discourse, which rejects traditional Left/Right divisions of the political spectrum, and is materialized in an emerging "democracy 2.0" based on the measurement of social media preferences (Gerbaudo 2014).

Even though these two analyses are advanced from antipodal positions-MarxistLeninist and post-ideological or populist, respectively - they both criticize the Global Justice Movement (GJM) for being too self-referential and incapable of building a large support base. Whereas for the Marxist-Leninists the GJM was weakly organized and weakly linked to the working class, for the theorists of the 2011 popular wave the GJM was not transversal enough and thus unable to exert a culturalpolitical hegemony within society. As Laclau and Mouffe (1985) point out, the notion of hegemony presupposes a capacity to establish an articulatory nexus among a plurality of demands and subject positions in the struggle against a common enemy. Whether the working class is the subject endowed with the historical task to institute this nexus (as the Marxist-Leninists argue) or any subject can potentially take up this role (as the post-Marxists have it) is a problematic that exceeds the scope of this article. What matters, at least for the purpose of this argument, is that in establishing a relation of equivalence among dispersed subject positions and demands, hegemonic practices tend to "fix the meaning of the social in an organized system of differences" (Ibid, 135). As such, the notion of hegemony may not be suited to analyze social movements such as the GJM, the Indignados or Occupy that eschew the politics of demands, alliances, and coalition-building in favour of a "prefigurative politics" (Downing 2001), that emphasizes the creation of inclusive and egalitarian processes of participation and deliberation as harbingers of broader societal transformations.

This is all the more true when we consider that digital networks have only enhanced the capacity of groups and individuals for self-representation. To be sure, networked social movements still coalesce around shared grievances and objectives. But the pursuit of these objectives does not necessarily entail a subordination of difference to political and organizational unity. Rather, as Juris points out, the GJM followed a "networking logic" that entailed a commitment to decentralization, convergence, and autonomy:

While the command-oriented logic of traditional parties and unions involves recruiting new members, developing unified strategies, pursuing political hegemony, and organizing through representative structures, network politics revolve around the creation of "convergence spaces," where diverse collectives, organizations, and networks converge around a 
few common hallmarks, while preserving their autonomy and specificity (Juris 2008, 14).

Thus Juris' insight is that the GJM activists did not see the network as a mere communication infrastructure but as an emerging organizational form. Hardt and Negri make a similar point when they observe that the internal organization of resistance movements has progressively evolved towards the network form and that the project of constructing the multitude as a movement of movements "resembles an open and expansive network in which all differences can be expressed freely and equally" (2004, XIV).

The analogy between the distributed nature of the Internet and the inherently democratic nature of network politics can be puzzling because the Internet can support any sort of organization-including hierarchical and centralized ones. Indeed Juris cautions that "discourses of open networking often conceal other forms of exclusion based on unequal access to information or technology" (Ibid.). Academic research has also shown that unconstrained and rapidly growing networks such as the Internet are characterized by the emergence of "power-law distributions," which endow a few highly connected nodes with a disproportionate amount of power and visibility (Barabási 2002; Hindman 2008). Further, as we have seen, if Internet protocols such as the TCP/IP are distributed, others (such as the DNS) are centralized (Galloway 2004), allowing authorities to filter and censor undesired information.

The above considerations should serve as a healthy reminder that "hegemony qua unequal power and centralized control is an ever-present possibility of the multitude in its actual and conceivable instances" (Kioupkiolis 2014, 159). This is particularly true if we understand the construction of the multitude as an endeavour that requires the indispensable mediation of networked technical systems and thus of a technoelite that knows how to run, customize, and develop such systems. Nonetheless, at the time of the GJM, the network form functioned as a powerful ideal, we might even call it a Master Signifier, that inspired and gave meaning to the actions of an entire generation of activists. For example, in the early 2000 s, the tech-savvy fringes of the GJM launched the European Social Consulta, an online platform modelled after the Zapatistas' consultation process that was supposed to scale assemblary and deliberative decision-making processes from a local to a regional and international level (Juris 2008, 282-285).

Even though the ESC proved to be an overly ambitious project, the idea of using the Internet to scale direct democracy and build participatory forms of governance from the ground up continues to this day. Indeed, the roots of contemporary technopopulism lie precisely in this notion that a network can govern itself. This is a far from obvious proposition as transnational sociotechnical networks often lack clearly defined constituencies. In contrast, the notion of governance presupposes the management (or self-management) of a bounded domain-which usually includes a population, a territory, and a set of resources. Perhaps it is no accident that all major experiments in online participatory democracy have occurred within parties that operate within specific national contexts. In other words, even though contemporary technopopulism is a transnational ideological orientation (Gerbaudo 2014), its actualization in national parties is in tension with the technolibertarian demand of a universal, postnational, and unregulated access to information. 


\section{The FOSS Mode of Governance and the Agonistic Politics of Forking}

I will return to the tension between the national and the universal in the discourse of technopopulism in the conclusion. For now, I would just notice that the notion of a self-governing network seemed a "plausible promise" (Raymond 1999) because it was inspired to an existing model of collaboration: the Free and Open Source Software (FOSS) development process. Many GJM activists looked in fact at the collaborative process whereby "geographically dispersed computers programmers" contribute code to nonproprietary software on a voluntary basis "as a model of political organizing and a potential harbinger of postcapitalist forms of economic, social, and political organizing" (Juris 2008, 16-17).

On an economic level, FOSS is a nonrival and nonexclusive good. Not only FOSS can be used without depleting (as any digital object), but is explicitly designed not to exclude anyone from studying, copying, modifying, and distributing the source code. In short, FOSS is a digital commons whose overabundance poses a challenge to capitalist accumulation, which is predicated on the exploitation of (artificial) scarcities. Such overabundance sets the conditions for a "commons-based" model of production that is alternative to the capitalist organization of labour in at least three respects: 1) Contributions to FOSS projects are by and large unpaid and voluntary; 2) Developers can contribute as much or as little as they want to each project; 3) FOSS engineers and principal developers constantly compete for the contributors' attention, time, and resources.

The voluntary nature of cooperation and the nonrival, nonexclusive nature of FOSS determines a specific mode of management and style of leadership. In particular, Linux distributions such as Debian and Ubuntu, open content encyclopedias such as Wikipedia, and large repositories of FOSS such as GitHub and Sourceforge allow anyone to copy existing code or content and use it as the basis for an alternate version of the same commons. To be sure, the threat of a "fork"-as FOSS programmers refer to the development of an independent version of existing software based on the same source code-is more potential than actual. Because forking involves a split within the base of contributors, prohibitions on forking operate as a social taboo within the FOSS community (Mako Hill 2005). At the same time, this constantly looming threat forces leaders to maintain a cooperative attitude so as not to alienate potential collaborators. From this point of view, forking is a "defining characteristic of FOSS" (Reagle 2010, 82) whose "constitutive nature" (Tkacz 2011, 86) for the open source mode of governance is evident on two distinct levels.

On a first level, the actual production of a fork "de-monopolizes power" (Bauwens $2005,96)$ and "simultaneously maximizes the freedom of individual participants" (Tkacz 2011, 97). On a second level, because forking involves a dissipation of resources, its very possibility "demands that whatever mode of rule or governance is adopted by a project, this mode must in the last instance be perceived by all members of the project as legitimate or else they will leave" (Ibid.). Thus the "right to fork" (Weber 2004, 159) informs the FOSS mode of governance regardless of whether or not a fork is actually implemented. In fact, the high costs of maintaining a large code base through voluntary contributions forces principal developers to search for consensus and collaboration rather than promoting decentralization and individual freedom (Famiglietti 2011). Obviously, searching for consensus does not mean that consensus is ever achieved. On the contrary, alternative forks of the same source code-whether potential or actual-compete for the attention and skills of the same base of contributors. 
If the political implications of this cooperative-competitive model are not new, recently they have begun to migrate from the governance of FOSS projects to the world of politics. The most significant example of this migration is LiquidFeedback, a decision-making software developed in 2009 that has been adopted by several Pirate Parties in Europe and across the world. LiquidFeedback has been closely associated with Liquid Democracy, an emerging decision-making protocol that mixes elements of direct democracy and representative democracy. Rather than assuming that all members of an organization or a political party are equally knowledgeable on every issue, LiquidFeedback (LF) lets participants decide whom to delegate on specific initiatives. Those who hold proxy votes can in turn transfer them to other delegates, facilitating the emergence of networks of trust. Such trust, however, is not a blank check as proxies can be revoked at any time so as to prevent the crystallization of power elites (Behrens et al. 2015).

In addition to implementing a reversible system of delegation, LF allows participants to propose amendments to existing political initiatives. If the author of an initiative refuses to amend it, other participants can fork it, that is, create an amended proposal that will compete with the original one in the voting phase. Additionally, voting does not follow the principle of majority rule or first-past-the-post, but is based on the Schulze method, a pairwise comparison voting system that allows participants to rank candidates and initiatives in order of preference (Schulze 2011). Similar to the practice of forking, the Schulze method has been used to make decisions about the direction of Linux distributions such as Debian, Ubuntu, and Gentoo, as well as to elect delegates and representatives within organizations such as the Free Software Foundation and the Wikimedia Foundation.

Thus we can see how a certain procedural knowledge has been migrating from the FOSS world to the realm of institutional politics-and in particular to those parties that have espoused the open source philosophy and its collaborative ethos. To be sure, political initiatives are neither computer programs nor Wikipedia articles. In fact, the problems software developers and software engineers try to solve are always specific to a technical world and cannot be transferred ipso facto to society as a whole (Dean 2010). Conversely, the wide range of problems faced by a political community such as a party or a social movement cannot be simply solved through technological solutions (Morozov 2013).

Nonetheless, this migration of a mode of governance from the world of open source programming to institutional politics is a phenomenon that has significant political implications. For example, the developers of LF believe that networked information technologies can help correct many democratic deficits in political parties, including lack of accountability, lack of transparency, lack of participation, or excessive centralization (Behrens et al. 2015). By thrusting ideas rather than leaders into the centre of the political process, allowing those ideas to compete with one another, and adopting voting procedures that are supposedly transparent and democratic, $L F$ presents itself as the diagram of an emerging mode of governance that is technocratic, leaderless, agonistic, meritocratic, and universalist.

Thus the leaderless-technocratic variant of technopopulism believes that democratic self-government can be achieved through the application of a standardized procedure to large-scale decision-making processes. Similar to the GJM's belief that a network can govern itself, this variant assumes that the social intelligence of the network is higher than any individual contribution and any leader's competence or charisma. Unlike the GJM, however, this brand of technopopulism does not privilege social movements as the driver of democratic participation and popular sovereignty. 
Rather, political organizations are invited to free the social intelligence of the network by adopting rational and carefully designed decision-making processes. It is worth noting that in the case of LF this social intelligence is harnessed through the staging of a competition among alternative proposals, which might only slightly differ from one another.

From the point of view of political theory, this agonistic politics of forking resonates with Chantal Mouffe's definition of agonistic democracy (2005) as a competition among adversaries within a shared symbolic space. Yet the imagined conditions of a technology-enabled agonistic democracy do not necessarily match their practical implementation. Indeed, the use of LF hasn't yielded the hoped for results-at least at the level of party organizing. For example, some have pointed out that in spite of its emphasis on decentralization and reversibility, LF's delegation system favours the concentration of proxies in few hands (Becker 2012). Further, the implosion of the German Pirate Party after its electoral success of 2011, and the limited penetration of small techno-parties such as Partido X (Spain), Partido de La Red (Argentina), Wikipartido (Mexico), as well as dozens of Pirate Parties around the world, may epitomize the inability of the leaderless variant of technopopulism to synthesize different positions in a coherent and recognizable political line (Deseriis 2015). By contrast, parties that have endowed a ruling group with the task of making decisions at the highest level have been far more successful than these parties in the electoral arena. I shall therefore now briefly consider this second strand of technopopulist parties before reaching my conclusion.

\section{The Leaderist Variant of Technopopulism and the Cybercratic Politics of Unity}

As noted, technopopulism emerges from the encounter of technolibertarian discourse and populist discourse. Even though these formations are historically distinct-as modern populism preexists technolibertarianism by several decades-there are many common elements that allow for their convergence and hybridization. As we have seen, technolibertarians harbour a deep distrust in bureaucratic and hierarchical forms of authority, which would pose a threat to the unrestrained circulation of information. Further, technolibertarians believe that digital information should be easily shareable, editable, and actionable, so as to allow ordinary Internet users to cooperate and take matters into their own hands. We have also seen how the growing automation of networked cooperation allows for the rapid scaling of political campaigns, which can be organized by loosely coordinated groups of Internet activists outside of institutional affiliations. Finally, the notion that a network can govern itself is embedded in GJM's early experiments in networked self-government, the open source mode of governance, and its extension to political parties that have opened their decision-making processes to the direct input of their members.

Whereas these elements indicate that technolibertarianism and technopopulism share many features, the latter would have never acquired its current status without the global financial crisis of 2008 and the popular wave of protest movements that began in 2011. As is known, the popular wave was fuelled by widespread frustration at corrupted political elites, soaring unemployment rates, austerity measures, and growing wealth inequality. In countries like Egypt, Spain, Greece, United States, Israel, and Turkey, protest movements have chosen the tactic of occupation of public space and the setting of encampments in public squares. The mass diffusion of social network sites - which did not exist at the time of the GJM-has provided both an outlet for the expression of popular dissent and for mobilizing ordinary citizens disaf- 
fected with traditional party politics. As previously noted, the mass diffusion of social network sites has allowed organizers to mobilize Internet users who were unreachable by the self-referential activist networks of the GJM. The combination of highly visible occupations, encampments, and mass assemblies with the popularity of social media has thus produced a distinctive protest culture, whose discourse focuses on unity and whose majoritarian vocation is epitomized by the Occupy slogan "We are the 99\%." Understandably, the popular wave's focus on aggregation (Juris 2012), the rejection of political representation (Sitrin and Azzellini 2014) and of traditional LeftRight divisions of the political spectrum, has prompted scholars to label these movements as populist (Gerbaudo 2012; 2014).

Even though populist movements vary greatly depending on their ideological traits, socioeconomic composition, and regional features, most scholars agree that populism can be generally described as an antagonistic discourse that pits the people against the establishment (Canovan 1999; Panizza 2005; Laclau 2005a). This general definition has its limitations in that both the people and the establishment are vague political concepts. In fact, the ambiguity of the people as a political category is already inscribed in its etymology as "the people can be conceived as populus, the body of all citizens; or as plebs, the underprivileged." (Laclau 2005a, 81). According to Laclau, populism begins when the underprivileged claim to be the only legitimate populus by establishing a chain of equivalence among different demands and subject positions (lbid.). Whereas the ruling class of a functioning democracy is able to address selectively the demands that emerge from the social field, the formation of a popular subject signals for Laclau that partial struggles and mobilizations are no longer absorbed differentially within the system. In this sense, the movements of the popular wave express the emerging solidarity of social demands and subjectivities that share the opposition to a common enemy.

Whereas in countries like Tunisia and Egypt this social solidarity was powerful enough to overthrow the government, the economic recovery in the United States has allowed for a partial reabsorption of these social demands within the traditional system of party politics (e.g. through the presidential bids of anti-establishment candidates such as Bernie Sanders and Donald Trump). In Southern Europe, the prolonged recession and stagnation that followed the financial crisis has created instead favourable conditions for the rise of new political formations such as Syriza, Five Star Movement, and Podemos. From the social movements of 2011, these "movementparties" have borrowed a strong anti-establishment stance and a radical participatory ethos. Similar to the Pirate Parties, M5S and Podemos have made an extensive use of information technologies to empower their party base, employing a vast array of software tools that allow their members to discuss and draft policy proposals, hold primaries online, crowdfund initiatives and campaigns, screen their elected representatives' expenses, and even vote on decisions that are yet to be taken in Parliament.

Unlike the leaderless variant of technoparties, however, M5S, Podemos, and Syriza are all led by clearly recognizable, telegenic, and charismatic leaders. On a first level, the electoral successes of these parties can be explained with the fact that TV and audiovisual media still play a central role in forming the public opinion. And Beppe Grillo, Pablo Iglesias, and Alexis Tsipras' "virtuosity" in performing before large audiences (Virno 2004, 52) allows them to reach out to sectors of the electorate who do not have the interest, time, or skills to participate in networked politics. On a second level, these leaders perform the critical function of conferring unity and identity to their parties by setting them in opposition to the traditional political establishment. For example, at the first Congress of Podemos, Pablo Iglesias motivated the 
reason for appointing only one Secretary General, himself, at the helm of the party rather than three (as suggested by his political opponents) with the need for Podemos of having one recognizable leader who could challenge and defeat the leaders of the Popular Party and the Socialist Party. Similarly, Beppe Grillo and the recently departed Gianroberto Casaleggio have strategically positioned the M5S at the centre of the Italian political spectrum in spite of progressive and Leftist pressures coming from the M5S activist base.

The leadership's role in imparting unity and a strategic direction to these parties is also evident from the unresolved question of the actual power that is to be attributed to online decision-making. In the case of Podemos, after an initial attempt to develop the party program through Plaza Podemos-a discussion board enabled by the social news site Reddit-the online participatory drive has been mostly confined to the use of the application Agora Voting for the party primaries and the adoption of the decision-making software Loomio at a local level. Whereas the latter is built upon the consensual decision-making protocols of the 15-M and Occupy assemblies (as Loomio gives each participant the right to veto any proposal), the software has little capacity to scale participation from a local to a national level. In the case of the Five Star Movement, the party derives its very name from the five policy areas-Water, Environment, Transportation, Connectivity, and Development-that were originally defined through online discussions in 2009, when hundreds of Meetup groups provided the organizational backbone of the nascent movement-party. At the same time, the Beppe Grillo blog, the Web portal movimento5stelle.it, and more recently the platform Rousseau constitute centralized hubs where M5S members are consulted on critical Parliamentary decisions that are to be taken by the MPs, and can participate in the drafting of regional, national and European laws (Deseriis 2016). The collaboration between local, regional, and the national cadres, however, has also been fraught with tension as the Casaleggio Associati - the company that manages the M5S Web server - has often been accused of little transparency and centralization (Mosca 2015).

From this angle, we could say that the Southern European way to technopopulism agitates the promise of networked democracy only to frustrate it with centralized decisions that foreclose demands for more participation and inclusion that emerge from the netroots. Yet it would be reductive to read centralization as the true and therefore only face of Southern European technopopulism. On the contrary, as Laclau points out, the hegemonic articulation of differential demands in and through the name of a populist leader presupposes difference and is inseparable from it (Laclau 2005b, 46). In this respect, it is no accident that the leaderships of M5S and Podemos openly encourage networked participation so as to extract important political indications from it. In other words, these Southern European parties free the social intelligence of the network and simultaneously channel it through ongoing online consultations. Thus, if cyberocracy is the "rule by way of information" (Ronfeldt 1992), then M5S and Podemos have developed a cybercratic politics of unity, which enables grassroots initiatives insofar as they do not interfere with decisions that are made at the highest level.

At the same time, in guaranteeing a retroactive unity (Žižek 1989) to instances that would otherwise remain separate from one another, the name of the leader performs the critical function of suturing an heterogeneous discursive space while allowing it to enter the field of political representation. In this sense, the electoral successes of the leaderist variant of technopopulism can be explained with a realistic understanding of the electoral competition as an intrinsically reductive and thus hegemonic practice. This hegemonic aspect, it should be noted, is irreconcilable with the GJM's aspiration 
to build a self-governing network of communities that could redefine the notion of sovereignty beyond electoral politics and national boundaries.

\section{Conclusion}

In sum, in this article I have argued that contemporary technopopulism is a discursive formation or a materialized ideology that is predicated upon the belief that "the government of the people, by the people, for the people" is achievable by means of networked information technologies. This discursive formation emerges from the convergence and hybridization of two distinctive discourses: technolibertarianism and populism. Technolibertarianism is a stratified discursive formation that incorporates three distinct strands-capitalist, communalist, and activist. The social web's automation of cooperation has allowed for the activist and communalist strands to coordinate massive political campaigns such as the Internet Blackout and to experiment with increasingly sophisticated decision-making processes for the management of digital commons. Even though the lack of autonomy of social media activism from the commercial platforms that enable it should be a matter of serious concern to activists, the mass diffusion of social network sites has allowed them to reach ordinary citizens, which were by and large unreachable by the self-referential networks of the GJM. At the same time, the GJM experimentation with networked forms of selfgovernment has anticipated many political experiments to come. Indeed, the idealistic notion that society can govern itself from below as a network of networks, combined with the actual governance of large open source projects, and the popular wave of protest movements that begun in 2011, has inspired a new generation of technoparties, which try to reconcile the open, decentralized, and participatory nature of networked activism with electoral politics.

These parties can be divided in two main variants: a leaderless-technocratic variant whose anti-establishment stance is embedded in an emerging mode of governance derived from the open source world; and a leaderist-cybercratic variant wherein charismatic leaders confer unity to their parties by synthesizing different positions that emerge from the network to mobilize them against the establishment. Even though these two variants seem to embody irreconcilable tendencies, from a discursive point of view, they complement each other. Decentralization and forking are in fact politically productive only insofar as they occur within a shared discursive space that is bounded and strategically oriented. And centralized management is effective only insofar as it does not obliterate differences, but allows them to express themselves while having a vision of the whole.

Yet the two variants code their anti-establishment messages differently. The leaderless variant sees in fact the Network as the empty signifier for a radically participatory model of democracy, which should allow lay citizens to introduce, deliberate, and vote on legislation directly, that is, outside of the mediation of political parties. In this sense, the (utopian) project of a fully realized digital direct democracy entails nothing less than the demise of the professional class of politicians, the end of political representation, and "the abolition of all political parties" (Weil 2013), which would become redundant vis-à-vis networked self-government.

Significantly, these utopian elements are also present within the discourse of the leaderist variant of technopopulism. In fact, both Podemos and M5S disdainfully refer to career politicians as members of a self-serving "casta" and endow the network with the task of returning power to ordinary citizens. The M5S goes as far as presenting itself as a "non-party" regulated by a "non-statute" that openly denies the autonomy of candidates and elected representatives from their constituents' will (Del Savio and 
Mameli 2014). Further, the leaders of M5S and Podemos have attributed themselves the critical task of developing a political line that brings together a plurality of demands and subject positions through a strong anti-establishment stance. As we have seen, this hegemonic articulation passes through the name of a leader, a signifier whose tendency towards an abstract and "empty" universality increases with the progressive extension of the equivalential logic to realities that have little in common with one another (Laclau 2005b, 39-40).

Yet in lending a proper name to the network of citizens who refuse representation, the leader becomes necessarily exposed to the pressures that emerge from the network for self-representation. In this sense, we could say that the challenge for the technopopulisms to come is to open up the unifying function of the name of the leader to manifold uses, without letting such uses undermine such function. In other words, it is only when the name of the leader is understood as an abstract function whose symbolic and decisional power is made available to networked decisionmaking, that technopopulism will be able to merge technolibertarianism and populism in an assemblage that is more than the sum of its parts. At the moment, the presence of centralizing and charismatic leaders on one side, and the difficulty of constructing the Network as an empty signifier for a fully realized democracy on the other side, makes the distinction between the two variants significant both in analytical and political terms. Differently put, if the discourse of technopopulism emerges from an ensemble of differential positions, as a political project technopopulism cannot fully solve the tension between its constitutive components: the pluralistic nature of networks and the totalizing tendency of populism.

This constitutive tension mirrors a second tension that I have identified earlier onnamely, the tension between the national dimension of populism and the universalism of technolibertarianism. Whereas popular sovereignty is inherently exclusive (as the people define themselves in opposition to an other) and technolibertarianism is inherently inclusive (as access to information is a universal human right) the tension between the people and humanity is not an irresolvable contradiction, but a paradox that lies at the heart of modern democracy (Mouffe 2005). If the most successful technopopulist experiments of the early twenty-first century have privileged popular sovereignty, the question remains open as to whether the leaderless variant will be able to develop a robust vision, ethos, and actionable party programs that will propel libertarian technopopulism beyond its current niche position.

\section{References}

Althusser, Louis. 1971. Ideology and Ideological State Apparatus. In Lenin and Philosophy and Other Essays, 121-176. New York: Monthly Review Press.

Barabási, Albert László. 2002. Linked: How Everything Is Connected to Everything Else and What It Means for Business, Science, and Everyday Life. New York: Perseus Books.

Barbook, Richard and Andy Cameron. 2014. The Californian Ideology (1995). In The Internet Revolution, edited by Richard Barbrook with Andy Cameron, 12-27. Amsterdam: Institute of Network Cultures.

Barlow, John Perry. 1996. A Declaration of the Independence of Cyberspace, Electronic Frontier Foundation website. Accessed May 26, 2016. https://www.eff.org/cyberspaceindependence

Bauwens, Michel. 2005. P2P and Human Evolution: Peer to Peer as the Premise of a New Mode of Civilization. Accessed May 26, 2016.

http://www.altruists.org/static/files/P2P\%20and\%20Human\%20Evolution\%20(Michel\%20B auwens).pdf 
Becker, Sven. 2012. Liquid Democracy: Web Platform Makes Professor Most Powerful Pirate. Accessed May 26, 2016. http://www.spiegel.de/international/germany/liquiddemocracy-web-platform-makes-professor-most-powerful-pirate-a-818683.html

Behrens, Jan, Axel Kistner, Andreas Nitsche, Björn Swierczek, and Marco Deseriis. 2015. Liquid Democracy, Its Challenges and Its Forebears. OpenDemocracy. Accessed May 26, 2016. https://www.opendemocracy.net/can-europe-make-it/jan-behrens-axel-kistnerandreas-nitsche-bj\%C3\%B6rn-swierczek-marco-deseriis/liquid-de

Boltanski, Luc and Ėve Chiapello. 2006. The New Spirit of Capitalism. London: Verso.

Brand, Stewart. 1985. 'Keep Designing': How the Information Economy Is Being Created and Shaped by the Hacker Ethic. Whole Earth Review 46 (May 1985): 44-55.

Canovan, Margaret. 1999. Trust the People! Populism and the Two Faces of Democracy. Political Studies 47 (1): 2-16.

Clark, David. 1992. A Cloudy Crystal Ball: Visions of the Future. Plenary Presentation at the $24^{\text {th }}$ Meeting of the Internet Engineering Task Force, Cambridge, MA, July 13-17, 1992. Accessed May 26, 2016. http://groups.csail.mit.edu/ana/People/DDC/future ietf 92.pdf

Coleman, E. Gabriella. 2013. Coding Freedom: The Ethics and Aesthetics of Hacking. Princeton, NJ: Princeton University Press.

Dean, Jodi. 2010. Blog Theory: Feedback and Capture in the Circuits of Drive. Cambridge: Polity.

Del Savio, Lorenzo and Matteo Mameli. 2014. Anti-representative Democracy: How to Understand the Five Star Movement. OpenDemocracy. https://www.opendemocracy.net/caneurope-make-it/lorenzo-del-savio-matteo-mameli/antirepresentative-democracy-how-tounderstand-fi

Deseriis, Marco. 2015. Podemos' Dilemma and Why Leadership Still Matters. OpenDemocracy. Accessed May 26, 2016. https://www.opendemocracy.net/can-europe-makeit/marco-deseriis/podemos\%E2\%80\%99-dilemma-and-why-leadership-still-matters

Deseriis, Marco. 2016. A Preliminary Analysis of the Political Values Embedded in Rousseau, the Decision-Making Platform of the Five Star Movement (Parts I and II). Accessed October 27, 2016. https://scalingdemocracy.net

Downing, John D. H. 2001. Radical Media: Rebellious Communication and Social Movements. London: Sage.

Dyson, Esther, George Gilder, George Keyworth, and Alvin Toffler. 1994. Cyberspace and the American Dream: A Magna Carta for the Knowledge Age. Future Insight. 1.2. The Progress \& Freedom Foundation.

Famiglietti, Andrew. 2011. The Right to Fork: A Historical Survey of De/centralization in Wikipedia. In Critical Point of View: A Wikipedia Reader, edited by Geert Lovink and Nathaniel Tkacz. 296-308. Amsterdam: Institute of Network Cultures.

Foucault, Michel. 1972. The Archaeology of Knowledge. London: Tavistock.

Freeman, Jo. 1970. The Tyranny of Structurelessness. Accessed May 26, 2016. http://www.jofreeman.com/joreen/tyranny.htm

Galloway, Alexander. 2004. Protocol: How Control Exists After Decentralization. Cambridge, Mass.: MIT Press.

Gerbaudo, Paolo. 2012. Tweents and the Streets: Social Media and Contemporary Activism. London: Pluto.

Gerbaudo, Paolo. 2014. Populism 2.0: Social Media Activism, the Generic Internet User and Interactive Direct Democracy. In Social Media, Politics and the State: Protests, Revolutions, Riots, Crime and Policing in the Age of Facebook, Twitter and YouTube, edited by Daniel Trotter and Christian Fuchs, 67-87. London: Routledge.

Ghonim, Wael. 2012. Revolution 2.0: the power of the people is greater than the people in power: a memoir. New York: Houghton Mifflin Harcourt.

Gibson, William. 1984. Neuromancer. New York: Ace Books.

Gladwell, Malcolm. 2010. Small Change, The New Yorker. Accessed May 26, 2016. http://www.newyorker.com/magazine/2010/10/04/small-change-malcolm-gladwell 
Habermas, Jurgen. 1984. The Theory of Communicative Action, Volume One: Reason and the Rationalization of Society. Boston: Beacon Press.

Hands, Joss. 2011. @ Is for Activism: Dissent, Resistance and Rebellion in a Digital Culture. London: Pluto.

Hardt, Michael and Antonio Negri. 2004. Multitude: War and Democracy in the Age of Empire.

Hindman, Matthew. 2008. The Myth of Digital Democracy. Princeton, NJ: Princeton University Press.

Johnson, Steven. 2001. Emergence: The Connected Lives of Ants, Brains, Cities and Software. New York: Scribner.

Juris, Jeffrey S. 2008. Networking Futures: The Movements against Corporate Globalization. Durham, NC: Duke University Press.

Juris, Jeffrey S. (2012). Reflections on \#Occupy Everywhere: Social media, public space, and emerging logics of aggregation. American Ethnologist, 39: 259-279.

Kelly, Kevin. 1994. Out of Control: The New Biology of Machines, Social Systems, and the Economic World. New York: Basic Books.

Kioupkiolis, Alexsandros. 2014. A Hegemony of the Multitude: Muddling the Lines. In Radical Democracy and Collective Movements Today: The Biopolitics of the Multitude versus the Hegemony of the People, edited by Aleksandros Kioupkiolis and Giorgios Katsembekis. 149-68. Farnham and Burlington, VT: Ashgate.

Laclau, Ernesto. 2005a. On Populist Reason. London and New York: Verso.

Laclau, Ernesto. 2005b. Populism: What's In a Name? In Populism and the Mirror of Democracy, edited by Francisco Panizza. 32-49. London and New York: Verso.

Laclau, Ernesto and Chantal Mouffe. 1985. Hegemony and Socialist Strategy: Towards a Radical Democratic Politics. London: Verso.

Levine, Fredrick, Christopher Locke, Doc Searls, and David Weinberger. 2001. The Cluetrain Manifesto: The End of Business as Usual. New York: Perseus Books.

Lincoln, Abraham. 1953 [1863]. Address Delivered at the Dedication of the Cemetery at Gettysburg. In Collected Works of Abraham Lincoln, Vol. 7, edited by Roy P. Basler. 18-23. New Brunswick, NJ: Rutgers University Press.

Mako Hill, Benjamin. 2005. To Fork or Not to Fork: Lessons from Ubuntu and Debian. Accessed May 26, 2016. https://mako.cc/writing/to fork or not to fork.html

Markoff, John. 2005. What the Dormouse Said: How the Sixties Counterculture Shaped the Personal Computer Industry. New York: Penguin.

Morozov, Evgeny. 2011. The Net Delusion: The Dark Side of Internet Freedom. New York: Public Affairs.

Morozov, Evgeny. 2013. To Save Everything Click Here: The Folly of Technological Solutionism. New York: Public Affairs.

Mosca, Lorenzo. 2015. Problemi e limiti del modello organizzativo "cybercratico" nell'esperienza del Movimento 5 Stelle [Problems and Limitations of the "Cybercratic" Organizational Model in the Five Star Movement Experience]. Ragion Pratica 44: 37-52.

Mouffe, Chantal. 2005. The Democratic Paradox. London and New York: Verso.

Netburn, Deborah. 2012. Wikipedia: SOPA Protest Led 8 Million to Look Up Reps in Congress, Los Angeles Times. Accessed May 26, 2016.

http://latimesblogs.latimes.com/technology/2012/01/wikipedia-sopa-blackoutcongressional-representatives.html

Nunes, Rodrigo. 2012. The Lessons of 2011: Three Theses on Organisation. Mute magazine. Accessed May 26, 2016. http://www.metamute.org/editorial/articles/lessons-2011three-theses-organisation

Panizza, Francisco. 2005. Populism and the Mirror of Democracy. London and New York: Verso.

Raymond, Eric S. 1999. The Cathedral and the Bazaar: Musings on Linux and Open Source by an Accidental Revolutionary. Sebastopol, CA: O'Reilly Media. 
Reagle, Joseph. 2010. Good Faith Collaboration: The Culture of Wikipedia. Cambridge, MA: MIT Press.

Ronfeldt, David. 1992. Cyberocracy Is Coming. Santa Monica, CA: Rand Corporation.

Schulze, Markus. 2011. A New Monotonic, Clone-Independent, Reversal Symmetric, and Condorcet-Consistent Single-Winner Election Method. Social Choice and Welfare 36 (2): 267-303.

Shirky, Clay. 2008. Here Comes Everybody: The Power of Organizing without Organizations. New York: Penguin.

Sitrin, Marina and Dario Azzellini. 2014. They Can't Represent Us: Reinventing Democracy from Greece to Occupy. London: Verso.

Timm, Trevor. 2011. Proposed Copyright Bill Threatens Whistleblowing and Human Rights. Electronic Frontier Foundation (website), November 2, 2011. https://www.eff.org/deeplinks/2011/11/proposed-copyright-bill-threatens-whistleblowingand-human-rights

Tkacz, Nathaniel. 2011. The Politics of Forking Paths. In Critical Point of View: A Wikipedia Reader, edited by Geert Loving and Nathaniel Tkacz, 94-109. Amsterdam: Institute of Network Cultures.

Turner, Fred. 2006. From Counterculture to Cyberculture: Stewart Brand, the Whole Earth Network and the Rise of Digital Utopianism. Chicago: Chicago University Press.

Virno, Paolo. 2004. A Grammar of the Multitude. Los Angeles: Semiotext(e).

Weber, Steven. 2004. The Success of Open Source. Cambridge, MA: Harvard University Press.

Weil, Simone. 2013. On the Abolition of All Political Parties. New York: New York Review of Books.

Wolfson, Todd. 2014. Digital Rebellion: The Birth of the Cyber Left. Springfield: University of Illinois Press.

Wortham, Jenna. 2012a. Public Outcry Over Antipiracy Bills Began as Grass-Roots Grumbling, New York Times. Accessed May 26, 2016.

http://www.nytimes.com/2012/01/20/technology/public-outcry-over-antipiracy-bills-beganas-grass-roots-grumbling.html

Wortham, Jenna. 2012b. A Political Coming of Age for the Tech Industry. New York Times, Accessed May 26, 2016. http://www.nytimes.com/2012/01/18/technology/web-wideprotest-over-two-antipiracy-bills.html

Žižek, Slavoj. 1989. The Sublime Object of Ideology. London and New York: Verso.

\section{About the Author}

\section{Marco Deseriis}

Marco Deseriis is Assistant Professor in the Program of Media and Screen Studies at Northeastern University and Marie Curie Fellow at the Institute of Humanities and Social Sciences at the Scuola Normale Superiore in Florence. Titled Scalable Democracy, and based on an extensive set of semi-structured interviews with software developers and software users, his current research project analyzes the political values embedded in the affordances of a new generation of decision-making software and their use within parties such as Podemos, Five Star Movement, and the Pirate Parties. Deseriis' research also explores cultural and political dimensions of Internet-based activism, the emergence of new forms of subjectivity in the network society, and genealogies of experimental forms of authorship. His book Improper Names: Collective Pseudonyms from the Luddites to Anonymous (University of Minnesota Press, 2015) brings together some of these threads by examining the contentious politics and the struggles for control of a shared alias from the early nineteenth century to the age of networks. 


\title{
The Alternative to Occupy? Radical politics between protest and parliament
}

\author{
Emil Husted ${ }^{*}$ and Allan Dreyer Hansen ${ }^{* *}$ \\ "Department of Organization, Copenhagen Business School, Copenhagen, Denmark, \\ www.cbs.dk/en/staff/ehioa
}

"Department of Social Sciences and Business, Roskilde University, Roskilde, Denmark, www.ruc.dk/ adh

\begin{abstract}
In this paper, we compare the political anatomy of two distinct enactments of (leftist) radical politics: Occupy Wall Street, a large social movement in the United States, and The Alternative, a recently elected political party in Denmark. Based on Ernesto Laclau's conceptualization of 'the universal' and 'the particular', we show how the institutionalization of radical politics (as carried out by The Alternative) entails a move from universality towards particularity. This move, however, comes with the risk of cutting off supporters who no longer feel represented by the project. We refer to this problem as the problem of particularization. In conclusion, we use the analysis to propose a conceptual distinction between radical movements and radical parties: While the former is constituted by a potentially infinite chain of equivalent grievances, the latter is constituted by a prioritized set of differential demands. While both are important, we argue that they must remain distinct in order to preserve the universal spirit of contemporary radical politics.
\end{abstract}

Keywords: Radical Politics, Radical Movements, Radical Parties, Discourse Theory, Ernesto Laclau, Universalism, Particularism, Occupy Wall Street, The Alternative

Acknowledgement: First of all, we would like to thank the anonymous reviewers and the editorial team at tripleC for their constructive comments. Secondly, we would like to thank Ursula Plesner and Sine Nørholm Just at Copenhagen Business School for their equally valuable feedback on earlier drafts of this paper.

\section{Introduction}

Crowds are forcing the Left to return again to questions of organization, endurance and scale. Through what political forms might we advance? For many of us, the party is emerging as the site of an answer.

Dean $(2016,4)$

On September 17, 2011, scores of protesters responded to a call from the Canadian magazine, Adbusters, by pouring into New York's financial district to join the occupation of Wall Street, the so-called "financial Gomorrah of America" (Adbusters 2011b). The occupation, which quickly became known as Occupy Wall Street (OWS), was said to mark a shift in revolutionary tactics, in which a swarm of people would repeat one single demand. Though without settling on such a demand, the OWS protesters quickly descended on the nearby Zuccotti Park to create a miniature version of direct democracy based on active participation and consensus-based decision-making 
(Welty et al. 2013). For months, however, the struggle over demands waged, with one group arguing that the movement should present the established system with a list of tangible demands, and an anti-demand group arguing otherwise (Gitlin 2012). Ultimately, OWS completely abandoned the pursuit of demands. The diversity of the movement's participants and the principle of "modified consensus" at general assemblies made it virtually impossible for the movement to settle on particular objectives (Kang 2012). Accordingly, OWS ended up as an irreconcilable crowd without any kind of positive articulation of political demands.

Even though several prominent scholars have celebrated the movement's aversion to parliamentary politics as a way of de-legitimizing the established system (e.g. Butler 2012; Graeber 2012; Hardt and Negri 2011; Pickerill and Krinsky 2012), OWS has received equally harsh criticism for its unwillingness to engage with existing political institutions. For instance, as Deseriis and Dean (2012, n.p.) argue: "the movement has to dispel the illusion that all proposals and visions are equivalent as long as they are democratically discussed, and begin to set priorities to a truly transformative and visionary politics". Similarly, Roberts (2012) argues that one reason why OWS "failed" to disrupt the neoliberal status quo was its inability to issue concrete demands and its reluctance to forge strategic alliances with established groups or politicians. Building on similar assumptions, Epstein (2012) makes a distinction between what she calls "resistance" and "social change", with OWS belonging to the former category, which is concerned with drama and spectacle, while the latter involves actually thinking about "how we get from where we are to the society that we want" (Epstein 2012, 81-82). To many observers - as well as participants - OWS thus failed the progressive agenda because of its minimal impact at the level of 'realpolitik'.

On September 17, exactly two years later, the former Minister of Culture in Denmark, Uffe Elbæk, left the Social-Liberal Party in order to launch a new political project called The Alternative. The stated purpose of The Alternative was to challenge the unsustainable program of neoliberalism and the pro-growth agenda by representing and promoting social, economic, and environmental alternatives to the current state of affairs. Besides this grand objective, however, The Alternative started out with no political program whatsoever. All they had was a manifesto and six core values (The Alternative 2016). With inspiration from the open-source community, the program was later developed through so-called "political laboratories" in which anyone could participate, regardless of political convictions (The Alternative 2014). During the national elections in June 2015, The Alternative entered the Danish Parliament with almost five percent of the votes. As such, both in terms of processual arrangements and the initial lack of particular demands, The Alternative could be viewed as an attempt to institutionalize the spirit of movements like OWS.

In this paper, we compare the political anatomy of OWS and The Alternative and argue that they should be viewed as two distinct enactments of contemporary radical politics. While OWS is viewed as an example of "critique as withdrawal", The Alternative is characterized as an example of "critique as engagement" (Mouffe 2009). ${ }^{1}$ Accordingly, we suggest that, at least on a conceptual level, The Alternative could be

\footnotetext{
${ }^{1}$ In this categorization, we follow Laclau and Mouffe's notion of politics as articulations, which entails forging connections with different demands and groups (Laclau and Mouffe 1985, 105). It is, of course, only in this light, and not in the light of, for instance, Hardt and Negri's (2004) notion of the multitude as separate identities and points of resistance that OWS appears as an instance of withdrawal.
} 
seen as a continuation of OWS' project; as a project that began where OWS ended by presenting the established system with a detailed list of political demands. Drawing on the vocabulary of Laclau (1996a; 1996b; 2001), we conceptualize The Alternative's transformation from a loosely defined movement to a well-defined political party as a move from a position of universality towards a position of particularity. In this case, the institutionalization of radical politics thus entails a particularization of The Alternative's political project, which ultimately sparks a greater need for political management in order for the party to maintain its universal appeal and, by implication, its radical identity. In conclusion, we use this conceptualization to propose a distinction between what we call "radical movements" and "radical parties": While the former is constituted by a potentially infinite chain of equivalent grievances, the latter is constituted by a prioritized set of differential demands.

The paper is structured as follows. We start by briefly reviewing the discourse theory of Laclau and Mouffe $(1985 ; 1987)$. Here, special attention will be paid to explaining Laclau's (1996a; 1996b) conceptualization of the unbridgeable chasm between 'the universal' and 'the particular', which constitutes the backbone of the paper's theoretical framework. Building on those insights, we proceed to discuss the nature of radical politics today. ${ }^{2}$ A key argument here will be that the word 'radical' implies negativity and otherness, which makes it particularly difficult to advance positive articulations of radical politics. We will refer to this difficulty as the problem of particularization. After this theoretical exercise, we continue with a section on the methodological considerations guiding the forthcoming analysis. This leads us to the actual analysis of OWS and The Alternative, in which we tease out the difficulties of institutionalizing radical politics through parliament. This analysis is dovetailed by a concluding discussion of radical movements and radical parties. Building on key insights from the examination of OWS and The Alternative, we will attempt to distinguish between those two types of organizations. This distinction allows us to argue that both movements and parties are of great importance to contemporary radical politics, as long as they remain discrete parts of the "mosaic left" (Urban 2009). Finally, we propose possible avenues for further research.

\section{Discourse Theory and Radical Politics}

Laclau and Mouffe's discourse theory was initially developed as an attempt to advance the socialist agenda by providing the academic Left with new thinking tools that would exceed the explanatory power of classical Marxist theory (Laclau and Mouffe 1987). By replacing the economic determinism of Marxist thinking with a poststructuralist focus on pluralism and contingency, Laclau and Mouffe sat out to create a theory that was capable of explaining the crisis of traditional leftist politics and the concomitant proliferation of 'new social movements' from the late 1960s and onwards. Even though this theoretical venture started with some of especially Laclau's earlier writings (e.g. Laclau 1977), the theory rose to prominence with the publication of the seminal work, Hegemony and Socialist Strategy (Laclau and Mouffe 1985). Not only did this book spark intense debate amongst leftist scholars and practitioners about the true nature of socialist politics, it also helped pave the way for a new understanding of democracy, and hence, a new conception of politics altogether.

\footnotetext{
${ }^{2}$ It should be noted that while this paper solely deals with leftist radical politics, the argument conveyed throughout the text equally applies to other enactments of radical politics. So when we later speak of a 'mosaic left', one could just as well talk about a 'mosaic right'.
} 
Drawing on the work of Gramsci (1971), Laclau and Mouffe place the concept of hegemony at the heart of political analysis. Instead of merely associating hegemony with leadership and superiority (as is often the case in mainstream political science), they appropriate the concept to explain how political projects generally emerge and become dominant. To Laclau and Mouffe, hegemony is understood as the articulatory practice of expanding a discourse - or a series of discourses - into what Gramsci called a "national-popular collective will" $(1971,125)$. Hegemony is achieved, they argue, when unity is established in a concrete social formation (Laclau and Mouffe $1985,7)$, and in that way, the concept of hegemony becomes closely related to another slippery concept in political science, namely the notion of ideology (Laclau 1997). In practice, a discourse becomes hegemonic by provisionally fixing the meaning of the social through the articulation of a signifying system, which is structured around sufficiently empty signifiers (also referred to as "nodal points" [Laclau and Mouffe 1985, 112]). Put briefly, empty signifiers are signifiers that lack a signified. Instead of pointing to something positive within a signifying system, empty signifiers point to the outside of the system and, by implication, to the very limits of the system: Its so-called "radical otherness" (Laclau 1996b, 52). Accordingly, the strictly positive character of that which is signified by empty signifiers is what Laclau terms the 'systematicity of the system', meaning that elusive universal beyond the actual particularity of the elements involved (Laclau 1994, 169).

A good example of an empty signifier is the word 'sustainability', which has recently become a frequent buzzword in leftist politics and which plays a central part in the political project of The Alternative in particular. Even though most people feel they know what the word means, it always escapes attempts to define it in any consensual way. This is the case because the term does not point to anything particular within a signifying system. It holds little positive meaning and cannot be substituted for more specific terms like, for instance, 'degrowth' or 'veganism'. Instead, 'sustainability' is the empty signifier giving sense to the signifying system in its totality. In this way, the emptiness of 'sustainability' points to the very limits of the system and to that which lies beyond the system, namely the ungraspable calamities of climate change. Of course, this inherent emptiness allows for a lot of window-dressing on the part of politicians and decision-makers, but it likewise provides environmentalists with the possibility of articulating various progressive initiatives within a shared frame of reference (see Brown 2016 for a discussion of this matter). Hence, contrary to most common understandings, the concept of empty signifiers is not used by Laclau as a pejorative label for a destitute kind of politics, but rather as a defining feature of politics altogether.

As Laclau (1994) notes, empty signifiers are important to politics for several reasons. For one, empty signifiers are able to mobilize and represent a wide range of political identities, precisely because they do not signify anything particular. By not signifying (and thus prioritizing) particularities, empty signifiers are able to structure the identities of a signifying system in equivalential chains. An equivalential chain is a chain of political identities that have surrendered some of what initially made them differential in order to unite against a common adversary (i.e. the system's constitutive outside). As such, while the equivalential chain provides the individual identities with stability and solidarity, it likewise curbs their autonomy (Laclau 2005, 129). This is why Laclau refers to empty signifiers as signifiers of "the pure cancellation of all difference" (Laclau 1994, 170). Secondly, empty signifiers are important to politics because they help build antagonistic relations towards opposing forces. As both Laclau and Mouffe have shown, the production of social antagonisms is a prerequisite 
for all political projects, as the fantasy of a completely reconciled society remains unachievable (Laclau and Mouffe 1985, 122; Mouffe 2005). As we shall see, both OWS and The Alternative are founded on the erection of antagonistic frontiers demarcating themselves from a radical otherness. In both cases, it is 'the establishment' that is excluded from the system, which enables the projects to mobilize an almost infinite chain of counter-hegemonic identities.

\subsection{The Universal and the Particular}

Hegemony is thus not only the name of a political logic but also the name of a process that brings us from the undecidable terrain of discursivity (the ontological level) to the decidable level of discourse (the ontic level) by provisionally fixing the otherwise contingent character of the social (Torfing 1999, 102). Another way of conceiving this hegemonic process is through the asymmetrical relationship between what Laclau calls "the universal" and "the particular" (1996a; 1996b). Usually when political projects emerge and become hegemonic, they undergo a process of universalisation in which a particular struggle is detached from its local context and transformed into a universal project capable of representing a host of political identities (Laclau 2001). A recent example of this might be the transformation of the Pirate Party from a Swedish protest party concerned with copyright laws and Internet freedom to an international party concerned with a wide variety of political struggles (Miegel and Olsson 2008). In that way, the Pirate Party assumes the task of representing something much bigger than a particular struggle about copyright laws in Sweden, which is ultimately what led to the project becoming universal.

As such, particular identities (or struggles or demands) are differential, in the sense that they can be clearly separated from other particularities. As such, all social groups that are structured around specific interests can be characterized as particular identities (Laclau 2001, 6). On the other hand, universal identities are former particular identities that have surrendered what initially made them differential in order to represent what Laclau calls the "absent fullness of the community" $(1997,304)$. Whenever an identity assumes the task of representing the community in its entirety, it becomes universal and, hence, hegemonic. The hegemonic process is thus constituted by a 'dialectic' relationship (without Aufhebung) between the universal and the particular as two unbridgeable levels of the social. The reason why the chasm between universality and particularity is unbridgeable is related to the plurality of the social and the impossibility of reaching a fully reconciled society. In fact, the preservation of this chasm is a fundamental trait of democracy. The moment when the universal becomes commensurable with a certain particularity is the moment we enter the world of totalitarianism (Laclau 2001, 12).

By definition, the universal is an unachievable beyond, which can only be manifested by an empty signifier. Accordingly, the universal identity must itself lack positive content, as the attribution of positive content to a universal identity inevitably entails a prioritization of some kind of particularity (Laclau 2001, 10). The dialectic relationship between the ongoing production of emptiness, closely associated with the universal, and the specificity of the particular will be paramount to our forthcoming analysis. Here, we shall see how OWS was forced to abandon their initial quest for particularity and adopt a highly universal identity, and how The Alternative - contrary to OWS - began as a highly universal project but ended up with the perhaps most particular political program of all parties in the Danish parliament. These opposing transformations are what distinguish the two organizations and, ultimately, what con- 
stitutes the difference between radical movements and radical parties. However, before we get ahead of the argument, let us first consider the nature of contemporary radical politics.

\subsection{From Identity Politics to Radical Politics}

With the rise of the Alterglobalization movement, famously initiated during the Battle of Seattle in 1999, a new type of radical politics seems to have emerged (Maeckelbergh 2009; Taylor 2013). Previously, the label of radical politics was reserved for the many 'new' social movements that transpired during the latter part of the 20th century, such as second wave feminism and the African-American civil rights movement (Newman 2007, 174). These movements are often associated with the term identity politics' because they advocated freedom and recognition for clearly designated constituencies. In other words, rather than trying to represent 'the people' as a whole, they struggled for the recognition of oppressed identities by seeking to transform the dominant conception of specific groups of people (Young 1990).

Drawing on a Laclauian vocabulary, one could argue that the new social movements were chiefly concerned with the assertion of particular identities within a broader discourse of postmodernity, in which the grand narratives of modernity had been replaced by an incommensurable sea of differences (Laclau 1985, 41). Instead of building hegemonic projects through the articulation of universalistic ideas, the goal of identity politics was simply to secure the recognition of yet another particular identity. However, as Newman (2007) makes clear in his book Unstable Universalities, radical politics after the Alterglobalization movement has another agenda. Rather than fighting for the rights of so many differences, contemporary radical politics has revived the Left's interest in universalities. As explained by Laclau's former supervisor, Hobsbawm (1996, 43):

The political project of the Left is universalist: it is for all human beings. However we interpret the words, it isn't liberty for shareholders or blacks, but for everybody. It isn't equality for all members of the Garrick Club or the handicapped, but for everybody. It is not fraternity only for old Etonians or gays, but for everybody. And identity politics is essentially not for everybody but for the members of a specific group only.

Contrary to the particularistic objectives of identity politics, contemporary radical politics assumes the task of representing the pure being of 'the people' (as a whole) by negating that which threatens its very existence (Laclau 2006). The difference between identity politics and what we call contemporary radical politics can thus be summarized as a difference between abundance and lack (Tønder and Thomassen 2005). While the former seeks to offer recognition to an abundance of particularities, the latter operates with a constitutive lack as its only point of unity. As previously alluded to, this lack is caused by the emptiness of universality and the associated cancellation of particular differences (Laclau 1996a). It is precisely the lack of positive content, and the shared opposition towards established "positives", that unifies political organizations like the Alterglobalization movement (Newman 2007). And as we shall see, this also applies to OWS and the initial stage of The Alternative.

Radical politics, conceived as involving the production of emptiness through the articulation of empty signifiers, may thus be conceptualized as politics based on negativity and otherness. Of course, this does not mean that there is nothing positive 
or meaningful about radical politics. It merely means that the defining feature of radical politics is negativity towards 'the establishment'. This kind of negativity does, however, characterize a wide range of political forms like, for instance, populism (Laclau 2005). As such, The Alternative might appear as a populist party, and the early dominance of equivalential logics as well as the undeniably decisive role played by its leader, Uffe Elbæk, arguably points in that direction. However, one of the defining features of populism is the explicit articulation of 'the people' as a figure being threatened by an adversary but also as having the potential to overcome this threat. In the case of The Alternative, 'the people' do not play a dominant role (at least not explicitly). Likewise, despite Elbæk's central position, the organization of The Alternative points strongly in the opposite direction. The so-called political laboratories, in which everyone is invited to shape the party's policies, suggest that it is neither a populist nor a leader's party.

Our conception of radical politics has a series of consequences for political organizations that, like OWS and The Alternative, consider themselves radical. Perhaps the most important implication for this paper concerns the problem of institutionalizing radical politics through the parliament. This is the case because, in the context of radical politics, the move from protest to parliament entails a move from a position of universality towards a position of particularity. ${ }^{3}$ This transformation is caused by the need to respond to the logic of the established system, which requires a positive articulation of political demands. The task of attributing positive content to an otherwise universal identity is difficult for two reasons: First, it cuts short the equivalential chain, which essentially means that the scope of representation is significantly narrowed. Secondly, it differentiates and isolates demands that were previously united in opposition to a common adversary. The most pertinent consequence of these two processes is that the move from universality towards particularity risks cutting off supporters who no longer feel represented by the project. In other words, the more particular a political project gets, the harder it gets to claim to represent 'the people' as a whole (Laclau 2005, 89). In what follows, we will refer to this as the problem of particularization.

\section{A Brief Note on Methods}

Even though the forthcoming analysis revolves around the empirical story of two "critical cases" (Flyvbjerg 2006), the gist of this paper is thoroughly theoretical. That is, the main purpose of the paper is to raise and unfold a general problem inherent to all radical political projects that seek to particularize an otherwise universal identity. Thus, the purpose of the paper is not to ponder the empirical complexity of either case or to investigate the problem of particularization across a representative sample of political organizations. Instead, the point is to strategically appropriate two illustrative cases as a way of allowing for a logical deduction of the type: "If this is (not) valid for this case, then it applies to all (no) cases" (Ibid., 230). Naturally, this does not render methodological considerations obsolete, which is why we below shed some light on the way in which data has been collected and analyzed for the purpose of the present paper.

\footnotetext{
${ }^{3}$ In the context of identity politics, the opposite would most likely be the case. Since identity politics is concerned with the assertion of isolated particularities, the entry into parliament would most likely entail a universalization of the political project, not a further particularization. This was, for instance, the case for the Pirate Party.
} 
First of all, it should be noted that this paper is part of a larger study of The Alternative's transformation from movement to party carried out by the first author. The empirical foundation of the larger study consists of well over 1000 pages of written material, 34 semi-structured interviews, and almost 200 hours of participant observation, all of which was collected and conducted during 18 months, from May 2014 to October 2015. Hence, even though the present paper relies on only a handful of documents, the remaining bulk of data has naturally helped us arrive at the points that are conveyed throughout the text. For instance, when we, towards the end of the analysis, suggest that The Alternative has managed to maintain a degree of universality despite the party's sudden claim to particularity, this argument is supported by more data than what is explicitly presented here (most notably observations and interviews with different members of The Alternative). Unfortunately, limitations of space prevent us from unfolding the richness of that data here.

Now, turning to the data that is examined in this paper, the following analysis consists of a close reading of a few central documents. These documents have all played a crucial role in defining the political projects of OWS and The Alternative, and they continue to shape the way supporters relate to both organizations. In the case of OWS, two documents are examined: The first is Adbusters Magazine's initial call to "occupy Wall Street", manifested in a now iconic poster and an associated email (Adbusters 2011a; 2011b). The second is The Declaration of the Occupation of New York City, which serves as the movement's first official statement (Occupy 2011). In the case of The Alternative, we rely on a total of seven documents, including the party's manifesto (The Alternative 2013b) and two versions of the political program (The Alternative 2014; 2015b). The reason for this unevenness of data has to do with the paper's main objective. As mentioned, besides splitting the difference between radical movements and radical parties, the paper's chief goal is to empirically demonstrate what we call the problem of particularization, which is a problem faced by The Alternative and evaded by OWS. As such, the analysis of OWS, while certainly an interesting case in and of itself, primarily serves to set the stage for the introduction of The Alternative.

Analytically, we approached all of the documents through Laclau's conceptualization of the universal and the particular, which meant that we sat out to explore whether these documents point to particularities within the two organizations, or whether they, instead, point to some kind of radical otherness. In practice, we identified particularity as the positive articulation of specific political objectives. This meant that whenever the documents contained actual policy proposals or suggestions for demands, we interpreted this as signs of particularity. In contrast, whenever the documents only contained negative claims about some externality, or when they predominantly revolved around empty signifiers, we interpreted this as a sign of universality.

\section{Analysis: Institutionalizing Radical Politics}

Before proceeding to the analysis, it should be noted that there are important differences between Danish and American forms of government. For instance, while the Danish system is built on proportional representation, which tends to favour multipartism, the American system is built on plurality voting, which (according to Duverger's law) tends to favour a two-party system. Besides this, the electoral threshold in Denmark stands at a mere 2 percent, making it comparatively easier for extraparliamentarian groups in Denmark to enter parliament. As such, one might argue 
that OWS and The Alternative are part of two somewhat incommensurable realities. And indeed, this would have been the case, had we set out to explain why The Alternative engages with the state and why OWS did not. This is, however, not the purpose of the forthcoming analysis. As stated in the introduction, the purpose is to tease out the theoretical implications of institutionalizing radical politics. We will do so by first recounting the story of OWS, and the movement's aversion to parliamentary politics, as a way of setting the stage for the introduction of The Alternative. The way the two organizations move between protest and parliament, universality and particularity, will ultimately assist us in characterizing OWS and The Alternative as two distinct enactments of radical politics: One that withdraws from the state and one that engages with the state and, consequently, the problem of particularization.

\subsection{Occupy Wall Street: 'A movement without demands'}

Even though the Occupy movement was a product of many people's shared ambitions to bring the spirit of the Arab Spring and the Spanish Indignados to America (Kroll 2011), most observers trace the birth of OWS back to a poster issued by $A d$ busters Magazine in July 2011. The poster shows a ballerina dancing atop Wall Street's famous statue of a charging bull. Right above the ballerina, a text reads: "What is our one demand?" (Adbusters 2011a). Accompanying the poster was an email written as a "tactical briefing" to all those "redeemers, rebels and radicals out there". Besides encouraging its receivers to flood Wall Street on September 17, the email likewise suggested that a shift in revolutionary tactics was underway. Instead of attacking the system "like a pack of wolves", which presumably was the tactic of the Alterglobalization movement, the occupation of Wall Street would be more like a swarm of people repeating one easily comprehensible demand. In fact, the email even contained a suggestion for one such demand, namely the appointment of a "presidential commission to separate money from politics" (Adbusters 2011b).

As such, OWS began as an attempt to create a highly particularized movement, initially only concerned with articulating one single demand. However, once the first protesters assembled in Zuccotti Park, just north of Wall Street, it quickly dawned on everyone that settling on one specific objective would be more than difficult. While some participants debated whether OWS should focus on "ending corporate personhood" or "getting money out of politics" (Kang 2013, 59), the movement's anarchist wing advocated a complete withdrawal from the state and, hence, an anti-demand approach to radical politics (Graeber 2013). Zeroing in on one demand became even harder when OWS adopted a 90\% threshold at general assemblies (what was called "modified consensus"), which made it virtually impossible for participants to resolve any issue related to the question of demands. So, instead of presenting the established system with one tangible demand - or even a list of demands - the movement decided to refrain from advancing positive articulations of political objectives. In that way, OWS officially abandoned the pursuit of particularity and adopted a highly universal identity represented by the well-known meme, "We are the 99 percent" (van Gelder 2011).

At a general assembly on September 29, the movement's participants voted in favour of adopting a document entitled The Declaration of the Occupation of New York City (Occupy 2011). In the absence of positive articulations, the declaration contained a long list of negatively framed grievances targeted at an unspecified actor called 'they'. In total, the declaration lists no less than 21 accusations regarding a wide range of issues. For instance, while the first grievance addresses the topic of 
illegal foreclosures, the third concerns gender and race inequality at the workplace, and while the fifth grievance concerns animal welfare, the twelfth points to issues of press freedom infringements. At the very end of the list, a footnote reads: "These grievances are not all-inclusive" (Ibid.). Two things about this declaration are immediately interesting to this paper. The first has to do with the seemingly infinite sequence of grievances. From a Laclauian point of view, this sequence is easily interpreted as an "equivalential chain". As explained in the theory section, an equivalential chain is a series of non-prioritized identities united against a common adversary, thereby obtaining a high degree of universality (Laclau 2005, 77). In accordance with the definition of equivalence, none of the listed grievances are prioritized or hierarchically ordered, and they all share the same overriding dissatisfaction with 'they'. This leads us to the second point of interest in OWS' declaration, namely the erection of an antagonistic frontier between 'the people' (represented by OWS) and 'they'. It takes little knowledge of OWS to realize who they are. 'They' is, of course, the name of the movement's logical counterpart, the wealthiest 1 percent of the population, who function as the constitutive outside of the 99 percent (van Gelder 2011).

The equivalential chain, and the associated splitting of the social into two opposing camps - the people and its Other - is a key feature of all universal political projects and, thus, a central part of any radical politics (Newman 2007; Laclau 2006). As such, The Declaration of the Occupation of New York City helps establish the universal character of OWS' political project by ultimately cancelling all particularity through the articulation of "the 99 percent" as an empty and radically inclusive signifier (Maharawal 2013). Towards the end of 2011, OWS revived the discussion of demands by issuing an official statement against the "Stop Online Piracy Act" (Kang 2014, 80), but by then the movement had already sealed its legacy as "a movement without demands" (Deseriis and Dean 2011). Due to the lack of positive articulations, OWS continued to grow wider in scope, and when the movement later substituted its physical presence for purely online endeavours, the proliferation of grievances exploded (Husted 2015). ${ }^{4}$

It is an ongoing debate whether OWS had any impact on 'realpolitik'. While some argue that the recent US presidential nominations were notably influenced by the overall message of OWS (Levitin 2015), the main conclusion seems to be that, besides a few unauthorized co-optations by politicians like Al Gore and Nancy Pelosi, the movement has had little "assessable impact" on parliamentary politics (Malone and Fredericks 2013). The general agreement about the lack of impact has earned OWS a reasonable amount of criticism from observers and participants alike (e.g. Chomsky 2012; Epstein 2012; Perlstein 2012). In fact, some even argue that OWS 'failed' because of its unwillingness - or inability - to issue concrete demands and its reluctance to forge strategic alliances with parts of the established system (Ostroy

\footnotetext{
${ }^{4}$ Research on OWS within media studies suggests that social media platforms, such as Facebook and Twitter, played a crucial role in allowing the movement to survive, expand, and renew itself after the eviction from Zuccotti Park (e.g. Castells 2012; Juris 2012). However, as Bennett (2012) points out, the growing impact of digital media on contemporary politics has likewise helped spawn a more personalized approach to political participation in which individuals are mobilized around 'personal action frames' rather than collective identities. This may be one reason why the OWS crowd remained fundamentally irreconcilable.
} 
2012; Roberts 2012). ${ }^{5}$ Dean, one of the more avid critics, has gone to great lengths to show why the movement's anarchist-inspired aversion to parliamentary politics was, in fact, a misguided attempt to preserve the egalitarian ethos of the initial occupation (Deseriis and Dean 2011; Dean 2012a; Dean 2012b). In her most recent book, Dean (2016) makes the argument that crowds, such as the one constituting OWS, are inherently non-political until they abandon "horizontalism" as an organizing principle and begin to set priorities by articulating a clear political orientation. In other words, until the chain of equivalences is turned into a prioritized chain of differences, the crowd cannot claim to have a politics. As she puts it:

The politics of the beautiful moment is no politics at all. Politics combines the opening with direction, with the insertion of the crowd disruption into a sequence or process that pushes one way rather than another. There is no politics until a meaning is announced and the struggle over this meaning begins. (Dean 2016, 125)

According to Dean, one way to make the crowd political is for it to crystallize into a political party that is capable of preserving the "egalitarian discharge", while simultaneously providing the crowd with a sense of direction. Only by doing so will the crowd move from being an opportunity for politics to becoming an actual political project (Dean 2016, 206). Even though Dean firmly believes that the Communist Party is best suited for assuming the task of institutionalizing the spirit of movements like OWS, she nonetheless suggests that any kind of (leftist) "movement party" will do. That is, a party that replaces the worn-out notion of a vanguard party with a party that provides a sense of political orientation while keeping open the space in which the crowd can picture itself as "the people" (Ibid., 229). In Laclauian terms, a movement party is thus a party that somehow manages to articulate particular objectives while maintaining some kind of universality. Coincidentally, since the rise and fall of OWS, a whole wave of such parties has swept across Europe: From Syriza in Greece and Podemos in Spain, to Movimento Cinque Stelle in Italy and LIVRE in Portugal. For the remainder of this analysis, we will explore the case of yet another movement party, namely a newly elected party in Denmark called The Alternative.

\subsection{The Alternative: From Movement to (Movement) Party}

In many ways, The Alternative began where OWS ended: With an almost infinite chain of equivalent grievances. In other words, while OWS ended up as a movement without demands, The Alternative began as such. At a press conference in November 2013, the former minister of culture in Denmark, Uffe Elbæk, and the head of a large umbrella organization for public sector workers, Josephine Fock, announced that they would be launching a new political project called The Alternative. The guiding idea behind The Alternative, they proclaimed, was to represent and promote social, economic, and environmental alternatives to the current state of affairs. However, to most people's surprise, Elbæk and Fock did not present any political program: "We don't have a grand party bible on the shelf", they told the press. Instead, they announced that the program would be developed during the following six months through a series of publically accessible "political laboratories". Through

${ }^{5}$ Even the former editor of Adbusters Magazine and OWS co-founder, Micah White, describes the movement as a "constructed failure" (2016) because of its inability to achieve social change by engaging actively with the established system. 
these laboratories, the goal was to arrive at concrete solutions to the most profound problems facing contemporary society and to figure out how to transform Denmark into "the place that we all dream of - a good society for everyone" (The Alternative 2013a).

Though no political program was presented at the press conference, Elbæk and Fock did provide some sense of direction by drawing attention to The Alternative's manifesto (The Alternative 2013b) and its six core values (Ibid. 2013c). Especially the manifesto, which, in the absence of concrete policy proposals, quickly became a main source of attraction for many supporters, is structured in much the same way as OWS' declaration. Even though it does not contain an equivalent sequence of grievance per se, the manifesto clearly testifies to the initial universality of The Alternative's political project. Instead of listing a series of grievances and emphasizing that these grievances are not all-inclusive, The Alternative's manifesto begins with the encouraging statement: "There is always an alternative", and it ends with the following lines:

The Alternative is for you. Who can tell that something has been set in motion. Who can feel that something new is starting to replace something old. Another way of looking at democracy, growth, work, responsibility and quality of life. That is The Alternative.

Throughout the text, The Alternative is described as "a hope", "a dream", and as "a yearning" for sense and meaning. It is also described as a "shout out" against cynicism and as a "countermeasure" to the various crises facing the world and its future generations (The Alternative 2013b). Just like OWS' declaration, The Alternative's manifesto subscribes to the logic of universality for two reasons. First of all, it lends itself to multiple interpretations of what it actually means to be alternative. By proclaiming that there is always an alternative, and by stressing that The Alternative is for anyone who can feel that "something new" is about to replace "something old", the manifesto allows an incredibly wide range of (counter-hegemonic) identities to identify with The Alternative. In that way, The Alternative assumes the task of representing all those who feel a need for change, and in doing so, 'The Alternative' automatically becomes a universal identity and, hence, an empty signifier without any explicit claim to particularity.

Secondly, the manifesto establishes an antagonistic frontier between The Alternative and its constitutive outside. As mentioned in the theory section, empty signifiers are important to politics because they manifest a divide of the social into two opposing camps: 'the people' and its Other (Laclau 1994; 2006). In the manifesto, this is done in a more subtle way than in OWS' declaration, where this division is quite clearly expressed. However, by positioning The Alternative as a countermeasure to the old way of perceiving "democracy, growth, responsibility and quality of life", a frontier is erected between 'the new', as represented by The Alternative, and 'the old', as represented by the establishment. As such, even though the language of 'the people' vs. 'the establishment' is never explicitly appropriated, the universality of The Alternative's project is thoroughly solidified by the manifesto's dialectic rhetoric of new and old, which - intentionally or not - quickly translates into a dialectic of us and them. This constitutive negativity towards the establishment is further emphasized elsewhere in the manifesto where the need to "take back ownership of the economy and of democratic decisions" is articulated (The Alternative 2013b). 
Through the manifesto, it becomes clear how The Alternative began as an incredibly universal project with no particular objectives; and this, combined with the lack of institutional representation, is the main reason why we conceive of The Alternative in its initial stage as a radical movement. ${ }^{6}$ However, as Elbæk and Fock promised at the press conference, a political program was to be expected. Hence, in the early weeks of 2014, more than 20 political laboratories were organized, and through these events, more than 700 people participated in the process of crafting Denmark's first "open-source" political program (The Alternative 2016). In late May, the program was accepted at the party's first general assembly and then presented to the public. At that point, the program contained a series of proposals revolving around six core policy areas (Ibid. 2014). However, The Alternative's political program was far from finished. During the remainder of 2014 and the beginning of 2015, more laboratories were organized and more proposals were added to the program. Besides organizing political laboratories and staging various happenings, however, members of The Alternative spend most of their time collecting signatures in order to become eligible to run for parliament. On March 3, 2015, they succeeded in reaching the threshold of 20,260 signatures, which allowed The Alternative to register as an official contender for seats in the Danish parliament. Not only did this mark the formal transformation from movement to party, it likewise made The Alternative's members much more focused on the upcoming elections: Campaign strategies were prepared, key policy areas were selected and, most importantly, more proposals were added to the program (Ibid. 2015a).

At the national elections in June 2015, The Alternative earned an unexpected 4.8 percent of the votes, which translated into nine seats in the Danish parliament. At that point, the political program had grown significantly, and it now contained 64 pages of highly specific policy proposals (Ibid. 2015b). In fact, this easily made The Alternative's political program the most detailed program across all nine parties in the Danish parliament. Not only is The Alternative's program now the longest and most detailed program in parliament, it likewise contains a range of very elaborate and sometimes rather controversial proposals, such as offering unconditional basic income to unemployed citizens (proposal 4.3.1), legalizing assisted euthanasia (proposal 9.7.4), and releasing bionoxes into state-owned forests as a way of enhancing biodiversity (proposal 3.3.1). As such, it no longer makes sense to speak of The Alternative as a universal project. In fact, more than any other party, The Alternative positions itself as a highly particularized project; and in doing so, it thus abandons the task of representing the pure being of 'the people' as a whole. Paraphrasing Hobsbawm (1996), one could argue that The Alternative is no longer for everyone.

This process of particularization poses a problem for The Alternative because it invariably entails a narrowing of the scope of representation. Today, The Alternative is no longer defined solely through its opposition towards the establishment, which essentially means that the equivalential chain has been cut short, and that the logic of

\footnotetext{
${ }^{6}$ What we mean by this is that, in the beginning, a movement logic was dominant in the Alternative. It is thus important to note that our conception of a movement differs from more traditional ones. While, for instance, Tilly and Wood $(2012,4)$ define a (social) movement as a synthesis of campaigns, repertoires, and so-called "WUNC displays", we conceptualize the logic of a (radical) movement as the grouping of loosely organized identities, tied together in equivalential chains and united against a common adversary. Hence, it matters less whether a movement has a certain size or whether its participants are committed or not. In relation to the present paper, the logic that structures the group is more important.
} 
(positive/particular) differences becomes dominant (Laclau 2005, 72). But how then might we still characterize The Alternative as a radical party? Does the loss of universality not automatically cancel the party's radical identity? In the case of The Alternative, the answer seems to be: No. First of all, one would assume that particularization entailed a decrease in registered memberships. It seems logical to assume that once the party goes from representing 'the people' to representing a particular constituency, a certain amount of identities would cease to identify with the overall project. However, this has in no way been the case. In fact, The Alternative has sextupled their membership base in only one year (Juul 2016). Furthermore, in terms of opinion polls, the party has likewise increased its numbers: From 0.2 percent four months prior to the elections to 7.1 percent at the time of writing (Berlingske 2016). Secondly, through one and a half years of qualitative data collection conducted by the first author, it has become clear that those members who could be expected to feel marginalized by and large remain supporters of The Alternative's political project, regardless of political disagreements. As one member put it during a discussion on a Facebook page associated with The Alternative:

I don't need to agree with the party's policy in that many areas to believe in the project. The most important thing for me is that it's a product of pure democratic debate without dogmatism. To me, it's a strength that we maintain a curious disagreement all the way through the party, and that we don't lock ourselves into political programs.

It thus seems as if The Alternative has somehow managed to maintain a degree of universality while going through a process of particularization; a universality that allows the equivalential chain to expand despite the party's sudden claim to particularity. As such, The Alternative seems to meet the requirements for a so-called "movement party" (Dean 2016, 229). However, further research is needed in order to explore how and why that is made possible: Are we witnessing a simple case of "impure" representation (Laclau 2005, 155) in which identity flows, not from represented to representative, but also the other way around? Or has The Alternative, in fact, managed to postpone or displace the problem of particularization by somehow masking the existence of a gap between the universal and the particular?

\section{Conclusion: Of Movements and Parties}

When political projects, such as The Alternative in Denmark or Podemos in Spain, channel the energy of popular mobilizations into the parliamentary system, they engage with the state in much the same way that many scholars have prescribed (e.g. Dean 2016; Mouffe 2009; White 2016). This engagement, however, comes at a cost. By substituting negativity and otherness for a positive articulation of political objectives, they replace the logic of equivalence with a logic of difference in which political demands are clearly separated and hierarchically prioritized (i.e. by selecting key campaign issues). This means that they effectively remove the 'counter' from an otherwise counter-hegemonic project, and in doing so, they risk compromising their radical identity. As such, political parties like The Alternative cannot be conceived as alternatives to movements like OWS but as a necessary supplement. We thus disagree with those who claim that OWS was a failure because of its inability to pose demands. There is clearly something valuable in maintaining a universal stance against the hegemony of dominant discourses, such as neoliberalism and the pro- 
growth agenda. That being said, we do agree with the critique levelled against the movement's unwillingness to forge strategic alliances with parts of the established system. As Mouffe (2009, 237) explains:

It's a 'war of positions' that needs to be launched, often across a range of sites, involving the coming together of a range of interests. This can only be done by establishing links between social movements, political parties and trade unions, for example. The aim is to create common bond and collective will, engaging with a wide range of sites, and often institutions, with the aim of transforming them. This, in my view, is how we should conceive the nature of radical politics.

Following that argument, the task for contemporary radical politics is neither to fully withdraw from nor to fully engage with the state. The task is, in our view, to forge links and alliances between various parts of what Urban (2009) has called the "mosaic left". That is, a left that consists of multiple entities that share a common goal but operate at different levels and according to different logics. For instance, while political parties are forced to engage in realpolitik through highly particularized negotiations and compromises with opposing parties, interest lobbies, and the media, movements are free to operate at a much more universal level by advocating and prefiguring alternative futures that transcend the oftentimes paralyzing cul-de-sac of parliamentary politics. Building on that conclusion, we thus propose a conceptual distinction between 'radical movements' and 'radical parties'. While the former is constituted by a potentially infinite chain of equivalent grievances (as was the case with OWS and the initial stage of The Alternative), the latter is constituted by a prioritized set of differential demands (as is the case with The Alternative today). This distinction allows us to view both movements and parties as vital parts of contemporary radical politics, as long as they remain discrete entities and refrain from collapsing into one single organizational form. Failing to maintain that distinction would most likely mean the end of universality.

However, as mentioned above, despite the recent transformation from movement to party, The Alternative has somehow managed to maintain a degree of universality in the face of rapid particularization. How and why that is the case remains to be fully explored. The most straightforward answer seems to be that The Alternative has found a way to bridge the otherwise unbridgeable gap between the universal and the particular. But, as explained in the theory section, that is simply not possible. At least in democratic societies, the chasm between universality and particularity must be kept open, as the conflation of the two levels would entail an immediate regression into the world of totalitarianism. Another explanation might be that young opposition parties, such as The Alternative, are less affected by the demand for particularization - at least as long as they maintain an oppositional stance and refrain from passing bills and striking compromises. This has, however, not been The Alternative's strategy. In fact, through the notion of a 'new political culture', which has been one of the party's trademark ideas, The Alternative has made it a virtue to collaborate with opposing parties and to enter productive negotiations despite political differences.

This leads us to the conclusion that The Alternative, rather than bridging and/or avoiding the gap, has found a way to mask or displace the very existence of a gap, which ultimately prevents it from collapsing into one organizational form. Further research is needed to explore how this is done in practice: What political strategies, organizational practices, or managerial technologies have assisted The Alternative in 
maintaining the ongoing production emptiness that is so vital to radical politics, while simultaneously engaging with the state? And more importantly perhaps, what political and organizational consequences does this have for all those radical parties that are currently flourishing across the European continent?

\section{References}

Adbusters. 2011a. \#Occupywallstreet: A Shift in Revolutionary Tactics. Accessed May 18, 2016. www.micahmwhite.com/occupywallstreet/

Adbusters. 2011b. Ballerina and Bull OWS Poster. Accessed May 18, 2016. www.micahmwhite.com/occupywallstreet/

Bennett, W. Lance. 2012. The Personalization of Politics: Political Identity, Social Media, and Changing Patterns of Participation. The ANNALS of the American Academy of Political and Social Science 644 (1): 20-39.

Berlingske. 2016. Berlingske Barometer. Accessed April 10, 2016. http://www.politiko.dk/barometeret

Brown, Trent. 2016. Sustainability as Empty Signifier: Its Rise, Fall, and Radical Potential. Antipode 48 (1): 115-133.

Butler, Judith. 2012. So what are the Demands? And here do they go from here? Tidal: Journal of Occupy Theory 2 (1): 8-11.

Castells, Manuel. 2012. Networks of Outrage and Hope: Social movements in the internet age. Cambridge: Polity Press.

Chomsky, Noam. 2012. Occupy. London: Penguin.

Dean, Jodi. 2012a. The Communist Horizon. London: Verso.

Dean, Jodi. 2012b. Occupy Wall Street: After the Anarchist Moment. Socialist Register 49: 52-62.

Dean, Jodi. 2016. Crowds and Party. London: Verso.

Deseriis, Marco and Jodi Dean. 2012. A Movement without Demands? Possible Futures, January 3.

Epstein, Barbara. 2012. Occupy Oakland: The Question of Violence. Socialist Register 49: 63-83.

Flyvbjerg, Bent. 2006. Five Misunderstandings about Case-Study Research. Qualitative Inquiry 12 (2): 219-245.

Gitlin, Todd. 2012. Occupy Nation: The Roots, the Spirit, and the Promise of Occupy Wall Street. New York: it Books.

Graeber, David. 2012. Occupy Wall Street's Anarchist Roots. In The Occupy Handbook, edited by Jane Byrne. New York: Back Bay Books.

Graeber, David. 2013. The Democracy Project: A History, a Crisis, a Movement. London: Allen Lane.

Gramsci, Antonio. 1971. Selections from the Prison Note Books of Antonio Gramsci. New York: International Publishers.

Hardt, Michael and Antonio Negri. 2004. Multitude: War and Democracy in the age of empire. New York: Penguin Press.

Hardt, Michael and Antonio Negri. 2011. The Fight for 'Real Democracy' at the Heart of Occupy Wall Street. Foreign Affairs, October 11.

Hobsbawm, Eric. 1996. Identity Politics and the Left. New Left Review 217 (1): 38-47.

Husted, Emil. 2015. From Creation to Amplification: Occupy Wall Street's Transition into an Online Populist Movement. In Civic Engagement and Social Media: Political Participation beyond the Protest, edited by Julie Uldam and Anne Vestergaard. Basingstoke: Palgrave Macmillan.

Juris, Jeffrey S. 2012. Reflections on \#Occupy Everywhere: Social media, Public Space, and Emerging Logics of Aggregation. American Ethnologist 39 (2): 259-279. 
Juul, Trine. W. 2016. Alternativet Stormer Frem - Også på Landet. DR, April 1.

Kang, Susan. 2013. Demands Belong to the 99\%? The Conflict over Demands, Issues, and Goals in OWS. In Occupying Political Science: The Occupy Wall Street Movement from New York to the World, edited by Emily Welty, Matthew Bolton, Meghana Nayak and Christopher Malone. New York: Palgrave Macmillan.

Kroll, Andy. 2011. How Occupy Wall Street Really Got Started. In This Changes Everything: Occupy Wall Street and the 99\% Movement, edited by Sarah van Gelder and Staff of YES! Magazine. San Francisco, CA: Berrett-Koehler Publishers.

Laclau, Ernesto. 1977. Politics and Ideology in Marxist Theory. London: Verso.

Laclau, Ernesto. 1985. New Social Movements and the Plurality of the Social. In New social Movements and the State in Latin America, edited by David Slater. Amsterdam: CEDLA.

Laclau, Ernesto. 1994. Why Do Empty Signifiers Matter to Politics? The Lesser Evil and the Greater Good, edited by Jeffrey Weeks. London: Rivers Oram Press.

Laclau, Ernesto. 1996a. Subject of Politics, Politics of the Subject. In Emancipation(s), edited by Ernesto Laclau. London: Verso.

Laclau, Ernesto. 1996b. Universalism, Particularism and the Question of Identity. In Emancipation(s), edited by Ernesto Laclau. London: Verso.

Laclau, Ernesto. 1997. The Death and Resurrection of the Theory of Ideology. MLN 112 (3): 297-321.

Laclau, Ernesto. 2001. Democracy and the Question of Power. Constellations 8 (1): 3-14.

Laclau, Ernesto. 2005. On Populist Reason. London: Verso.

Laclau, Ernesto. 2006. Why Constructing a People is the Main Task of Radical Politics. Critical Inquiry 32 (4): 646-680.

Laclau, Ernesto and Chantal Mouffe. 1985. Hegemony and Socialist Strategy: Towards a Radical Democratic Politics. London: Verso.

Laclau, Ernesto and Chantal Mouffe. 1987. Post-Marxism without Apologies. New Left Review 166 (1): 79-106.

Levitin, Michael. 2015. The Triumph of Occupy Wall Street. The Atlantic, June 10.

Maeckelbergh, Marianne. 2009. The Will of the Many: How the Alterglobalization Movement is Changing the Face of Democracy. London: Pluto Press.

Maharawal, Manissa M. 2013. Occupy Wall Street and a Radical Politics of Inclusion. The Sociological Quarterly 54 (2): 177-181.

Malone, Christopher and Violet Fredericks. 2013. OWS and US Electoral Politics: An Early Critical Assessment. In Occupying Political Science: The Occupy Wall Street Movement from New York to the World, edited by Emily Welty, Matthew Bolton, Meghana Nayak and Christopher Malone. New York: Palgrave Macmillan.

Miegel, Fredrik and Tobias Olsson. 2008. From Pirates to Politicians: The Story of the Swedish File Sharers Who Became a Political Party. In Democracy, Journalism and Technology: New Developments in an Enlarged Europe, edited by N. Carpentier, P. PruulmannVengerfeldt, K. Nordenstreng, M. Hartmann, P. Vihalemm, B. Cammaerts, H. Nieminen \& T. Olsson. Tartu: Tartu University Press.

Mouffe, Chantal. 2005. On the Political. New York: Routledge.

Mouffe, Chantal. 2009. The Importance of Engaging the State. In What is Radical Politics Today?, edited by Jonathan Pugh. Basingstoke: Palgrave Macmillan.

Newman, Saul. 2007. Unstable Universalities: Poststructuralism and Radical Politics. Manchester: Manchester University Press.

Occupy. 2011. The Declaration of the Occupation of New York City. Accepted by the NYC General Assembly, 29 September.

Ostroy, Andy. 2012. The Failure of Occupy Wall Street. Huffington Post, May 31.

Perlstein, Rick. 2012. Why Occupy Need to Start Making Demands. Rolling Stone, March 22.

Pickerill, Jenny and John Krinsky. 2012. Why Does Occupy Matter? Social Movement Studies 11 (3-4): 279-287. 
Roberts, Alasdair. 2012. Why the Occupy Movement Failed. Public Administration Review 72 (5): 754-762.

Taylor, Blair. 2013. From Alterglobalization to Occupy Wall Street: Neoanarchism and the New Spirit of the Left. City 17 (6): 729-747.

The Alternative. 2013a. Press conference: Launch of The Alternative. Accessed May 18, 2016. http://www.dr.dk/nyheder/politik/video-uffe-elbaek-praesenterede-sit-nye-parti

The Alternative. 2013b. Manifesto. Accessed May 18, 2016. https://en.alternativet.dk/manifesto/

The Alternative. 2013c. Our Values. Accessed May 18, 2016. https://en.alternativet.dk/values/

The Alternative. 2014. First Draft of the Party Program. Accessed May 18, 2016. http://www. altinget.dk/misc/Alternativets Partiprogram - UDKAST.pdf

The Alternative. 2015a. Party Program. Accessed May 18, 2016: http://alternativet.dk/partiprogram/

The Alternative. 2015b. The Alternative is Ready for the Elections. Accessed May 18, 2016. http://alternativet.dk/valg-tema/

The Alternative. 2016. The History of The Alternative. Accessed May 18, 2016. http://alternativet.dk/alternativets-historie/

Tilly, Charles and Lesley J. Wood. 2012. Social Movements 1768-2012. Boulder: Paradigm Publishers.

Tønder, Lars and Lasse Thomassen, eds. 2005. Radical Democracy: Politics Between Abundance and Lack. Manchester: Manchester University Press.

Torfing, Jacob. 1999. New Theories of Discourse: Laclau, Mouffe and Žižek. Oxford: Blackwell Publishers.

Urban, Hans-Jürgen. 2009. Die Mosaik-Linke: Vom Aufbruch der Gewerkschaften zur Erneuerung der Bewegung. Blätter Für Deutsche Und Internationale Politik 5 (1): 71-78.

van Gelder, Sarah, ed. 2012. This Changes Everything: Occupy Wall Street and the 99\% Movement. San Francisco: Berrett-Koehler.

Welty, Emily, Meghana Nayak and Nick Zukowski. 2013. Occupy Wall Street as a Palimpsest: Overview of a Dynamic Movement. In Occupying Political Science: The Occupy Wall Street Movement from New York to the World, edited by Emily Welty, Matthew Bolton, Meghana Nayak and Christopher Malone. New York: Palgrave Macmillan.

White, Micah. 2016. The End of Protest: A Playbook for Revolution. Toronto: Knopf Canada. Young, Iris. 1990. Justice and the Politics of Difference. Princeton: Princeton University Press.

\section{About the Authors}

\section{Emil Husted}

Emil Husted is a PhD fellow at the Department of Organization, Copenhagen Business School. His core research interest centres on the notion of 'political organizing' in radical politics and how radical political parties manage the process of entering parliament without losing legitimacy and support. Specifically, he investigates radical political parties, such as The Alternative in Denmark and Podemos in Spain, and their efforts to institutionalize radical politics through parliament. Furthermore, Emil is vice chair of the Danish Association of Media Researchers and editorial board member of the peer-reviewed journal Politik.

\section{Allan Dreyer Hansen}

Allan Dreyer Hansen is associate professor at the Department of Social Sciences and Business at Roskilde University, Denmark. He has published widely on the discourse theory of Laclau and Mouffe, including 'Laclau and Mouffe and the Ontology of Radical Negativity' and 
'Discourse, the Political and the Ontological Dimension: An Interview with Ernesto Laclau' (with André Sonnichsen) both in Distinktion, 2014. 


\title{
From Cyber-Autonomism to Cyber-Populism: An Ideological History of Digital Activism
}

\section{Paolo Gerbaudo}

\author{
Lecturer in Digital Culture, King's College, London, United Kingdom, \\ paolo.gerbaudo@kcl.ac.uk
}

\begin{abstract}
The analysis of digital activism has so far been dominated by a techno-determinist approach which views the content of various forms of activism supported by digital communication, as directly reflecting the properties of the technologies utilised by activists and the historical evolution of such technologies. This line of interpretation has been manifested in the popularity acquired by notions as "Twitter protest" or "revolution 2.0" in the news media and in academic discourse in reference to recent protests. Moving beyond this reductionist trend, this article proposes an ideological approach to the study of digital activism and its historical transformation, which may better account for the combination of political, cultural and social factors involved in shaping it. I identity two main waves of digital activism, which correspond not only to two phases of technological development of the Internet (the so-called web 1.0 and web 2.0), but also to two different protest waves, the antiglobalisation movement, and the movement of the squares that began in 2011, each with its own dominant ideology. I argue that reflecting the seismic shift in perceptions and attitudes produced by the 2008 financial crash, and the connected shifts in social movement ideology, digital activism has moved from the margins to the centre of the political arena, from a countercultural posture to a counterhegemonic ambition. I describe this turn as a transition from cyber-autonomism to cyber-populism as the two defining techno-political orientations of the first and second wave of digital activism. Reflecting the influence of neo-anarchism and autonomism in the anti-globalisation movement cyber-autonomism viewed the Internet as an autonomous space where to construct a countercultural politics outside the mainstream. To the contrary, informed by the populist turn taken by 2011 and post-2011 movements cyberpopulism approaches the Internet as a "popular space", a generic space which is populated by ordinary citizens, and mostly dedicated to non-political activities, such as gossip, celebrity culture, or interpersonal communication, but which can nevertheless be politicised, and turned towards the purpose of popular mobilisation against the neoliberal elites responsible for economic and social disarray. This shift which substantially modifies the way in which activists conceives of and utilise digital media goes a long way towards explaining the differences in digital activism practices, and their contrasting views of the Internet as a tool and site of struggle.
\end{abstract}

Keywords: Digital activism, ideology, social media, populism, autonomism, Internet, counterculture, popular culture, techno-politics, techno-determinism

\section{Introduction}

Digital activism, a term widely used to describe different forms of activism that utilise digital technology, has undergone a rapid transformation since its emergence at the dawn of the web. From the vantage-point of the mid 2010s it is possible to tentatively identify two main waves of digital activism. The first corresponds to the early popularization of the Internet and the rise of the web in the mid '90s which was accompanied by the development by a first wave of digital activism. This wave encompassed a number of projects and initiatives waged by tech and alternative 
media activists of the anti-globalisation movement, including the alternative news site Indymedia, as well as a number of alternative mailing lists and early hacker (or hacktivist) groups and labs. The second wave coincides with the rise of the so-called web 2.0 Internet of social networking sites such as Facebook, YouTube and Twitter, which has been accompanied by the rise of world-famous hacker collectives as Anonymous and Lulzsec, as well as the "social media activism" of 15-M, Occupy and the other movements of the squares, whose organisers have used social networking sites as platforms of mass mobilisation. To what extent are these two phases of digital activism simply a reflection of the evolution of digital technology, and of the shift from web 1.0 to web 2.0, as they are often portrayed? Is the difference between them to be understood merely as deriving from the changing material affordances of digital technology at a time of rapid technological innovation? Or is there something more to the equation?

The debate about the transformation of digital activism has so far tended to follow a typical techno-deterministic tendency which reads technology as the ultimate cause of social transformation. This conception is belied by the popularity acquired by terms as "revolution 2.0" (Ghonim 2012), "wiki-revolution" (Ferron and Massa 2011) or "Twitter revolution" (Morozov 2009), widely used in news media and scholarly accounts to refer to recent protest movements making use of digital technology. The underlying rationale of these expressions is that the adoption of a certain kind of platform, say Facebook or Twitter, automatically defines the form of activism channelled through it. This approach stems from a simplistic view of technology's effects, deeply informed by the media theory of McLuhan and his famous moniker "the medium is the message" $(1967 ; 2011)$, according to which the use of a given technological device results in a series of inevitable consequences. The school of media ecology, deeply informed by McLuhan's work has important things to say about the way in which technology structures action, for example the way in which different communication technologies (say telephone, TV or the Internet), carry with them different communication architectures (one-to-one, one-to-many, many-tomany), and different dispositions from the users of technology (Postman 1985; Lundby 2009). However, it tends to neglect a number of non-technological factors socio-economic, political and cultural ones - that intervene in defining activism's content. To go beyond such simplified view of technology as an un-mediated force reshaping organisational structures and protest practices after its own image, the analysis of digital activism needs to recuperate an understanding of ideology, understood as a worldview and value system which shapes collective action, and of how ideology interacts with technology in shaping activist practices.

Adopting this approach, in this article I develop a periodisation of digital activism which centres around two different waves, each with its own ideological characteristics and with its accompanying "techno-political" orientations, to use the term introduced by Rodotà to describe the nexus between politics and technology and since widely adopted by activists and researchers. To this end I draw from my previous theorising on digital activism (Gerbaudo 2012; 2016) in the movement of the squares of 2011 and other post-2011 movements.

My argument can be schematically summarised as follows. Anti-globalisation activists adopted a techno-political approach that I describe as cyber-autonomist. This approach was deeply informed by the 70 s and 80 s counter-culture, DIY culture, and the tradition of alternative media, from pirate radios to fanzines. These different inspirations shared an emphasis on the struggle for the liberation of individuals and local communities from the interference of large-scale institution. Drawing on these 
antecedents, cyber-autonomism approached the Internet as a space of autonomy. The movement of the squares has instead adopted what I describe as a cyberpopulist attitude which sees the Internet as a space of mass mobilisation in which atomized individuals can be fused together in an inclusive and syncretic subjectivity. This approach reflects the populist turn that has marked the movement of the squares, as seen in its adoption of a discourse of the people, or of the $99 \%$ against the elites (Gerbaudo 2017).

These two techno-political orientations evidently reflect the process of technological evolution from the more elitist web 1.0 to the massified web 2.0 of social network sites. But their understanding cannot be reduced to this technological transformation. It also needs to encompass a plurality of other factors, and account for the seismic shift in attitudes and perceptions caused by the financial crisis of 2008 and connected ideological developments. Paralleling the turn of social movements from anarcho-autonomism to populism as the dominant contestational ideology, digital activism has transitioned from a view of the Internet as a space of resistance and counter-cultural contestation, to its understanding as a space of counterhegemonic mobilisation.

The article begins with a theoretical discussion of different factors involved in the transformation of digital activism, and in particular the relationship between technology, politics and culture. I highlight the need to give more attention to political, cultural and ideological factors in the understanding of digital activism beyond the techno-determinism that currently dominates the literature. I continue by demonstrating how ideological shifts have shaped the transformation of digital activism, by exploring the transition from cyber-autonomism to cyber-populism, and how it manifests itself in a number of concrete examples. I conclude with some reflections on the implications for future research about digital activism, emphasising the need to bring ideology back into the analysis of protest movements of the digital era.

\section{Techno-politics Beyond Techno-Determinism}

Digital activism is a form of activism that by definition brings into question the relationship between politics and technology, or to use a term that has become en vogue among activists and researchers in recent years, the nature and dynamics of "techno-politics". Techno-politics is a term that has been coined by Italian politician and scholar Stefano Rodotà (1997) to express the nexus between politics and technology, and has since been popularised by activist scholars as Javier Toret (2013) in Spain to define the new field of analysis raised by the development of digital activism. Referring to the two constitutive concepts in the notion of technopolitics - technology and politics - one can argue that up to this point the scholarship on digital activism has excessively focused on the first element while neglecting the second. Scholars have tended to read political transformation as resulting from technological transformation, thus overlooking that also the converse is the case, namely that changes in political and ideological orientations modify the way technology is conceived of and used.

The techno-deterministic nature of much contemporary scholarship on digital activism is seen in the way in which the nature of digital activism is understood as deriving directly from specific properties of technology. This is clearly seen in the debate about the effects of media affordances on digital activism. An example, is the book by Earl and Kimport (2011) and the way it approaches digital media as a set of apparatuses that lower costs to participation and thus facilitate new forms of 
interaction that were previously impossible. In line with much literature coming from a political science perspective, this account proposes an instrumental and economic understanding of media effects, as seen in the language of "benefits" and "costs" which it utilises to explain the use of digital technology. This approach explains the practical advantages of digital technology to activists but it neglects the symbolic and cultural dimension of digital activism starting from the actual content that is channelled through this technology. A similar critique can be made to the work of Lance W. Bennett and Alexandra Segerberg, and their theory of what they describe as "connective action" (2012) in opposition to the notion of collective action. Bennett and Segerberg claim that social media with their allowing for increased connectivity, overcome the collective logic of earlier social movements, and their need for leadership and collective identity (2012). Thanks to digital technology movements can thus become more personalised and less controlled from organisational centres. What is overlooked in this context, is that this libertarian application of digital technology is far from being an inevitable result. The affordances of digital technology can be turned towards very different political ends and coupled with very different organisational formats. It is sufficient to think for example about the fact that radically different political phenomena as the Occupy Wall Street movement and Donald Trump campaign in the 2016 presidential elections have both proficiently used social media, yet in radically different ways, and on the back of radically different organisational structures.

A techno-deterministic element is arguably also present in the work of Manuel Castells on digital activism. To be fair, Castells' account is far more nuanced than purely structuralist accounts originating mostly from the field of political science. This is because Castells works in the sociological tradition and his approach also accounts for a number of cultural factors that are involved in shaping the Internet and digital activism. Differently from other authors he does not see technology as an almighty monolith but also as a social and cultural product. In this light, Castells has interestingly argued that an important factor to understand digital culture is the influence of the libertarian spirit of the 1960s and 1970s protest movements and the way it has inspired the de-centralised end-to-end architecture of the Internet (2004). Nevertheless, Castells' theory of the network society, and his view of digital technology as ushering in a shift away from the pyramidal structure of Fordist society, and towards network-like structures proper to the information society still contains some techno-deterministic elements. This is due to the view of technology as ushering what he describes as a "morphological" transformation that affects the entirety of society, and that has consequences on all social fields and organisations that adopt digital technology. This view no doubt contains an element of truth, but it seems to neglect the flexibility that such process of organisational influence usually manifests. Furthermore, it is wrong in assuming that digital technology tends to bring about an erosion of hierarchy. As I have demonstrated in my previous work, digital activism is not an horizontal and leaderless space, but is accompanied by the rise of new forms of leadership (2012; 2016).

A similar tendency is also seen in Castells' work on social media. Castells has argued that the diffusion of social media as Facebook and Twitter has transformed internet communication and introduce a new media logic which he describes as "mass self-communication" (2009), one which combines the logic of selfcommunication of face-to-face, telephone and other one-to-one media, with the mass and one-to-many of mass media. According to Castells this communication logic deeply informed the 2011 movements of the Indignados, Occupy and the Arab 
Spring, and it strongly contributed to their mass outreach (2012). This view certainly provides with a powerful rationale to understand the way in which the second wave of digital activism has managed to go beyond the minoritarian politics of the first wave. According to it, social media have provided the necessary technical conditions for new forms of digital activism to arise. However, Castells tends to neglect how in this shift also ideological and political factors have concurred. As I will demonstrate in the course of the article, without a change in ideology the new opportunities of mass mobilisation offered by social media would have not been reaped by protest movements.

The work of Jeffrey Juris, an anthropologist and a former student of Manuel Castells has followed a similar line of reasoning, reading the transformation of activism as resulting from technological transformation. In his influential book Networking Futures (2008) Juris argued that the anti-globalisation movement was informed by the imaginary of the network which constituted a key inspiration in a number of digital activism projects that emerged around this time, including the alternative news site Indymedia, and alternative mailing lists used by activists to organised specific activities and campaigns. In his work about the movement of the squares of 2011, Juris has argued that this wave has a different logic to the antiglobalisation one. He discusses a shift from the logic of networking of antiglobalisation activists, to what he describes as a "logic of aggregation", and argues that this transformation derives from the evolution from the web 1.0 to the web 2.0 and that the logic of aggregation reflects the new mass outreach affordances of social media platforms. This logic has been supported by the "virality", that is by the capacity for rapid diffusion afforded by corporate social networking sites as Facebook and Twitter, and has then been translated physically in the occupied squares of 2011 teeming with large crowds (2012). Juris' inspiring analysis provides some interesting insights about the technological underpinnings of the transformation of protest tactics. Yet, it overlooks how this change in the way of doing protest is also informed by significant changes in protest culture and ideology.

\subsection{Bringing Protest Culture Back into the Equation}

While these accounts are right in identifying the influence played by technology on contemporary politics, they often tend to adopt a reductive understanding of this relationship of causation. A certain type of technological arrangement is seen as automatically leading to a certain logic of action, with little attention paid to the process of political or cultural mediation that intervene in different concrete examples of digital activism. Indeed, digital activism is not just a technical phenomenon, it is a phenomenon. It is an activity that revolves around communicating certain messages, ideas, images, and therefore it possesses not only a technological but also a cultural dimension. The cultural, as well as more generally the political, nature of digital activism needs to be taken into account if we are to understand why digital activism has developed in certain way and why it has changed through time. To overcome the techno-deterministic bias of contemporary debates it is necessary to pay attention to the complex imbrication between politics, culture and technology, with specific reference to a) the relative autonomy of politics from technology; b) the symbolic and not only material character of technological processes; c) the role of technology as a mediator of social relationships and ways of life that cannot be reduced to technology alone.

First, a key problem in techno-deterministic accounts is the way in which technology is seen as the independent variable always bound to determine the logic 
of action of social movements and consequently steer in a certain direction. This approach neglects what we could described as the "relative autonomy of political and cultural processes from technology" that is the way in which culture and politics are influenced by but not reducible to technology. Technology does not single-handedly define activism, rather activism is always informed by the cultural contents it channels, by the ideas, images, views that it puts forward. A number of recent works illustrate this point.

Wolfson in his book CyberLeft looking at the anti-globalisation movement and its use digital media, highlights how digital media practices are accompanied by a certain ethos and "cultural logic", which approaches the Internet not just as a tool but also a space of solidarity in which different struggles can unite $(2014,17)$. Similarly Barassi and Treré have argued that besides the evolution of technology it is important to take into account the lived experience of the activists who utilize that technology, and the way they deconstruct assumptions about the nature and purpose of technology (2012). Coleman has argued that hacking is not just a technical practice but also a social one which carries specific ethics and aesthetics, aspects which are influenced by, but cannot be reduced to technology (2013). This is seen in the way in which hacker groups construct their own language and symbology, epitomised by the mask of Anonymous, taken from the cult movie $V$ for Vendetta. Thus, it is necessary to pay attention not only to the technical devices used by activists, but also by the cultural contents they channel through such technologies.

Second, it is important to account for the fact that technology is not just a material apparatus, a technical or instrumental structure possessing certain properties, but also a symbolic object to which a number of meanings and cultural uses are attached. This is an aspect that has been widely documented in the literature on the domestication of media and technology (Berker, Hartmann and Punie 2005) and in the cultural study of science and technology (Menser and Aronowitz 1996; Van Loon 2002). Scholars have shown that technologies can be associated with very different meanings depending on the different social and cultural contexts in which they are deployed and the values and beliefs of the groups that utilise them. As Kavada has demonstrated, not only does digital activism reflect the properties of the Internet as a set of technical devices, but also of the internet cultures that have emerged within it, such as hacker culture (2013). The Internet is not just a technology but also a cultural space, the two being difficult to separate from one another. This aspect calls for the need to explore the role played by various internet cultures and subcultures in influencing digital activism.

Third, we should avoid looking at technology instrumentally, as a self-standing tool but appreciate the way in which technology mediates social relationships, since this is ultimately the most important way in which technology has an effect on social phenomena. This view is ultimately the one which lied at the core of Marx and Engels account of industrial technology. For them what mattered was not just the way in which it allowed for new forms of production, but also the fact that it materialised a relationship of oppression, in their case the one of the bourgeoisie over the proletariat (2002 [1848]). Techno-deterministic analysis tends to bracket this aspect, overlooking the fact that technology is a mediator of a certain social relationship be it of oppression, leadership or cooperation. Furthermore, it overlooks the way in which technology is embedded in broader social (and not just communication) ecologies and the social relationships that are established within them.

Lim has for example demonstrated how the effectiveness of social media in circulating information relevant to the protest movements that eventually led to the 
Tahrir protests in 2011, was the presence of thick offline social networks. These were exemplified by the way in which cab drivers in Cairo facilitated the circulation of information via word-of-mouth, repeating to others what they had heard from passengers about "what Facebook was saying" on any given day (2012). The effects of technology thus depend not just on its affordances but also on the social relationships and ways of life with which it is entangled. This aspect highlights the need to appreciate the embeddedness of technology in different cultural communities, and the way in which technological use depends on the customs, values and norms adopted by these communities.

These different critiques call for a more nuanced account of the relationship between technology and politics, which may render not just how technology influences politics, but also how in turn politics influences technology. In my contention, the way to achieve this objective is to resurrect the notion of ideology, hereby understood in the neutral sense as a system of values and beliefs adopted by political and social actors and allowing them to act as a collective. Ideology is a term that provides a way to explore the complex imbrication of cultural, political and social factors which alongside technology influence the way in which digital activism is performed.

A number of scholars have already begun to explore how different technological practices carry their own ideologies. For example, Turner has argued that the development of cyberculture was informed by the ideology of techno-utopianism and techno-libertarianism, which was in turn informed by the 70 s and 80 s counterculture, with their emphasis on individual self-realisation and their suspicion for large-scale institutions (2010). Barbrook and Cameron argued that the rise of the digital economy in the 1990s manifested an inchoate ideology they described as the Californian ideology: a techno-libertarian worldview bringing together hippies and yuppies (1995). An ideological element is also clearly visible in social media. Social media are in fact not just a set of applications with given material affordances. Alike other media, they also carry their own media ideologies (Gershon 2010), or in this case what we could described as "the ideology of social media" manifested for example in the language, of sharing, crowd-sourcing, friendship and collaboration they have introduced (see for example Fuchs 2013, 98; Lovink 2011; Van Dijck 2014, 172). Building on this literature about the nexus between technology and ideology in the continuation of this article I develop a periodisation of digital activism in two waves with distinct ideological characteristics, and connected "techno-political orientations", that is different ideologically informed ways of conceiving of the relationship between politics and technology.

\section{1990s-2010s: Digital Activism from Counterculture to Counterhegemony}

Looking at the transformation of digital activism through the lens of ideology, allows to appreciate the way in which political and cultural factors combine with technological ones in shaping the content of various forms of activism channelled via social media. Being a form of activism that is deeply entangled with technology, digital activism reflects the nature and transformation of the ecosystem of digital communication (Treré 2012). However, this technological influence is "filtered" through a number of political and cultural factors, and more specifically "technopolitical orientations" that determine how a certain technology is conceived of and utilised. This conception of technology that I describe through the term technopolitical orientation is highly ideological in character since it involves a value-laden 
view of the Internet and of its role in society and politics, and ideological are its consequences, in the way in which it guides collective action.

Following this line of thinking we need to explore how processes of evolution of digital activism that are usually understood as stemming simply from the evolution of technology do in fact also reflect a change in the ideology of protest movements and in their techno-political stance. This is most clearly seen in the view of an activism 1.0 followed by activism 2.0, as paralleling the transition from web 1.0 to web 2.0 and reflecting the change in technology and affordances. It is obvious that there is some truth to this parallel. However, as I will endeavour to demonstrate the causes of this transformation are more complex and cannot be reduced to technological factors alone. In fact, these two waves of digital activism do not only coincide with two waves of technological evolution, but also to two phases of social movement mobilisation each with its own defining characteristics.

These two protest phases are the anti-globalisation movement around the turn of the millennium and the movement of the squares of 2011. These two protest movements have shared many similarities, to the point that some activists have seen the second wave to be a continuation of the first. At the same time these waves have also displayed different ideological orientations, which reflect the change in the social and political situation since the onset of the economic crisis of 2008 , and thus make these two movements interesting case studies for the purpose of comparative analysis. While the anti-globalisation movement's dominant ideology was anarchoautonomism (or autonomism for short) as a combination of anarchism and autonomism, the movement of the squares has been characterised by the influence of left-wing populism (Gerbaudo, forthcoming). As I will endeavour to show this ideological shift in social movements maps onto the changing techno-political orientations of social movements: the cyber-autonomism of the first wave, and the cyber-populism of the second wave of digital activism.

\subsection{An Ideological Periodisation of Digital Activism}

The transformation of digital activism in the last decades can be viewed schematically as a move from the margins to the centre, of the political arena, from a countercultural politics of resistance to a counterhegemonic politics of popular mobilisation. According to this interpretation, while an early form of digital activism conceived of the Internet as a separate countercultural space, the second wave of digital activism has approached the Internet as part of a political mainstream to be occupied by protestors (Gerbaudo 2015). Thus, the first views position the Internet as a sort of sanctuary space, in which activists can find solace from the oppressive character of society. Conversely the second view considers the Internet as a centrepiece of contemporary society, one which manifests its contradiction, but also one where activists can hope to develop a process of mass mobilisation, capable of attracting not only highly politicised people, but a significant section of the general population.

My understanding of the evolution of digital activism and of the presence of two distinct waves comes close to the view of Karatzogianni, a media scholar who has been working on digital activism since the early 2000s. Karatzogianni proposes the existence of 4 waves of digital activism (2015). The first one from 1994 to 2001 coincides with the early phase of the anti-globalisation movement, from the Zapatista uprising in Mexico in 1994, to the protests in Genoa 2001, which were violently crushed by police. The second phase from 2001 to 2007 comprises the second phase of the anti-globalisation movement, and its rise to prominence worldview. The 
third phase which she describes as the "spread of digital activism", refers to the migration of digital activism to BRICS and other countries beyond Europe and the US where digital activism had first developed. The fourth phase finally is when digital activism invades mainstream politics, with the rise of phenomena as Wikileaks, the Arab Spring uprisings, and the Snowden affair, making digital activism, no longer a marginal phenomenon but one that is at the very centre of political conflicts.

Rather than encompassing four phases, as proposed by Karatzogianni, my analysis is more simplified and focuses on two main waves. Furthermore, it explains the transformation as resulting from changes in ideology, which in turn reflect changes in the social and political situation and connected shifts in opinions and attitudes. Focusing on ideology does not mean to deny the role played by technological factors, and in particular the shift from web 1.0 of static websites to web 2.0 of social network sites. Rather it suggests that technological impact cannot be understood merely from an instrumental perspective, but needs to encompass an understanding of the cultural change that is facilitated and influenced by technology, yet not reducible to technology alone. We shall now see how this approach can be applied to the two different phases that have been identified for the present analysis: the anti-globalisation movement and the movement of the squares.

The anti-globalisation movement developed around the turn of the millennium and was manifested in a series of large-scale protests against global economic institutions such as the World Bank, the World Trade Organisation and the Group of Eight (G8) meetings. It was a multi-faceted movement that encompassed very different ideological streams including trade unions, Trotskyist groups, environmentalists, third world development NGOs, and religious organisations. However, at its core this movement and especially its younger section was deeply informed by the ideology of autonomism or anarcho-autonomism, an hybrid ideology drawing inspiration from post-68 anarchist and Marxist autonomist movement, and marked by a strong anti-authoritarian and anti-statist spirit. This ideology centred on the project of a politics of autonomy, away from the state and the market and attempting to construct a self-governed space of "the common". The movement of the squares has instead turned towards leftwing populism, or more specifically to a peculiar brand of populism which I describe as citizenism, that is a populism of the citizen, rather than a populism of the people. This ideology centres on a bottom-up recuperation and reclamation of democracy and political institutions by ordinary citizens, starting on their gathering in public spaces and on social media. It yearns for the construction of a radical democracy that may allow a more authentic participation than the one offered by corrupt liberal-democratic institutions.

As we shall see, this opposition between anarcho-autonomism and populism maps onto the opposition between cyber-autonomism and cyber-populism, as the dominant techno-political orientations of the first and second wave of digital activism. The way in which activists have conceived of and utilised the Internet reflects their general worldview, their attitude towards the state, towards politics and towards the general population and its prevalent opinions and attitudes.

\subsection{Anti-Globalisation and Cyber-Autonomism}

Let's begin from the anti-globalisation movement and its digital activism. Antiglobalisation activists pursued what could be described as a "cyber-autonomist" strategy that saw the Internet as a space to construct islands of resistance outside of the control of state and capital. As the name suggests this communication logic revolved around the idea of creating autonomous spaces of communication on the 
Internet, away from a society controlled by capital and the state. As I have proposed in my previous work about this issue (2014) activists were convinced that setting up an autonomous communicative infrastructure was a fundamental condition for any genuine alternative communication (2014). Building on the tradition of alternative media in the $60 \mathrm{~s}, 70 \mathrm{~s}$, and $80 \mathrm{~s}$, in the context of the underground press, fanzine cultures and pirate radios, tech activists hoped to use the Internet to break the monopoly of corporate news media responsible for channelling neoliberal propaganda and shutting down all alternative points of view. This vision lay at the foundation of an array of alternative media initiatives pursued between the late $90 \mathrm{~s}$ and early 2000s (Pickard 2006; Juris 2008).

The most visible manifestation of this strategy was Indymedia, the first global alternative news initiative with tens of editorial nodes all over the world. At the height of counter-summit protests, Indymedia became the unofficial yet semi-official voice of the anti-globalisation movement and it also constituted a fundamental organisational infrastructure for protestors, with editorial nodes often doubling up as political collectives directly involved in organising protest campaigns. Besides Indymedia, alternative service providers (ISPs) such as Riseup, Aktivix, Inventati and Autistici catered for the internal communication needs of the movement. These groups provided secure personal email accounts as well as listservs allowing conversations on a number of topics of interest, ranging from protest organisation to squatting and permaculture. The imaginary underlying all these activities was one of "Islands in the Net", as expressed in the name of one of the most important activist ISPs in Italy. Activists thought of the Internet as something akin to the Temporary Autonomous Zones (T.A.Z.) described by Hakim Bey, a space comprising temporary islands in a rebel archipelago outside of the control of State and capital. The Internet was thereby conceived as an autonomous space, one in which the movement could find a more hospitable place to develop its action than the one otherwise offered by a consumerist society which was heavily dominated by neoliberal hegemony. This is why the techno-political attitude of this phase was also strongly countercultural. It saw the Internet as a space where to cultivate an alternative culture, clearly different from the majority culture of the time, considered to be irremediably corrupt. The movement of the squares projects what can be considered to a great extent as a reversal of this position.

\subsection{The Movement of the Squares and Cyber-Populism}

Digital activism in the movement of the squares has instead been characterised by a techno-political orientation I have elsewhere (2014) described as "cyber-populism". By this term I define a techno-political orientation that regards the mass web of commercial internet services controlled by monopolistic corporations such as Facebook, Google and Twitter, as a space that despite its inherent capitalist biases needs to be appropriated by activists, and whose mass outreach capabilities need to be harnessed and used for their own ends. Rather than creating an alternative Internet - a free, self-managed and non-commercial space of communication contemporary tech activists have been more concerned with harnessing the outreach capabilities of corporate social networking sites such as Facebook and Twitter and the digital-popular culture that has emerged on these platforms.

The examples of this cyber-populist trend abound in the wave of 2011 protests, from the Facebook page Kullena Khaled Said in Egypt, to call hundreds of thousands to take to the streets, to the work of activists in Spain, Greece, the US, Turkey and Brazil, who have used social media as a means for mass mobilisation. Instead of 
trying to create alternative spaces, digital activists within these movements attempted to occupy the digital mainstream, appropriating social media as people's platforms.

This strategy bears the mark of the majoritarian and popular ambition of the Occupy wave, and the fact that these new movements do not content themselves with constructing minoritarian spaces of resistance. By using corporate social networking platforms, activists invade spaces they know do not belong to them and over which they have little control, but they do so in the persuasion that it is necessary to take them in order to construct forms of popular mobilisation matching the technical conditions of our era. Instead of aiming to create temporary autonomous zones on the Internet as their predecessors in the anti-globalisation movement, the new generation of digital activists harboured the desire to break out of their life-style ghettoes and reconnect with the $99 \%$ of the population they purported to fight for. One could thus describe this position as more 'opportunistic' in that it tries to exploit the political opportunities that unfold within a space which is otherwise morally questionable because of its subservience to a market logic. However, this is also the element that has allowed these movements to be so successful and to achieve a magnitude of mobilisation that evidently surpasses the one achieved by anti-globalisation activists.

\section{Conclusion}

In order to understand the transformation of digital activism it is necessary to pay attention not just to changes in the materiality of technology, but also to cultural, social and political factors that come to shape its understanding and use. This is why it is imperative to recuperate the notion of ideology, understood as the system of beliefs and values that informs the activist worldview in any given historical period.

As I have demonstrated in this article the difference between the first wave of digital activism around the turn of the millennium, and the second wave in the late 2000s and 2010s, has been shaped not just by the transformation of digital technology and the shift from web 1.0 to the web 2.0 of social network sites but also by changes in the ideology of connected social movements, and in particular by the shift from anarcho-autonomism of the anti-globalisation movement to the populism of the movement of the squares. This ideological turn has translated, in the context of digital activism, into a shift from cyber-autonomism to cyber-populism, two technopolitical orientations which carry different assumptions about the role of digital technology as both a means and site of struggle. While cyber-autonomism conceives of digital technology as an autonomous space separate from the state and capital, cyber-populism conceives it as a space of popular gathering and mobilisation.

This ideological interpretation of digital activism does not entail ignoring the role played by technology in shaping collective action. Digital activism certainly reflects the nature of technological affordances. For example, the process of massification of the web that has paralleled the diffusion of social media goes a long a way towards explaining the shift from a minoritarian to a majoritarian logic of mobilisation in digital activism. However, technological transformation is not the only determining factor. Its effect on the content of activism is filtered through ideological narratives and worldviews which contribute in shaping the way activists conceive of the Internet as a political battlefield, an aspect that can be captured through the notion of "technopolitical orientations" which has been utilised in this article.

What is required going forward is thus research that can better account for the complex ways in which ideology shapes activist practices and their content. This perspective would allow us to overcome some of the shallowness of much 
contemporary analysis of digital activism and better render the way in which this form of activism reflects the themes, attitudes, and motivations of connected social movements, besides technological factors.

\section{References}

Barassi, Veronica, and Emiliano Treré. 2012. Does Web 3.0 come after Web 2.0? Deconstructing theoretical assumptions through practice. New Media \& Society 14(8).

Barbrook, Richard and Andy Cameron. 1995. The Californian Ideology. Science as Culture 6.1 (1996): 44-72.

Bennett, W. Lance, and Alexandra Segerberg. 2012a. The Logic of Connective Action: Digital media and the personalization of contentious politics. Information, Communication \& Society 15(5): 739-768.

Bennett, W. Lance, and Alexandra Segerberg. 2012b. The Logic of Connective Action: Digital media and the personalization of contentious politics. Cambridge: Cambridge University Press.

Berker, Thomas, Maren Hartmann, and Yves Punie. 2005. Domestication of Media and Technology. McGraw-Hill Education.

Castells, Manuel. 2004. Informationalism, networks, and the network society: a theoretical blueprint. In The Network Society: a Crosscultural Perspective, edited by Manuel Castells, 3-48. Northampton, MA: Edward Elgar.

Castells, Manuel. 2009. Communication power. Oxford: Oxford University Press.

Castells, Manuel. 2012. Networks of Outrage and Hope: Social Movements in the Internet Age. Cambridge: Polity Press.

Coleman, E. Gabriella. 2013. Coding Freedom: The ethics and aesthetics of hacking. Princeton: Princeton University Press.

Earl, Jennifer, and Katrina Kimport. 2011. Digitally Enabled Social Change: Activism in the Internet age. Cambridge: MIT Press.

Fenton, Natalie, and Veronica Barassi. 2011. Alternative Media and Social Networking Sites: The politics of individuation and political participation. The Communication Review 14(3): 179-196.

Ferron, Michela, and Paolo Massa. 2012. The Arab Spring| wikirevolutions: Wikipedia as a lens for studying the real-time formation of collective memories of revolutions. International Journal of Communication 5(20).

Fuchs, Christian. 2013. Social Media: A Critical Introduction. London: Sage.

Gerbaudo, Paolo. 2012. Tweets and the Streets: Social Media and Contemporary Activism. London: Pluto Press.

Gerbaudo, Paolo. 2014. Populism 2.0: Social media activism, the generic Internet user and interactive direct democracy. In: Social Media, Politics and the State: Protests, Revolutions, Riots, Crime and Policing in the Age of Facebook, Twitter and YouTube, edited by Christian Fuchs and Daniel Trottier, 67-87. London: Taylor and Francis.

Gerbaudo, Paolo. 2015. Protest Avatars as Memetic Signifiers: Political profile pictures and the construction of collective identity on social media in the 2011 protest wave. Information Communication \& Society 18(8).

Gerbaudo, Paolo. 2016. Rousing the Facebook Crowd: Digital enthusiasm and emotional contagion in the 2011 protests in Egypt and Spain. International Journal of Communication 10(1): 254-273.

Gerbaudo, Paolo. 2017. The Mask and the Flag: Populism, Citizenism and Global Protest. London: New York: Oxford University Press.

Gerbaudo, Paolo. 2018 (forthcoming). Pirate Democracy: Net Parties and Interactive Mass Politics. London: Pluto Press.

Gershon, Ilana. 2010. Media ideologies: An introduction. Journal of Linguistic Anthropology 20(2): 283-293. 
Ghonim, Wael. 2012. Revolution 2.0: The power of the people is greater than the people in power: A memoir. Boston: Houghton Mifflin Harcourt.

Hands, Joss. 2011. @ is for activism: Dissent, resistance and rebellion in a digital culture. London: Pluto Press.

Juris, Jeffrey S. 2008. Networking Futures: The movements against corporate globalization. Durham, NC: Duke University Press.

Juris, Jeffrey S. 2012. Reflections on\# Occupy Everywhere: Social media, public space, and emerging logics of aggregation. American Ethnologist 39(2): 259-279.

Karatzogianni, Athina. 2015. Firebrand Waves of Digital Activism 1994-2014. London: Palgrave Macmillan UK.

Kavada, Anastasia. 2013. Internet Cultures and Protest Movements: The cultural links between strategy, organizing and online communication. In: Mediation and Protest Movements, edited by Bart Cammaerts, Alice Mattoni and Patrick McCurdy, 75-94. London: Intellect.

Lim, Merlyna. 2012. Clicks, Cabs, and Coffee Houses: Social media and oppositional movements in Egypt, 2004-2011. Journal of Communication 62(2): 231-248.

Lovink, Geert. 2011. Network Without a Cause: A critique of social media. London: Polity Press.

Lundby, Knut. 2009. Mediatization: Concept, Changes, Consequences. Bern: Peter Lang.

Marx, Karl, and Friedrich Engels. 2002 [1848]. The Communist Manifesto. London: Penguin.

Mattoni, Alice. 2016. Media Practices and Protest Politics: How precarious workers mobilise. London: Routledge.

McLuhan, Marshall and Quentin Fiore. 1967. The Medium is the Massage: An inventory of effects. London: Penguin.

McLuhan, Marshall, W. Terrence Gordon, Elena Lamberti, and Dominique Scheffel-Dunand. 2011. The Gutenberg Galaxy: The making of typographic man. Toronto: University of Toronto Press.

Menser, Michael, and Stanley Aronowitz. 1996. On cultural studies, science, and technology. In Technoscience and Cyberculture, edited by Stanley Aronowitz, Barbara Matinsons and Michael Menser, 7-28. London: Routledge.

Morozov, Evgeny. 2009. Moldova's Twitter Revolution. Foreign Policy 7(1).

Pickard, V.W., 2006. United yet autonomous: Indymedia and the struggle to sustain a radical democratic network. Media, Culture \& Society 28(3): 315-336.

Postman, Neil. 1985. Amusing Ourselves to Death. New York: Penguin.

Rodotà, Stefano. 1997. Tecnopolitica. Bologna: II Mulino.

Toret, Javier. 2013. "Tecnopolítica: la potencia de las multitudes conectadas. El sistema red $15 \mathrm{M}$, un nuevo paradigma de la política distribuida." IN3 Working Paper Series.

Treré, Emiliano. 2012. Social Movements as Information Ecologies: Exploring the coevolution of multiple Internet technologies for activism. International Journal of Communication 6(19).

Treré, Emiliano and Alice Mattoni. 2016. Media Ecologies and Protest Movements: Main perspectives and key lessons. Information, Communication \& Society 19(3), 290-306.

Tufekci, Zeynep, and Christopher Wilson. 2012. Social Media and the Decision to Participate in Political Protest: Observations from Tahrir Square. Journal of Communication 62(2): 363-379.

Turner, Fred. 2010. From Counterculture to Cyberculture: Stewart Brand, the Whole Earth Network, and the Rise of Digital Utopianism. Chicago: University of Chicago Press.

Van Dijck, José. 2013. The Culture of Connectivity: A Critical History of Social Media. Oxford: Oxford University Press.

Van Loon, Joost. 2002. Risk and Technological Culture: Towards a Sociology of Virulence. Abingdon: Psychology Press.

Wolfson, Todd. 2014. Digital Rebellion: The Birth of the Cyber Left. Champaign, IL: University of Illinois Press. 


\section{About the Author}

Paolo Gerbaudo

Paolo Gerbaudo is a cultural and political theorist looking at the transformation of social movements and political parties in a digital era. He is the Director of the Centre for Digital Culture at King's College London and the author of Tweets and the Streets: Social Media and Contemporary Activism (Pluto 2012), and of the forthcoming volume The Mask and the Flag: Populism, Citizenism and Global Protest (Hurst/OUP 2017). 


\title{
Occupy and the Temporal Politics of Prefigurative Democracy
}

\author{
Kamilla Petrick \\ Postdoctoral Research Fellow, Lakehead University Orillia, Canada, \\ kpetrick@lakeheadu.ca
}

\begin{abstract}
This article sheds new light on the Occupy movement by foregrounding its temporal dimensions, particularly in relation to a previous major cycle of transnational contention, the alter-globalization movement (AGM). The discussion engages three temporal considerations in particular: 1) the centrality of instantaneous digital media to both movements' rapid rise and diffusion 2) the pervasiveness - especially within Occupy - of the temporal ethos of prefigurative politics, and 3) the sustainability and longer term legacy of the Occupy cycle, from the temporal vantage point of the year 2016, i.e. five years since the movement's rise and prompt demise, and fifteen years since the peak of the AGM. The article's conclusion insists on the importance of a long term vision when it comes to evaluating the outcomes of collective action.
\end{abstract}

Keywords: Occupy movement, Alter-globalization movement, Time, Temporality, Capitalism, Prefigurative politics, Strategy.

On October 15, 2011, about three weeks after a group of activists began to camp in Zuccotti Park in lower Manhattan, thousands of people around the world responded to a global "call to action," and in a massive display of solidarity and shared antistatus quo sentiment, began to Occupy public spaces in 951 cities in 82 countries, including St. James park in downtown Toronto, Canada. ${ }^{1}$

Later that month, in a column published on the alternative news website Rabble.ca, Canadian journalist, activist, and author of No Logo (2000), Naomi Klein waxed enthusiastic about the future prospects of the transnational Occupy movement. She commended the protesters for learning from the mistakes of the so-called "anti-globalization" movement, as evidenced, first of all, by Occupy's commitment to non-violence, and second, by the protesters' choice of sustained physical presence as their "fixed target" (Klein 2011). Since the anti-globalization movement was oriented primarily to organizing ephemeral protests against international summits, Klein argued, it would "regularly appear, grab world headlines, then disappear," making it easier for the movement to "fall apart" after 9-11. By contrast, the Occupy Wall Street movement had "time to put down roots, which makes it a lot harder to sweep them away, even if they get kicked out of one physical space" (Ibid.).

Naomi Klein was certainly right to assert the "counter-temporality" of Occupy's defining tactic of open-ended duration, in contrast to the event-driven, "one-off" mode of engagement typified by the "counter-summit" protests of the anti-or, better yet, alter-globalization movement (AGM). Yet a couple of months after her optimistic

\footnotetext{
${ }^{1}$ Though the original source of these figures remains unclear and conflicting figures can be found, the numbers cited above have been widely accepted by both mainstream and activist media as "the standard definition of the scale of the Occupy protests," according to The Guardian ("Occupy Protests").
} 
assessment, the Occupy encampments were dismantled in a wave of evictions that swept the globe in late fall and early winter 2011-2012. Having lost physical ground, the movement also lost the mainstream media spotlight, and then much of its momentum. As public interest and support began to wane, the Occupy assemblies relocated to other spaces, where activists sought to regroup and reconfigure their movement without a permanent physical presence. What can and has been said to remain of Occupy today? In what ways, if any, did it manage to transcend the tendency of the alter-globalization movement toward short-term and largely ephemeral forms of mobilization? What role did the temporal outlook inherent in prefigurative politics play in influencing the movement's strategic orientation? The temporal analytical lens espoused in this article allows us to examine these questions in order to reveal significant yet under-studied temporal dimensions of the Occupy movement, particularly as compared to one of its major transnational precursors, the alter-globalization movement.

The ensuing discussion focuses specifically on the following set of temporal considerations: 1) the centrality of instantaneous digital media to both movements' rapid rise and diffusion 2) the pervasiveness - especially within Occupy - of the temporal ethos of prefigurative politics, and 3) the sustainability and longer term legacy of the Occupy cycle, from the temporal vantage point of the year 2016, i.e. five years since the movement's rise and prompt demise, and fifteen years since the peak of the AGM.

The research approach adopted in this article is qualitative, involving analysis of secondary as well as primary sources, including activist blogs and other movement writings, combined with my first-hand observations inside Occupy Toronto (OT) and (both recorded and unrecorded) informal conversations with core OT organizers, carried out on-site in 2011 and later in 2013. Using this multiplicity of sources, my aim is to render explicit some of the rarely acknowledged temporal dynamics that influenced the trajectory and outcomes of the Occupy movement, and continue to shape the logic and tendencies of collective contentious action today.

\section{New Media Activism and the Speed of Diffusion}

To begin, it may be useful to offer a cursory overview of the AGM, the older of the two transnational "cycles of contention" considered here (see Tarrow 1998). Like Occupy, the AGM was largely driven by opposition to corporate greed and often to capitalism itself; however, the Occupy movement seems to have focused more on exposing the corrosive influence of wealth on the political process, as made manifest by Occupy Wall Street's attempts to pass state and local resolutions to overturn Citizens United and draft a constitutional amendment declaring that corporations are not people and money is not speech (Levitin 2015). For its part, the AGM tended to concentrate mostly on combating free trade, sweatshops, and consumerism; in so doing, its constituents often sought to engage with formal state politics, arguably more so than the Occupy movement ever did (the aforementioned resistance to Citizens United notwithstanding) in targeting formal political institutions such as the World Trade Organization, the World Bank, the International Monetary Fund, plus various multilateral trade agreements among national governments. Commonly considered to have emerged in the mid- to late 1990s - most spectacularly as protests in the streets of Seattle in 1999 against the World Trade Organization - the AGM adopted as its main tactic the organizing of "counter-summit" protests in opposition to the meetings and policies of these global governance institutions. Having peaked at the turn of the millennium, with massive, multiple Global Days of Action transpiring in 
cities around the world, the AGM subsequently declined in many ways and places in the repressive political climate created post-9/11. Briefly if spectacularly resurgent in 2003 in the form of mass protests against the ensuing US invasion of Iraq, the AGM proceeded from there in distinct ways depending on domestic political opportunities (see della Porta 2007); however, as of the mid-2000s, the AGM may be said to have largely waned as a wave of protest.

That is not to say that the AGM's influence has been lost in the dustbin of history. Although the reliance on short-term organizing networks did not endow the movement with the sort of durable infrastructure required to survive amidst a crackdown on dissent, elements of the AGM's tactical approach and legacy could be clearly seen in the principles animating an ensuing transnational cycle of protest to rise and circulate rapidly around the globe, the Occupy movement. A temporal lens can help us to illuminate the relevant continuities and tendencies, shedding new light on patterns and biases of contemporary activism more broadly.

First, a key way in which the AGM paved the path for Occupy was by pioneering the use of digital media for activist purposes. Starting in the mid-1990s, as digital technologies began to proliferate in social life, the nascent AGM became the first social movement cycle to have the internet and related tools at its disposal. The role of the internet in the uprising of the Zapatistas, the campaign against the Multilateral Agreement on Investment, and the creation of Indymedia, the world's first grassroots, internet-based, alternative news network that spread to 150 sites across six continents (see Cleaver 1995; Ayers 1998; Pickard 2006; Wolfson 2014), has been widely celebrated in scholarly accounts as proof of the emancipatory power of "new media activism." According to these optimistic accounts (Castells 1996; Meikle 2002; DyerWitheford 1999), the internet permitted the AGM's highly heterogeneous actors to come together in fluid, decentralized, horizontal networks to "rhizomatically" target shared political targets. Influenced by a confluence of postmodern and anarchist, anti-authoritarian sensibilities, much of the AGM eschewed the perceived hierarchies of the Old Left as well as those of the state and the capitalist system (Wolfson 2014, 187), and the new digital technologies of communication at its disposal both mirrored and amplified this political orientation.

As in the case of the AGM, new media were central to the rapid rise and spread of Occupy. In addition to email and the World Wide Web, Occupy protesters were further able to marshal novel media platforms and technologies, notably social media, Livestreaming and related platforms like InterOccupynet, Globalrevolution.tv, and NYCGA.cc. (Constanza-Chock 2012). The initial callout to Occupy Wall Street was likewise issued online, by the Vancouver-based alternative magazine Adbusters, which had played a key role in shaping the anti-consumerist orientation of the AGM (in tandem with Naomi Klein's No Logo), and had over the years managed to build up and maintain a network of thousands of supporters, expanding its activities to the social media realm.

In mid-2011, Adbusters issued on social media the spark that would ignite the Occupy movement: a poster showing a ballerina poised atop a bull sculpture near Wall Street in Manhattan, captioned with the Twitter hashtag \#OCCUPYWALLSTREET. The hashtag also accompanied a Tweet in which Adbusters called on people to "flood into lower Manhattan, set up tents, kitchens, peaceful barricades and occupy Wall Street" on September 17 - a call to action subsequently endorsed by Anonymous (Constanza-Chock 2012, 2). Digital media were thus central to mobilizing the initial group of several hundred protesters, many of whom decided to stay put and set up camp in Zuccotti Park (formerly known as Liberty Plaza Park), a few blocks north 
of Wall Street. Not insignificantly from our temporal perspective, Zuccotti Park was the only public park in the area open 24/7, due to its curious New York designation as a "privately owned public space" (Gitlin 2012, 19).

Yet despite the activists' ongoing online activity, the occupation in Zuccotti park initially attracted little mainstream media attention. Without reducing the movement's origins to the power of technology, one important factor that did help to propel Occupy Wall Street into global popular consciousness was the rapid online proliferation of amateur videos showing police brutality against the protesters camping out in Zuccotti Park. Having gone viral, the videos were soon afterwards noticed and broadcast by mainstream media. A similar situation occurred on October $1^{\text {st }}$, during the OWS march across the Brooklyn Bridge that resulted in hundreds of arrests and ended up generating a lot of broadcast, print, and social media attention (Constanza-Chock 2012).

The central role played by digital and social media in the emergence and organizing of the AGM and Occupy (see Kavada 2015; Juris 2012; Castells 2012; for a critical perspective see Fuchs 2014) attests to their shared status as movements constitutive of a mode of political engagement commonly considered in communication studies literature as "new media activism," or alternatively, the "cyber left" (Wolfson 2014). Central to this mode of activism is the ease and perhaps most importantly, the speed of communication that allows both internal coordination and external outreach to transpire rapidly across transnational borders. But for all its strengths and advantages, this mode of activism is not without problems.

\section{Fast Capitalism In and Out of Crisis}

From a critical temporal perspective, it is important to acknowledge that the speed of communication flows facilitated by global media is also and primarily, a boon to neoliberal capitalism. As recognized by a growing literature of "time studies," the speed imperative constitutes a core dynamic of the capitalist system, predicated on competition and the need to commodify labour time and accelerate the turnover time of capital by speeding up research and development, production, distribution, and consumption cycles (see Harvey 1989, Hassan 2003, 2009; Manzerolle and Kjøsen 2012).

Though some of them in particular are not immune to class-based critique, oppositional cultural movements, such as the slow cities or the slow food movement, have emerged in order to challenge consumer society's hegemonic "culture of speed" (Tomlinson 2007), along with popular works bearing titles like In Praise of Slowness (Honoré 2004), which recommend mindfulness and digital detoxes as ways to cope with contemporary time pressures. French farmer José Bové's protest of the agricultural policies of McDonald's restaurants likewise formed part of one of the AGM's main fronts of resistance, specifically to fast profits being made in the agricultural sector by short-sighted and unaccountable multinational corporations.

Another effort at slowing down the speed of capitalism undertaken by elements within both AGM and Occupy involved a concerted push for a financial transactions tax. During the AGM cycle, this endeavour was organized as the campaign for the Tobin tax, named after the economist James Tobin who first proposed a small (up to $0.5 \%$ ) FTT in the belief that its implementation would facilitate a slow-down of the pace of finance capital, making the system less sensitive to daily political news and the anticipation of economic policy changes (Patomäki 2000). The campaign involved a coalition of NGOs but was led mainly by the French NGO Association pour la taxation des transactions financières et pour l'action citoyenne (the Association for the 
Taxation of Financial Transactions and for Citizens' Action), or ATTAC. While this campaign subsequently waned in tandem with the AGM cycle, a group of British NGOs revived the demand in 2010, re-branding it as the "Robin Hood Tax." In the fall of 2011, the rebranded campaign got a major boost when Adbusters asked the Occupy General Assemblies, somewhat controversially, to unite behind the demand for the Robin Hood Tax as its "one demand," and to mobilize for a Global Day of Action on the RHT ahead of the 2011 G20 leaders' summit in France (see Elliott 2011). Apart from the new sexy name, the objective of the Robin Hood Tax, embraced by the minority within Occupy interested in engaging with formal politics, remained essentially the same: to curb reckless financial speculation by targeting transactions involving stocks, bonds, foreign exchange, and derivatives, whose short-term, casino-style trading was commonly identified by Occupy activists as responsible for the 2008 economic crisis.

To elaborate, the systemic volatility of capitalism has been exacerbated significantly since the 1970s, with the rise of the nexus between global information and communication technologies (ICTs) and neoliberal globalization. The resulting postFordist "regime of flexible accumulation" (Harvey 1989) has put in place informational facilities for around-the-clock financial trading, now increasingly executed at hyperspeeds with the aid of complex algorithms. The widespread turn to high-frequency trading (HFT) has all but removed from the equation the unprofitably slow human trader. Near-instantaneous financial flows enabled by new technologies have exacerbated the built-in tendency toward crisis of a mode of accumulation that various scholars have conceptualized as fast, turbo, or casino capitalism (Agger 2004; Luttwak 1999; Strange 1986).

To be sure, "fast capitalism" does not constitute a fundamental break with Fordism or capitalism itself; it is but the latest phase of the financialization of the capital accumulation process that makes trading in "fictitious capital" assets, such as stocks, bonds, and derivatives, particularly lucrative, as demonstrated by the growth of financial profits as a percent of total profits (see Bellamy Foster 2008). Buffered by the American state, finance capital has played a central role in the making of global capitalism, and was pivotal in the creation of the giant bubble inside the US housing sector. Like the 1920s bubble that ushered in the Great Depression, the few years before the 2009 crisis were marked by feverish financial speculation that inflated real estate prices and stocks and ended in financial meltdown (Panitch, Gindin and Albo 2010). Capitalism's tendency crisis was recognized over a century ago by Karl Marx, who predicted that the system would bring about its own ruin by eventually destroying its supporting social structures. The last four decades of neoliberal restructuring have achieved just that, effectively impoverishing the working classes by making employment fast and flexible, outsourcing jobs, and gutting state services. Personal debt ballooned as debt markets rapidly expanded, further boosting the process of financialization. This processes likewise transpired within the American housing market, but when the debt markets hit their inevitable expansion limit and no new borrowers could be found, the bubble burst and a mega crisis ensued, with devastating results for millions of people. Marked by rising unemployment, record home foreclosures, and ever-higher personal debt, the period between 2008 and 2011 saw the conditions ripen for a major popular uprising.

\section{Prefiguration and the Pace of Decision Making}

In addition to calling for more state regulation of finance, as some elements within the Occupy movement have done, the Occupy cycle was also a show of resistance to 
capitalism's speed imperative through its emphasis on slow and prefigurative living and decision-making. In fact, both the alter-globalization movement and the Occupy movement can be said to have been shaped by the specific temporality implicit in prefigurative politics. The prefigurative ethos stresses the importance of the process by which the decisions are made collectively, rather than or in addition to the outcomes of such deliberations. In contradistinction to the orthodox socialist telos that sees revolution as a future event, prefigurative politics seeks to enact desired social changes in the present moment.

This prefigurative ethos at the heart of the Occupy movement was summarized aptly by an editorial in the progressive alternative Canadian magazine Briarpatch, in their article "Reimagining Revolution":

In addition to bringing income inequality to the forefront of political discourse, the movement has demonstrated new ways (or ancient ways, reimagined) of organizing and taking care of one another. Through strategies such as consensus-based general assemblies, the human microphone, gift economies and volunteer committees to feed, clothe, inform and entertain one another, the movements have begun to model a sustainable, non-hierarchical alternative to the capitalist system (Briarpatch 2012).

In other words, the internal functioning of the Occupations was meant to prefigure the kind of future society desired by the activists - building a new society in the shell of the old, as the saying goes. It is an ethos associated with anarchism and its tradition of mutual aid as well as with feminism and its notion that "the revolution begins at home," and that alternative life and reproductive practices produce desirable alternative social relations (see Federici in Haiven 2011; Conway 2013, 149).

Within the AGM, the World Social Forum seems to offer the closest equivalent to Occupations as a site of prefigurative politics. The WSF continues to take place as an annual conference of activists from various social movements around the world. Its "knowledge ethos" as analyzed by Janet Conway closely resembles that prioritized by Occupy insofar as it is centred on "practices, process, prefiguration, and the longue durée over theory, content, instrumental reason, and immediacy" (Conway 2013, 148). As noted further by Conway, the "central insight of the WSF rests in creating an open space and initiating an open-ended process, not in producing an authoritative body of content, nor in creating a political instrument with a fixed strategy and programme which is oriented to pre-established outcomes" (Ibid.).

At the same time, the Occupy movement took place in public spaces in hundreds of urban settings, meaning that locals could easily join the encampments with little resources at their disposal. For its part, the WSF faced criticism that it was exclusionary to the extent that it requires access to resources (and associated class privilege) to be able to attend the event as an international participant; hence participation has tended to be limited to Westerners and/or urban-based professionals or students organized through NGOs, the internet, and their knowledge of colonial languages (Ibid., 156-57). To redress this issue and rebuke what was seen as elitism of the WSF organizing committees, the Inter-Continental Youth Camp was created in 2011 as an affordable camping site for young WSF delegates. Representing a closer equivalent to Occupy than the WSF in this respect, the Youth Camp, associated by Conway with AGM's autonomist currents, was focused on enacting direct or what I am calling here prefigurative democracy, by virtue of operating as a "laboratory of 
practices" and "collective experimentation in horizontalism, self-management, and ecologically sustainable practices" (Ibid.).

From the temporal perspective, however, a further difference between Occupy and WSF/ICY may be observed, in that the latter were and remain short-lived events that are not structurally designed to conduce to long-term coalition work. In large measure for this reason, a decade following the AGM's peak and the first WSF, the excitement on the Left about a new cycle of protest on the rise called Occupy Wall Street derived in large part from the uniqueness and the gravitas of its open-ended temporality: to Occupy was no limited-term commitment.

The prefigurative focus was also manifest in the strategic organizing priorities of the various Occupations, and I would like to suggest, somewhat problematically so. At least in Toronto, the focus of the twice-daily General Assemblies revolved heavily around logistics and the internal operations of the camps. Maintaining the camp was time-consuming and immediate. In this fashion, it became an end in itself, as noted by a core OT organizer, whose socialist politics rendered her somewhat critical of this tendency as she noted that "a lot of people were just there to be there, they weren't in an activist frame of mind, and a lot of them were contributing to food tent or logistics but in terms of actually organizing there weren't that many people involved." This critique of the Occupy movement, which another anarchist activist I spoke with encapsulated with a characterization of the OT encampment as "a glorified anarchist soup kitchen," echoes that made by OWS participant Smucker (2014), who noted the presence of two tendencies within Occupy Wall Street: the "strategic politics" tendency that he sees a subordinate to the competing tendency he called the "prefigurative politics tendency" and characterized as "the most visible," and "fixated on its own decision-making process."

This latter preoccupation within both the AGM and the Occupy could clearly be seen in activists' commitment to collective decision-making on the basis of the consensus model. Within AGM, this model was espoused by ad-hoc decision-making convergences known as "spokescouncils," which comprised representatives of "affinity groups," in turn made up of a handful of people interested in organizing together and attending protests as an ensemble for the sake of mutual safety. In the consensus model, full agreement from everyone present at the meeting is required, and every person has the power to "block" (i.e. veto) a decision that they find utterly unacceptable - for this reason, the consensus model is widely supported among anarchists and anti-authoritarians, who see it as "the only form of decision-making that could operate without coercive enforcement - since if a majority does not have the means to compel a minority to obey its dictates, all decisions will, of necessity, have to be made by general consent" (Graeber 2011, n.p.).

Over a decade following the height of the AGM, the "spokescouncil" model proved equally if not more significant to the functioning of the Occupy movement. Given a new name ("the General Assembly"), the model remained influenced by anarchist principles of horizontalism and direct democracy, and it brought Occupiers together at least once daily in large and open camp gatherings where to make decisions.

There are solid advantages to using consensus decision-making. In the words of one OWS activist, "When they [Occupiers] finally get to consensus on some issue, often after days and days of trying, the feeling is quite incredible. A mighty cheer fills the plaza" (quoted in Schneider 2011). The main disadvantage of consensusbuilding is temporal: a lot of time is typically required to achieve full agreement during a General Assembly. In a section called "Time" found in an online consensusmodel manual, the author deploys the terminology of the AGM in noting that "[a]II 
decision making techniques are going to need time if the quality of the decision is going to be good. Consensus is no different - it needs enough time both for making decisions and for learning to work by consensus. In spokes councils you need to allow time for affinity groups to consult and come to their own consensus" ("Consensus in Large Groups"). The availability of time thus emerges as a key ingredient in attempts at truly democratic decision making (see Rosa 2005). As one OWS activist put it bluntly: consensus building is "really hard, frustrating and slow" (quoted in Schneider 2011).

Considering the conditions of life in late capitalist, high-speed society where time pressures are experienced more acutely than before (see Rosa 2013; Scheuerman 2009; Hassan 2009), the length of time usually required to reach full consensus often carries unintended, exclusionary consequences. Often, it is only those with relatively fewer external commitments (e.g. caretaking, employment) who are in the position to continue their participation in long discussion. Therefore, although it is prefiguratively democratic in the sense of being inclusive and participatory, the inefficiency of $100 \%$ consensus decision-making typical of AGM and Occupy alike (in contrast to modified consensus requiring less than $100 \%$ agreement among all) means that it is also not necessarily nor optimally democratic.

This problem came to a head inside Occupy Toronto in the wake of its eviction from St. James park in November of 2011. Through December 2011 and the first weeks of 2012, a group of activists continued to meet daily in General Assemblies held in a city square, braving the brutal cold of Canadian winter. Exemplifying the shortcomings of consensus, it took almost the entire winter before activists reached consensus to move the General Assembly process indoors. Anecdotal evidence combined with social media posts by Occupy Toronto at the time revealed that when spring finally arrived, Occupy Toronto had split internally into two camps, including the so-called "Cloud Gardens General Assembly," whose first move was to shift to a supermajority model requiring 90 rather than 100 percent consensus. From the temporal perspective espoused in this article, it is significant that (as recorded in the minutes from its March 8, 2012 General Assembly, posted online) this decision was made because " $90 \%$ consensus is more representational than $100 \%$, as $100 \%$ represents the people who have the patience to have slow discussions" ("GA minutes"; emphasis added). To "patience," we may wish to add "capacity," given that involuntary life obligations are equally if not more significant factors when it comes to one's ability to participate fully in lengthy consensus-building processes.

Yet, even when decisions are made by a supermajority rather than 100 percent consensus, other temporal pressures can and have emerged to challenge and undermine the prefiguratively democratic functioning of Occupy. Like the broader movement, Occupy Toronto was committed to operating in a leaderless, horizontal manner; however, as feminist activist Jo Freeman recognized in the early 1970s, even the most resolutely anti-authoritarian movements are prone to what she called "the tyranny of structurelessness," involving the emergence of informal and thus often unaccountable leaders (see Freeman n.d.)

As with the AGM and other movements before it, this also proved to be the case in Occupy Toronto, as a group of several young leaders gradually emerged within Occupy Toronto and assumed an informal leadership role. While their status in St. James park was without a doubt rooted in their hard work and dedication, it was also based in part on a temporal hierarchy of sorts, determined by their length of stay in the camp. While this may be said to apply to activists fighting for any cause, the cachet associated with sustained presence as Occupy's defining tactic meant that there 
was an extra degree of credibility and influence to be derived from being a full-time Occupier. Based on my first-hand observation and participation in the OT's General Assemblies, it was commonplace for the long-term Occupiers to preface their comments by stating their name and the number of days they had been staying in the park - all in one breath.

Though they were widely recognized by fellow protesters as the "go-to" people, their movement's commitment to horizontality and prefigurative democracy meant that the informal leaders of Occupy Toronto possessed no formal authority to make executive decisions independently of the General Assembly, even in times of perceived urgency. This situation sparked a controversy in the camp when an eviction notice was served to Occupy Toronto on November 15, 2011. Reacting to this new and urgent development, the group of informal leaders within Occupy Toronto took it upon themselves to make a fast executive decision, and moved to file an emergency injunction against the eviction notice. They announced this move after the fact, at the General Assembly that same evening, adding that in order to appease the judge appointed to make a ruling on the case, they had also decided to disallow any new tents or Occupiers. The emergency support rally already in motion for that night was also cancelled. Although one of the decision-makers explained at the time that the injunction would buy Occupy Toronto extra time to prepare and decide what to do ("Protesters"), many Occupiers were less than impressed, and many voices argued during that night's General Assembly that decisions regarding the eviction notice should have been made collectively.

The same disgruntlement appears to have emerged in other Occupations; protesters in NYC were, for example, reportedly likewise frustrated - in the words of one observer, "as with every ostensibly leaderless movement, there seem to be things happening behind the scenes" (quoted in Roberts 2012, 757). From the temporal perspective of this paper, it becomes clear that even in a modified form, the slow and prefiguratively democratic model of the GA was clearly limited and hampered by the imperatives of speed and efficiency, including the need for immediate responses when under threat.

There is one more temporal dimension to this that is worth mentioning, insofar as the frequency of the General Assemblies made it difficult for some outside supporters to participate meaningfully in the Occupations when the constraints of the capitalist wage economy meant they could only do so only on a limited, part-time basis. In this light, it is possible to recognize the vitality of the availability of the intangible resource of time, to use the language of social movement studies, which the Occupiers possessed differentially, and often in inverse relationship to their employment security. Those who were full-time Occupiers were not infrequently under- or unemployed, sometimes homeless, often on account of the very austerity policies that became a target of the Occupy movement. As expressed by a poster captured in a widely circulated image, Occupy protesters had "lost a job, found an Occupation."

\section{Durability}

The final temporal dimension to be considered in this article pertains to movement sustainability, or durability. When the Occupy Wall Street movement began in New York City, few thought that the encampment would last very long. Some protesters reportedly thought that it would "fizzle out in a couple of days" (see Schwartz 2011). But it did not, not that quickly anyway. In early October, the movement cycle was only beginning to take off, but already there were reasons for concern concerning its staying power. In a speech she gave at Occupy Wall Street on October 6, AGM 
veteran Naomi Klein pleaded with the protesters to avoid getting trapped in a shorttermist, navel-gazing mentality:

Being horizontal and deeply democratic is wonderful (...) But these principles are compatible with the hard work of building structures and institutions that are sturdy enough to weather the storms ahead...this is not group therapy - we also want to change the world. This movement has to create democratic structures. It just can't happen overnight, but I beg you not to fetishize not having a structure. We made that mistake, and it destroyed our movement (quoted in Pinto 2011).

This plea, of course, can be quite challenging to enact in practice, and the case of Occupy Toronto is yet again helpful in illustrating the difficulties. Following their eviction from St. James park in late November, the activists of OT continued their efforts in a reduced capacity for another year or so. According to a core organizer, these activities included a series of "Occupy Talks" on issues ranging from Indigenous perspectives on Occupy to labour and the environment; they also co-organized some events with local activist groups such as the Ontario Coalition Against Poverty and the Toronto chapter of the migrant justice organization No One Is Illegal. However, the organizer recalled, "we no longer had this mini city where we were all living together and communicating on a regular basis. It went down to fewer GAs, and then fewer each week, and so it was no longer the same kind of activism." The Occupy movement's momentum and activist energies were noticeably waning. Hence, following the rally she had helped to organize to mark the first anniversary of OWS, the activist I spoke with recalled being "the last one standing. By that point, most of the other organizers abandoned ship," she added, noting that they were "broke" and had to find jobs. Her comment confirms the aforementioned temporal dimension of Occupy, namely the differential availability of time as a resource of collective action. To reiterate, it was mostly persons possessed of "extra" time (willingly or not) who could dedicate themselves full-time to participation in the Occupy movement. In the context of a high-speed society such as Canada, in which the pervasive sense of "busyness" militates against social actors' perceived ability to engage in democratic life (see Scheuerman 2009), the defining yet highly demanding temporal quality of the Occupy movement limited in substantial ways the individual and collective capacity of Occupy activists to continue to engage in resistance, especially posteviction.

By now it should be clear that the Occupy movement proved too preoccupied with its internal processes to prioritize the formation of political goals or sustained movement infrastructure. Ensuring the survival of the camps became an instrumental end it itself, rather than a means to build a mass base of support among those most deleteriously impacted by corporate greed and global capitalism. As a result, strategic thinking and outreach were for the most part foreshortened, or at best, relegated to the work of smaller sub-committees. The urgency of ensuring Occupy's survival played a key role in shaping this myopic outlook: in the words of a core OT activist who devoted much of her energy to the OT outreach committee, "it would have been helpful to do activism in a setting where we weren't frantically pulling things together on a regular basis... most of the time we were so busy with maintaining this mini city, there was so much work to do to run this space and a lot of problems that came up that there wasn't a lot of time for reflection." This "addiction to urgency," as one activist put it in relation to the AGM, had previously informed the AGM's tactical preoccu- 
pation with organizing "counter-summits," feeding a tendency on the contemporary activist Left toward a mode of engagement which prioritizes short term, one-off mobilizations, and which I have termed "fast activism" on the basis of empirical research on the trajectory and tendencies of the (Canadian) AGM (Pietrzyk 2013). As this article has sought to illuminate, both the AGM and Occupy were largely focused on the present and short-term concerns to the neglect of building lasting social movement infrastructure. Largely though not exclusively for this reason, both found it difficult to survive and rebuild in the aftermath of their respective moments of crisis.

\section{Final Thought: The Long Game of Revolution}

Ultimately, however, it would hypocritically serve a short-termist bias to deny or overlook the lasting impact of both cycles of contention. Both the AGM and Occupy certainly made a difference insofar as they informed, inspired, and mobilized thousands of people to oppose corporate greed and support associated social justice causes. This commonly made argument was further affirmed by an activist of Occupy Toronto during our informal interview in 2013:

The impact that I see is the wide scale education that happened, and I would argue a chunk of the city is way more aware of various issues as a result of that movement. People gaining organizing skills, more people going to rallies, more people connected to the activist world, more people connected over Facebook and seeing all the events that are happening, so I think it gave the activist movement a big push in general.

In addition, a frequently invoked impact credited to the Occupy movement pertains to the popularization of awareness of growing wealth disparity, as captured by the now famous slogan contrasting the "99 percent" and the "1 percent." The centring of class struggle within popular discourse inside the "belly of the beast" and beyond surely counts as a win for those advocating against capitalism in favour of equality and prosperity for all.

On the other hand, critical voices, including that of Micah White, a former Adbusters editor credited as one of the instigators of OWS, have asserted that merely raising awareness about wealth disparity and the toxic influence of money on democracy does not constitute success - concrete outcomes do. To White's mind, the Occupy movement did not ultimately achieve what he sees as its overarching goal, i.e. removing money from politics. Consequently, he views the movement as a "constructive failure" (White, quoted in Hunter 2016, n.p.). As 2011, "the year of living dangerously" (Žižek 2012), passed, it seemed that the revolutionary moment waned without having effectively changed much.

Nonetheless, it is important to acknowledge and celebrate the variety of commendable and concrete initiatives that did emerge in the name of the Occupy since its decline. "Occupy Sandy" provided grassroots relief for victims of the hurricane; "Occupy Our Homes" network has fought foreclosures as part of a campaign to support workers' resistance to precarious labour conditions, and the "Occupy Debt" network and its Rolling Jubilee campaign have been fundraising in order to buy up (thus abolishing) US student loan and other debts on the secondary and tertiary markets, where they are sold for pennies on the dollar (see StrikeDebt.org). As noted on its website, as of May 2016, it has raised over $\$ 700,000$ dollars, with which it has managed to abolish almost $\$ 32$ million of debt (rollingjubilee.org). A version of 
Occupy erupted and lasted for several months in Hong Kong, led by students demanding democratic input into their society.

Moreover, the Occupy movement can also be said to have inspired a new wave of labour mobilization, in the US and beyond. As Levitin (2015) argues, "[o]ne of Occupy's largely unrecognized victories is the momentum it built for a higher minimum wage", motivating fast-food workers in New York City to walk off the job in November 2012, and helping to spark a movement for "\$15 and fairness" that has now spread to other US cities as well as other countries, including Canada. The uprisings against Wal-Mart and McDonald's, the Chicago teachers' strike, can all be seen as components of the Occupy-inspired wave of resurgence within the U.S. labour movement.

These are worthy and important initiatives, and they were directly informed and inspired by Occupy, in addition to being composed of many former Occupiers. Thus, even if Occupy did not fully succeed in uniting the 99 percent into a new, stable historic bloc capable of defeating neoliberalism, it is not at all my intention to discredit or diminish this movement or the ensuing initiatives carried out under its banner, for it is undeniable that they are making a difference, and constitute the less visible but no less vital or important organizing links between the Occupy cycle and whatever organizational form is assumed by the next mass mobilization. And so, although we may take issue with the source of these words of wisdom, Thomas Jefferson was right to observe that "the generation which commences a revolution rarely completes

it." In this light, as navel-gazing prone as it can be, prefigurative politics is also right to insist that revolution is not an event, but rather a process. Critical reflection upon contemporary revolutionaries' tendencies, as attempted in this paper, might not necessarily speed up this historic process, but it can, one hopes, permit it to grow in power.

\section{References}

Adbusters. 2011. Robin Hood Global March: Adbusters Tactical Briefing \#15, 17 October. Accessed 12 January, 2015. https://www.adbusters.org/action/occupywallstreet/robinhood-global-march/

Agger, Ben. 2004. Speeding up Fast Capitalism: Cultures, Jobs, Families, Schools, Bodies. Boulder, CO: Paradigm Publishers.

Ayers, Jeffery. M. 1998. Defying Conventional Wisdom: Political Movements and Popular Contention against North American Free Trade. Toronto: University of Toronto Press.

Bellamy Foster, John. 2008. The Financialization of Capital and the Crisis. The Monthly Review 9 (11). Accessed Sept 30, 2016. http://monthlyreview.org/2008/04/01/thefinancialization-of-capital-and-the-crisis/

Briarpatch Staff. 2012. Reimagining Revolution. Briarpatch Magazine, January 1. Accessed March 5, 2012. http://briarpatchmagazine.com/articles/view/reimagining-revolution

Castells, Manuel. 1996. The Rise of the Network Society. The Information age: Economy, Society and Culture, Vol. I. Blackwell, Cambridge, MA.

Castells, Manuel. 2012. Networks of Outrage and Hope: Social Movements in the Internet Age. Cambridge: Polity.

CBC News (online staff). 2011. Protesters celebrate Occupy Toronto stalled eviction. CBC News Toronto, 15 November. Accessed 25 March, 2012. http://www.cbc.ca/news/canada/toronto/protesters-celebrate-occupy-toronto-stalledeviction-1.980198

Cleaver, Harry. 1995. The Zapatistas and the Electronic Fabric of Struggle. Accessed January 6, 2016. https://la.utexas.edu/users/hcleaver/zaps.html 
Consensus in Large Groups (n.d). Seeds for Change. Accessed 11 June, 2015. www.seedsforchange.org.uk/conslarge.pdf

Conway, Janet M. 2013. Edges of Global Justice: The World Social Forum and Its 'Others' New York: Routledge.

Constanza-Chock, Sasha. 2012. Mic Check! Media Cultures and the Occupy Movement. Social movement Studies: Journal of Social, Cultural and Political Protest 11 (3-4): 375385

della Porta, Donatella, ed. 2007. The Global Justice Movement: Cross-national and transnational perspectives. Boulder: Paradigm Publishers.

Dyer-Witheford, Nick. 1999. Cyber-Marx: The Circuits of Struggle. Urbana, IL: The University of Chicago Press.

Elliott, Justin. 2011. The Origins of Occupy Wall Street Explained. Salon.com, October 4. Accessed March 12, 2016. http://www.salon.com/2011/10/04/adbusters occupy wall st/

Freeman, Jo. n.d. The Tyranny of Structurelessness. Accessed March 21, 2012. http://www.jofreeman.com/joreen/tyranny.htm

Fuchs, Christian. 2014. Occupy Media! The Occupy Movement and Social Media in Crisis Capitalism. Winchester: Zero Books.

GA Minutes: March 82012 @ Harvest Moon. Accessed April 18, 2012 http://occupyto.org/committees/general-assembly-ga/docs/ga-minutes-march-8-2012harvest-moon\#more-961

Gitlin, Todd. 2012. Occupy Nation: The Roots, the Spirit, and the Promise of Occupy Wall Street. New York: it Books.

Graeber, David. 2011. Occupy Wall Street's Anarchist Roots. Al Jazeera English, November 30. Accessed December 14, 2015. http://www.aljazeera.com/indepth/opinion/2011/11/2011112872835904508.html

Graeber, David. 2009. Direct Action: An Ethnography. Oakland, CA: AK Press.

Haiven, Max. 2011. Occupy and the Struggle Over Reproduction: An Interview with Silvia Federici. Rabble.ca. Accessed 21 September, 2016.

http://rabble.ca/news/2011/12/occupy-and-struggle-over-reproduction-interview-silviafederici

Harvey, David. 1987. Flexible Accumulation Through Urbanization: Reflections on 'PostModernism' in the American City. Antipode 19: 260-286.

Hassan, Robert. 2003. The Chronoscopic Society: Globalization, Time and Knowledge in the Network Economy. New York: Peter Lang.

Hassan, Robert. 2009. Empires of Speed: Time and the Acceleration of Politics and Society. Lieden: Brill.

Honoré, Carl. 2004. In Praise of Slowness: How a Worldwide Movement is Challenging the Cult of Speed. New York: Harper.

Hunter, Jennifer. 2016. The "constructive failure" of Occupy and the future of social activism. The Toronto Star, March 28.

Juris, Jeffrey S. 2012. Reflections on \#Occupy everywhere: Social media, public space, and emerging logics of aggregation. American Ethnologist 39 (2): 259-279. doi:10.1111/j.1548-1425.2012.01362.x

Kavada, Anastasia. 2015. Creating the Collective: Social Media, the Occupy Movement and its Constitution as a Collective Actor. Information, Communication \& Society 18 (8): 872886. doi: 10.1080/1369118X.2015.1043318

Kayden, Jerold S. 2011. Meet me at the plaza. New York Times, October 19. Accessed March 12, 2016. http://www.nytimes.com/2011/10/20/opinion/zuccotti-park-and-theprivate-plaza-problem.html? $r=0$

Klein, Naomi. 2011. Occupy Wall Street: Lessons from Anti-globalization Protests. Rabble.ca. Accessed November 27, 2011. http://rabble.ca/columnists/2011/10/occupywall-street-lessons-anti-globalization-protests 
Levitin, Michael. 2015. The Triumph of Occupy Wall Street. The Atlantic, June 10. Accessed December 15, 2015. http://www.theatlantic.com/politics/archive/2015/06/the-triumph-ofoccupy-wall-street/395408/

Luttwak, Edward. 1999. Turbo-Capitalism Winner and Losers in the Global Economy. New York: Harper Collins.

Manzerolle, Vincent R. and Atle Mikkola Kjøsen 2012. The Communication of Capital: Digital Media and the Logic of Acceleration. triple C: Communication, Capitalism \& Critique 10 (2): 214-229.

Marx, Karl. 1973. The Grundrisse. Penguin: Harmondsworth.

McNally, David. 2002. Another World Is Possible: Globalization and Anti-capitalism. Winnipeg: Arbeiter.

Meikle, Graham. 2002. Future Active: Media Activism and the Internet. London: Routledge.

Occupy Protests Around the World: full list visualised. 2011. The Guardian, October 17. http://www.guardian.co.uk/news/datablog/2011/oct/17/occupy-protests-world-list-map Accessed January 30, 2012.

Panitch, Leo, Sam Gindin and Greg Albo. 2010. In and Out of Crisis: The Global Financial Crisis and Left Alternatives. Oakland, CA: PM Press.

Patomäki, Heike. 2000. The Tobin Tax: A New Phase in the Politics of Globalization? Theory, Culture and Society 17 (4): 77-91.

Pickard, Victor. 2006. United yet Autonomous: Indymedia and the Struggle to Sustain a Radical Democratic Network. Media, Culture \& Society 28 (3): 315-336.

Pietrzyk, Kamilla. 2013. Time, Technology and Troublemakers: "Fast Activism" and the AlterGlobalization Movement in Canada. PhD Dissertation. York University, Toronto, Canada.

Pinto, Nick. 2011. Naomi Klein to Occupy Wall Street: get organized. Village Voice, October 7. Accessed January 11, 2012. http://blogs.villagevoice.com/runninscared/2011/10/naomi klein to.php.

Reimagining Revolution. 2012. Briarpatch Magazine, January 1. Accessed March 5, 2012. http://briarpatchmagazine.com/articles/view/reimagining-revolution

Roberts, Alasdair. 2012. Why the Occupy Movement Failed. Public Administration Review 72 (5): 754-762.

Rosa, Hartmut. 2005. The Speed of Global Flows and the Pace of Democratic Politics. New Political Science 27 (4): 445-459.

Rosa, Hartmut. 2013. Social Acceleration: A New Theory of Modernity. New York: Columbia University Press.

Scheuerman, William E. 2009. Citizenship and Speed. In High Speed Society: Social Acceleration, Power, and Modernity, edited by Hartmut Rosa and William E. Scheuerman, 287-306. University Park, PA: Pennsylvania State University Press.

Schneider, Nathan. 2011. Occupy Wall Street: FAQ. The Nation, September 29. Accessed January 12, 2013. http://www.thenation.com/article/163719/occupy-wall-street-faq\#

Schwartz, Mattathias. 2011. Pre-Occupied: The Origins and Future of Occupy Wall Street. The New Yorker, November 28. Accessed January 12, 2015. http://www. newyorker.com/magazine/2011/11/28/pre-occupied

Smucker, Jonathan M. 2014. Can Prefigurative Politics Replace Political Strategy? Berkeley Journal of Sociology 58, Accessed October 2, 2016. http://berkeleyjournal.org/2014/10/can-prefigurative-politics-replace-political-strategy/

Strange, Susan. 1986. Casino Capitalism. Oxford: Blackwell.

Tarrow, Sidney. 1998. Power in Movement: Social Movements and Contentious Politics. New York: Cambridge University Press.

Tomlinson, John. 2007. The Culture of Speed: The Coming of Immediacy. London, LA: Sage.

White, Micah. 2016. The End of Protest: A New Playbook for Revolution. Toronto: Knopf Canada. 
Wolfson, Todd. 2014. Digital Rebellion: The Birth of the Cyber Left. Urbana, IL: University of Illinois Press.

Žižek, Slavoj. 2012. The Year of Living Dangerously. New York: Verso.

\begin{abstract}
About the Author
Kamilla Petrick

Kamilla Petrick is a postdoctoral researcher in the Department of Interdisciplinary Studies at Lakehead University Orillia and a lecturer in Communication Studies at York University (Canada). She holds a doctorate in political science and two prior degrees in media studies. Her research interests include digital culture, social movements, political economy, time and temporality, collective memory, and the role of technology in social transformation.
\end{abstract}




\title{
(Digital) Activism at the Interstices: Anarchist and Self- Organizing Movements in Greece
}

\author{
Eugenia Siapera* and Michael Theodosiadis** \\ *Dublin City University, eugenia.siapera@dcu.ie \\ ${ }^{* * G o l d s m i t h ’ s, ~ U n i v e r s i t y ~ o f ~ L o n d o n, ~ m t h e o 001 @ g o l d . a c . u k ~}$
}

\begin{abstract}
The paper traces the history and evolution of the anarchist and self-organising movements in Greece, paying attention to their communicative practices and their implications for political praxis. After years of repression, and following the hegemony of the social democratic Pasok, and subsequently Syriza, the movements are currently coming to their own. Beginning with a brief history of the movements and more broadly of the left in Greece, the paper focuses on the current moment, determined by three events: the revolt of 2008, the movement of the squares in 2011, and the rise and U-turn of Syriza in 2015. Examining the critiques, discourses and communicative practices of the antagonistic movement as a whole, the paper argues that these tendencies can make up an alternative path to organizing beyond populist hegemony. The antagonistic movement tried to eschew the problems associated with the so-called folk politics, by paying attention to the growth of popular alternatives through combining affect and experience, new learning and action, ultimately contributing to fundamental shifts in political subjectivities.
\end{abstract}

Keywords: Greece, Syriza, populism, media, digital media, social media, anarchism

\section{Introduction}

Greece has been experiencing crisis and contention since the December 2008 events, which played a pivotal role in the emergence of the 2011 Syntagma Square movement (Douzinas 2013, 143) and the rise to power of the populist left-wing party Syriza to power. This, however, only tells part of the story. At the interstices created by state repression and state withdrawal, by the hegemonic project of Syriza and the escalation of reactionary populism, Greece saw the emergence of anarchist and selforganizing initiatives that defy any straightforward categorization. What is the role and impact of such movements for the future of political activism? How do these movements appropriate and socialize digital media? This paper addresses these questions, examining their communicative and political practices and discourses. It also brings into discussion the project of populist hegemony, conceptually developed by Laclau (2007) (a project utilized by Syriza), and includes a critical examination of the so-called folk politics, which, as Srnicek and Williams (2015) argue, instead of proposing a coherent organizing strategy or purposeful political action, relies solely on affect and contagion. The discussion provides an insight into the actual political world created by such movements and their use of digital media. We argue that these movements - to which we refer collectively as the antagonistic movement, and which includes anarchists, libertarian communists, radical socialists and autonomists - rely on communication strategies that retain a link to the past, creating bonds and connecting with others in the present, imagining and constructing a common future. This allows them to establish a common political world inhabited by strong and con- 
sistent political identities. In this way, they differ from other movements in Greece and elsewhere that use communication as a form of propagation and persuasion, and which rely on loose connections and vague ideologies.

\section{Background and Genealogy}

This section investigates the political discourses of the Left as well as of the selforganization movements in Greece, from a genealogical perspective, examining, also, their articulations with media of communication. It aims to understand morals and modes of being in relation with succeeding events and notions that symmetrically appear on different stages of the historical process (Foucault 1977, 152). Two arguments emerge from this perspective: firstly, that the media are not cut off from their historical and political environment, and secondly, that it is expected that variations in political 'modes of being' will be associated with variations in media 'modes of being'. These variations can operate both genealogically but also in a contemporaneous, synchronic manner. In this section we identify three milestones of Greece's modern history, which shaped the formation of the current left-wing discourses. These are: the political climate after the end of the First World War; the German Occupation and the Civil-War era; and the period of Metapolitefsi, a term "used to describe the historical period of modern Greek history that follows the end of the colonels' dictatorship (1974)" (Vradis and Dalakoglou 2011, 339).

The emergence of socialist movements in Greece can be traced back to in the beginning of the twentieth century. Some of the most notable cases include: the clashes between workers and employers in the Lavrio mines (1906) and Serifos (1916), as reported by Kordatos (Kорбátos [1956, 184-5]). But the most significant developments took place after the end of the First World War, with the further spread of socialist ideas across the country.

The rise of the dictator loannis Metaxas to power in 1936 resulted in brutal suppression of dissent and trade-unionism (Mazower 2001, 103). The regime was characterized by intense media censorship, targeting mainly socialist newspapers, such as Rizospastis (the Radical) the newspaper of the Greek Communist Party (KKE), and publications such as Class Struggle and New Society, both Trotskyist and socialist variants. Metaxas imprisoned hundreds of thousands of socialists and tradeunionists. Repression and persecution of communists, anarchists and socialists continued during and after the German occupation. In response to the German invasion, in September 1941, the KKE in collaboration with small left-wing parties, established the National Liberation Front (EAM), which quickly became the largest movement of the Greek National Resistance against the Axis occupation (Mazower 2001, 96: Kouooupńs 2014, 58 [Kousouris 2014, 58]). EAM's attempts had a strong radicalising influence on the Greek people, through public speeches and propaganda, distributed mainly by Rizospastis (Mazower 2001, 288), and direct action: while food scarcity claimed hundreds of thousands of lives, many EAM/ELAS fighters (the andartes) managed to supply food to starving villages. EAM's discourses and actions influenced social and political struggles and are still influential; slogans used by EAM/ELAS during the Nazi occupation and the Greek civil war have recently resurfaced, along with photographs circulating as memes, while references to battles fought by EAM have re-entered the political vocabulary some seventy years later.

The appointment of Rallis as the third collaborationist Prime Minister of Greece in April 1943 inaugurated the official start of the 'war against communism' (Mazower 2001, 323). Rallis gathered together all 'disciplined citizens' "to restore order at 
home" (Ibid., 322). Reactionary anti-communist forces, the so-called Security Battalions (SB), were formed, receiving financial assistance by from the Germans. Their discourse was associated with the far-right call to 'save Greece from the Bolsheviks', classifying the forces of EAM as the enemies of Greece. EAM and the KKE, on the other hand, were criticised by many Trotskyists, such as Castoriadis and Stinas (Curtis 1998, viii), who believed that the KKE was using Stalinist repressive methods against anyone who challenged its ideological hegemony. Its communicative and media strategy, including communications between its members and between the party and the broader public, was one of total top down control of ideas and news. It was embodied by Rizospastis as the 'organ' of the central committee of the party and by the numerous 'instructors', or party apparatchiks responsible for the recruitment, ideological guidance, and coordination of party members.

After the liberation of Greece in 1944, major clashes had begun in Athens between EAM guerrillas and the forces of the British army and their Greek collaborators. The clashes of December 1944 ended with the defeat of EAM/ELAS, which was forced to hand over their weapons to the authorities. The andartes who refused to capitulate were hunted down by government troops (Mazower 2001, 373). A right-wing backlash followed the defeat of EAM and as a result bands of resistance fighters reformed, setting up the Democratic Army of Greece (DSE), which was "fundamentally controlled by KKE" (Vradis and Dalakoglou 2011, 338). DSE, however, was totally defeated by the British army. Thousands of its members were incarcerated, faced execution, or fled to Eastern Europe (Mazower 2001, 376). Meanwhile, "hundreds of men who had fought in the Security Battalions alongside the Germans found their way without any difficulty into the postwar National Guard" (Ibid., 334). This period established the ultra-repressive post-civil war state, marked by constant liquidation of communists and left-wing supporters and tough sentencing of dissidents in harsh forced labour camps in penal islands (Voglis 2000, 73-90). Operating in conditions of illegality, both during the German occupation and effectively until 1974, the Communist Party controlled almost all the leftist media, and the leftist ideological and political landscape, notwithstanding the great influence of thinkers such as Castoriadis, Stinas, Poulantzas, and Tamtakos et al.

During the years of repression, communications between political movements and the people were limited to face-to-face discussions, although a series of, for the most part, illegal newspaper and smaller publications circulated in the underground, and during the 1967-1974 junta, publications from Greek exiles in Europe (Radiobubble 2013). The Greek National Archiving Centre lists 40 illegal titles printed mostly in Athens, compared to the five legal print media that circulated during the German occupation. In 1944 there is an explosion of left media: EAM published 116 titles across Greece while KKE published another 93 (Ibid.). However, these titles were all banned following the defeat of DSE. The period of 1955-1963 was characterized by unprecedented repression, with the members of the Secret Police (KYP) were proportionally more than the members of the German Stasi, if we take population size into account (Radiobubble 2013). While the repression eased somewhat in the years 1963-1967, the period of persecutions ended with the collapse of the anti-communist dictatorship of 1967 in 1974 (Theodosiadis 2015). The fall of the dictatorship is attributed to the student revolt at the Polytechnic University of Athens in November 1973. According to Trocchi 2011, 303) the Polytechnic uprising "reduced the popular tolerance of the military junta, which was one of the factors that eventually led to its collapse in 1974". This revolt is considered as a milestone for the antagonistic movement in the country (Kaplanis 2011, 227). It is looked at as "an ultimate archetype of resistance" (Ibid., 2) 
that has shaped the consensus of Metapolitefsi (political changeover), signalling the end of the right-wing hegemony, and the termination of institutional discrimination,

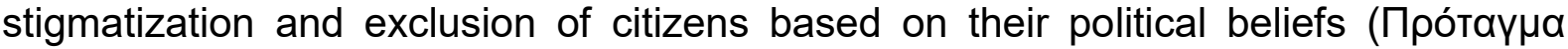
2013, 48 [Protagma 2013, 48]). This attitude of the victimization of the resisting and heroic Greek left is also reflected in the left-wing anti-austerity movements and especially in pre-2015 Syriza's official discourse. In this, Syriza merely took over and continued the discourses associated with Pasok - the 'Panhellenic Socialist Movement' led by Andreas Papandreou.

Under the populist/socialist reforms of Pasok's first government in 1981 things changed drastically in Greece (Kornetis 2013, 303). Civil marriages were introduced, whilst measures that restricted freedom of expression were repealed, in conjunction with the legalization of left-wing parties and the recognition of EAM/ELAS National Resistance. The new consensus contributed to the rapid folklorization of the student struggle and the institutionalization of anti-junta activism (Ibid., 301). As a result, a strong anti-rightist attitude in the public flourished, although reactionary discourses and ideas survived. Supporters of the post-Civil War anti-communist (and pro-Junta) consensus had to either hide their extremist profile by compromising with the most conservative wing of the centre-right party New Democracy (Theodosiadis 2015) or associate themselves with the discourses of many Christian fundamentalist Orthodox pastors, who became the pioneers of parochial isolationism and national-populism in Greece (Stavrakakis 2005, 227). After 2005, they gradually emerged from the fringes through the rhetoric of the right-wing populist party LAOS and later Golden Dawn. At the same time, during the Metapolifsi consensus, new tendencies and discourses emerged, including radical leftism, anarchism and feminism (Kornetis 2013, 301302).

The first re-appearance of the antagonistic movement took place during the Polytechnic uprising. During the 1980s and 1990s anarchism begun to spread among the young Greeks, primarily through alternative (collectively owned) media, creating an alternative discourse, beyond the statist ideology of left parties, neoliberalism or reactionary populism, as well as beyond liberal democracy. Punk subcultures and countercultural trends, emerged especially around the area the Exarcheia ${ }^{1}$ district of Athens. In a way such currents are the continuation of countercultural movements (like the yieyiedes and tediboydes - hippies and 'teddy boys') that initially emerged during the 1960s (Kornetis 2013; Ovenden 2015).

The dual repression, coming from the Communist Party and from the state, and which went on until the 1970s, is a significant explanatory factor for the reluctance of alternative political groups to follow party political structures and organizational methods. It was not until an internal division in the party in February 1968 that led to the creation of KKE 'Interior', a euro-communist variant, that the KKE began losing its stronghold (Ovenden 2015, 21). In the years of Metapolitefsi, the media and ideological-political landscape was characterized by the populist hegemony of Pasok, its appeal to a faux third-worldist and eurosceptic rhetoric, even as it upheld and inflated the clientalist relations established by its right-wing competitors. Pasok established a firm control of the media, through subsidizing publications via state advertising and making preferential deals with media owners. This was even more pronounced in the case of commercial broadcasting, established in 1989, in a confused, partially de-

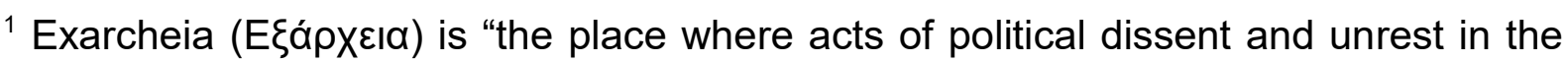
country's post-dictatorial era (1974-present) have been centred" (Vradis and Dalakoglou 2011, 77-78). 
regulated landscape which once again reinforced clientalism (Hallin and Papathanassopoulos, 2002). Papathanassopoulos (2001) argues that commercialisation in a completely unregulated media landscape gave rise to a kind of journalism that was liable to both political control by the state and to commercial pressures. On the other hand, however, throughout the 1990s, there was an explosion of alternative publications, for example the publishers 'Free Press' (Eleutheros Typos), but mostly through brochures, some magazines, some weekly newspapers, but most of these were small scale and ephemeral (Metropolitan Sirens, 2011).

The leftist, anarchist and libertarian movements in Greece have been involved in most large protests, and especially those against globalization. In June 2003, there were large- scale protests in Thessaloniki against the European Union summit, partially organized by the network Antiauthoritarian Movement (Antiexousiastiki Kinisi), which had also participated in major anti-globalization protests for example, in Rostock in Germany in 2007. The main medium of the movement during this period was indisputably Indymedia Athens, while other media included digital versions of print publications and a series of blogs. Digital archives, such as for example, eutopia.gr, show a vibrant alternative-anarchist media landscape, including print publications such as Nea Selene, The Anarchist, Counter-Information Bulletin, the Forbidden Press, Ideologio and more. The famous anarchist magazine Apatris (Stateless), one of the most notable Greek anarchist papers, recounts plenty of magazines and newspapers, such as Enantia (Against), Alfa, the Gilotina (Guillotine) as well as Mavri Simaia (Black Flag), Resalto, the anarcho-syndicalist Rocinante, and Drasi (Action) ${ }^{2}$. This vibrant landscape remains to this day, with some of these publications appearing still in print and digital forms, but a closer analysis reveals several points of departure. While in the early 2000s anarchist and alternative movements were marginal, by the mid-2010s their position in the Greek political landscape had changed dramatically. The pivotal moment was the December 2008 revolt.

\section{The Present Moment: 2008 and Beyond}

It is our contention that the events since 2008 cannot be understood outside the history of the movement discussed above. This history and what followed the events of 2008 show that it is impossible for this movement to ally itself to any political party of the left, including KKE and Syriza, even if briefly Syriza sought to recruit and subsume the movement under its hegemony. The turn of events following the murder of Alexandros Grigoropoulos on December 6, 2008 were both in direct continuity with Greece's anti-authoritarian past and signalled a break and rupture from it. The December revolt was not planned or led by any party (Douzinas 2013, 140). Syriza, nonetheless, was the only parliamentary group expressing "clear sympathy for the youth in revolt" (Ovenden 2015, 52) while all other parties (as well as the media) condemned the events, while MPs of the then ruling party, New Democracy, threatened to impose military law in the streets of Athens. The media and the mainstream political forces made no effort to understand the meaning of the events, focusing exclusively on violence and looting. Echoing the events during the Polytechnic uprising, self-organization, togetherness and friendship replaced terror and mistrust, and a public realm began to emerge; "neighbourhood assemblies along with the occupa-

2 For a brief history and discussion of anarchist publications in Greece see http://eagainst.com/articles/a-brief-historic-review-of-anarchist-newspapers-ingreece/ 
tions of schools, universities, municipal offices and theatres taking place and a widespread rejection of apathy, cynicism, the tyranny of financial uncertainty and political indifference" (Theodosiadis 2013). The December revolt was, according to Kouki $(2011,170)$ an "experience of socialisation". In the words of those who participated in the events, "by living in an egalitarian moment, we changed in one night the terms of inclusion and exclusion. We transformed from invisible solitary figures rambling around in our urban misery into political subjects who managed to challenge, not the solutions that had to be applied to a situation, but the situation itself" (Kouki 2011, 169). Hence, the December revolt, although it was not exclusively an anarchist event, was partially inspired by anarchist ideals. It shaped a discourse that set the foundations for the emergence of the movement of the squares in Greece and Spain (Douzinas 2013, 147).

The revolt further highlighted the role played by the new media and more specifically Indymedia Athens, which shortly after the December events became the main channel that disseminated anarchist ideas to the Greek public. During the revolt, Indymedia Athens transmitted news through the eyes of activists and demonstrators (Metropolitan Sirens 2011, 139), and it reached tens of thousands visitors per day (Vradis and Dalakoglou 2011, 18), while up to 2011 it was among the ten most popular websites in the country (Metropolitan Sirens 2011, 139). At the same time, the anarchist space grew rapidly, and squats, self-organized parks and social centres emerged almost in every neighbourhood (Filippidis 2011, 54). In many ways, therefore, the 2008 revolt prefigured the movements that followed.

The years that followed 2008 were extremely traumatic for the Greek social body, characterized by political meltdown, following the financial crisis. Two further events were significant in understanding the present moment in Greece. The first was the Aganaktismenoi or movement of the squares in 2011 and the second the electoral win of Syriza in 2015. The former was characterized by a popularization and broadening of a protest culture, wide inclusivity and popularity. While the movement of the squares folded in the summer of 2011, Syriza managed to capitalize on the generalized discontent, to successfully adopt and adapt the rhetoric of the squares and the left tradition in Greek politics. Syriza succeeded in getting elected in January 2015, forming a coalition government with a right-wing, national-populist party, the Independent Greeks (ANEL).

\subsection{The Squares and the Rise and Fall of Syriza}

The protest media landscape at this stage has been usefully discussed in a series of studies that position it within broader and more global developments, revolving around the rise in the power of social media, the Arab Spring, the Occupy movements in Europe and the US, and the 15M movement in Spain. Researchers here have focused on the use of social media in constructing an identity and collective voice for the movement (Kavada 2015), on the emergence of organic leaders or hubs from within the movements (Gerbaudo 2012), on the varied and innovative media practices (Costanza-Chock 2012), on the role of the hackers and information technology experts (Postill 2014) and more broadly on the shifting paradigm of protest politics (Bennett and Segerberg 2013). From a critical perspective, Fuchs (2014) has outlined the role of social media corporations, censorship and surveillance while Dean (2012), though recognizing the value of these movements, poses broader questions of capitalizing on the gains without becoming part of the system and moving towards a more stable form of organization such as a political party. 
With respect to the Greek movement of the squares, Theocharis $(2015,185)$ identifies four points of departure from previous protests: firstly, while previous protests were organized and coordinated by trade unions and political parties, the movement of the squares self-organized without any support or guidance from such actors - although it has to be said that some became involved at some stage, notably Syriza and groups allied to Syriza. Theocharis, however, is not taking into account the ongoing actions of the antagonistic movement which always operates at the interstices and had always turned away from political parties and trade unions. Secondly, Theocharis argues, through social media, the movements succeeded in establishing ties with similar protest movements in Greece and abroad, most notably with the 15M movement in Spain. As we have seen however, in the case of Genoa, Rostock and Thessaloniki, the antagonistic movement had already built such international solidarity ties. Thirdly, these movements succeeded in mobilizing people who were not involved in any protests before, while finally, Theocharis (2015) argues that the loosely connected networks formed during this time (2011) were sustained beyond and were tied to solidarity initiatives months and years after the movements were evicted from the squares. Following Theocharis, we would argue that the novelty lies in the opening up of the protest space, which became more inclusive of a variety of people, beyond the confines of Exarcheia, as well as in the maintenance of the bonds created in the squares, which fed into solidarity initiatives. This happened in part because social media allowed for the continuous connection of people, but as Rakopoulos (2014) has shown, bonds of trust require (also) face-to-face contact.

In the elections that followed the movement of the squares in Greece in 2012, it became clear that the political winner was Syriza, whose rhetoric was very similar to the rhetoric in the squares, speaking of anti-austerity, an end to corruption, 'real democracy', and social justice (Prentoulis and Thomassen 2014, 213). Stavrakakis and Katsambekis (2014), drawing on Laclau (2007), have argued that Syriza's success can be attributed to the way in which it managed to concatenate demands in chains of equivalence around the notion of the people and to create an internal frontier between 'them' and 'us', those in power and the underdogs. But it is also clear that these equivalences and the internal polarization were already part of the Greek public discourse and they were apparent in the movement of the squares, and also long before, in the genealogy of the Greek left discussed above. Syriza can then be seen as successful only insofar that it managed to present itself as an empty signifier, and to distance itself from Pasok, which was very closely associated with the period of Metapolitefsi. In these terms, the electoral victory of Syriza in 2015 shows that it successfully subsumed the popular demands articulated not only in the movement of squares but throughout the history of the Greek left. It was voted in with the mandate to restore social justice and avenge those who had died for it. Tsipras's highly symbolic gesture to lay a wreath in the Kaisariani monument, where the Nazis had executed 200 communists in 1944 was a testament to that, alongside the (now ironic) slogan 'left for the first time'.

However, events since showed that the popular demands for social justice were frustrated in the long months of the supposed negotiations between the Syriza coalition government and the institutions representing the creditors (the infamous 'Troika', the EC, ECB and IMF) - though some commentators argue that Syriza had already changed in the months following the 2012 elections when it became obvious that they had the potential to govern (Ovenden, 2015; Sheehan, in press). The turning point for Syriza was the 5 July 2015 referendum (Ovenden 2015, 157). Although 62\% voted against any further bailout agreements with the creditors, Tsipras performed a 
U-turn and announced an agreement to sign a third bailout programme with even more stringent terms a week after the referendum. Despite this, Syriza was elected once again in September 2015, on the platform of the so-called parallel programme, a 'social justice' programme that was supposedly going to be implemented in parallel with the 'reforms' demanded by the creditors. However, the great social force and dynamism that accompanied Syriza was lost, along with a good chunk of its members and supporters. In May 2016, the Syriza government voted in favour of another bailout, the worst yet, which effectively privatizes everything and moreover hands over the control of the 'reforms' (i.e. privatizations) to the creditors.

Moving from Syriza's hegemonic practices to the practices of those who operated outside this hegemony whilst still subscribing to social justice agendas and to ideas of freedom, we identify an altogether different political modus operandi. Although these groups were involved in the 2008 revolt and in a number of protests, they voiced significant criticisms towards the movement of the squares even as they participated in it. During and after the movement of the squares, we can observe a clear split between those who followed Syriza and the political party line pursuing hegemony and those who self-organized and who ran self-management and social solidarity initiatives. This is not to say that these were immediately positioned against Syriza but that they operated in parallel or beside Syriza, at least for the period before the summer of 2015.

\subsection{The Squares and the Critiques}

This split can be observed already in the days of the movement of the squares, where anarchist and libertarian groups were voicing their criticisms and objections: four main and inter-related points that were raised included firstly, the dominant role of affect in the mobilizations; secondly, the demand for the immediate implementation of direct democracy without paying attention to the actual subjectivities and practices that such a political regime requires; thirdly, the underlying demand was understood as a (re)turn to social democracy or to some form of benign capitalism, pointing, fourthly, to the uncritical openness to all, without considering the diverse social positions and ideologies they represented ${ }^{3}$.

As we shall see later, the criticisms of these groups concerning the affective dimension of the movement of the squares and its communicative practices reflect in some ways the criticisms levelled by Srnicek and Williams (2015) against what they call folk politics. The problem is not that affect is expressed or that it forms the impetus for mobilizations, but that it is pegged against more rational and sober analyses of the situation, against strategic planning and effective organization. Ultimately, the problem with affect according to this line of thought is that it opens itself to easy solutions expressed by 'messianic' political parties that will somehow parachute in and make everything good again. In these critiques, affective expressions are accepted but they have to be accompanied by grounded reflection as to what caused them and what may be the way forward.

\footnotetext{
${ }^{3}$ The discussion here relies on an analysis of the discourses of a number of blogs and websites of the field, as published at the time. See for example, eAgainst, 2011, Criticisms of the Aganaktismenoi movement, http://eagainst.com/articles/\%CE/; Mila $\mathrm{Re}$, the Indignants of Mordor, May 2015; the blog of the group Libertarian Communists, http://eleftheriakoi.blogspot.ie)
} 
For these critics therefore, the problem of affect as the motivator of action is that it needs to be articulated politically. The inability of fusing affect with critical and politico-strategic thinking allowed on the one hand its use by reactionary elements that existed in the squares. On the other hand, affect was associated with the formulation of 'naïve demands' for direct democracy, that overlooked both the actual social labour that this involves and its incompatibility with the present capitalist system. For some groups, the people in the squares merely play-acted the procedures of direct democracy, such as going to a podium to speak, but without an overall frame that would allow for a fruitful discussion eventually leading to a political decision. This watered down version of direct democracy was attributed to the lack of a developed political subjectivity and know-how: an article in the blog AvantGarde shows the contradictions involved, pointing to the number of people who went to work on a day of a general strike only to join the squares and complain about the system in the evening ${ }^{4}$.

The lack of a systematic political critique alongside affect and biopolitical experiences was in turn associated to superficial and naïve demands for a 'capitalism with a human face' or some form of a return to the social democracy of early Pasok, which represented a historical compromise between the demands of labour and those of capital. But such demands were seen as impossible and contradictory to demands for direct democracy, and were exposed as such ${ }^{5}$. The ideas for a democratic reform of society that circulated in the squares and that were subsequently mobilized in Syriza's rhetoric were already received very critically by those who were seeing in these the promise of a generalised revolt appeased and domesticated by political parties ${ }^{6}$.

In part, the movement of the squares brought this about through their insistence on the openness and inclusivity of the movement. By refusing to address the question of 'them' and 'us' within the squares they opened up to elements such as the fascists and nationalists, as well as those committed to a reformist view of representative democracy. "There was no confrontational philosophy since half [of those in the squares] wanted to offer a rose to the riot police that had drowned them with tear gas and had battered protesters [...] They were not interested in changing the system, they were not interested in self-organising, they just wanted to be in the squares. This is not a movement, it's 'hippyism'” (Re 2015).

A parallel approach here focused on different parameters mainly reflecting the ideas of Cornelius Castoriadis, Hannah Arendt and Jean-Claude Michea - expressed through the website Eagainst.com and print/online magazines such as Babylonia and Protagma. This line of thought was frustrated with the isolationism of some of the anarchist elements. They saw the reluctance of many anarchists to become engaged with the people in the squares as representing a form of isolationism, revealing a tendency of some anarchists to become trapped within an ideological microcosm, instead of influencing movements and popular initiatives (Theodosiadis 2014) ${ }^{7}$. Additionally, this strand of thought claims that the sectarian Leninist left is unable to un-

\footnotetext{
${ }^{4}$ AvantGarde, 2011, 16/6, Where were the Indignant yesterday? (https://avantgarde2009.wordpress.com/2011/06//)

${ }^{5}$ See: http://eleftheriakoi.blogspot.ie/2011/06/blog-post 1067.html and eAgainst, http://eagainst.com/articles/\%CE/

${ }^{6}$ See: http://eleftheriakoi.blogspot.ie/search?updated-max=2011-06-27T22:34:0007:00\&max-results $=5 \&$ start $=5 \&$ by-date $=$ false

${ }^{7}$ See: http://www.nostimonimar.gr/\%CE\%
} 
derstand the spontaneity of many popular uprisings ${ }^{8}$, whilst some appear trapped within the logic of Stalinism. In the same line, Protagma condemns not only the escapist attitude of the anarchists, but also attacks the tactics of many left-wing orators, politicians and party followers to hijack the squares ${ }^{9}$.

These critiques show the tensions and contradictions between and within the squares, Syriza and those following the genealogy of anarchist, libertarian, communist (non-KKE) and self-organizational/autonomist thought. The discussion also reveals inner splits and contradictions within the libertarian spaces themselves, primarily between anarcho-communists and supporters of direct democracy/autonomy. However, the main split is between mainstream left political parties such as Syriza and KKE and the antagonistic movement in its entirety, notwithstanding the tensions between its constituent parts. Taking these into account, the communication strategies and practices of the antagonistic movement are different, corresponding to a different communicational 'mode of being'. These communicational approaches follow through the criticisms elaborated above seeking to build a political movement that is able to address the challenges of the present.

\section{Communication Strategies}

We use the term strategy to point to the ultimate political goals of the communications of the antagonistic movement; we are interested in the ways in which these strategies contribute to achieving the movement's political goals of freedom, justice and autonomy. The analysis therefore asks: what is it that the antagonistic movement communicates and how? What are the political implications that this has? We address these through looking at both the contents and the means by which these contents were communicated. The analysis showed the following: the communications of the antagonistic movement have a pragmatic orientation to the needs of the here and now; communication is understood as way of strengthening the bonds and building solidarity between various groups in Greece and abroad, connecting them laterally; communication is construed as critique and discussion beyond dogmatic ideological approaches and attempts to persuade, and as a contribution towards the strengthening of critical analysis through the free publication and translation of important theoretical works, attention to archiving, and in depth critical articles and analyses.

Overall, our analysis relied on a close examination of the digital presence of the antagonistic movement. This includes blogs, social media pages and websites of groups, collectives, and individual participants. Specifically, we have looked at the blogs, Facebook pages and Twitter feeds of groups such as the anarcho-syndicalist Rocinante, Rising Galaxy, Anarchiki Bibliothiki (Anarchist Library), Mpalothia, the Anti-Authoritarian Movement, the various interconnected Networks for Social Solidarity (for example, Network for Social Solidarity, Solidarity for All, Initiative for Solidarity to Vio.Me, Social Solidarity Clinic and others), Anarchiki Ichoripansi (Anarchist Sound Pollution), Dromografos, Kollect, the many pages of the Greek AntiFa Movement, No Borders and the refugee solidarity initiatives, for example, City Plaza and Solidarity2Refugees, Omnia TV, Protagma, Babylonia Magazine and many others, as well as individual accounts of activists on Twitter and Facebook. The common parameter here is that all these belong to the antagonistic movement and would describe them-

\footnotetext{
${ }^{8}$ See: http://eagainst.com/articles/all-power-to-the-assemblies/

${ }^{9}$ See https://protagma.wordpress.com/2011/06/10/\%CE\%
} 
selves politically as anarchist, libertarian communist, radical socialist, and autonomist.

In terms of the material aspects of communication, we should note that, following several attempts to shut down Indymedia Athens, and commensurable with the critiques against corporate control of the internet and social media, part of the movement, and specifically the Cybrigade collective, has set up and runs its own server, espiv.net which offers a number of digital services ${ }^{10}$. The digital part of the movement is therefore not limited to corporate social media but exists across the web, and includes live ongoing blogs, accounts and pages, online radio, online counterparts of print magazines, as well as inactive blogs and sites, which function as archives.

With respect to the contents we see a clear orientation towards pressing needs in the here and now. They call for ongoing and immediate action, for example, participating in street protests, supporting arrested protesters, but also gathering food and supplies for refugees and others in need. In particular, the refugee crisis galvanised the movement into action, firstly because of the immediate needs that refugees have, in terms of food and shelter, and secondly, because of the threat of attacks by fascists. Calls for immediate action pay attention to the need for survival in the present but also require the institution and organization of structures that can address such needs. In the first instance this involves the setup of communicational structures, mainly through social media pages and accounts that can quickly reach a significant number of people in the vicinity and beyond.

Secondly, groups communicate the actions, requests and news of groups elsewhere in Greece or abroad. Articles that offer details about actions undertaken, future plans and projections for future needs, news about events, strikes, protests and news about self-organizing and self-governing initiatives elsewhere are posted, shared and commented upon in social media pages and in blogs.

Thirdly, communication is concerned with the in-depth analysis and understanding of the world. This is a crucial element and it is carried out primarily in blogs, and reposted, publicized and promoted through social media accounts. Through translations, interviews, articles and analyses, groups that belong to the antiauthoritarian/self-organizing tradition undertake the sharpening, clarification and discussion of their political positions. Torrent sites such as Black Tracker (http://www.black-tracker.gr/), communal translation sites such as Rebel.gr and Contra-Info, archives and online libraries such as Anarcheio (anarxeio.gr) and Eutopia (eutopia.gr), offer a great variety of important theoretical texts translated in Greek, back archives of anarchist and autonomist publications from Greece, as well as videos and music. Moreover, online (and print) magazines such as Babylonia (http://www.babylonia.gr/), Respublica (http://www.respublica.gr/) (the successor to Eagainst), Provo (provo.gr) and Protagma (https://protagma.wordpress.com/) are involved in the production of articles and commentary about the world, Greece, selforganization and autonomy.

Though these blogs and social media pages are in principle open, they are very clear in terms of their publication policies. One of the clearer statements comes from one of Mpalothia's social media accounts, that of a Facebook group:

${ }^{10}$ In a significant linkage between the past and the present, the servers of Indymedia Athens and Espiv are hosted at the Polytechnic University and Panteion University respectively. 
"The group Mpalothia-Counterinformation is concerned exclusively with topics of counter-information primarily for the anarchist/anti-authoritarian movement, the antifascist struggle and for any form of struggle against any state and any authoritarian construct. [...] Any posts that are considered irrelevant or supportive of the parliamentary and bourgeois political system will be deleted. The same goes for any posts linking to regime or for profit media or sites"11.

This statement is typical in drawing clear boundaries as to who can be part of this group and under what conditions. In doing so, they seek to retain a clear identity and prevent co-optation or exploitation. In this manner, the movement is open but only to a select group of people. Their 'them' and 'us' is therefore posited in clear rather than ambiguous terms preventing any misinterpretation, wilful or not.

Drawing out the political implications of these communications, we note that notwithstanding the conditions placed, the communications of these groups are addressed to broader publics and are not esoteric, obscure, or exclusionary. We understand these as an attempt to reach out to publics but outside typical populist frames that fudge ideological issues by references to a generic people. At the same time, we note that communications of the antagonistic movement operate beyond attempts to scale and persuade. For example, there is very little use of symbols or affective signs. Indeed, while symbols are used (for example, the colours red and black, the sign of anarchy etc.) these are mobilized as affirmations of identity in cover and profile photos, rather than as memes to be shared. Evidently, the antagonistic movement's communications do not look for shares or likes nor are they interested in persuasion through propaganda; rather, they seek to contribute to shifts in consciousness and, as they put it, to 'enlighten'12 in the literal sense: to throw light into a situation continuously obscured and distorted by the mainstream media and other authoritarian institutions. The movement itself understand their communications as counterinformation: this refers to the production and circulation of information outside of dominant institutions and the commodified for-profit economy, while also being antagonistic towards the dominant ideology. Counter-information is seen as having a dual role: to diffuse the views of those in the movements and to actively undermine the monopoly in the production and circulation of ideas and meanings (Katalipsi ESIEA, 2013).

In short, taken together these communicative strategies sustain, strengthen and support the antagonistic movement in Greece. They provide continuity with the past, bonding with others and organising in the present, while they also enact the future through their involvement in the solidarity economy and in various occupations/squats and refugee support initiatives. In the next section we will argue that these aspects and the broader discussion of counter-information explicit in these groups has the important political function of socializing the anarchist, libertarian, radical socialist and autonomist movements in the sense of returning and repositioning them from the margins to the centre of society, building local and global solidari-

${ }^{11}$ See https://www.facebook.com/groups/796512193720081/. Very similar policies are found in other sites, for example in the Contra-Info network (https://encontrainfo.espiv.net/terms-of-publication/), Mia epochi stin kolasi

(https://www.facebook.com/notes/\%CE) and others.

${ }^{12}$ See for example the interview of the Exarcheia publisher Giorgos Garmpis in 2013: http://eagainst.com/articles/garmis/ 
ties while sharpening and refining critical skills for political analysis thereby restructuring political subjectivities.

\section{Connecting the Threads}

Following the above discussion on the communication strategies of the antagonistic movement, we note a significant departure from the genealogy of leftist movements in Greece. Looking at the discourses or the substantive parts of their communications, these are outward looking and guided by three pivots: capitalist crisis, people in need (refugees and impoverished Greeks), and self-organization and autonomy. Questions of fighting state power remain important but have become secondary because of the pressing needs to understand and deal with the present situation and because of the dramatic retreat of the state in recent years. Nevertheless, critiques and actions against the state repressive apparatuses such as the police and prisons remain important. Discourses that follow and build upon the gains, failures and critiques of the movement of the squares and the fall of Syriza, point to the reformulation and reconstitution of the antagonistic movement as an important political actor. In these terms, we can observe an important shift and movement from the margins to the centre, because the antagonistic movement has made important contributions to the need to understand, survive and move beyond the crisis and because of this they have found resonance in Greek society at the present historical juncture. This section will begin with a brief discussion of the collective identity, publics, and communications of the movement. Building on this, it will mark their departure from current political thought as expressed on the one hand in the Laclauian theories of populist hegemony and on the other in the critique of folk politics expressed in Srnicek and Williams (2015).

A question that has been at the forefront of recent discussions of current protests and activism is that of the movements' identity (Bennett and Segerberg 2012; Gerbaudo and Treré 2015). Bennett and Segerberg (2012) posit that in instances of connective action where personalized networks and weak connections are favoured over stronger ties and ideological affinities, a collective identity is no longer necessary. This is clearly not the case in the kinds of groups examined here, which have a strong collective identity and sense of who they are and what they are about. At the same time, we can observe both continuity and rupture. These can be seen as the result of historical and material changes, including those of the crisis and the increasing availability of the internet and social media. We traced the antagonistic movement from the long years of state repression and persecution through the marginalisation by the popular hegemony of Pasok. However, it was in the years following the 2008 revolt and the subsequent deepening and intensifying crisis, and during and after the movement of the squares that the groups that comprise the movement began to shift their attention from police fights and rioting to consistent social action across urban centres and neighbourhoods beyond Exarcheia. At the same time, the position of Greece at the crossroads of two major and related capitalist crises, the debt crisis and the refugee/migration crisis, has reoriented the movement and its purpose from a narrow and localized focus towards a more global outlook. The movement acknowledges, and refers to, its historical antecedents which had a strong anarchosyndicalist component, but moves beyond the local and national focus of the previous era. Instead of channelling all energies to strikes and fighting the police, their political energies are invested in building up and maintaining self-managed social spaces and contributing to solidarity networks across Greece. In all this we can ob- 
serve the contribution of digital communications. Translations and interviews help build digital global solidarities and connect similar movements across the world in a lateral manner, spreading experiences and know-how; this not contagion but purposeful dissemination of knowledge that underpins and guides action. Online maps and links connect initiatives in various cities in Greece and coordinate actions. Archives of books, brochures and digitised old magazines retain links to the historical past of the movement. The ideological and theoretical texts alongside position articles and political analyses, provide a strong backdrop that justifies and explains actions, while crucially they allow the field to be ideologically coherent and systematic.

Because of their strong political collective identity, the public to whom they are addressed is very specific: in the first instance, it includes those who share the same class background and this means members of the working class, those in low-paid and precarious positions, the unemployed, immigrants and refugees ${ }^{13}$. Secondly, everyone else provided that they agree with their political ideas. Explicitly excluded are those who are seen as upholding bourgeois and petty bourgeois ideology and who promote for-profit relations. In a movement that underwent so many years of persecution and repression, secrecy and barriers to membership have served to protect them, but in today's environment barriers and controls are further imposed to retain a sense of the movement's identity and prevent co-optation. Moreover, the emphasis on the class credentials and the deep divides between classes point to an explicit class positioning rather than an address to a general public or 'the people'. Blogs such as Prolenet (prolenet.gr) or accounts such as @misos_taksiko ('class hatred') are very clear in terms of where they stand and who they are addressing. Although this has a cost in terms of scaling or attracting larger numbers, it is a cost they are prepared to pay.

In their opening to others, the communications of these groups engage in what may be seen as new learning, in the sense of seeking to produce behavioural changes ${ }^{14}$. In this manner, their communications have a clear pedagogical function that contributes to the development of new forms of consciousness, using on the one hand experiences and affects and on the other texts and analyses that ground, explain and contextualize these experiences and affects. The 'about us' section of the Contra-Info blog and translation network offers the most succinct example of this combination: 'Rage and consciousness!' ${ }^{15}$ It is not a temporary alliance that they seek but deep and permanent changes in how the world is viewed and understood. Scaling therefore takes place through the conscious, purposeful and consistent dissemination of learning, including both practice-based and conceptual-theoretical.

It is clear from the above that the communications and political practices of these groups differ both from Laclau's populist hegemony but also from the notion of folk politics as criticised by Srnicek and Williams. Populist hegemony as discussed by Laclau (2007) looks to bind together unsatisfied demands into chains of equivalence, coalescing around symbols and slogans, subsequently capitalized upon by leaders

${ }^{13}$ In a significant gesture of opening and solidarity, the historical anarchist newspaper Apatris published an Arabic edition (both print and online), found here: https://issuu.com/apatrisinternational/docs/aparab1-webdraft

\footnotetext{
${ }^{14}$ Morgan et al. $(1986,170)$ cite a typical definition of learning as involving relatively permanent changes in behaviour or mental processes as a result of practice or experience.

${ }^{15}$ See https://en-contrainfo.espiv.net/2015/03/01/contra-info-translation-counterinformation-network-2010-2015/
} 
who then construct 'the people' they are supposed to represent in their confrontation with the existing political order. However, the communicative and political strategies of the groups under study are explicitly against the notion of leadership and the construction of a united people. Their emphasis is on direct and localized action and organizing, and instead of looking to unite the people they are more interested in pointing the fault lines that separate people across class and other divides. Instead of using communication to form equivalences and symbols to point to these equivalences, they use it on the one hand instrumentally to achieve immediate and pragmatic goals and on the other to reinforce their identity, and to instigate and disseminate new learning.

Does this make them part of folk politics? This kind of politics, according to Srnicek and Williams $(2015,12)$ refers to "a collective and historically constructed political common sense that has become out of joint with the actual mechanisms of power" and because of this, it holds the left back. Folk politics revolves around three kinds of immediacy: temporal, spatial and conceptual. Temporally, it is reactive, as it reacts to actions initiated by corporations and governments and prioritizes the voluntarist and spontaneous over the institutional. Spatially, it prioritizes the local and the small and emphasises direct action, while finally in terms of conceptual immediacy there is a preference of the everyday, the affective, the personal and the particular over the structural, the abstract and the universal. Srnicek and Williams are quick to point out that this is an abstraction that is not embodied by any single position; rather folk politics must be seen as instantiated in varying degrees in concrete political positions. The problem, argue Srnicek and Williams, is that while folk politics is a necessary condition for any political project, it is not sufficient because it cannot address the question of scaling and strategy and for this reason it cannot adequately deal with global capitalism and any postcapitalist political project. In Srnicek and Williams' view, we require a combination of strategic, structural and analytic thinking in politics with ways of doing politics that pay attention to expansion and scaling. For this to be accomplished the left has to develop a project that can become counter-hegemonic to neoliberal capitalism.

It is evident that the insistence on direct and localized action, on forms of leaderless horizontal organization, and a dislike of both populism and hegemony are central to the field of thought we encountered here, even if they are also critical of affect on its own. Does this mean that this political thought and action is ineffectual? A closer look reveals certain tensions in the argument put forward by Srnicek and Williams. Their view of folk politics as necessary but insufficient hinges on the question of scaling: it is only insufficient because it cannot scale. Only hegemony can scale, because it is universalist in its orientation and only populism can succeed because it seeks to create a common language and project in spite of the various particularities of all those forming 'the people'. Scaling and a universalist horizon gloss over particularities at least temporarily as differences and particularities can never be totally resolved or suppressed. But in the above analysis we saw that the political perspective of the anarchist, libertarian and autonomist groups approach the question of scale in a different manner: rather than scaling by glossing over or subsuming particularities, they are more concerned with the production of new forms of subjectivity based on the one hand on experience and on the other on learning. The various experiences are then linked or connected together in solidarity but without converging. From this point of view, the issue is not one of scaling into a hegemony that subsumes different and occasionally contradictory demands but one of long lasting change in political subjectivities that will emerge out of experiences, out of thinking and theorizing and 
out of collaboration and exchange. Not one therefore of a mass political project but a series of interconnected multiple socio-political projects linked but not becoming equivalent, while also confronting state and authority structures. For this line of thought, building commonalities and common spaces is not the preserve of populism but can be arrived at in a different method, and potentially with less contradictions and with more attention to difference.

\section{Conclusion}

The paper has examined the genealogy of left-wing movements in Greece, detailing the emergence and defeat of EAM/ELAS, the ideological stronghold of KKE, and the post-civil-war authoritarian political climate. Following the imposition of the right-wing military dictatorship (1967-1974), which intensified repression and political persecutions, we identified a certain political imaginary created by these dramatic events, an imaginary that is echoed in the discourses of many Greek leftist movements, including the 'early Pasok' and Syriza, as well as in the relatively small anarchist space. We have seen that the hegemonic left was firstly controlled by the KKE, then by Pasok, and finally by Syriza. Pasok, lost its populist character once it embraced economic liberalism, and more importantly, when it accepted the EU directed austerity policies as inevitable. Syriza, on the other hand, collapsed due to its unsuccessful attempts not only to break with the unpopular policies of the Troika, but also to mobilize European publics against neoliberalism; while it still mobilises populist rhetoric, words and deeds are totally disconnected.

In parallel, we traced the anarchist and self-organising collectives, paying attention to their communicative practices. We followed the evolution of the antagonistic movement, from small, marginal and repressed initiatives, countercultural trends and autonomist currents. Finally, we tracked the movement from its occasional irruptions to the more consolidated, stronger and more socialised movement that has emerged, revolving around the revolt of 2008, the squares of 2011 and following Syriza's simultaneous victory and defeat in 2015. Tracing the parallel history of those operating outside the left party hegemony and outside state control, we sought to identify and make sense of their communication strategies, contextualized within the social and political history of Greece.

Broadly conceived, the horizontal antagonistic activists run occupied social spaces, and have become involved in the solidarity and cooperative economy, including self-managed factories and shops, and in the solidarity clinics, food banks, and refugee support centres. Some activists are also involved in anti-statism, targeting its apparatus, especially the police, having also established connections with struggles taking place in other parts of the world. Communication is an integral part in all this, relying on a vibrant sphere of communal and individual blogs, social media pages, online radio broadcasts, websites and individual accounts. Using instrumental communication to get things done, using news and crosslinks but also translations to connect to others, and by developing their own accounts, explanations, and interpretations of classic and current texts, local and global events, they attempt to spread and socialise their ideas, creating a common space in order to develop a social movement in a lateral manner without compromises. These practices we see as part of a different political strategy that opposes hegemonic populism (the type of populism that is controlled by party bureaucracies and mechanisms of representation), but still revolves around the principles of socialism and social justice, direct democracy and political participation. 


\section{References}

Bennett, W. Lance and Alexandra Segerberg. 2012. The Logic of Connective Action. Information, Communication \& Society 15 (5), 739-768.

Bennett, W. Lance and Alexandra Segerberg. 2013. The Logic of Connective Action: Digital media and the Personalization of Contentious Politics. Cambridge: Cambridge University Press.

Costanza-Chock, Sasha, 2012. Mic Check! Media Cultures and the Occupy Movement. Social Movement Studies 11.3-4: 375-385.

Dean, Jodi. 2012. Occupy Wall Street: After the Anarchist Moment. Socialist Register 49.

Douzinas. Kostas. 2013. Philosophy and Resistance in the Crisis. Cambridge: Polity Press.

Filippidis, Christos. 2011. Spatial Legacies of December and the Right to the City. In Revolt and Crisis in Greece, edited by Antonis Vradis and Dimitris Dalakoglou, 59-76. Edinburgh: AK Press.

Foucault, Michel, 1977. Language Counter-Memory Practice: Selected Essays and Interviews. New York: Cornell University Press.

Fuchs, Christian. 2014. Occupy Media!: The Occupy Movement and Social Media in Crisis Capitalism. John Hunt Publishing.

Gerbaudo, Paolo, 2012. Tweets and the Streets: Social Media and Contemporary Activism. London: Pluto Press.

Gerbaudo, Paolo and Emiliano Treré, 2015. In Search of the 'We' of Social Media Activism: Introduction to the Special Issue on Social Media and Protest Identities. Information, Communication \& Society 18(8), 865-871.

Hallin, Daniel C., and Stylianos Papathanassopoulos. 2002. Political Clientelism and the Media: Southern Europe and Latin America in Comparative Perspective. Media, Culture \& Society 24 (2): 175-195.

Kaplanis, Yiannis. 2011. An Economy that Excludes the Many and an "Accidental" Revolt. In Revolt and Crisis in Greece, edited by Antonis Vradis and Dimitris Dalakoglou, 207-214. Edinburgh: AK Press.

Karyotis, Georgios and Wolfgang Rudig, 2015. Protest Participation, Electoral Choices and Public Attitudes towards Austerity in Greece. In The Politics of Extreme Austerity, edited by Roman Gerodimos and Georgios Karyotis, 123-141. Hampshire: MacMillan.

Kavada, Anastasia. 2015. Creating the Collective: Social Media, the Occupy Movement and its Constitution as a Collective Actor. Information, Communication \& Society 18 (8): 872886.

Kornetis, Kostis. 2013. Children of the Dictatorship. Oxford: Bergham Books.

Kouki, Hara. 2011. Short Voyage to the Land of Ourselves. In Revolt and Crisis in Greece, edited by Antonis Vradis and Dimitris Dalakoglou, 167-180. Edinburgh: AK Press.

Laclau, Ernesto. 2007. On Populist Reason. London: Verso.

Mazower, Mark. 2001. Inside Hitler's Greece. Yale: Yale University Press.

Metropolitan Sirens. 2011. The (Revolt) Medium is the Message: Counter-Information and the 2008 Revolt. In Revolt and Crisis in Greece, edited by Antonis Vradis and Dimitris Dalakoglou,133-150. Edinburgh: AK Press.

Morgan, Clifford Thomas, Richard Austin King, John R. Weisz, and John Schopler. 1986. Introduction to Psychology. New York: McGraw-Hill.

Ovenden, Kevin. 2015. Syriza: Inside the Labyrinth. London: Pluto.

Papathanassopoulos, Stelios. 2001. Media Commercialization and Journalism in Greece. European Journal of Communication 16(4), 505-521.

Prentoulis, Marina, and Lars Thomassen. 2014. Autonomy and Hegemony in the Squares: The 2011 Protests in Greece and Spain. In Radical Democracy and Collective Movements Today, edited by Alexandros Kioupkiolis and Giorgios Katsambekis, 213-234. Surrey: Ashgate. 
Rakopoulos, Theodoros. 2014. Resonance of Solidarity: Meanings of a Local Concept in Anti-Austerity Greece. Journal of Modern Greek Studies 32(2): 313-337.

Re, Mila. 2015. The Indignants of Mordor.

Sheehan, Helena. 2017. The Syriza Wave: Surging and Crashing with the Greek Left. New York: Monthly Review Press.

Shiner, Larry. 1982. Reading Foucault: Anti-Method and the Genealogy of PowerKnowledge. History and Theory 21 (3): 382-398.

Srnicek, Nick, and Alex Williams. 2015. Inventing the Future: Folk Politics and the Left. London: Verso.

Stavrakakis Yiannis, and Giorgos Katsambekis, 2014. Left-wing Populism in the European Periphery: The Case of Syriza. Journal of Political Ideologies 19 (2): 119-142.

Stavrakakis, Yiannis. 2005. Religion and Populism in Contemporary Greece. In Populism and the mirror of democracy, edited by Francisco Panizza, 224-249. London: Hurst and Company.

Theocharis, Yannis. 2015. Every Crisis is a Digital Opportunity: The Aganaktismenoi Movement's Use of Social Media and the Emergence of Networked Solidarity in Greece. In The Routledge Companion to Social Media and Politics, edited by Axel Bruns, Gunn Enli, Eli Skogerbo, Anders Olof Larsson and Christian Christensen, 184-197. New York: Routledge.

Theodosiadis, Michael, 2013. Lessons from 6 December, 2008. Open Democracy [online]. Accessed October 10, 2016. https://www.opendemocracy.net/can-europe-makeit/michael-theodosiadis/lessons-from-6-december-2008

Theodosiadis, Michael. 2015. The Greek December Revolt and its Current Relevance. The Institute of Anarchist Studies. Accessed March 10, 2016.

http://anarchiststudies.org/2015/04/08/the-greek-december-revolt-and-its-currentrelevance-by-michail-theodosiadis/

Trocchi, Alex. 2011. For the Insurrection to Succeed, We Must First Destroy Ourselves. In Revolt and Crisis in Greece, edited by Antonis Vradis and Dimitris Dalakoglou, 299-328. Edinburgh: AK Press.

Voglis, Polymeris. 2000. Between Nation and Self-Negation: Political Prisoners in Greece 1945-1950. In After the War Was Over: Reconstructing the Family, Nation and State in Greece, 1943-1960, edited by Mark Mazower, 73-90. New Jersey: Princeton University Press.

Vradis, Antonis, and Dimitris Dalakoglou (eds.), 2011. Revolt and Crisis in Greece. Edinburgh: AK Press.

In Greek:

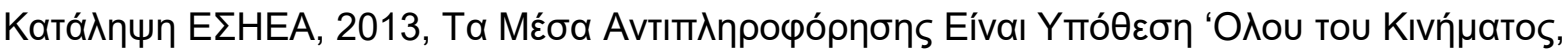
[Occupy ESIEA (Journalists' Union) Counter-information Media are an Issue for the Whole Movement] April 26. Accessed May 10, 2016: http://katalipsiesiea.blogspot.ie/2013/04/blog-post 1607.html

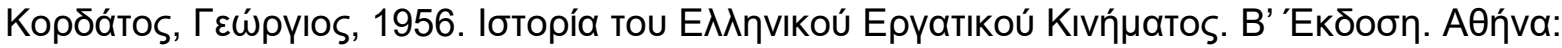
Пદ́тро $\Delta$. Kapaßákо [Kordatos, Georgios, 1956. History of the Greek Labour Movement. 2nd ed. Athens: Petros Karavakos].

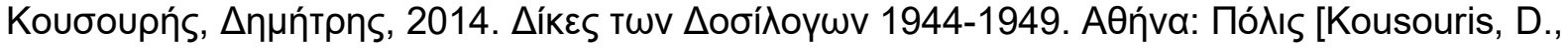
2014. The Trials of Collaborationists 1944-1494. Athens: Polis].

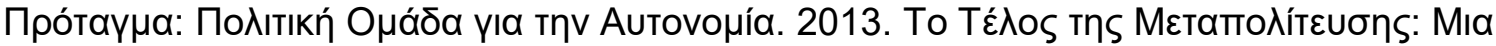

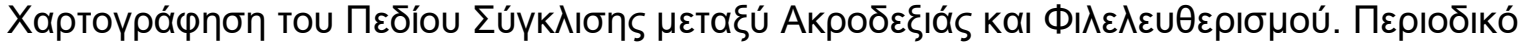

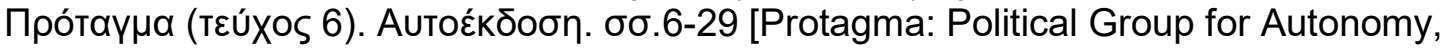
2013. The end of the Metapolitefsi: A Mapping of Convergence Between the Extreme Right and Liberalism. Protagma magazine (issue 6). Greece: Self-published. pp.6-29] 


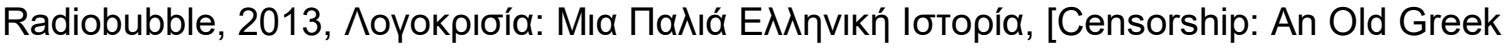
Story] June 16. Accessed May 10, 2016 http://news.radiobubble.gr/2013/06/blogpost_16.html

\section{About the Authors}

\section{Eugenia Siapera}

Eugenia is a Senior Lecturer at the School of Communications in Dublin City University. She is the editor of Radical Democracy and the Internet (with Lincoln Dahlberg, Palgrave, 2007) and the Handbook of Global Online Journalism (with Andreas Veglis, Wiley, 2012), and the author of Global Media and Cultural Diversity (Wiley, 2010) and Understanding New Media (2012, second edition 2017).

\section{Michael Theodosiadis}

Michael is a PhD Candidate and academic mentor in Goldsmiths, University of London. He has also studied Social and Political Theory in Birkbeck, University of London (MSc). He is an academic mentor in Goldsmiths and his research field is focused on populism, direct democracy, civic republicanism, civic humanism, modern Greek politics and American Literature. 


\title{
Student Protests. Three Periods of University Governance
}

\author{
Joan Ramon Rodriguez-Amat* and Bob Jeffery** \\ Sheffield Hallam University, United Kingdom, *mon.rodriguez@shu.ac.uk, \\ **.f.jeffery.shu.ac.uk
}

\begin{abstract}
Exploring the idea of student protests as an autonomous object of research and discussion, this paper leads to the understanding that the transforming role of the university and its governance defines the possibilities for the political role of students. In this perspective, there is a particular constellation of the different forms of higher education governance that provides students with the right and even the responsibility of protesting as politically engaged citizens of the university and of the state. Approaching the transformation of the models of university governance as a set of archaeologically organised states this paper identifies the sequential roles provided to the students and the meaning of their protests and demonstrations. After visiting some antecedents of more contemporaneous student movements and protests, this paper focuses on the UK to explore three manifestations of university governance that can be roughly differentiated as the enduring democratic period that extends from the late 1960 s to the late 1980 s, the globalisation period that extends from the early 1990 s to the mid-2000s and as the post-millennial turn. These periods, embodying three different styles of governance of higher education, not only demonstrate conformity with the political and economic contexts in which they are embedded, they also correspond to particular socio-technological and communicative ecosystems and determine the specificities of the role of the students and their capacity for political action.
\end{abstract}

Keywords: Student Protests, Higher Education Governance, Social Movements, United Kingdom, Information Ecologies

The relationship between students and protests is a commonplace of university life: "Any student community without a protest of some sort on the stocks invites the charge of complacency and will be looking for a grievance" (The Guardian June 1968, quoted in Thomas 2002, 280). This assumption is taken for granted but not unproblematic. Yet even if the representations of students have changed over time, social discourses around university students stress the attributes of youth, rowdiness, rebellion and anti-authoritarianism. These considerations, which will be explored further in detail below, carry implications that echo through university administration and media representations, but can also serve as an explanatory- symptom of a broader scheme of social, economic and political frames.

Indeed, the roles and representations of university students do not stand in isolation from the transformations of the societies in which they are embedded. The changes in the perception of students and their claims relate to broader transformations at social, technologic, economic and political levels, as well as to the changing logic of the varied interests-in-tension that shape university governance. The converse is also true: governance changes serve to reproduce different "models" of studenthood. On occasions, students have been constructed as political actors within the institution or in society, whereas on others students are treated and enabled as consumers. In this sense, whatever current narrative defining the social role of the university modifies the "logic" of student behaviour to the extent that students are 
provided spaces of identity beyond their own decision-making and performative capacity. The constellations of factors are broad enough and complex enough to obfuscate any casual mechanisms that form them and to appear not as linear changes of a teleological nature but rather as epistemologies, instead. Consequently, this article approaches the stages of students' protests from a genealogical point of view (Foucault 1970), according to which the three stages identified form discontinuous archaeological layers instead of as the result of an ongoing, continuous and linear historical process. This is to allow for a holistic view of the definition of the social space of students' protests, and also their nature as information ecologies (Treré 2012).

\section{Students and Protests: State Authority, Market and Academic Oligarchy}

It has been noted that: "[...] the history of Western education is a history of power struggles, and student resistance is as old as the university itself; students developed and used their individual and collective power, defining themselves in relation to the societies and social institutions they fought against." (Boren 2013, 20).

However, even if the drive behind student actions might seem to call for total revolution, "it is wrong to regard the student movement as a revolutionary movement in itself $(. .$.$) 'In the long run these come to an impasse [...] for students do not have real$ power to transform society' (Harman, 1970; 1)" (Woodcock 2013, n.p.).

The university has been part of the European landscape for a thousand years and has transformed in step with broader societal change. In this sense, university governance has changed in parallel to the transformational role of university in society and in national, regional and local economic development. A good example of the recurrent exploration of this issue is the extensively cited systems approach explored by Clark (1986; see for example, Jongbloed 2003, 131). Pace Clark, the changes in the balance between the three dimensions that explain the governance of higher education are: state authority, the market and the academic oligarchy, which in combination serve to modify the position and the value of the students. Later Braun and Merrien (1999) described four models of university governance: the 'collegium', the 'bureaucratic-oligarchic', the 'market' and the 'new managerialism' governance models. The relationship between these four models has also been described by Lazzeretti and Tavoletti $(2006,25)$ as "an antique archaeological site", meaning that they can be approached and explored as differentiated layers overlapping and independent from one another, while keeping in mind that "none of the different epochs seems to be finished. Traces of each level refract upon the present making them really contradictory, complex and remarkable institutions" (Lazzeretti and Tavoletti 2006, 25).

The changes in the governing logic of universities also involve student unions. They have historically played a fundamental role in student mobilisations. Despite the changes in both the role of students' unions within the universities or in their juridical form, their value and continuity as political agencies for the collective will of students can be also perceived in the representations of students as protestors. These have been approached in the academic research from multiple angles: enlightenment and co-optation; authority and youth; networking and location. For instance, social psychologists like Smelser (1968) focused on the continuity between youth, students and protests by arguing that rebellion against the institution takes the place of rebellion against the father; or a "biological urge of the adolescent to assert himself" (The Sun 2 June 1969: 8)" (Moore 2006, 5). Indeed, the generational struggle has dominated the literature on student protests in the sixties: "for the first time, large numbers of young people challenged the decisions and attitudes of authorities and members of older generations" (Thomas 2002, 278). Other approaches instead focus on the con- 
ditions of the university that foster the politicisation of students, for example Marsh (1977) argued that the university instils particular values into students: providing a space for the fermentation and tolerance of new ideas. Universities provide not only potentialities linked to social networks and the ability to network, but allow for the development of a 'critical mass' of politically engaged young people (Crossley and Ibrahim 2012). Recent developments of these perspectives have explored the role of student societies in constituting networks: "[...] to understand the precise political dynamics of these protests, we should focus on the university campus itself and how it is conducive to (indeed, facilitates) mobilisations because of its very network-like structure and those of its students' union and political societies." (J. Ibrahim 2011, 416).

And even more; not only physically enabled campus networks but also those virtually constituted by social media (see Maireder and Schwarzenegger 2012, Brantner and Schwarzenegger 2012) and appropriated by those with a surfeit of free time: "Students are often at the cutting edge of social radicalism, since they alone possess the sometimes volatile combination of youthful dynamism, naïve utopianism, disrespect for authority, buoyant optimism and attraction to adventure, not to mention a surplus of spare time. They perceive themselves as the leaders of a future generation and are often over-eager to thrust themselves into the task of reshaping their society." (DeGroot 1998, 4).

Nonetheless, the link between students and protests also extends to the trope of student protest as a core component of wider revolutionary struggles. As in France in the sixties, when they were strongly related to the role of the working class and the labour unions in joining the claims as Les Enragés: "these protests were, for some people at least, the possible vanguard of a future workers' revolution" (Thomas 2002, 283). These arguments are part of a burgeoning field of research on student action, social movements and protests. However, this tradition and discussion cannot be extended here. It is more urgent to deal with the communicative environments and with the transformation of student protest over time.

Student protests are enabled by participants communicatively networked and in interaction with an environment of media reports and police activity that has changed over time. This techno-communicative environment must be understood as extending beyond the media that construct and represent the students, their claims and protests, or the disorder that sometimes results - that is, beyond the traditional definition of media. Actually, this milieu also includes the means that the students use to interact among themselves to create networks, and with their environment, higher education institutions, governments and other collectives and political actors depending on their claims, range and intentions. As Treré (2012) has contended, the environment of student protests is formed not only by the contents of the communication - the languages, the representations and the interaction between actors - but also by the ecosystem of technologies and devices as well as by the configurations of space and place that result from the (re)structuring of urban public space (Rodriguez-Amat and Brantner 2014) or the role of media in propagating protests waves across space and time (Andrews and Biggs 2006).

There is a complex mesh of factors that explain why student protests remain under perpetual transformation. It is impossible to discern a line of historical transformation that identifies stable elements. As J. Ibrahim notes, "[...] student protest movements are not homogeneous; they vary in size, cultural identities, resources, values and grievances; each national or local case must be examined on its own merits and 
theoretical frameworks established from those specific empirical examples." (2011, 419)

Having said that, on examining chronologies of student protests and the changes in the university governance (Boren 2013; Ruegg 2010), three major moments can be perceived. This article therefore prefers to explore these histories through Foucault's metaphor of the archaeology of knowledge (1970); that is, by identifying three layers that correspond to three logics of university governance. This genealogical approach (Foucault 2002; Foucault 1970) highlights the rationale within each one of these three epistemic moments. The resulting epistemes of university governance distinguish three positions for the students: reducing the diverse collective of students to a single homogeneous entity is part of the epistemic machinery of order; and this includes a certain form of university, a certain set of practices, of values and of students. Stated thus the claims of students understood as politically engaged versus the claims of students understood as lazy consumers or as users of the university have scant regard to the perspective of the students, but rather represents that of the institution that is constructing them.

\section{Student Protests: Three Stages and an Antecedent}

The historical explorations of Boren (2013) and Ruegg (2010) allow for multiple ways of organising a chronology. During the last century, universities have changed forms and roles within the also changing state structures and the transforming student organisations and their communicative environments. Aware of the diversity of political environments and of policies involving student fees, access to university, understandings of higher education and regulatory frames between countries, this article focuses on the United Kingdom, noting, as examples, cases from other countries. Three grand moments help explain the transformations of the university and student bodies in the United Kingdom. The following section is organised accordingly, with a prologue describing the first student protests in history.

\subsection{Once Upon a Time: Students}

Universities originally referred to informal guilds of scholars and their students; "the word universitas signalled only a collection of students, similar to the guilds of weavers or carpenters" (Boren 2013, 8). The notion of students as a community was therefore not originally a principle that altered the functioning of the city until the university began to develop its own autonomous institutional structures. This is the period that corresponds loosely to what Braun and Merrien (1999) called the 'collegium' governance model. "According to this concept the "community of scholars" would administer its own affairs, having few dealings with bureaucratic officials" (Baldridge $1971,4)$. The insertion of scholarly communities into cities during the European Middle Ages (Bologna in 1088, Oxford in 1096, and Salamanca in 1134) invited the growth of economic strategies to exploit students with higher rents and higher prices. Students were visitors, strangers to the city inhabitants and often (as today) of a higher social class. Not only had they different habits and routines but they were also easy to distinguish and often accused of uncivil practices. Students were not invested "in the towns in which they studied; they felt neither personal nor social pressures to conform to their foster towns' notions of proper behaviour or proper respect for person or property" (Boren 2013, 10). Differences emerged sometimes in the form of the so-called 'town-and-gown' clashes (Ward's book of days 2006; Miller 1993; Headlam 1912) centred on room rents, manners and the quality of wine served at inns. These disputes were typically resolved in favour of an increase in the power of the university 
over the city: the prestige of the elites in the academe and the economic opportunity for the growth of the city, forced settlements upon the townspeople that granted security for the students and exemptions from municipal control for the institutions of the university. These social clashes carried major economic, urban and political implications.

The associations of students were politically relevant and acted as transformative forces, for instance in the $16^{\text {th }}$ Century Renaissance and Protestant Reformation, shaping the intellectual debates (Boren 2013); or in the $19^{\text {th }}$ Century, when the demonstrations and student organisations or Burschenschaften played a role in the formation of the German state, articulating the demands for national unification and the writing of the German constitution. Perhaps the most consequential event of the early twentieth century was also related to student protest: the assassination of Prince Franz Ferdinand of Austria was committed by the student militant Gavrilo Princip in Sarajevo, triggering the start of the First World War.

The public expression of students is linked to key events in world political history; it would therefore be unfair and historically false to identify the students as a political body that has only emerged since the mid- $20^{\text {th }}$ century. Nonetheless, the aims of this article are particularly concerned with the transformations of students as political actors in protests since the 1960s.

\subsection{Enduring Democracy 1965-1985: University and the State Control}

The explosive combination of a generational conflict of baby boomers, the cultural revolution, the growth of youth subcultures and the technological changes that enabled the visualisation of what can be considered the first mediated protests, has made the sixties the epitome of student protest for generations to come (Y. Ibrahim 2010). Yet this only marks the beginning of an epistemic moment that extends over two decades of student organisation and of world geopolitical events; shaping a model of university governance. Efforts - and struggles - to steer the university by emulating the possibilities of the state and adopting a logic of democratisation were evident, as was happening with the state authorities around the cold war capitalist block. Protests were seemingly linked to the geopolitical world events and to national policies relating to labour or gender and race, rather than university business per se. The sense of solidarity positioned the university - and the students-citizens - as actors for altruistic political claims related unacceptable events on the world stage, such as the case of British students protesting against the Vietnam war (Thomas 2002). However, the university was struggling with a generational change within its disciplinary walls. Students were citizens practicing and claiming rights both outside and inside the university. There are examples of these protests from around the world, ranging from France to the United States, Germany to Mexico, Australia to Japan.

In the United Kingdom, there were street demonstrations and sit-ins. Probably the most significant of them was held in protest at the Vietnam War at the American Embassy in London on October $27^{\text {th }}$ of 1968. It gathered around 20,000 demonstrators in Grosvenor Square. The organisation was done by "an ad hoc committee that was comprised of a variety of groups, with different political aims" (Ibid., 287). Perhaps the most important outcome of this demonstration was a sense from the establishment that it had been caught off-guard, which led to the creation of the covert Special Demonstration Squad - a policing squad aimed at the undercover infiltration of UKbased protest movements (Evans and Lewis, 2013). During that period a wave of sitins spread across the country affecting "higher and further education institutions [in- 
cluding] those at LSE, and Birmingham, Manchester, Leeds, Liverpool, Bristol, Keele, and Leicester Universities" (Thomas 2002, 278).

The centres of reference for the student protests during the period have been however France for the intellectual revolt and the rebellion in the USA against racial segregation. On the back of a combination of sophisticated statements of political, social and economic needs, students at the University of Nanterre, Paris, calling themselves Les Enragés, began protesting against the hegemonic capitalist and conservative/reactionary values (Perry 2008) of authoritarianism and the consumer society. Concurrently, in the USA, groups such as the Student Nonviolent Coordinating Committee led campaigns against racist segregation in the face of violence by the state and reactionary interests. In Germany, the killing of a student protestor by police in 1967 also raised intensive resistance, and on October $2^{\text {nd }} 1968$ the Mexican army opened fire with machine guns on massed student protestors at the Plaza of the Three Cultures. In Japan, armed protestors occupied Tokyo University forcing the university president to step down.

In this period, a new generation of post-war youth were entering adulthood under a whole new regime of consumption, expression and cultural identity mid-way between the readymade productions emerging from the media industries and their own negotiated performances. These young citizens were "members of a generation that had enjoyed unprecedented access to wealth, opportunity, education and employment" (Thomas 2002, 279). These youngsters found themselves caught between three imperatives that included a still exotic but growing globally market driven cultural industry; an effort to maintain social and traditional values embodied by parental and other regimes of authority, including the teaching authorities; and the urge for a double shift that would enable them to grow their own democratic views free from the consumerist ethic and from the pre-democratic authoritarian mode of education: 'Marcuse in particular singled out students as the social group which was sufficiently removed from the corrupting influences of capitalist society to be able to challenge and undermine it' (Ibid., 293). This triple tension is well represented by what university was: an old institution of authoritarian and patronising structure that did not apply democratic principles to itself, and without the capacity of accommodating a growing number of socially diverse students. The values of change, rights and innovation were in tension with those of the university as a space of discipline.

Even if according to the National Union of Students (NUS), the students in the United Kingdom suffered from apathy in the sixties (Thomas 2002), they were considered to be the promising generation of baby boomers born in the post-war peace with a responsibility for extending democratic values, universal human rights and the welfare state principles of solidarity and tolerance of diversity. The state contributed by changing the structures of the university governance: facilitating the autonomous organisations of students and by incorporating the students in managerial organs: "In the months afterwards, Essex students won representation on most university committees and over fifty per cent representation on several which directly concerned student interests" (Hoefferle 2012, 9:86).

Those student movements of the enduring democratic moment were (in this instance) not demonstrating for revolution but as part of a general drive for a progressive improvement or transformation of the institutions in accordance with democratic rule. The techno-communicative ecosystem also embodied the tensions between ideological and generational clashes. From one angle, the established media fabricated some significant myths in its representations of the protests: short-sighted understandings premised on the fear of absolute revolution (sometimes expressed as 
contagion from France) and the common interpretation that protests were caused by permissive parenting (see Parkin 1968). But as Andrews and Biggs (2006) put it, "news media were crucial for conveying information about protests elsewhere" even if they did not intend to encourage them. The novelty of the protests was reported with alarmism in the press: The Daily Telegraph (March 19 ${ }^{\text {th, }}$ 1968) stated "there were moments when the crowd seemed bent on violence as an end in itself" (Thomas 2002, 289). However, the demonstrations and protests were "more complex and less threatening than the media image would seem to have allowed" (Ibid., 290). At the same time, the students creatively expanded the communicative ecosystem by incorporating some media to their expressive action: "Although the Free University and occupation were carried out peacefully and seriously; at other times, the protest resembled a carnival of sorts. Evenings were filled with music and dancing, vivid artwork and graffiti sprung up around campus, and television crews and even a film crew established themselves on campus to document the ongoing drama." (Hoefferle 2012, 9:85).

Students themselves were either using the student newspapers or creating communicative structures under the forms of independent and ideologically combatant political and cultural newspapers like the Black Dwarf in the UK (see Hoyland 2008 and Thomas 2002), without ever taking the eyes off the coverage by the mainstream media.

These complex circumstances redefine the position of the students within the new university governance frame. The principle implemented at the university, aiming at more democratic forms and for equality of access under a transparent meritocratic framework, sets conditions for the profile of the students as political actors in permanent tension; permanently asking for fairness, clarity and intellectual worthiness. Students born from the new university logic were also engaged citizens aware and reactive to global geopolitical injustices.

This idea of the student as a citizen (of the university-city, agent of socio-political justice and equality, and citizen of the world) mirrors well the idea of a University under the governance regime of what Van Vught (1989) calls "state control" (see also Jongbloed 2003). That is, the state granting universities and investing in them to further its own growth and development; and attributing to the students their role as claimants upon and actors within the governance system.

A common ground for the universities from the late 1960s and those of twenty years later can appear to be reductive of the multiple and complex transformations that took place in particular countries and across universities in the Western world; nevertheless, the opportunity of framing the period in the terms suggested here helps in understanding other aspects of the wider picture. For instance, challenging the twin myths of revolutionary students and the patronising forms of othering of the conservative narrative.

\subsection{Globalisation 1985-2005: University and State Supervision}

Obviously, there is no singular event that establishes a change of paradigm; but multiple developments unfolding throughout the eighties crystallise during the early nineties. As symptomatic problems and the readjustments of the previous decade give way to important shifts in university regimes and the roles of the state all over Europe - but particularly in the United Kingdom -the results are significant changes to policy. . Several Acts modify the university environment, aligning the institutions, their governance and the environmental conditions around a logic the features of which could be already perceived during the last half of the eighties. This section explores the 
major features of the new episteme of a university governance model that turns the university, increasingly autonomous now from the state institutions, towards what the Clark (1986), and Braun and Merrien (1999) models would name 'the market'. This is a knowledge-for-the-market driven system in which the university provides a workforce for a growing labour market, and produces ideas for the economy and for the state.

A chain of Acts modifying the statuses of the United Kingdom universities (1988, 1992 and 1994) illustrates well this change of paradigm. The Education Reform Act of 1988 created universities, polytechnics and college funding councils and gave power to the Secretary of State for Education to direct funding councils and debarred University Funding Councils to encourage universities to raise external funds (Richards 1997). Furthermore, in 1992 the "Further and Higher Education Act" abolished the binary line between universities and polytechnics, incorporating 35 new universities that allegedly "have done the heavy lifting in terms of overall student expansion and in widening participation for students from "middle England, working-class homes and ethnic minorities" (Scott 2012, n.p.). The Act was considered part of a process of "democratisation" of the university access that increased dramatically the numbers of university students frontally challenging the former university structures of labour and of organisation. The 1992 Act also created the national unitary funding councils, one for England (HEFCE), one for Scotland, and one for Wales. These 1988 and 1992 Acts, prior to the Higher Education Act of 1994, underline a change of position of the state as a major funding entity of the University system and incorporates a logic of competition and of external funding that will progressively grow towards 1998, when tuition fees are first introduced in the UK.

The policies implemented also reached the role and forms of the student unions. The increase in the number of students parallels the stepping up of efforts to depoliticise their action. Reforms affecting the student unions work as attempts to eliminate spaces of autonomous political activity. It is a long path symptomatic of the end of the democratic expansion and cementation of the grip of the 'New Right' upon western states. In 1984, legislation in the UK concerning free speech on university campuses outlawed the National Union of Students' "No platform for Fascists" policy (Richards 1997). In 1985 courts ruled illegal two donations by the Student Union of the Polytechnic of North London (U.K) to support the miners' strike and for the relief of an Ethiopian famine. In both cases it was established that since the universities they were attached to had charitable status, the unions themselves also had this status. Furthermore, the UK Education Secretary John Patten, pushed to end the closed shop system of Union recruitment forcing them to ensure membership of all students who volunteer. These were not only changes in the funding structures of the Union but also, "the charitable status of student unions, though largely taken for granted now, is intimately linked to a political agenda to erode solidarity between students and workers in struggle" (Swain 2011).

Student unions still had an ambiguous status, lacking uniform structures and organisation. But the Education Act of 1994, aimed at dampening down student protests, contributed to the transformation of the culture of student unions from campaigning bodies to service providers. Slowly, the services side of most unions - bars shops night clubs - increasingly tended to outweigh the representative side, both in the agenda of the union and in the way it is viewed externally: "The corporate aspect gives rise to a permanent apparatus of full-time unelected union employees, whose interest lies in not rocking the boat" (Ibid.). The changes in funding and role of the unions impacts their communication patterns: now they need to gain presence within 
the community of students to finance their more complex structures as employers rather than lobbying at the political extra-university level. These changes echo also in the ways unions communicate and embody the university students' interests.

In June 1987, the European Commission adopted the European Region Action Scheme for the Mobility of Students. Despite the resistance of the most powerful European countries (France, Germany and the United Kingdom), the Erasmus Programme would go ahead with the strategic help of the largest transnational, interdisciplinary student organisation in Europe, the Brussels-based Association des États Généraux des Étudiants de l'Europe (AEGEE). The ERASMUS Programme embodies a major turning point in the systems of university ruling. The idea of exchanging students across Europe fits as part of the initial European project of building a union of states premised on peaceful cooperation and the free movement of capital and labour. The exchange of university students, then, goes beyond the strictly educational opportunity and reaches a symbolic level of European solidarity, egalitarianism and cultural identity (Tamcke et al. 2013) that will be a first step towards the construction of the European Higher Education Area (EHEA): "the basic idea behind all educational EU-plans is economic: the basic idea is the enlargement of scale of the European systems of higher education, [...] in order to enhance its 'competitiveness' by cutting down costs" (Lorenz 2006). In preparation to the first European student programs, major university reforms also take place outside of the UK. For instance, in Spain, the numbers of university students doubled within a decade, from 788,168 students in 1984/85 to 1,445,322 students in 1994/1995 (Rahona Lopez 2008, 40). Also in Germany, considered to be a late arrival in terms of recent higher education reforms (Wollter 2004), the increase in the number of students after reunification drove a transformation of the higher education system during the nineties that would develop in the direction of increasing the logic of competition between them (see Wollter 2004).

Communicatively speaking, this period marks a transitional and paradoxical moment combining the expansion of the still expensive personal computer and the increased access of students to digitalised and interconnected contents with the isolation and reduction of their strength as a collective. The ecosystem of communication networks included analogic media with a strong dominance of the audio-visual news industry in Europe owned by national broadcasting corporations or by global conglomerates; in parallel, the independent strongly nationalising presses and later the first mobile phones and computers accessing the internet. Basic computer-user literacy spread across the students' curricula and universities invested strongly on granting technological access to the increasingly demanding students. In this landscape, the students' publications become a residue unable to afford powerful and expensive audio-visual infrastructures.

In spite of the structural and fundamental differences between the countries, there is a general perception that the changes have a clear direction: "a retreat of the state from a very detailed administrative control system to cautious institutionalisation of a new triangle of steering, relying on goal setting and contract-management at different levels, strengthening the executive and planning functions of the university management, and an elaborate system of output and performance evaluation in research and teaching." (Wollter 2004).

The European higher education system saw reforms clearly oriented towards the autonomy of the universities, bringing a state supervision model into place. This new governance model of universities drastically shifts the position of students. The once liberal educational values and the inculcation of a capacity for critical thinking within 
the university context (see (Marsh 1977) may have shaped students into a group aiming to participate in the university system as students-as-political actors; but the increasingly commodified system demotes students to a position of merely celebrating the chance of having earned their path to a university education valued only in terms of the titles and income that can be earned as a result.

\subsection{The Millennium Turn: an Understanding of the Suicidal State}

A little less than a decade ago the world found itself in a new fundamental struggle, one that is not yet over. The foundations of capitalism shook with a financial crisis caused by the global operations of fictitious capital and a debt charged to civil societies through their national finances. The state has become the laundering device that transformed the private debt of a capitalist elite into a public debt, forcing exceptional/permanent measures of budget reduction, attenuation of fundamental rights and social tensions emerging as resurgent right wing parties, xenophobic measures led by supposedly social-democratic parties and unprecedented levels of unemployment, precarious labour and regulatory enforcements that militate against any capacity to respond. Universities and higher education institutions live these struggles in their very bones when the funding is systematically cut, wages, terms and conditions are forced down, and students are taxed through increased fees and loans that turn their university dream into a life-long payback nightmare: "They are being told to bear the burden of an economic crisis that they didn't create" (Power 2012, 419).

In the derived university governance constellation, a financial vector has grown dominant by turning universities into major agencies of debt, in which knowledge is depreciated in front of a marketing service whose only promise is to ward off serious unemployment. If in the previous paradigm, the marketisation was already feared and students were preparing for real jobs while crossing the university toll on knowledge; in the current situation the university becomes a service for employability that dismisses the contents of the knowledge by dedicating increasing amounts of the curriculum to polishing CVs, training for interviews and simulating employability opportunities. In this context, aside from whatever expertise, students learn to become a new precariat. As Judith Butler puts it: "The precariat may not have jobs at all. They may have a job and lose a job in quick succession. They may be transient labourers. They may have shelter and lose it the next day. The future is radically unpredictable" (Soloveitchik 2016). And this is the experience of the millennial students. They now exist in a world where expectations of future security and even affluence have given way to an onerous debt-mountain, as:"[... for the first time in living memory, the whole class of graduates faces a high probability, almost certainty, of ad hoc, temporary, insecure and part time jobs, unpaid 'trainee' pseudo-jobs deceitfully rebranded 'practices' - all considerably below the skill they have acquired and eons below the level of their expectations"." (Bauman, 2012, quoted in Giroux 2013, 11.)

As Swain (2011) notes, gone are the days where students could be said to be a privileged section or society, or at least this is the case, we may add, for a majority of students, given the increasingly differentiated experiences of higher education that have been the logical consequence of marketisation and competition. This marginalisation is evident not only in the poor jobs to which students are consigned following graduation, but also those they must take to 'pay their way through' university, as well as the increasing difficulties they face in obtaining housing. As seen, for instance, in the student rent strike in London in May 2016 (Taylor 2016). The economic imperative driving the expansion of $\mathrm{HE}$ of the previous decades has instigated an increase in the uptake of vocational degrees (UCAS 2007), which, coupled with the 
employability agenda, prioritises the needs of industry for such universities. And this is implicit in policy: "the massification of HE is designed to support industry by providing a "better" workforce" (Molesworth, Scullion, and Nixon 2010, 279). Parallel to the transformation of the university governance drives, the student population with access to higher education has multiplied spectacularly. "widely surpassing, in Western Europe, one-third of people interested in the first university enrolment" (Lazzeretti and Tavoletti 2006, 19). In the UK, the number of higher education students has increased from 600,000 in 1971 to 2.5 million in 2009. (BBC News 2011). This reflects the restructuring of an economy requiring an increasingly educated workforce (Swain 2011). An avalanche of policy documents also constructs higher education only in terms of profit making, efficiency maximising entities; set against a growing critical literature that opposes the transformation of students into consumers.

The geo-political tensions produced by the crisis of capital have led to protest movements emerging in variety of places, with the reference point being the global anti-war demonstrations of the $15^{\text {th }}$ February 2003 that engaged more than 600 cities, and is considered 'the biggest protest ever to have been held in one single day' (Walgrave and Verhulst 2003), even though it was ignored by political elites (Tharoor 2013). Student participation has been a constant feature in these movements to the point of becoming fundamental forces in the massive protests against what have been called Austericide measures, like the Spanish Indignados movement of 2011 (Toret 2013); or protests such as the Vienna \#unibrennt and \#audimaxismus in 2009, against the implementation of Bologna policies in the Austrian universities (Brantner and Schwarzenegger 2012), or the Millibank protest in the UK in 2011 (Haywood 2011).

In the meantime, the British attempts to curtail the power of student unions during the last decade led to a further Act of Parliament in 2006. The Charities Act forces the Unions to become registered charities, further shifting the balance away from activism. Even later, in 2010 the Charities Commission dictated that: "union funds cannot be used to promote or support campaigns on matters which may be of general interest or concern but which do not affect members of the union as students" (Woodcock 2013). Furthermore, the state is rapidly formulating measures that criminalise the right to protest. Following the occupations of 2011, the government of the United Kingdom turned its attention to squatting legislation that would make residing in both unoccupied buildings and educational institutions a criminal, rather than a civil, offense (Power 2012, 414). Indeed, the efforts to spread the de-politicisation and criminalisation drives generalised during the 1990s and 2000s seemed to shift with the occupation at Middlesex University in May 2010, following the announcement of the closure of the award-winning philosophy department (Swain 2011). Protest reached a significant crescendo later that year, when students protesting at the tripling of tuition fees to $£ 9,000$ per year occupied the Conservative Party headquarters at Millbank in November, breaking the illusion of apathy. Students were supposed to be lazy and apolitical; Britain was supposed to be the home of moderation, non-confrontational political action. Millbank shattered these ingrained myths (Haywood 2011, 69). Without dismissing the specifics of each case and country, there is a growing perception that a process of re-politicisation of students started during the last decade, experimenting with new forms of action, as well as provoking new forms of reaction.

The specifics of the British tuition fee protests have been explored at length in the literature and for some, this feels almost like a return to the student protest of the 1960s (see for example, Bloom 2012; Dean 2015; J. Ibrahim 2011). Alongside this, 
there is also a perception that something new inhabits these protests, such as the role of social media in raising consciousness and coordinating action. And perhaps most strikingly, these student protests have been able to mobilise networks from around the globe: the impact of \#yosoy132 has been global, as well as the Printemps érable actions of 2012 in Québec or the Chilean winter (2011/13). These examples show the creative and extended networks that student protests have built, thanks to the online possibilities and the use of social media.

The information ecology (Treré 2012) of the students' activism is fundamentally composed by social media, the use of mobile devices, and integrating physical and virtual activity as part of the protest. The information ecology lies somehow at the heart of these novel social actions. Now, in the hands of the students, their protests expand and conquer virtual spaces as well as the physical spaces of the university lecture theatres. But also these novel virtual-physical actions might lead to technooptimistic biases far from being empowering or liberating for the protestors. Such optimism is evident when scholars "have argued that social media had created the basis for the emergence of new, horizontal forms of social organizing, which would overhaul existing political and economic structures" (Barassi 2016). But critical scholars raised their eyebrows too: whatever smartness and shared creativity impelling citizens to spread online and to articulate as social movements seems outsmarted by structures of power. For example, as Treré has demonstrated, the policing of the Mexican student demonstrations \#yosoy132 was characterised by "authoritarian engineering", including "the algorithmic construction of consent and the artificial sabotage of dissent [demonstrating] that there is nothing inherently democratic in digital technologies" (Treré 2016, 136). Indeed, scholars like Andrejevic (2016) and Barassi (2016) write about datafied citizens, to insist that, after all, the internet and the social software platforms are the ring-fenced territories of private companies, more interested in cropping our data while evading taxes than in liberating the oppressed.

Also, similarly to the UK, measures to criminalise protests and to track social media, confronting consolidated citizens' rights to protest and of freedom of expressions, have been put into place. But also, the draconian reduction of university budgets and the steering of financial gains are obtained through the cutting of the rights of university staff and by inviting the students, now cursed into tamed job seekers, to fund the university through ever higher fees. This system built on personal debts will force the students to keep their heads down and to take whatever work opportunities to pay it back, rather than using their glorious time and energy to improve the world: "Youth no longer occupy the hope of a privileged place that was offered to previous generations. They now inhabit a neoliberal notion of temporality marked by a loss of faith in progress along with the emergence of apocalyptic narratives in which the future appears indeterminate, bleak and insecure." (Giroux 2013,10)

This picture reduces the position of the university to an accomplice of an economic system that is not only mutilating the state's role as equaliser of social differences but, instead, is actively contributing to undermine its own earned role of maintaining an acceptable social contract. The state dismantles itself voluntarily to make room for ultraliberal policies and to enable the global financial structures to take over the regulatory frames. This is something for which the concept of a suicidal state (Giroux 2012) seems apt, even if Foucault and Virilio referred to it in slightly different terms.

\section{Concluding Remarks}

This exploration of a genealogical structure of the university governance and the mirrored role for the students and the student unions within the epistemic frame is a 
signpost towards a broader research program. There are numerous possibilities of using this initial theoretical frame as a reference for the understanding of the transformations taking place in the universities of other countries, or as a comparative tool that enables both the temporal and the geographic contrasts. Also, this initial model leaves some room for improvement at the conceptual level, for instance by exploring to what extent this model needs to be modified when applied to other contexts or even if the model holds when specifically approached from other perspectives. For this, more research is necessary and welcome. Certainly, the next area of exploration that would help consolidating this model would be to expand what has been barely drafted in this piece: the possibilities of an analysis of the techno-communicative ecosystems in each one of these periods and the extent to which the communication networks can enable an autonomous (political) reaction or identity growing from the student collectives, or if instead, the informational fields have to be understood as embedded in the governance logic of the university.

For now, however, the contribution of this paper hinges on the notion that university students are to be understood mostly as the product of the material relations of society, and, crucially, the university governance regime, rather than as the expression of a substantial identity. This means that instead of intending to give them a space, a claim and a political role of their own, students and student associations can only be explained as part of the broader context by which the university is governed in relation to the tensions between dissenting interests. That is, state authority, the market and academic oligarchy. The articulation of these three factors helps also to explain the transformation of the core higher education governance systems and by extension, the role provided to the students, to the student associations and to their protests.

Through an exploration of the changing models of higher education governance the paper has shown that three main layers can be discerned: the enduring democratic period, the globalisation period and the Millennium turn. These three periods correspond, not only to differentiated configurations of the three factors of governance but also provide different roles for the students and the student associations. Whereas the first period constructs students as citizens that are enabled to engage politically both at the university level and at the state level, and in which the university seems to emulate the possibilities of the state in adopting a logic of democratisation; the second period constructs students as consumers and as earners of knowledge and degrees of an integrative university system that grows in numbers and in networks for the final achievement of a job. During this period, the popularity of university and the possibilities of employment at the end of the academic circuit, builds cohorts of students rather happy with their own possibilities. Knowledge seems thus to lead to the way of industry and the graduates can actively contribute to the development of the economic system. Finally, in the third period, as financial structures increasingly dominate the economic vector, knowledge is depreciated and the students are shaped for the precarious conditions of a work system that does not need the university knowledge but uses individuals bent at the disciplined capacity for the tolerance of uncertainty. In this context, the software commanded possibilities of social interaction might have led us to believe that the students earned some new capacity for protesting, for interacting and for organising; however, the governance model drives the university towards a position of agency that connects students to a financial labour system that favours a profit-making logic, feeding from progressively more indebted individuals. The options for protest are as scarce as the skills of the graduates endangered by a labour system that ultimately discredits university degrees 
(Ferenstein 2014). Yet, as recent rebellions demonstrate, the possibility of action has not yet fully extinguished.

\section{References}

AMSU, Association of Managers in Students Unions. 2003. The Law Relating to Students' Unions and the Responsibilities of Elected Officers as Trustees.

Andrejevic, Mark. 2016. Theorizing Drones and Droning Theory. Drones and Unmanned Aerial Systems, edited by Aleš Završnik, 21-43. Cham: Springer International Publishing. http://link.springer.com/10.1007/978-3-319-23760-2_2.

Andrews, Kenneth T., and Michael Biggs. 2006. The Dynamics of Protest Diffusion: Movement Organizations, Social Networks, and News Media in the 1960 Sit-Ins. American Sociological Review 71 (5): 752-77. doi:10.1177/000312240607100503.

Baldridge, J. Victor. 1971. Models of University Governance: Bureaucratic, Collegial, and Political. http://eric.ed.gov/?id=ED060825.

Barassi, Veronica. 2016. Datafied Citizens? Social Media Activism, Digital Traces and the Question about Political Profiling. Communication and the Public 1 (4): 494-99. doi:10.1177/2057047316683200.

BBC News. 2011. Graduate Unemployment at Highest for over a Decade. BBC News, January 26. http://www.bbc.co.uk/news/education-12286264

Bloom, Clive. 2012. Riot City: Protests and Rebellion in the Capital. Basingstoke: Palgrave Macmillan.

Boren, Mark Edelman. 2013. Student Resistance: A History of the Unruly Subject. Routledge.

Brantner, Cornelia, and Christian Schwarzenegger. 2012. Der Fall unibrennt: Mobilisierung, Kommunikationsverhalten und kollektive Verständigung von Protest- und Kampagnengemeinschaften heute. SWS-Rundschau 52 (3): 227-48.

Braun, Dietmar, and Francois-Xavier Merrien, eds. 1999. Towards a New Model of Governance for Universities?: A Comparative View. London; Philadelphia: Jessica Kingsley Publishers.

Cammaerts, Bart. 2013. The Mediation of Insurrectionary Symbolic Damage: The UK 2010 Student Protests. International Journal of Press-Politics 18 (4): 525-48.

Clark, Burton R. 1986. The Higher Education System: Academic Organization in CrossNational Perspective. University of California Press.

Crossley, Nick, and Joseph Ibrahim. 2012. Critical Mass, Social Networks and Collective Action: Exploring Student Political Worlds. Sociology, 38038511425560.

Dean, Jonathan. 2015. 'Angelic Spirits of "68": Memories of 60s' Radicalism in Responses to the 2010-11 UK Student Protests. Contemporary British History, October, 1-21. doi:10.1080/13619462.2015.1099438.

DeGroot, Gerard J. 1998. The Culture of Protest: An Introductory Essay. Student Protest, 311.

Evans, Rob. and Paul Lewis. 2013. Undercover: The True Story of Britain's Secret Police. London: Guardian Books.

Ferenstein, Gregory. 2014. Why Google Doesn't Care about College Degrees, in 5 Quotes. VentureBeat, April 25. http://venturebeat.com/2014/04/25/why-google-doesnt-care-aboutcollege-degrees-in-5-quotes/

Foucault, Michel. 1970. The Archaeology of Knowledge. Routledge. 2002.

Foucault, Michel. 2002. The Order of Things: An Archaeology of the Human Sciences. Psychology Press.

Giroux, Henry A. 2012. The 'Suicidal State' and the War on Youth. Truth-Out, October 4.

Giroux, Henry A. 2013. The Occupy Movement Meets the Suicidal State: Neoliberalism and the Punishing of Dissent. Situations: Project of the Radical Imagination 5 (1). http://ojs.gc.cuny.edu/index.php/situations/article/viewFile/1432/1467 
Haywood, James. 2011. The Significance of Millbank. Springtime: Springtime: The New Student Rebellions, London: Verso.

Headlam, Cecil. 1912. Oxford and Its Story. Second. London: J.M. Dent and Sons, Ltd. https://archive.org/stream/oxforditsstory00headuoft\#page/n267/mode/2up/search/Vesper

Hoefferle, Caroline. 2012. British Student Activism in the Long Sixties. Vol. 9. Routledge.

Hoyland, John. 2008. Power to the People. The Guardian, March 15, sec. World news. https://www.theguardian.com/music/2008/mar/15/popandrock.pressandpublishing

Ibrahim, Joseph. 2011. The New Toll on Higher Education and the UK Student Revolts of 2010-2011. Social Movement Studies: Journal of Social, Cultural and Political Protest, 415-21. doi:10.1080/14742837.2011.614110.

Ibrahim, Yousaf. 2010. Between Revolution and Defeat: Student Protest Cycles and Networks. Sociology Compass 4 (7): 495-504.

Jongbloed, Ben. 2003. Marketisation in Higher Education, Clark's Triangle and the Essential Ingredients of Markets. Higher Education Quarterly 57 (2): 110-35.

Lazzeretti, Luciana, and Ernesto Tavoletti. 2006. Governance Shifts in Higher Education: A Cross-National Comparison. European Educational Research Journal 5 (1): 18-37. doi:10.2304/eerj.2006.5.1.18.

Lorenz, Chris. 2006. Will the Universities Survive the European Integration? Higher Education Policies in the EU and in the Netherlands before and after the Bologna Declaration. Sociologia Internationalis 44 (1): 123.

Maireder, Axel, and Christian Schwarzenegger. 2012. A Movement of Connected Individuals. Information, Communication \& Society 15 (2): 171-95. doi:10.1080/1369118X.2011.589908.

Marsh, Alan. 1977. Protest and Political Consciousness. Sage Publications (CA).

Miller, Carol, M. 1993. THE ST. SCHOLASTICA DAY RIOT OXFORD AFTER THE BLACK DEATH. FCH Annals - Journal of the Florida Conference of Historians 1 (June): 29-42.

Molesworth, Mike, Richard Scullion, and Elizabeth Nixon. 2010. The Marketisation of Higher Education. Routledge.

Parkin, Frank. 1968. Middle Class Radicalism. Manchester.

Perry, Matt. 2008. May 1968 across the Decades - International Socialism, March 31. http://isj.org.uk/may-1968-across-the-decades/\#118perry 35

Power, Nina. 2012. Dangerous Subjects: UK Students and the Criminalization of Protest. South Atlantic Quarterly 111 (2): 412-20.

Rahona Lopez, Marta Mercedes. 2008. La Educacion Universitaria En Espana Y La Insercion Laboral de Los Graduados En La Decada de Los Noventa. Un Enfoque Comparado. Madrid: Universidad Autonoma de Madrid.

Rodriguez-Amat, Joan Ramon and Cornelia Brantner. 2014. "Space and Place Matters: A Tool for the Analysis of Geolocated and Mapped Protests." New Media \& Society. September. doi:10.1177/1461444814552098.

Richards, Huw. 1997. The Collision of Two Worlds. Times Higher Education (THE), December 5. https://www.timeshighereducation.com/news/the-collision-of-twoworlds/104836.article

Ruegg, Walter, ed. 2010. A History of the University in Europe: Volume 4, Universities since 1945 -. Cambridge: Cambridge University Press.

Scott, Peter. 2012. It's 20 Years since Polytechnics Became Universities - and There's No Going Back. The Guardian, September 3. http://www.theguardian.com/education/2012/sep/03/polytechnics-became-universities1992-differentiation.

Smelser, N. 1968. Essays in Social Explanation. Prentice Hall.

Soloveitchik, Rina. 2016. Judith Butler: 'Trump Is Emancipating Unbridled Hatred.' Die Zeit, October 28, sec. Kultur. http://www.zeit.de/kultur/2016-10/judith-butler-donald-trumppopulism-interview

Swain, Dan. 2011. The Student Movement Today. International Socialism 130: 95-112. 
Tamcke, Martin, Janny de Jong, Lars Klein, and Margriet van der Waal, eds. 2013. Europe Space for Transcultural Existence? Studies in Euroculture, volume 1. Göttingen: Universitätsverlag Göttingen.

Taylor, Diane. 2016. University Students across London Take Part in Rent Strike. The Guardian, May 6. http://www.theguardian.com/education/2016/may/06/universitystudents-across-london-take-part-in-rent-strike

Tharoor, Ishaan. 2013. Viewpoint: Why Was the Biggest Protest in World History Ignored? Time, February 15.

Thomas, Nick. 2002. Challenging Myths of the 1960s: The Case of Student Protest in Britain. Twentieth Century British History 13 (3): 277-97. doi:10.1093/tcbh/13.3.277.

Toret, Javier. 2013. Technopolitics: The Potential of Connected Multitudes. The 15M Network-System as a New Paradigm of Distributed Politics. Barcelona: Universitat oberta de Catalunya. https://datanalysis $15 \mathrm{~m}$.files.wordpress.com/2013/06/technopolitics-15msummary.pdf

Treré, Emiliano. 2012. Social Movements as Information Ecologies: Exploring the Coevolution of Multiple Internet Technologies for Activism. International Journal of Communication 6: 19.

Treré, Emiliano. 2016. The Dark Side of Digital Politics: Understanding the Algorithmic Manufacturing of Consent and the Hindering of Online Dissidence. IDS Bulletin 41 (1): 127-38. doi:10.19088/1968-2016.111.

Van Vught, Frans A. 1989. Governmental Strategies and Innovation in Higher Education. Higher Education Policies Series, 7. ERIC.

Walgrave, Stefaan, and Joris Verhulst. 2003. The February 15 Worldwide Protests against a War in Iraq: An Empirical Test of Transnational Opportunities. Outline of a Research Programme. In International Workshop on Contemporary Anti-War Mobilizations, Agonistic Engagement Within Social Movement Networks, Corfu, Greece.

Ward's Book of Days. 2006. St Scholastica Day Riot. http://www.wardsbookofdays.com/10february.htm

Wollter, Andrä. 2004. From State Control to Competition. The Canadian Journal of Higher Education XXXIV (3).

Woodcock, James. 2013. The National Union of Students and the Left. The Oxford Left Review. February 24. https://oxfordleftreview.com/olr9-3/

\begin{abstract}
About the Authors
Joan Ramon Rodriguez-Amat

Senior Lecturer and Course Leader for the BA. Media (Hons) in Sheffield Hallam University since June 2015. Before that he spent four years as a Postdoc at the University of Vienna (Austria) and taught in universities in Spain, France, Germany and Austria a part from the United Kingdom. He obtained his PhD in 2010 at the University Autonoma de Barcelona (Spain). His current work turns around the Governance of communicative spaces and times and the technologies that operate it. Address: Cantor Building, Sheffield Hallam University, 153, Arundel Street, S1 2NU Sheffield , United Kingdom. [email: mon.rodriguez@shu.ac.uk]
\end{abstract}

\title{
Bob Jeffery
}

Senior Lecturer in Sociology and Course Leader for the MRes Social Sciences in the Department of Psychology, Sociology and Politics at Sheffield Hallam University. His research interests include social class, work and employment, urban studies, trade unions, social movements and policing. Recent published work has included an examination of the 2011 Salford Riot, a history of public order policing in Greater Manchester and an analysis of modes of belonging in a gentrifying inner-city neighbourhood. His current research examines precarious employment, punitive welfare reform and class identities in post-recession Sal- 
ford. Address: 2.06 HOTC, Collegiate Crescent Campus, Sheffield Hallam University, S10 2BQ [email: r.f.jeffery@shu.ac.uk] 